\title{
Towards a strenghts-based approach in multidimensional frailty
}

Citation for published version (APA):

van der Vorst, A. (2018). Towards a strenghts-based approach in multidimensional frailty: Conceptualisation and screening of frailty, and contributors to daily functioning in old age. [Doctoral Thesis, Maastricht University, Vrije Universiteit Brussel]. Maastricht University. https://doi.org/10.26481/dis.20181206av

Document status and date:

Published: 01/01/2018

DOI:

10.26481/dis.20181206av

Document Version:

Publisher's PDF, also known as Version of record

\section{Please check the document version of this publication:}

- A submitted manuscript is the version of the article upon submission and before peer-review. There can be important differences between the submitted version and the official published version of record.

People interested in the research are advised to contact the author for the final version of the publication, or visit the DOI to the publisher's website.

- The final author version and the galley proof are versions of the publication after peer review.

- The final published version features the final layout of the paper including the volume, issue and page numbers.

Link to publication

\footnotetext{
General rights rights.

- You may freely distribute the URL identifying the publication in the public portal. please follow below link for the End User Agreement:

www.umlib.nl/taverne-license

Take down policy

If you believe that this document breaches copyright please contact us at:

repository@maastrichtuniversity.nl

providing details and we will investigate your claim.
}

Copyright and moral rights for the publications made accessible in the public portal are retained by the authors and/or other copyright owners and it is a condition of accessing publications that users recognise and abide by the legal requirements associated with these

- Users may download and print one copy of any publication from the public portal for the purpose of private study or research.

- You may not further distribute the material or use it for any profit-making activity or commercial gain

If the publication is distributed under the terms of Article $25 \mathrm{fa}$ of the Dutch Copyright Act, indicated by the "Taverne" license above, 


\section{TOWARDS A}

STRENGTHS-BASED
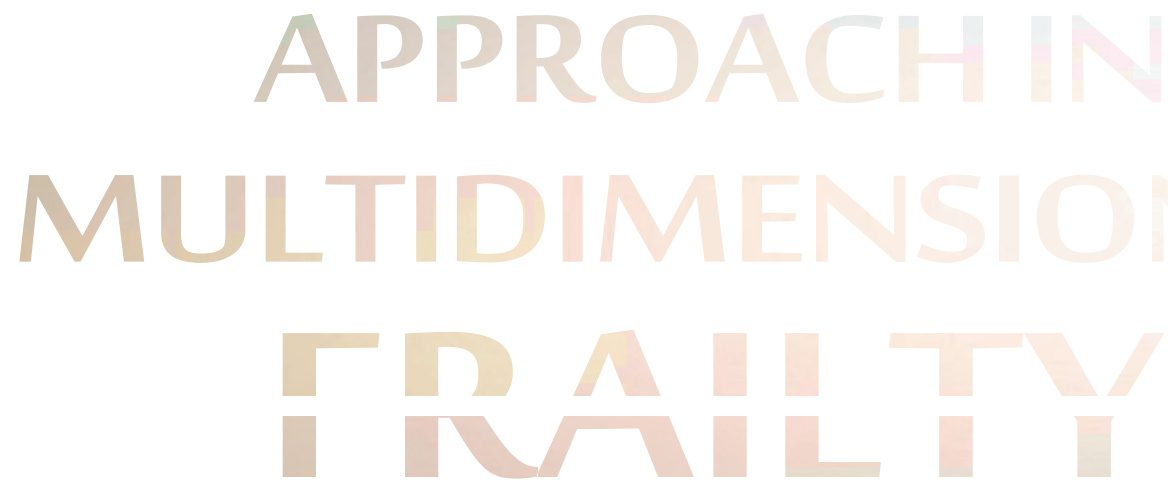

\section{Conceptualisation and screening of frailty, and contributors to daily functioning}





\section{TOWARDS A STRENGTHS-BASED APPROACH IN}

MULTIDIMENSIONAL FRAILTY

Conceptualisation and screening of frailty, and contributors to daily functioning in old age

Anne van der Vorst 
Copyright (c) Anne van der Vorst.

All rights reserved. No part of this dissertation may be reproduced or transmitted in any form or by any means without prior permission of the author.

Cover design: Anne van der Vorst | Fred van der Spek, Ridderprint BV

Lay-out: Anne van der Vorst

Printing: Ridderprint BV | www.ridderprint.n|

ISBN: 978-94-6375-037-0 


\section{TOWARDS A STRENGTHS-BASED APPROACH IN MULTIDIMENSIONAL FRAILTY}

Conceptualisation and screening of frailty, and contributors to daily functioning in old age

\section{PROEFSCHRIFT}

Ter verkrijging van de graad van doctor aan de

Universiteit Maastricht en de Vrije Universiteit Brussel op gezag van Rectores Magnifici Prof. dr. Rianne M. Letschert en Prof. dr. Caroline Pauwels, volgens het besluit van het College van Decanen, in het openbaar te verdedigen op donderdag 6 december 2018 om 16.00 uur in Maastricht

door

Anne van der Vorst 


\section{PROMOTORES}

Prof. Dr. J.M.G.A. Schols

Prof. Dr. G.I.J.M. Kempen

Prof. Dr. N. De Witte (Vrije Universiteit Brussel)

\section{COPROMOTOR}

Dr. G.A.R. Zijlstra

\section{BEOORDELINGSCOMMISSIE}

Prof. Dr. F.R.J. Verhey (voorzitter; Universiteit Maastricht)

Dr. R.M.M. Crutzen (Universiteit Maastricht)

Prof. Dr. E. Gorus (Vrije Universiteit Brussel)

Prof. Dr. K. Lombaerts (Vrije Universiteit Brussel)

Prof. Dr. M.M.G. Olde Rikkert (Radboud Universiteit Nijmegen)

Prof. Dr. B.J.M. Steverink (Rijksuniversiteit Groningen)

The research presented in this dissertation was conducted at CAPHRI Care and Public Health Research Institute, Department of Health Services (HSR), of Maastricht University (the Netherlands), and at the Department of Educational Sciences of the Vrije Universiteit Brussel (Belgium).

CAPHRI participates in the Netherlands School of Public Health and Care Research CaRe.

The studies presented in this dissertation were part of the D-SCOPE project (Detection, Support and Care for older people: Prevention and Empowerment), funded by the Flemish government Agency for Innovation by Science and Technology, embedded in the Strategic Basic Research (IWT-140027-SBO). 
Voor papa en mama 



\section{CONTENT}

CHAPTER 1 General introduction

CHAPTER 2 Cognitive frailty in older people with and without cognitive dysfunctioning: prevalence and associations with various frailty domains

Submitted

CHAPTER 3 Can proxy assessments serve as a first screener for identifying people at risk for multidimensional frailty?

European Geriatric Medicine (2018)

CHAPTER 4 Limitations in activities of daily living in community-dwelling people aged 75 and over: a systematic literature review of risk and protective factors PLoS One (2016)

CHAPTER 5 The impact of multidimensional frailty on dependency in activities of daily living and the moderating effects of protective factors.

Archives of Gerontology and Geriatrics (2018)

CHAPTER 6 Explaining discrepancies in self-reported quality of life in frail 141 older people: a mixed-methods study

BMC Geriatrics (2017)

CHAPTER 7 General discussion 165

ADDENDA Summary 189

Samenvatting 193

Valorisation 199

Dankwoord 207

About the author

Publications and conference contributions

D-SCOPE 

1

GENERAL INTRODUCTION 


\section{Ageing in place}

The proportion of people aged $\geq 65$ years in the European Union is expected to increase from $18 \%$ in 2013 to $28 \%$ in 2060 , although the fastest growing age group is those aged $\geq 80$ years, with an expected increase from $5 \%$ to $12 \%$ [1]. Therefore, concepts such as 'active and healthy ageing' and 'ageing in place' are becoming more and more important. According to the WHO [2], active and healthy ageing "allows people to realize their potential for physical, social, and mental wellbeing throughout the life course and to participate in society according to their needs, desires and capacities", while ageing in place is defined as "meeting the desire and ability of people, through the provision of appropriate services and assistance, to remain living relatively independently in the community in his or her current home or an appropriate level of housing" [3]. Indeed, ageing in place is one of the wishes older people have [4], and they identify it as an important feature of healthy ageing [5].

Older people often even prefer to stay at home if there is no optimal personenvironment fit, as they favour living in an environment to which they are emotionally attached [6]. In addition, overcoming difficulties, such as having to walk stairs, makes them feel empowered [5]. The home and its environment give older people a feeling of connectedness through all the memories they have [5, 7-8]. In addition, 'home' provides a sense of belonging, it is related to values and beliefs [9], and it is often the centre of older people's social life $[5,7]$. Moreover, being able to age in place gives older people the feeling they have control over their life [7], for example by having the freedom to decide for themselves as they are the ones who make the decisions [8]. The home environment shapes their identity [7], and is a place where people can just be who they are [8].

However, ageing in place is not just the wish of most older people [4]. For example, it is also encouraged from a policy perspective, in order to reduce the high costs of institutionalisation [10]. Previous research has shown that providing community care and/or care at home is less expensive than providing institutional care [11-12]. Initiatives such as the 'age-friendly cities [13] and policies focusing on care at home [14-15], should enable or support ageing in place. Nonetheless, it is not possible for everyone to 'age healthy'. Older age is associated with a higher prevalence of cooccurring health problems. Prevalence rates of multimorbidity range between $55-98 \%$ in those aged $\geq 60$ years [16]. These health problems often occur in different domains of human functioning (for example on both a physical and cognitive level) [16], which consequently are likely to threaten the ability to age in place safely. In addition, it is expected that the prevalence of health problems will increase even more in future generations [17]. In order to minimise or slow down the negative consequences of health problems, and in so doing to facilitate ageing in place, early detection and prevention of the health risks associated with ageing is important. 


\section{Frailty}

Frailty is one of the risks associated with ageing that might threaten the need and wish of older people to live at home for as long as possible [18]. A recent search in PubMed on research on frailty has shown a rapid increase in recent years-from 302 publications in 2010, to 1745 in 2017 . Nonetheless, consensus about the definition of frailty is still lacking. In general, two approaches can be distinguished. In the first approach, frailty is conceptualised as a unidimensional approach including merely physical aspects of functioning. For example, the widely acknowledged frailty phenotype, as defined by Fried et al. [19], examines unintentional weight loss, selfreported exhaustion, physical activity, grip strength, and walking speed. However, other measures including solely biomedical aspects exist as well, such as the Fatigue, Resistance, Ambulation, Illness (FRAIL) scale [20]. In the second approach, frailty is operationalised as a multidimensional construct that takes other domains of functioning into account as well. A well-known example of an instrument to measure multidimensional frailty is the Frailty Index, as developed by Rockwood and colleagues. They theorise frailty as an accumulation of deficits, and take a non-fixed set of clinical deficits into account, including, among others, physical status, memory and mood [21-22]. Other multidimensional frailty approaches measure frailty with a fixed set of questions. For example, Gobbens [23] developed the Tilburg Frailty Indicator (TFI), which includes items referring to physical, psychological and social functioning [23], while the Groningen Frailty Indicator (GFI) [24] includes cognitive, physical, psychological and social frailty. The Comprehensive Frailty Assessment Instrument (CFAI) [25] and the recently developed CFAI-Plus [26], measure cognitive, environmental, physical, psychological and social frailty.

Until recently, relatively little attention was paid to environmental and cognitive frailty, compared to physical, psychological and social frailty. Environmental frailty comprises, among other factors, poor housing quality and appreciation of the neighbourhood environment, which are especially important in light of ageing in place [27-28]. For example, neighbourhoods might become unsafe or deprived, or generate exclusion due to social, cultural or economic changes in society [29]. In addition, barriers within the home, for example when people can no longer perform the necessary and desired activities, might diminish the ability to age in place. Cognitive frailty can be defined as subjective cognitive complaints [30], and it increases the risk of actual cognitive impairment [31-33]. However, it is not a clinical condition itself [33]. A focus on all five frailty domains (i.e. cognitive, environmental, physical, psychological and social) is of clinical importance, as it gives insight into the person as a whole [34]. Nonetheless, for the development of multimodal strategies, it is key to know the relationships between these domains, or 'frailty patterns'. Frail older people are a heterogeneous group [35], however, by knowing these 'frailty patterns', it would be 
possible to develop more individually tailored interventions. While associations between environmental, physical, psychological and social frailty have been studied previously [25], the relationship between cognitive frailty and the other domains is relatively unclear. Nonetheless, cognitive impairment has been shown to be associated with social [23] and physical frailty [23, 31, 36-38]. Moreover, a prospective cohort study with a follow-up period of 5 years showed that a combination of cognitive and physical dysfunctioning may lead to adverse outcomes such as an increased risk of progression to dementia [39]. The latter indicates that it would be important to develop interventions focusing on both cognitive and physical frailty. However, up till now, research on 'frailty patterns' is relatively sparse.

In accordance with the different definitions, prevalence rates on frailty vary between $4.0 \%$ and $59.1 \%$, with higher prevalence rates for the multidimensional approaches compared to the unidimensional approaches [34]. Nonetheless, both approaches have some common features. First, frailty is associated with an increased risk of adverse outcomes such as disability in activities of daily living (ADLs) [40], hospitalisation, early institutionalisation, and death [41-42]. Second, frailty is associated with a loss of reserve capacities or resources; for example in physiological systems [19], mobility or psychological functioning [25]. Third, frailty is a dynamic state, and it is potentially reversible or modifiable by interventions [43-45]. Fourth, the risk of frailty increases with increasing age, although there are numerous other risk factors as well [18]. Given the high prevalence of multidimensional frailty, i.e. $\geq 40 \%$ in most studies [34], the increased risk of adverse outcomes and the potential for treatment/interventions, early detection is important.

\section{Early detection methods for people at risk of frailty}

To facilitate early detection, several detection instruments for frailty have been developed. These instruments differ in at least three aspects: (1) the underlying definition; (2) the way of administering (i.e. self-report questionnaires, performancebased assessments, a combination of both, or a non-fixed set of clinical conditions); and (3) the way of scoring (i.e. dichotomous [frail or non-frail]; into three categories [including pre-frail]; or continuous) [46, for an overview]. Regarding the unidimensional approaches, the frailty phenotype as defined by Fried et al. [19], is widely acknowledged. According to these criteria, a person is frail when he or she meets at least three of the following criteria: unintentional weight loss, self-reported exhaustion, low levels of physical activity, low grip strength, and/or slow walking speed [19]. In addition, the FRAIL scale [20] also measures merely biomedical constructs. Nonetheless, while Fried's phenotype of frailty is based on a combination of both performance-based assessments and self-reported questions, and scores people as robust, pre-frail or frail, the FRAIL scale is entirely based on self-reported questions 
and scoring is dichotomous. Regarding the multidimensional measures, the Frailty Index is continuous and takes a non-fixed set of clinical deficits, such as physical status, memory, and mood, into account [21-22]. In contrast, measures such as the GFI [24], TFI [23], CFAI [25], and CFAI-Plus [26] measure frailty with a fixed set of questions and are self-reported measures. Nonetheless, while the final scoring for the GFI and TFI is dichotomous (frail or non-frail), the outcome on the CFAI is divided into three categories: no-mild, middle, and high frail (De Witte et al., available upon request).

\section{Methodological and theoretical considerations}

Despite strong evidence for the reliability and validity of some frailty instruments [47], as well as for their predictive value [48], some limitations should be noted as well. First, for most instruments, administration time ranges from 10 to 30 minutes, and all instruments with administration times less than 5 minutes merely take only physical items into account [48], or were only validated in hospitalised older people [49-52]. Second, sensitivity and specificity of multidimensional measures are relatively low [53], making currently available instruments less valuable for focused screening. Some scholars have suggested a two-step approach, with a short first screener (i.e. a 'rule of thumb'), as an initial indicator of whether a more extended assessment is needed, might be favourable $[48,54]$. Previously the use of a Frailty Index based on routine healthcare data has been suggested as such a first step in screening for frailty [55]. However, the perspectives of formal caregivers such as general practitioners (GPs) can be important as well. GP consultation rates are highest for older age groups [56], so GPs should know when something is not right. However, not every frail older adult has regular contact with their GP [57], and GPs still focus mainly on medical aspects [58]. Therefore, the perspective of informal caregivers might be of value as well, especially in light of ageing in place. A third area of concern is that the existing detection instruments do not endorse the needs and wishes most older people have. While older people prefer a more positive approach, detection instruments focus merely on things people can no longer do (e.g. difficulties with walking) and adverse outcomes [41-42], or they define frailty as an accumulation of deficits [21-22]. However, older people reject an approach where they are perceived as persons with (a risk of) deficits, and they might feel stigmatised by it [59]. Older people prefer support that improves their autonomy and wellbeing, instead of interventions that only focus on shortfalls [59-60]. In addition, older people do not recognise the many geriatric syndromes detected by means of a comprehensive geriatric assessment [61]. They feel patronised by early detection initiatives, which do not fit with their wish to act autonomously [62]. Older people often have limitations or diseases, but based on their own capacities and strengths, and with the right care and support, they are still capable of doing various activities. 
Indeed, rather than merely focusing on deficits and things people can no longer do, it is important to focus also on strengths and on the things people still can do. As the WHO already mentioned in 2004 [63], 'The primary objective of health policies directed towards older persons must be to promote the attainment and maintenance of 'healthy' and 'successful' ageing in advanced years. The emphasis should be on people-centered health maintenance and improvement through promotion of a positive approach to health and healthy lifestyles, in addition to the traditional goals of disease prevention, treatment and rehabilitation. The challenge is to understand and promote those factors that keep people healthy, with a focus on both personal and external resources". This strengths-based approach has already been applied in previous research. For example, the disablement process model describes the progressive worsening from pathology to impairments, functional limitations and disability, but also takes personal capacities that can slow down the process of disablement, such as coping, into account [64]. In addition, other initiatives, such as the 'Healthy Ageing Phenotype' [65], use a more strengths-based approach.

\section{Towards a strengths-based approach in frailty}

While it has been acknowledged for decades that frailty is the result of a complex interplay between losses and deficits on one side, and support and resources on the other side [66-67], most research on frailty still focuses merely on deficits and losses. Therefore, in order to move towards a strengths-based approach, it is important to also assess protective factors against adverse outcomes, rather than only focusing on risk factors. While it might not always be possible to diminish the level of frailty, it might be possible to reduce adverse consequences and to sustain or even to improve daily functioning and wellbeing. While some might argue that risk and protective factors are different sides of the same coin, research has shown that predictors for positive and negative health outcomes differ [68-69]. For example, employment status had a stronger relationship with ill-health than with excellent health [69]. In addition, Kempen et al. [68] showed that, among other factors, depressive symptoms and low levels of mastery were risk factors for functional decline, while self-efficacy and higher levels of self-perceived health were protective factors. Previously, resources such as educational level, mastery and support were examined as protective factors against adverse outcomes in frailty such as functional decline, hospitalisation and mortality. However, no moderating effects of these resources on the relationship between frailty and adverse outcomes were revealed [70-71]. Nonetheless, it could be argued that adverse outcomes such as functional decline, hospitalisation and mortality are not the ideal measures when assessing resources such as mastery, selfmanagement and emotional support. These resources might help older people to deal 
with functional decline, or improve wellbeing, rather than prevent them from becoming disabled.

Besides focusing on protective factors against adverse outcomes, focusing on promoting positive outcomes might be just as important. This contributes to the understanding of people's strengths and abilities, which is the specific aim of a strengths-based approach [72-73]. For example, $\geq 50 \%$ of frail older people still report a satisfactory to good quality of life ( $\mathrm{OoL}$ ) [74-75]. Identifying factors that contribute to higher levels of QoL despite frailty, rather than trying to elucidate lower QoL levels, could therefore be an important entry point for such a strengths-based approach. While previous research has shown that frail people with a higher age, and those who compared themselves with others who are worse off, report higher levels of QoL [76], no studies so far were specifically focused on identifying strengths in older people with higher levels of QoL. However, such knowledge is particularly important when aiming for a strengths-based approach [72-73].

\section{Aims and outline}

This dissertation has several objectives. First, as frail older people are a heterogeneous group, for the development of more personalised interventions, it seems helpful to gain insight into the associations between the different frailty domains. By knowing 'patterns of frailty', interventions can be more specific and individually tailored. While associations between environmental, physical, psychological and social frailty have been studied previously [25], the relationship between cognitive frailty and the other domains is still relatively unclear. Second, prevention of frailty is important, and early detection methods are needed for this. A two-step approach with a short first screener (i.e. a 'rule of thumb') as an initial indicator for the need of a more extended assessment might be preferable. Especially in light of ageing in place, (in)formal caregivers are becoming increasingly engaged. Therefore, they might be the ones to notice the first signs of something being wrong. However, it is unclear if caregivers' perspectives are related to the perspectives of older people themselves. Third, a strengths-based approach to frailty may be of value. Older people themselves reject current approaches which focus merely on deficits, and might be perceived as stigmatising. However, until now, little research has been conducted on the strengths older people have despite their frailty. To conclude, the objectives of this dissertation are threefold: (1) to expand the knowledge about the strength of the associations between the different frailty domains; (2) to examine whether overall proxy assessments by (in)formal caregivers can serve as a screener for multidimensional frailty; and (3) to identify countervailing strengths older people have despite frailty, by identifying determinants contributing to daily functioning and wellbeing. To achieve this, the following specific research questions are answered: 
Conceptualisation multidimensional frailty

1. Is cognitive frailty associated with other domains of frailty, and do such associations differ in people with different levels of objective cognitive impairment? (Chapter 2)

(Pre)screening

2. Can GPs and informal caregivers make reliable estimations about the level of frailty as perceived by older people themselves? (Chapter 3 )

Towards a strengths-based approach in multidimensional frailty

3. What are the risk factors for and the protective factors against developing ADL disability in community-dwelling people aged 75 years and over? (Chapter 4)

4. Is multidimensional frailty a predictor of ADL dependency, and can this relationship be moderated by protective factors? (Chapter $\mathbf{5}$ )

5. How do community-dwelling frail older people with higher levels of QoL differ from frail older people with lower levels of QoL? (Chapter 6)

Chapter 2 presents the results of a cross-sectional study that focuses on the association of cognitive frailty with other frailty domains. Three different samples were assessed: a random sample of community-dwelling older people, community-dwelling older people with an increased risk of multidimensional frailty, and communitydwelling older people visiting a memory clinic. Chapter 3 describes a cross-sectional study investigating if one-item questions completed by (in)formal proxies can serve as a first screener for identifying people at risk for multidimensional frailty. In Chapters 4 and $\mathbf{5}$ we study factors related to ADL disability, which is known to be an adverse outcome in frailty. Chapter 4 provides the results of a systematic literature review on identifying risk factors for and protective factors against developing ADL disability in community-dwelling people aged $\geq 75$. In Chapter 5, the findings of this systematic literature review are empirically tested. Longitudinal data is used to assess if the identified protective factors can moderate the relationship between multidimensional frailty and ADL dependency. Chapter 6 shows the results of a mixed-methods study that explores differences between frail older people with higher levels of QoL and frail older people with lower levels of QoL to identify strengths despite frailty, or in other words, determinants of wellbeing. Finally, Chapter 7 summarises and discusses the main findings and implications regarding all of the studies. In addition, methodological and theoretical considerations are discussed, and implications for clinical practice and future research are made. 


\section{References}

1. European Commission. The 2015 ageing report. 2014. Available: http://ec.europa.eu/economy_finance/publications/european_economy/2014/pdf/ ee8_en.pdf.

2. WHO. Active ageing: a policy framework. 2001. p. 12. Available: http://apps.who.int/iris/bitstream/10665/67215/1/WHO_NMH_NPH_02.8.pdf

3. WHO. A glossary of terms for community health care and services for older persons. 2004. p. 9. Available:

http://www.who.int/kobe_centre/ageing/ahp_vol5_glossary.pdf

4. Wiles JL, Leibing A, Guberman N, Reeve J, Allen RES. The meaning of "ageing in place" to older people. Gerontologist. 2012;52(3):357-66. https://doi.org/ 10.1093/geront/gnrog8.

5. Sixsmith J, Sixsmith A, Fänge $A M$, et al. Healthy ageing and home: the perspectives of very old people in five European countries. Soc Sci Med 2014;106:1-9

6. Lien $L L$, Steggell $C D$, Iwarsson $S$. Adaptive strategies and person-environment fit among functionally limited older adults ageing in place: a mixed methods approach. Int J Environ Res Public Health. 2015;12(9), 11954-74.

7. Cutchin MP, Malcolm P. Using Deweyan philosophy to rename and reframe adaptation-to environment. Am J Occup Ther. 2004;58(3): 303-12.

8. Stones D, Gullifer J. 'At home it's just so much easier to be yourself': older adults' perceptions of ageing in place. Ageing Soc. 2016;36(3), 449-81.

9. Lecovich, E. Ageing in place: From theory to practice. Anthropol Noteb. 2014;20(1), 21-33.

10. Scharlach A. Creating ageing-friendly communities in the United States. Ageing Int. 2011;37(1):25-38

11. Marek KD, Stetzer F, Adams SJ, Popejoy LL, Rantz M. Aging in place versus nursing home care: Comparison of costs to Medicare and Medicaid. Res Gerontol Nurs. 2012;5(2): 123-9.

12. Rantz M, Popejoy LL, Galambos C, et al. The continued success of registered nurse care coordination in a state evaluation of aging in place in senior housing. Nurs Outlook. 2014;62(4): 237-46

13. WHO. Global Age Friendly Cities: A Guide. 2007. Available:

http://www.who.int/ageing/publications/Global_age_friendly_cities_Guide_Englis h.pdf

14. Ministerie van Volksgezondheid, Welzijn en Sport. De maatschappij verandert. Verandert de zorg mee? 2014. Available:

http://vwshuisstijl.nl/uploads/2014/07/vws-veranderingzorg-web.pdf 
15. Vlaamse Regering. Conceptnota Vlaams welzijns- en zorgbeleid voor ouderen. Dichtbij en integraal. Visie en veranderagenda. 2016. Available:

https://www.zorgneticuro.be/sites/default/files/general/160205_Conceptnota_Vla ams\%2owelzijns-\%2oen\%2ozorgbeleid\%2ovoor\%2oouderen_o.pdf

16. Marengoni A, Angleman S, Melis $R$, et al. Ageing with multimorbidity: a systematic review of the literature. Ageing Res Rev. 2011;10: 430-9.

17. Kingston A, Robinson $L$, Booth $H$, Knapp $M$, Jagger C. Projections of multimorbidity in the older population in England to 2035: estimates from the Population Ageing and Care Simulation (PACSim) model. Age Ageing. 2018. https://doi.org/10.1093/ageing/afx201

18. Dury $S$, De Roeck $E$, Duppen $D$, et al. Identifying frailty risk profiles of homedwelling older people: focus on sociodemographic and socioeconomic characteristics. Ageing Ment Health 2017; 21(10): 1031-9.

19. Fried LP, Tangen CM, Walston J, et al. Frailty in older adults: evidence for a phenotype. J Gerontol A Biol Sci Med Sci. 2001;56: 146-56.

20. Morley JE, Malmstrom TK, Miller DK. A simple frailty questionnaire (FRAIL) predicts outcomes in middle aged African Americans. J Nutr Health Ageing 2012; 16(7): 601-8.

21. Mitnitski AB, Mogilner AJ, Rockwood K. Accumulation of deficits as a proxy measure of ageing. ScientificWorldJournal. 2001;1: 323-36.

22. Rockwood K, Mitnitski A. Frailty in relation to accumulation of deficits as a proxy measure of ageing. J Gerontol A Biol Sci Med Sci. 2007;62: 722-7

23. Gobbens RJJ, van Assen MALM, Luijkx KG, Wijnen-Sponselee MT, Schols JMGA. The Tilburg Frailty Indicator: Psychometric Properties. JAMDA. 2010;11(5):344-55

24. Steverink N, Slaets JPJ, Schuurmans $H$, van Lis M: Measuring frailty: Development and testing of the Groningen Frailty Indicator (GFI). Gerontologist. 2001, 41 (special issue 1): 236- 7.

25. De Witte N, Gobbens R, De Donder $L$, et al. The Comprehensive Frailty Assessment Instrument: development, validity and reliability. Geriatr Nurs. 2013;34(4):274-81.

26. De Roeck EE, Dury S, De Witte, $\mathrm{N}$ et al. CFAl-Plus: Adding cognitive frailty as a new domain to the comprehensive frailty assessment instrument. Int J Geriatr Psychiatry. 2018. https://doi.org/10.1002/gps.4875

27. Costa-Font J, Elvira D, Mascarilla-Miro O. 'Ageing in Place'? Exploring Elderly People's Housing Preferences in Spain. Urban Stud. 2009; 46(2): 295-316. doi: $10.1177 / 0042098008099356$

28. Schröder-Butterfill $E$, Marianti R. A framework for understanding old-age vulnerabilities. Ageing Soc. 2006;26(1): 9-35. 
29. Phillipson C. The 'elected' and the 'excluded': Sociological perspectives on the experience of place and community in old age. Ageing Soc. 2007;27: 321-42.

30. Panza F, Seripa D, Solfrizzi V, et al. Targeting cognitive frailty: clinical and neurobiological roadmap for a single complex phenotype. J Alzheimers Dis. 2015; 47(4): 793-813.

31. Canevelli M, Cesari M, van Kan GA. Frailty and cognitive decline: how do they relate? Curr Opin Clin Nutr Metab Care. 2015; 18(1): 43-50.

32. Fitten LJ. Thinking about cognitive frailty. J Prev Alzheimers Dis. 2015; 2(1): 7-10.

33. Kelaiditi $E$, Cesari $M$, Canevelli MV, et al. Cognitive frailty: rational and definition from an (IANA/IAGG) international consensus group. J Nutr Health Ageing 2013; 17(9) 726-34.

34. Collard RM, Boter H, Schoevers RA, Oude Voshaar RC. Prevalence of Frailty in Community-Dwelling Older Persons: A Systematic Review. J Am Geriatr Soc. 2012;60(8): 1487-92.

35. Eklund K, Wilhelmson K. Outcomes of coordinated and integrated interventions targeting frail elderly people: a systematic review of randomised controlled trials. Health Soc Care Community. 2009; 17(5): 447-58.

36. Fougère $B$, Daumas $M$, Lilamand $M$, et al. Association between frailty and cognitive impairment: Cross-sectional data from Toulouse frailty day hospital. JAMDA. 2017;18(11): 990.

37. Jacobs JM, Cohen A, Bin-Mor E, et al. Frailty, cognitive impairment and mortality among the oldest old. J Nutr Health Aging. 2011;15: 678-82.

38. Panza F, Seripa D, Solfrizzi V, et al. Targeting cognitive frailty: clinical and neurobiological roadmap for a single complex phenotype. J Alzheimers Dis. 2015; 47(4): 793-813.

39. Montero-Odasso MM, Barnes B, Speechley $M$, et al. Disentangling cognitivefrailty: results from the Gait and Brain Study. J. Gerontol. A Biol. Sci. Med. Sci. 2016; 71(11): 1476-82

40. Coelho T, Paúl C, Fernandes L. Physical, Psychological and Social Frailty in Prediction of Disability and Quality of Life. Eur Psychiatry. 2015;30: 447.

41. Gobbens RJJ, van Assen MALM, Luijkx KG, Schols JMGA. The predictive validity of the Tilburg frailty indicator: disability, health care utilization, and quality of life in a population at risk. Gerontologist. 2012;52(5):619-31.

42. Song $X$, Mitnitski A, Rockwood K. Prevalence and 10-year outcomes of frailty in older adults in relation to deficit accumulation. J Am Geriatr Soc. 2010;58(4): 6817.

43. Cameron ID, Fairhall N, Gill L, et al. Developing interventions for frailty. Adv Geriatr. 2015;2015: 7 . 
44. Gill TM, Gahbauer EA, Allore HG, Han L. Transitions between frailty states among community-living older persons. Arch Intern Med. 2006;166(4): 418-23.

45. Hubbard RE, Fallah N, Searle SD, Mitnitski A, Rockwood K. Impact of exercise in community-dwelling older adults PLoS One. 2009;4(7)

46. De Vries, N. M., Staal, J. B., Van Ravensberg, C. D., Hobbelen, J. S. M., Olde Rikkert, MMG, \& Nijhuis-Van der Sanden, M. W. G. Outcome instruments to measure frailty: a systematic review. Ageing Res Rev. 2011;10(1): 104-14.

47. Sutton JL, Gould RL, Daley S, et al. Psychometric properties of multicomponent tools designed to assess frailty in older adults: A systematic review. BMC Geriat. 2016;16(1): 55 .

48. Dent $E$, Kowal $P$, Hoogendijk EO. Frailty measurement in research and clinical practice: a review. Eur J Intern Med. 2016; 31: 3-10.

49. Basic $D$, Shanley $C$. Frailty in an older inpatient population: using the clinical frailty scale to predict patient outcomes. J Ageing Health 2015;27(4):670-85.

50. Graham MM, Galbraith PD, O'Neill D, Rolfson DB, Dando C, Norris CM. Frailty and outcome in elderly patients with acute coronary syndrome. Can J Cardiol 2013; 29(12):1610-5.

51. Partridge JS, Fuller M, Harari D, Taylor PR, Martin FC, Dhesi JK. Frailty and poor functional status are common in arterial vascular surgical patients and affect postoperative outcomes. Int J Surg 2015;18:57-63.

52. Rolfson DB, Majumdar SR, Tsuyuki RT, Tahir A, Rockwood K. Validity and reliability of the Edmonton frail scale. Age Ageing 2006;35(5):526-9

53. Clegg A, Rogers L, Young J. Diagnostic test accuracy of simple instruments for identifying frailty in community-dwelling older people: a systematic review. Age Ageing. 2014; 44(1): 148-52.

54. De Lepeleire J, Degryse J, Illiffe S, Mann E, Buntinx F. Family physicians need easy instruments for frailty. Age Ageing 2008;37: 484-5

55. Drubbel I, Bleijenberg N, Kranenburg G, et al. Identifying frailty: do the Frailty Index and Groningen Frailty Indicator cover different clinical perspectives? A cross-sectional study. BMC Fam Pract. 2013; 14(1): 64 .

56. Wang Y, Hunt K, Nazareth I, Freemantle N, Petersen I. Do men consult less than women? An analysis of routinely collected UK general practice data. BMJ Open. 2013 doi:10.1136/bmjopen-2013-003320

57. van Campen C. (ed) Kwetsbare ouderen. Sociaal en Cultureel Planbureau. 2011 [in Dutch]

58. Cès $S$, Flusin $D$, Schmitz $O$, et al. Mantelzorgers van thuiswonende ouderen in België: een cruciale en complexe rol. Data-onderzoek. 2016; Koning Boudewijnstichting [in Dutch] 
59. Lette M, Baan CA, van den Berg M, de Bruin SR. Initiatives on early detection and intervention to proactively identify health and social problems in older people: Experiences from the Netherlands. BMC Geriatr. 2015;15: 143. http://dx.doi.org/10.1186/s12877-015-0131-z

6o. van Kempen JAL, Robben SHM, Zuidema SU, Olde Rikkert MGM, Melis RJF, Schers HJ. Home visits for frail older people: a qualitative study on the needs and preferences of frail older people and their informal caregivers. $\mathrm{Br} J$ Gen Pract. 2012;62(601):554-60.

61. van Rijn $M$, Suijker JJ, Bol $W$, et al. Comprehensive geriatric assessment: recognition of identified geriatric conditions by community-dwelling older persons. Age Ageing. 2016;45(6): 894-99.

62. De Bruin S, Lette $M$, Baan, $C$. Op weg naar betere aansluiting bij wat ouderen willen en kunnen. [In Dutch]

63. WHO. A glossary of terms for community health care and services for older persons. 2004. p. 4. Available

http://www.who.int/kobe_centre/ageing/ahp_vol5_glossary.pdf

64. Verbrugge LM, Jette AM. The disablement process. Soc Sci Med. 1994; 38(1): 1-14.

65. Lara J, Godfrey A, Evans E, et al. Towards measurement of the Healthy Ageing Phenotype in lifestyle-based intervention studies. Maturitas. 2013;76(2): 189-99.

66. Brocklehurst JC (ed): The day hospital. In Textbook of Geriatric Medicine and Gerontology. 3rd ed, Churchill. London, England. 1985: p. 982-995

67. Sipsma DH. Modellen en paradigma's in de geriatrie. Medisch Contact. 1993; 48(8):1229-31.

68. Kempen GIJM, Ranchor AV, Sonderen E van, Jaarsveld CHM van, Sanderman R. Risk and protective factors of different functional trajectories in older persons. Are these the same? J Gerontol Psy Sci Soc Sci 2006; 61B: 95-101

69. Mackenbach JP, Van den Bos J, Joung IMA, Van de Mheen H, Stronks K. The determinants of excellent health: different from the determinants of ill-health? Int J Epidemiol. 1994; 23: 1273-81.

70. Hoogendijk EO, van Hout HP, van der Horst HE, Frijters DH, Dent E, Deeg DJ, Huisman M. Do psychosocial resources modify the effects of frailty on functional decline and mortality? J Psychosom Res. 2014; 77(6): 547-51.

71. Op het Veld LPM, Ament BHL, van Rossum E, Kempen GIJM, de Vet HCW, Hajema $\mathrm{KJ}$, Beurskens AJHM. Can resources moderate the impact of levels of frailty on adverse outcomes among (pre-)frail older people? A longitudinal study. BMC Geriatr. 2017;17. doi: 10.1186/s12877-017-0583-4

72. Graybeal C. Strengths-based social work assessment: transforming the dominant paradigm. Fam Soc. 2001;82(3):233-42. 
73. Minimol K. Risk assessment and strengths based case Management in Elderly Care-Scope of social work practice. Artha-J Soc Sci. 2016;15(2):121-33.

74. Ament BHL, de Vugt ME, Verhey FRJ, Kempen GIJM. Are physically frail older persons more at risk of adverse outcomes if they also suffer from cognitive, social, and psychological frailty? Eur J Ageing. 2014;11(3): 213-9.

75. Puts MTE, Shekary N, Widdershoven G, Heldens J, Lips P, Deeg DJH. What does quality of life mean to older frail and non-frail community-dwelling adults in the Netherlands? Qual Life Res. 2007;16(2): 263-77. https://doi.org/10.1007/s11136006-9121-0

76. Bilotta C, Bowling A, Casè A, Nicolini P, Mauri S, Castelli M, Vergani C. Dimensions and correlates of quality of life according to frailty status: a cross-sectional study on community-dwelling older adults referred to an outpatient geriatric service in Italy. Health Qual Life Outcomes. 2010;8(56): 1-10. 
$-24$ 


\section{2}

Cognitive frailty in older people with and without cognitive dysfunctioning: prevalence and associations with various frailty domains

Submitted as

De Roeck, E.*, van der Vorst, A.*, Engelborghs, S., Zijlstra, G.A.R., Dierckx, E., \& DSCOPE Consortium. Cognitive frailty in older people with and without cognitive impairment: prevalence and associations with various frailty domains.

* E. De Roeck \& A. van der Vorst are joint first author. 


\section{Abstract}

Background: The relationship between the relatively new construct of cognitive frailty and other frailty domains is unclear. The aim of this study was to determine whether cognitive frailty is associated with the other types of frailty and if the pattern of associations observed in community-dwelling older people varies with level of objective cognitive impairment.

Methods: Cross-sectional data from three research projects among communitydwelling people aged $\geq 6$ o years were used: (1) a random sample $(n=353)$; (2) a sample at increased risk of frailty $(n=95)$; (3) a sample of memory clinic patients $(n=73)$. Multidimensional frailty was assessed with the Comprehensive Frailty Assessment Instrument Plus and general cognitive functioning with the Montreal Cognitive Assessment. Descriptive statistics and linear regression were used to determine the prevalence of cognitive frailty and to explore the relationship between cognitive frailty and the other types of frailty in each sample.

Results: Cognitive frailty increased with level of objective cognitive impairment (range: 35.1-82.2\%). Cognitive frailty was positively associated with mood disorder symptoms in all three samples $(p \leq .01)$. Associations between cognitive frailty and the other types of frailty differed between the samples.

Conclusion: Psychological and cognitive frailty are strongly associated, irrespective of objective level of cognitive impairment. A broad approach to frailty, taking all the domains into account, seems particularly important in the general population. In people who have cognitive difficulties or are at risk of frailty a focus on cognitive, psychological and, to a lesser extent, environmental frailty seems to be especially important. 


\section{Introduction}

With the global growth of the proportion of elderly people [1], and recognition of the importance of ageing in place [2-4], frailty has become an increasingly important concept. Instead of focusing purely on physical aspects [5], there is a growing tendency to view frailty from a multidimensional perspective, taking psychological, social [6-7) and environmental factors into account as well [8]. Within this multidimensional approach, cognitive frailty is a relatively new concept. A recent multidimensional measure of cognitive frailty [9] defines it as the presence of subjective cognitive complaints [10] and a condition that increases the risk of cognitive impairment [11-13], but is not a clinical condition itself [13]. On a conceptual level, cognitive frailty differs from the other types of frailty as it measures additional aspects (e.g. difficulty learning new things). Little is known about cognitive frailty in older populations or its relationship with other types of frailty.

Most previous research has examined the relationship between objective cognitive impairment, as measured by instruments, rather than cognitive frailty (i.e. subjective complaints), and one or more other types of frailty. For example, Gobbens et al. [6] found that cognitive impairment, as assessed with the Mini Mental State Examination, was correlated with physical and social frailty, but not with psychological frailty. The most frequently studied relationship is that between objective cognitive impairment and physical frailty [10-11, 14-15], which have consistently been found to be positively associated. The combination of cognitive and physical dysfunction has been linked to adverse outcomes, such as increased risk of progression to dementia [16] or other neurocognitive disorders [17]. There have been no studies examining the relationship between environmental frailty and cognitive impairment and no studies investigating how stable these potential associations are across levels of cognitive frailty. However, associations between frailty domains may vary between groups (e.g. the general community-dwelling older population versus memory clinic patients), which would make it possible to make interventions more individually tailored (i.e. by knowing on which frailty domains the focus should be in each population).

Although previous research indicates that it is important to assess cognitive frailty in relation to the other domains, there is a dearth of research in this area, which makes it more difficult to design effective interventions. Multidisciplinary, tailored interventions can only be developed and implemented when the relationships between the different types of frailty are understood and when information about individuals' pattern of frailty is available. The aims of this study were, therefore, to examine the prevalence of cognitive frailty in groups with different levels of cognitive impairment and to explore the associations between frailty domains. 


\section{Methods}

\section{Study participants}

Cross-sectional data from three different research projects were used. The general inclusion criteria were as follows: community-dwelling people aged 60 years and over, living in Flanders or Brussels. The first sample was a random sample of 353 individuals; people with a diagnosis of dementia, Mild Cognitive Impairment $(\mathrm{MCl})$, severe psychiatric disorders or analphabetism were excluded. These participants were recruited and tested by final year undergraduate psychology students from the Vrije Universiteit Brussel (Brussels, Belgium). The second sample compromised 121 older people with a high probability of being frail who were recruited on behalf of the Detection, Support and Care of Older People: Prevention and Empowerment (DSCOPE) project with help from different Flemish care organisations and through snowball-sampling. People with a diagnosis of dementia or severe psychiatric disorder were excluded. During the selection process risk profiles for frailty [18] were taken into account in order to oversample frail older people. Data were collected by six trained PhD students. The third sample consisted of 76 memory clinic patients. The exclusion criteria were a history of neurological diseases or comorbid neurological disorder, and severe psychiatric illness. Patients were recruited from the Memory Clinic of Hospital Network Antwerp and had been diagnosed with subjective cognitive decline (SCD), $\mathrm{MCl}$ or dementia. Diagnostic testing consisted of a general physical and neurological examination, blood screening, structural neuroimaging and a neuropsychological assessment. SCD, $\mathrm{MCl}$ and dementia were diagnosed using the "Working group of the Subjective Cognitive Decline Initiative (SCD-I)" criteria [19], Petersen's criteria [20] and the National Institute of Neurological and Communicative Disorders and Stroke Alzheimer's Disease and Related Disorders Association (NINCDS-ADRDA) criteria) [21], respectively. Data were collected by one trained PhD student (psychologist). Hereafter the three samples will be referred to as the 'community', 'potentially frail' and 'clinical' samples respectively.

People were excluded from all samples if there were missing values in the Comprehensive Frailty Assessment Instrument Plus (CFAI-Plus) or Montreal Cognitive assessment (MoCA) (community sample $n=2$; frail sample $n=26$; clinical sample $n=$ 10). The mean age of participants $(M=77.46)$ was similar to that of people who were excluded $(M=76.64 ; \mathrm{p}=.538)$, but the mean MoCA score of the excluded people was lower $(M=19.44)$ than that of participants $(M=23.79 ; p \leq .001)$.

All participants were recruited between December 2015 and April 2017. Research protocols were approved by the local ethical committee (Vrije Universiteit Brussel for the frail sample; ECHW_031; University of Antwerp / Antwerp University Hospital for the community and clinical samples: B300201525772). Written, informed consent was obtained from all participants prior to data collection. 


\section{Measurements}

First, the following socio-demographic characteristics were assessed: age, gender, education, and marital status. Second, frailty was measured with the 25-item CFAIPlus [8-9]. This self-report questionnaire measures cognitive (e.g. 'I have trouble remembering things that happened recently'), environmental (e.g. 'My house is in a bad condition/poorly kept'), physical (e.g. 'I have been hampered by my state of health in less demanding activities like carrying shopping bags'), psychological (e.g. 'I feel unhappy and depressed'), and social (e.g. 'I know many people whom I can totally trust') frailty. There are two components to both psychological and social frailty, respectively mood disorders and emotional loneliness, and social loneliness and social support network. Cognitive, environmental and social frailty are rated on a five-point scale (o = completely disagree; 4 = completely agree), as is emotional loneliness (a subdomain of psychological frailty). Physical frailty is rated on a three-point scale ( $0=$ not at all; 1 = up to three months; 2 = more than three months) and mood disorders ( $a$ subdomain of psychological frailty) on a four-point scale ( $0=$ not at all; $3=$ considerably more than usual) [8-9]. Scores for each frailty domain range from o to 25 , and cut-offs for high frailty are as follows, cognitive: 10.94; environmental: 7.51; physical: 18.81; psychological: 11.51; social: 16.018,9 (data available upon request). Lastly, the MoCA, a brief cognitive screening tool designed to detect $\mathrm{MCl}$ or mild dementia, was used to assess overall cognitive functioning. The MoCA examines multiple domains of cognitive functioning including short-term memory, executive functioning, attention, and temporal and spatial orientation. Total score ranges from o to 30 and higher scores indicate better cognition [22]. To correct for educational effects participants with $\leq 12$ years of education received one extra point [23].

\section{Statistical analyses}

First, descriptive statistics for each sample were calculated. Second, skewness and kurtosis of each variable were checked in each sample to determine whether the distribution violated the assumption of normality [24]. The frail and clinical samples were medium-sized so the cut-off for non-normality was set at $z>3.29$ for both skewness and kurtosis [25]. Absolute values of skewness and kurtosis were assessed for the community sample $(n>300)$ [25]. Third, differences between the three samples were assessed using one-way ANOVAs in the case of normally distributed variables (age; MoCA; cognitive and social frailty; potential support network subdomain), Kruskal-Wallis tests in the case of non-normally distributed variables (environmental and physical frailty; psychological frailty (both subdomains); emotional loneliness) and chi-squared tests for categorical variables (gender). Any overall differences were analysed pairwise using independent sample $t$-tests (normally distributed variables) or Mann-Whitney $U$ tests (non-normally distributed variables). In addition, co-occurrence 
of cognitive frailty was assessed using crosstabs and chi-squared tests. Finally, separate multiple linear regression models were used to examine the relationship between cognitive frailty and the other frailty domains in each sample, after checking collinearity using the VIF and tolerance statistics [26]. Because previous research had shown that cognition has different relationships with social loneliness (social frailty subdomain) and emotional loneliness (psychological frailty subdomain) [27], the subdomains were taken into account, rather than the overall domains. To conclude, age and environmental and physical frailty, and the subdomains of psychological and social frailty were predictors, while cognitive frailty was the dependent variable. Age was taken into account as it was associated with cognitive frailty (data not presented). Statistical significance was set at $p \leq 0.05$ and analyses were performed using SPSS 24 (IBM Corp., Armonk, NY, USA).

\section{Results}

\section{Sample characteristics}

A total of 521 participants were enrolled (community sample $n=353$; frail sample $n=$ 95; clinical sample $n=73$ ). Table 1 shows socio-demographic characteristics, mean MoCA and frailty scores by sample. There were differences between the three samples with respect to MoCA score and cognitive, environmental, physical, and psychological frailty, including both subdomains. Post hoc tests revealed differences between the community and frail samples with respect to mean MoCA score $(p<.001)$ and cognitive $(p=.006)$, environmental $(p<.001)$, and psychological $(p=.002)$ frailty $(p<.001)$, as well as the psychological frailty subdomains of mood disorders $(p<.001$ ) and emotional loneliness $(p=.031)$. The community and clinical samples differed with respect to mean age $(p<.001)$, mean MoCA score $(p<.001)$, cognitive frailty $(p<.001)$, physical frailty $(p<.001)$ and mood disorders $(p=.001)$. Lastly, the frail and clinical samples differed with respect to mean age $(p<.001)$, mean MoCA score $(p=.006)$, cognitive $(p<.001)$, environmental $(p=.016)$ and physical frailty $(p<.001)$ and emotional loneliness $(p=.035)$ (post hoc comparisons are not tabulated). 
Table 1. Sociodemographic characteristics and MoCA and CFAI scores by sample

\begin{tabular}{|c|c|c|c|c|}
\hline & $\begin{array}{l}\text { Community } \\
(n=353)\end{array}$ & $\begin{array}{l}\text { Frail } \\
(n=95)\end{array}$ & $\begin{array}{l}\text { Clinical } \\
(n=73)\end{array}$ & $\mathrm{p}$-value \\
\hline \multicolumn{5}{|l|}{ Sociodemographic characteristics } \\
\hline Age (mean, SD) & $77.7(8.3)$ & $78.2(8.3)$ & $75 \cdot 4(6.6)$ & .056 \\
\hline Gender ( $\%$ female) & $55.0 \%$ & $57 \cdot 9 \%$ & $53.4 \%$ & .827 \\
\hline \multicolumn{5}{|l|}{ Cognition } \\
\hline MoCA (mean, SD) & $25.1(3.2)$ & $21.6(4.6)$ & $19.5(5.3)$ & $\leq .001$ \\
\hline \multicolumn{5}{|l|}{ Multidimensional frailty (CFAI-Plus) } \\
\hline Cognitive (mean, SD) & $6.8(5.4)$ & $8.5(5 \cdot 31)$ & $15 \cdot 3(7.0)$ & $\leq .001$ \\
\hline Environmental (mean, SD) & $2.6(3.5)$ & $4.6(4.14)$ & $3.5(4.8)$ & $\leq .001$ \\
\hline Physical (mean, SD) & $9.1(8.4)$ & $10.8(8.77)$ & $2.1(7 \cdot 7)$ & $\leq .001$ \\
\hline Psychological (mean, SD) & $4.4(4 \cdot 5)$ & $6.6(5.75)$ & $6.0(6.6)$ & .007 \\
\hline Mood disorders (mean, SD) & $1.7(2.2)$ & $2.7(2.7)$ & $3.4(3.8)$ & $\leq .001$ \\
\hline Emotional loneliness (mean, SD) & $2.8(2.9)$ & $3.9(3.8)$ & $2.6(3.3)$ & .044 \\
\hline Social (mean, SD) & $9.8(4.9)$ & $10.1(5.04)$ & $9.0(4.8)$ & .292 \\
\hline Social loneliness (mean, SD) & $3.2(3.3)$ & $3.2(3.0)$ & $2.5(3.2)$ & .063 \\
\hline Potential support network (mean, SD) & $6.6(3.0)$ & $6.9(3.0)$ & $6.4(2.3)$ & .555 \\
\hline
\end{tabular}

Note: MoCA: high scores indicate good cognitive functioning (range: o 30). CFAI-Plus: high scores indicate high frailty (domain ranges: 0-25, subdomain ranges (psychological and social frailty): 0-12.5). Pairwise comparisons are reported in the text.

\section{Prevalence per frailty domain, and co-occurrence with cognitive frailty}

Table 2 shows the prevalence of frailty in each domain by sample. The prevalence of cognitive frailty was $35.1 \%, 51.1 \%$ and $82.2 \%$ in the community, frail and clinical samples, respectively. Environmental frailty was most prevalent in the clinical sample (17.8\%) and least prevalent in the community sample (9.6\%). Physical, psychological and social frailty were most prevalent in the frail group $(16.8 \%, 22.1 \%$ and $15.8 \%$, respectively).

\section{Relationship between cognitive frailty and the other domains}

Table 3 shows the findings from the multiple linear regression analyses. In the community sample cognitive frailty was positively associated with age, physical frailty and both subdomains of psychological frailty, and negatively associated with potential support network. In the frail sample, mood disorders were related to cognitive frailty. In the clinical sample environmental frailty and mood disorders predicted cognitive frailty. 
Table 2. Prevalence of cognitive frailty and other types of frailty by sample

\begin{tabular}{llll}
\hline & $\begin{array}{l}\text { Community } \\
(\mathrm{n}=353)\end{array}$ & $\begin{array}{l}\text { Frail } \\
(\mathrm{n}=95)\end{array}$ & $\begin{array}{l}\text { Clinical } \\
(\mathrm{n}=73)\end{array}$ \\
\hline Cognitive frailty & $35.1 \%(\mathrm{n}=124)$ & $51.6 \%(\mathrm{n}=49)$ & $82.2 \%(\mathrm{n}=60)$ \\
Environmental frailty & $9.6 \%(\mathrm{n}=34)$ & $16.8 \%(\mathrm{n}=16)$ & $17.8 \%(\mathrm{n}=13)$ \\
Co-occurrence & $\mathrm{n}=17 * * *$ & $\mathrm{n}=11 *$ & $\mathrm{n}=12$ \\
Physical frailty & $12.7 \%(\mathrm{n}=45)$ & $16.8 \%(\mathrm{n}=16)$ & $9.6 \%(\mathrm{n}=7)$ \\
Co-occurrence & $\mathrm{n}=25 * * *$ & $\mathrm{n}=14 *$ & $\mathrm{n}=6$ \\
Psychological frailty & $7.1 \%(\mathrm{n}=25)$ & $22.1 \%(\mathrm{n}=21)$ & $20.5 \%(\mathrm{n}=15)$ \\
Co-occurrence & $\mathrm{n}=14 * * *$ & $\mathrm{n}=17 * *$ & $\mathrm{n}=14$ \\
Social frailty & $12.7 \%(\mathrm{n}=45)$ & $15.8 \%(\mathrm{n}=15)$ & $15.1 \%(\mathrm{n}=11)$ \\
Co-occurrence & $\mathrm{n}=11$ & $\mathrm{n}=15 *$ & $\mathrm{n}=11$ \\
\hline
\end{tabular}

Note: Prevalence figures represent the proportion of participants with above-threshold scores (see Methods section for thresholds). Co-occurrence relates to cognitive frailty. $* p \leq .05, * * p \leq .01, * * * p \leq .001$

Table 3. Relationship between cognitive frailty, the other types of frailty and age by sample

\begin{tabular}{|c|c|c|c|c|c|c|c|c|c|}
\hline & \multicolumn{3}{|c|}{$\begin{array}{l}\text { Community } \\
(\mathrm{n}=353)\end{array}$} & \multicolumn{3}{|c|}{$\begin{array}{l}\text { Frail } \\
(n=95)\end{array}$} & \multicolumn{3}{|c|}{$\begin{array}{l}\text { Clinical } \\
(n=73)\end{array}$} \\
\hline & $\mathrm{B}$ & SE & $\beta$ & $\mathrm{B}$ & SE & $\beta$ & $B$ & SE & $\beta$ \\
\hline Age & .205 & .032 & $.315^{* * *}$ & .043 & .058 & .067 & -.096 & .107 & -.090 \\
\hline \multicolumn{10}{|c|}{ Multidimensional frailty } \\
\hline Environmental & .056 & .074 & .037 & .152 & .126 & .118 & .334 & .167 & $.227^{*}$ \\
\hline Physical & .097 & .032 & $.151 * *$ & .069 & .062 & .114 & .056 & .096 & .061 \\
\hline \multicolumn{10}{|l|}{ Psychological } \\
\hline Mood disorders & .353 & .136 & $.143^{* *}$ & .919 & .216 & $.466 * * *$ & 1.073 & .264 & $.583 * * *$ \\
\hline $\begin{array}{l}\text { Emotional } \\
\text { loneliness }\end{array}$ & .351 & .105 & $.187^{* * *}$ & .131 & .163 & .094 & -.437 & .349 & -.207 \\
\hline Social & & & & & & & & & \\
\hline $\begin{array}{l}\text { Support } \\
\text { network }\end{array}$ & -.222 & .084 & $-.123^{* *}$ & -.241 & .180 & -.136 & -.375 & .346 & -.125 \\
\hline $\begin{array}{l}\text { Social } \\
\text { loneliness }\end{array}$ & .039 & .078 & .024 & -.059 & .180 & -.034 & -.317 & .306 & -.144 \\
\hline
\end{tabular}

Note: The independent variables were as follows: age, environmental frailty, physical frailty, mood disorders and emotional loneliness (psychological frailty subdomains), social loneliness and potential social support (social frailty subdomains); the dependent variable was cognitive frailty. * $p \leq .05, * * p \leq .01, * * * p \leq .001$

\section{Discussion}

The prevalence of cognitive frailty and its associations with other frailty domains were studied in community-dwelling people aged $\geq 60$ years with different levels of cognitive impairment. Cognitive frailty was most prevalent in the clinical sample $(82.2 \%)$, followed by the frail sample (51.6\%) and finally the community sample (35.1\%). This is consistent with previous research indicating that objective cognitive impairment and subjective cognitive complaints often co-occur [28]. These prevalence 
figures are also consistent with previous research on community samples. For example, Fritsch et al. [29] reported that $27.1 \%$ of participants living at home reported subjective memory complaints, whilst Mewton et al. [30] reported a prevalence of $33.5 \%$ in a similar sample. Co-occurrence of cognitive frailty and other types of frailty was most frequent in the frail and community samples.

Two patterns were observed consistently in the analyses of associations between cognitive frailty and the other types of frailty. First, social loneliness (e.g. not having enough people to rely on, an aspect of social frailty) was not related to cognitive frailty in any of the samples. This might seem unexpected, as Holmén et al. [27] found that social loneliness was negatively related to cognitive impairment, but the people in our clinical sample were aware of their impairment and it was at an early stage, so it seems likely that they were receiving social support from people around them.

Second, the mood disorders variable (psychological frailty subdomain), which captures minor depressive symptoms (e.g. feeling unhappy and depressed) [8], was positively associated with cognitive frailty in all three samples. Although it is wellknown that depression is associated with objective cognitive deficits [31, for example], there is less evidence on its relationship with subjective cognitive complaints. Nonetheless, Zlatar et al. [32] found that subjective cognitive complaints were associated with depression, even after adjusting for objective cognitive impairment. It is also possible that the combination of subjective cognitive complaints and depressive symptoms might be a precursor of dementia [33]. Our findings and those of Seo et al. [33] seem related, as mood disorders and cognitive frailty were associated in all samples, but co-occurred more frequently at higher levels of cognitive impairment (93.3\% of those in the clinical sample who had mood disorders also reported cognitive frailty). It therefore is important to assess the cognitive frailty level of people who report mood disorders, and to assess mood disorders in people who report cognitive frailty.

Differences between samples were also observed. First, emotional loneliness (e.g. missing having people around), which is a component of psychological frailty, was strongly associated with cognitive frailty in the community sample, but not in the frail or clinical samples. Previous research by Holmén et al. [27] found that emotional loneliness decreased with cognitive functioning, which might explain why we only detected an association between emotional loneliness and cognitive frailty in participants with relatively high levels objective cognitive functioning. Therefore, our findings indicate that the same relationship might hold for cognitive frailty (i.e. emotional loneliness decreases in people with lower levels of cognitive frailty), although we were not able to determine causal relationships. 
Analysis of the other component of social frailty, potential social support network, suggested that it was negatively associated with higher cognitive frailty, but only in the community sample. Previous studies have found that people who lack social ties are at increased risk of objective cognitive decline relative to their counterparts with more extensive social networks, as social networks are important for mental stimulation and maintenance or enhancement of cognitive reserve [34]. On this basis we might have expected to find the same negative association in all three samples, but it should be remembered that we measured subjective cognitive functioning (cognitive frailty) rather than objective cognitive impairment and there is a difference between one's potential social support network and one's actual social network.

Furthermore, physical frailty was only associated with cognitive frailty in the community sample. Numerous studies have examined the association between physical frailty and objective cognitive impairment. An overview by Canevelli \& Cesari [11] concluded that cognitive impairment and physical frailty were strongly linked, but the vast majority of studies on which this review was based has assessed communitydwelling older people, i.e. a sample analogous to our community sample, the only sample in which we observed an association between physical and cognitive frailty. In addition, physical frailty increases with age [18], and our clinical sample had the lowest mean age of the three samples, which might explain why physical frailty was not (yet) that prevalent and was not associated with cognitive frailty.

In addition, environmental frailty was only associated with cognitive frailty in the clinical sample. This might be explained by the fact that respondents in the clinical group had a relatively high awareness of their illness, and consequently might have been aware that they would need to make adjustments to their home if their cognitive impairment were to worsen, as it is known that adaptations are sometimes needed to enable ageing in place [35]. However, as environmental frailty is a relatively new construct, this relationship should be investigated in more depth in future research.

Lastly, age was strongly associated with cognitive frailty, but only in the community sample, yet on the basis of previous research [36] we had expected to find this association in all three groups. Possible explanation are that participants in the frail sample were selected on the basis of a broad range of risk variables, not just age [18], and the participants in the clinical sample were relatively young, as mentioned before.

\section{Strengths and limitations}

This study has several strengths. First, we analysed three different samples with varying levels of objective cognitive impairment, including a random sample of people living in their own homes. Thus we were able to explore whether the relationship between cognitive frailty and other types of frailty varied with level of cognitive 
functioning. Second, we assessed several aspects of frailty, whereas most previous studies have only looked at one or two frailty domains (usually physical and social frailty). Some limitations of the study should also be acknowledged. First, full neuropsychological assessments of the community and frail sample were not available. Our aim, however, was to get an overall indication of level of cognitive functioning in each sample and the MoCA is adequate for this purpose. Second, there was a relatively high proportion of potential participants whom were excluded from the frail sample due to missing data and, as described previously, the excluded individuals were more frail and had a higher mean level of objective cognitive impairment. In other words, the most frail participants were probably excluded from the frail sample. Third, selection bias may have influenced the results, especially in the case of the clinical sample. It seems reasonable to assume that clinical participants generally had a high awareness of their illness (they had visited a memory clinic because of their symptoms), so it is understandable that levels of cognitive frailty were higher in this sample. Fourth, we cannot state with certainty that none of the participants in the community and frail samples had $\mathrm{MCl}$ or dementia. Lastly, the community sample was by far the largest ( $n$ $=354$; frail $n=95$, clinical $n=73$ ), so the analyses of this sample had greater statistical power.

\section{Implications for future research and clinical practice}

In today's ageing society, with the number of frail older people increasing, there is a need for longitudinal research on the time course of relationships between the different frailty domains. Our results suggest that both researchers and clinicians should pay special attention to the relationship between cognitive and psychological frailty. Longitudinal research projects could study whether the presence of both cognitive and psychological frailty, and specific mood disorders, can indeed be used as a marker for risk of dementia, as suggested by Seo et al [33]. When this is the case, this sample might particularly benefit from early, multimodal prevention strategies integrating interventions focusing on cognitive and psychological functioning. Moreover, longitudinal research is needed to evaluate the temporal course of interactions between the various frailty domains, for example to determine whether the pattern of associations between frailty domains is different in the general population of older people living in the community from what it is in more vulnerable populations. This knowledge could be used to develop clinical guidelines for detection of frailty and follow-up of older people deemed at risk of adverse outcomes. From a clinical perspective it appears that it would be sensible to assess a broad spectrum of frailty domains in the general population of older people living at home, but to focus on mood disorders and cognitive frailty - and to a lesser extent environmental frailty in more vulnerable populations. 


\section{Conclusion}

In older people living at home cognitive frailty increases with level of cognitive impairment and is often accompanied by one or more other types of frailty, especially physical and social frailty. It is important to include cognitive frailty in multidimensional clinical assessments of frailty. Robust associations were found between cognitive and psychological frailty, in particular the mood disorders subdomain. Physical and social frailty, specifically the potential social support network, seem to be particularly associated with cognitive frailty in the general population of older people living at home. Environmental frailty was the only other type of frailty associated with cognitive frailty in the clinical sample.

\section{Acknowledgments}

The D-SCOPE Consortium is an international research group and is composed of researchers from University of Antwerp, Vrije Universiteit Brussel, University College Ghent, Catholic University of Leuven (Belgium), and Maastricht University (the Netherlands): Peter Paul De Deyn, Liesbeth De Donder, Jan De Lepeleire, Ellen De Roeck, Nico De Witte, Eva Dierckx, Daan Duppen, Sarah Dury, Sebastiaan Engelborghs, Bram Fret, Sylvia Hoens, Lieve Hoeyberghs, Tinie Kardol, Gertrudis I.J.M. Kempen, Deborah Lambotte, Birgitte Schoenmakers, Jos M.G.A. Schols, An-Sofie Smetcoren, Lise Switsers, Michaël Van Der Elst, Anne van der Vorst, Dominique Verté, G.A. Rixt Zijlstra.

The authors would like to thank all participating older people. 


\section{References}

1. European Commission. The 2015 Ageing Report. 2014. Available:

http://ec.europa.eu/economy_finance/publications/european_economy/2014/pdf/ ee8_en.pdf

2. Walker A, Maltby T. Active ageing: A strategic policy solution to demographic ageing in the European Union. Int J Soc Welf. 2012; 21: 117-130. doi:10.1111/j.14682397.2012.00871

3. Wiles JL, Leibing A, Guberman N, et al. The meaning of "ageing in place" to older people.Gerontologist. 2012; 52(3): 357-66.

4. Scharlach A. Creating ageing-friendly communities in the United States. Ageing Int 2011; 37(1): 25-38. doi:10.1007/s12126-011-9140-1

5. Fried LP, Tangen CM, Walston J, et al. Frailty in older adults: Evidence for a phenotype. J Gerontol A Biol Sci Med Sci. 2001; 56(3): 146-56.

6. Gobbens RJJ, van Assen MALM, Luijkx KG, et al. The Tilburg Frailty Indicator: psychometric properties. JAMDA 2010; 11(5):344-55.

7. Rockwood K, Mitnitski A. Frailty in relation to accumulation of deficits as a proxy measure of ageing. J Gerontol A Biol Sci Med Sci. 2007; 62: 722-7

8. De Witte N, Gobbens R, De Donder L, et al. The comprehensive frailty assessment instrument: Development, validity and reliability. Geriatr Nurs. 2013; 34(4): 274-81. doi:10.1016/j.gerinurse.2013.03.002

9. De Roeck EE, Dury $\mathrm{S}$, De Witte, $\mathrm{N}$ et al. CFAl-Plus: Adding cognitive frailty as a new domain to the comprehensive frailty assessment instrument. Int J Geriatr Psychiatry. 2018. https://doi.org/10.1002/gps.4875

10. Panza F, Seripa D, Solfrizzi V, et al. Targeting cognitive frailty: clinical and neurobiological roadmap for a single complex phenotype. J Alzheimers Dis. 2015; 47(4): 793-813.

11. Canevelli M, Cesari M, van Kan GA. Frailty and cognitive decline: how do they relate? Curr Opin Clin Nutr Metab Care. 2015; 18(1): 43-50.

12. Fitten LJ. Thinking about cognitive frailty. J Prev Alzheimers Dis. 2015; 2(1):7-10.

13. Kelaiditi $E$, Cesari M, Canevelli MV, et al. Cognitive frailty: rational and definition from an (IANA/IAGG) international consensus group. J Nutr Health Ageing 2013; 17(9) 726-34.

14. Fougère $B$, Daumas $M$, Lilamand $M$, et al. Association between frailty and cognitive impairment: Cross-sectional data from Toulouse frailty day hospital. JAMDA. 2017 [Epub ahead of print]

15. Jacobs JM, Cohen A, Bin-Mor E, et al. Frailty, cognitive impairment and mortality among the oldest old. J Nutr Health Ageing 2011: 15: 678-82. 
16. Montero-Odasso MM, Barnes $B$, Speechley $M$, et al. Disentangling cognitivefrailty: results from the Gait and Brain Study. J. Gerontol. A Biol. Sci. Med. Sci. 2016; 71(11): 1476-82

17. Feng L, Nyunt MSZ, Gao Q, et al. Physical frailty, cognitive impairment, and the risk of neurocognitive disorder in the Singapore Longitudinal Ageing Studies. J Gerontol A Biol Sci Med Sci. 2016; 72(3), 1-7.

18. Dury $S$, De Roeck $E$, Duppen $D$, et al. Identifying frailty risk profiles of homedwelling older people: focus on sociodemographic and socioeconomic characteristics. Aging Ment Health 2017; 21(10): 1031-9.

19. Jessen $F$, Amariglio RE, van Boxtel $M$, et al. A conceptual framework for research on subjective cognitive decline in preclinical Alzheimer's disease. Alzheimers Dement. 2014; 10(6): 844-52. doi: 10.1016/j.jalz.2014.01.001.

20. Petersen RC, Smith GE, Waring SC, et al. Mild cognitive impairment: clinical characterization and outcome. Arch Neurol, 1999: 56(3): 303-8.

21. McKhann G, Drachman D, Folstein $M$, et al. Clinical diagnosis of Alzheimer's disease Report of the NINCDS-ADRDA Work Group* under the auspices of Department of Health and Human Services Task Force on Alzheimer's Disease. Neurology 1984; 34(7): 939

22. Nasreddine ZS, Phillips NA, Bédirian V, et al. The Montreal Cognitive Assessment, MoCA: a brief screening tool for mild cognitive impairment. J Am Geriatr Soc. 2005; (53)4:695-99.

23. Julayanont $P$, Hemrungrojn $S$, Tangwongchai. The effect of education and literacy on performance on the Montreal Cognitive Assessment among cognitively normal elderly. Alzheimers Dement. 2013; 9(4): 793.

24. Doane PD, Seward LE. Measuring skewness: A forgotten statistic? J Stat Edu. 2013; 19(2): 1-18

25. Kim HY. Statistical notes for clinical researchers: assessing normal distribution (2) using skewness and kurtosis. Restor Dent Endod. 2013; 38(1): 52-4

26. Field A. Discovering statistics using IBM SPSS statistics. London: SAGE; 2013.

27. Holmén K, Ericsson K, Winblad B. Social and emotional loneliness among nondemented and demented elderly people. Arch Gerontol Geriatr. 2000; 31(3): 17792.

28. Snitz BE, Small BJ, Wang T, et al. Do subjective memory complaints le ad or follow objective cognitive change? A five-year population study of temporal influence. J Int Neuropsychol Soc. 2015; 21(9): 732-42.

29. Fritsch T, McClendon MJ, Wallendal MS, et al. Prevalence and cognitive bases of subjective memory complaints in older adults: evidence from a community sample. J Neurodegen Dis. 2014; http://dx.doi.org/10.1155/2014/176843. 
30. Mewton L, Sachdev P, Anderson T, et al. Demographic, clinical, and lifestyle correlates of subjective memory complaints in the Australian population. Am J Geriatr Psychiatry 2014; 22(11): 1222-32.

31. Rock PL, Roiser JP, Riedel WJ, Blackwell AD. Cognitive impairment in depression: a systematic review and meta-analysis. Psychol Med. 2014i 44: 2029-40. doi:10.1017/So033291713002535

32. Zlatar ZZ, Muniz M, Galasko D, Salmon DP. Subjective cognitive decline correlates with depression symptoms and not with concurrent objective cognition in a clinicbased sample of older adults. J Gerontol B Psychol Sci Soc. 2017; https://doi.org/10.1093/geronb/gbw207

33. Seo EH, Kim H, Choi KY, Lee KH, Choo IH. Association of subjective memory complaint and depressive symptoms with objective cognitive functions in prodromal Alzheimer's disease including pre-mild cognitive impairment. J Affect Disord. 2017; 1: 217:24-8. doi:10.1016/j.jad.2017.03.062.

34. Fratiglioni $L$, Wang $H$, Ericsson $K$, et al. Influence of social network on occurrence of dementia: A community-based longitudinal study. Lancet 2000; 355: 1315-9.

35. Marquardt G, Johnston D, Black BS, et al. A descriptive study of home modifications for people with dementia and barriers to implementation. J Housing Elderly 2011; 25(3): 258-73.

36. Montejo $\mathrm{P}$, Montenegro $\mathrm{M}$, Fernández MA, Maestú F. Subjective memory complaints in the elderly: Prevalence and influence of temporal orientation, depression and quality of life in a population-based study in the city of Madrid. Ageing Ment Health 2011; 15(1): 85-96. doi:10.1080/13607863.2010.501062 
$-40-$ 


\section{3}

\section{Can proxy assessments serve as a first}

screener for identifying people at risk for multidimensional frailty?

Published as

Van der Vorst, A., Zijlstra, G.A.R., De Witte, N., De Lepeleire, J., Kempen, G.I.J.M., Schols, J.M.G.A., D-SCOPE Consortium (2018). Can proxy assessments serve as a first screener for identifying people at risk for multidimensional frailty? European Geriatric Medicine 9(4): 501-7. 


\begin{abstract}
Introduction: Timely detection of multidimensional frailty is important to prevent further negative outcomes. Perspectives of general practitioners (GPs) or informal caregivers might serve as a first, global screener to identify older people in need of a more extended assessment. Therefore, we aimed to investigate whether proxy assessments are associated with older people's self-reported environmental, physical, psychological, social and overall frailty.
\end{abstract}

Methods: A cross-sectional study was conducted on 78 community-dwelling people aged 60 years and over, their GPs $(n=57)$ and informal caregivers $(n=50)$. Selfreported frailty was assessed with the Comprehensive Frailty Assessment Instrument. GPs and informal caregivers rated each frailty domain and overall frailty on a scale of o (not frail at all) to 10 (severely frail). Associations between proxy scores and selfreported frailty were examined by correlation analyses.

Results: Significant low to moderate associations were found between (1) selfreported physical frailty and physical frailty scores given by the GPs $(r=.366, p \leq .01)$ and informal caregivers $(r=.305, p \leq .05)$; and (2) self-reported psychological frailty and psychological frailty scores given by the GPs $(r=.230, p \leq .05)$ and informal caregivers $(r=.254, p \leq .05)$. No significant associations were found between proxy scores and self-reported environmental, social and overall frailty.

Conclusion: Global proxy scores as short, subjective screeners for detecting frailty cannot completely replace self-reported frailty. Nonetheless, low to moderate correlations were found for physical and psychological frailty ratings, suggesting that proxy scores might be of value as a first sign of something being wrong for these domains. 


\section{Introduction}

Although frailty is often seen as merely a physical construct [1], it can also be regarded as a multidimensional phenomenon that includes experiencing losses in physical, psychological, social, and environmental aspects [2]. Depending on the definition and measure used, prevalence rates of frailty vary between $4.2 \%$ and $59.1 \%$ [3]. Recent studies have shown that multidimensional frailty is associated with higher age [4], amongst other factors, and may lead to negative consequences such as disability and increased health care utilisation [5]. Therefore, frailty might jeopardise the wish of older people to 'age in place' [6]. This is also important from a policy perspective, for example in terms of reducing the costs of long-term care [7]. In view of the larger proportion of older people in society today [8], and the possible negative consequences [5], timely detection of frailty is important for prevention strategies to reduce the risk of negative outcomes.

In recent years, various detection instruments for frailty have been developed, including self-report measures and performance-based assessments [9]. However, a short first screener, to indicate whether such a more extended assessment is needed, might be favourable [10]. Herewith, the perspective of formal and informal caregivers might be useful, especially within the context of 'ageing in place'. First, frail older people are likely to become one of the largest groups to visit their GP, with GP consultation rates at their highest for older age groups [11]. However, about $20 \%$ of community-dwelling frail older people do not have regular contact with their GP [12]. In addition, informal caregivers reported that GPs merely focus on medical aspects [13], which is not in line with our multidimensional approach. Therefore, it might be important to assess the perspective of informal caregivers as well. Of those aged $\geq 75$ years, $18.0 \%$ received informal care in 2015 [14], and it is expected that the proportion of people aged $\geq 65$ years to receive informal care will increase to $25 \%$ by 2030 [15]. Thus, it seems likely that GPs' and/or informal caregivers' perspectives could serve as a simple, short screener to indicate whether a more extended assessment is needed [10].

Some researchers have examined proxy assessments of frailty and compared them with objective measures such as Fried's criteria [16]. However, these studies did not focus on different frailty domains, nor did they compare proxy assessments with self-reported frailty. Hoogendijk and colleagues [17] did compare a multidimensional frailty assessment by a GP with a self-report measure. Their findings revealed some apparent differences between the two: a prevalence rate of multidimensional frailty of $28.6 \%$ according to the GPs, compared with $36.4 \%$ of the older people perceiving themselves to be frail based on the Groningen Frailty Indicator [17]. However, discrepancies between ratings on an individual level are unknown and ratings were not specified for different domains of frailty. Lastly, to the best of our knowledge, previous 
research has not investigated proxy assessments of multidimensional frailty by informal caregivers.

Therefore, the aim of this study was to assess whether GPs and informal caregivers can make reliable estimations about the level of frailty as perceived by the older adult, which then could serve as a first, global screener. We compared GPs' and informal caregivers' perspectives of the frailty level of the older adult, by asking simple, short, questions, with self-reported, multidimensional frailty. Based on previous research, it was hypothesized that agreement levels would be higher for observable aspects [18-19], such as environmental and physical frailty, and lower for subjective aspects [18-19], such as psychological and social frailty.

\section{Material and methods}

\section{Study design and participants}

Data from the cross-sectional D-SCOPE study (Detection, Support and Care for frail older people: Prevention and Empowerment) was used. 121 community-dwelling people aged 60 years and over were recruited via six healthcare organizations in Flanders, Belgium. Purposive sampling was used to over-sample people at risk for frailty [4], in addition to snowball sampling. Participants were interviewed in their home between November 2015 and April 2016 by trained interviewers. Afterwards, participants were asked whether their GP and/or informal caregiver could be invited for a proxy interview. However, 52 GPs were not interviewed: 1 older adult did not have a GP (0.8\%), 12 refused an assessment by their GP (9.9\%), 16 GPs could not be reached during the study period (13.2\%) and 23 GPs did not want to participate (19.0\%). In addition, for 62 older people no informal caregivers were interviewed because 33 respondents did not have an informal caregiver (27.3\%), 17 refused a proxy assessment by their informal caregiver (14.0\%), 9 informal caregivers could not be reached during the study period (7.4\%) and 3 refused to participate $(2.5 \%)$. In the current study, older people were only included if they and at least one of their proxies completed the frailty measures. The final sample consisted of 78 older people, 57 GPs and 50 informal caregivers (8 older people did not complete the self-reported frailty measure; 12 GPs and 9 informal caregivers did not complete each domain of the frailty measure).

Informed consent was obtained from all older people, and the Ethics Committee on Human Sciences of the Vrije Universiteit Brussel approved the study (ECHW_031).

\section{Measures}

\section{Sample characteristics}

The following socio-demographic characteristics of the older people were assessed: age, gender, place of birth, marital status and living arrangement. Additionally, cognition was assessed with the Montreal Cognitive Assessment (MoCA) which 
measures, amongst others, attention, memory and orientation [20]. Scores were corrected for educational effects by giving one extra point to those with $\leq 12$ years of education [21]. Whereas the 'original' cut-off of $<26$ has been found to lead to a high number of false positives [22-23], a cut-off of $<24$ has been proposed to indicate mild cognitive problems [22-23]; the latter was applied in the present study. Age, gender and type of practice were assessed for the GPs, and age, gender, nationality, place of birth, marital status, living arrangement and relationship with the older adult for the informal caregivers.

\section{Frailty}

Self-reported multidimensional frailty was assessed using the validated Comprehensive Frailty Assessment Instrument (CFAl; [2]), which measures overall frailty and its subdomains environmental, physical, psychological and social frailty (e.g. 'My house is in a bad condition/poorly kept'; 'Have you been hampered in less demanding activities like carrying shopping bags by your state of health?'; 'I feel unhappy and depressed'; and 'There are enough people whom I can rely on when I am in trouble', respectively). Scores on each scale range from o to 25 , while overall frailty ranges from o to 100. Higher scores indicate more severe levels of frailty, and cut-offs for high frailty per domain and for overall frailty have been determined based on twostep cluster analyses (De Witte et al., available upon request). Cut-off scores for high frailty per domain are as follows: 7.51 for environmental; 18.81 for physical; 11.51 for psychological; 16.01 for social; and 38.76 for overall frailty.

Proxies were asked to determine the level of frailty of the older person per domain and for overall frailty on a ten-point scale (e.g. - 'On a scale ranging from o to 10, how frail do you think [name of older adult] is regarding his/her environment (e.g. adaptation of the home, evaluation of the neighbourhood), ranging from "not frail at all" (o) to "severely frail" (10)?"). No exact cut-offs for frailty were calculated. This rating is suggested as a first step in identifying frailty to indicate whether a more comprehensive assessment is needed [10].

\section{Statistical analyses}

First, prevalence rates of high frailty according to the CFAI were calculated per domain as well as for overall frailty, based on the cut-offs as defined by De Witte et al. (available upon request). Second, self-reported frailty was transformed into scores with a range of o to 10 (rather than o to 25 or o to 100 , respectively) to facilitate interpretation and comparisons with proxy scores. Third, descriptive statistics were conducted to characterise the sample. Fourth, normality of the data was checked. Zscores for skewness and kurtosis were obtained and, due to the sample size $(>50)$, variables with z-scores > 3.29 were classified as non-normal [24]. Thereafter, chi 


\section{CHAPTER 3}

squares (categorical data) and independent samples t-tests were performed to explore differences in socio-demographics (age, gender, marital status, living arrangement), cognitive functioning (MoCA) and self-reported frailty scores between those included and excluded from the current study. Lastly, correlations between proxy scores and self-reported frailty were computed using one-tailed Pearson correlation. Statistical significance was set at $p<.05$. All statistical analyses were carried out using IBM SPSS Statistics, Version 24 (SPSS Inc., Chicago, IL, USA).

\section{Results}

The older people included in the current study $(n=78)$ did not significantly differ from those excluded $(n=43)$ in terms of age, MoCA scores, self-reported frailty and gender. However, those included in this study were more often living with their partner $(38.5 \%$ versus $18.6 \% ; p=.024)$ or married (37.2\% versus $14.0 \% ; p=.001)$.

\section{Sample characteristics}

The mean age of the older people was 80.0 years (SD $=8.2$; range $61-95)$, and $60.3 \%$ were female. Mean MoCA score was 21.1 (SD = 4.7, range 10-29). Out of 69 participants who completed the MoCA, $65.2 \%$ scored < 24 , indicating mild cognitive problems. Participating GPs had a mean age of 56.4 years (SD $=8.5$; range $26-78$ ). The majority were male (73.7\%) and solo-practitioners (64.9\%). Informal caregivers had a mean age of 61.8 years (SD $=13.8$; range $28-92), 72.0 \%$ were female and most were a child (in-law) of the older person (58.0\%). More sample characteristics are shown in Table 1. 
Table 1. Sample characteristics

\begin{tabular}{|c|c|c|c|}
\hline & $\begin{array}{l}\text { Older people } \\
(n=78)\end{array}$ & $\begin{array}{l}\text { GPs } \\
(n=57)\end{array}$ & $\begin{array}{l}\text { Informal caregivers } \\
(n=50)\end{array}$ \\
\hline \multicolumn{4}{|l|}{ Sample characteristics } \\
\hline \multicolumn{4}{|l|}{$\underline{\text { Socio-demographics }}$} \\
\hline Age (mean (SD)) & $80.0(8.2)^{1}$ & $56.4(8.5)^{2}$ & $61.8(13.8)$ \\
\hline Females (\%) & 60.3 & 26.3 & 72.0 \\
\hline Migration background (\%) & $15 \cdot 4$ & - & 2.0 \\
\hline \multicolumn{4}{|l|}{ Current marital status (\%) } \\
\hline Married & 37.2 & - & 66.0 \\
\hline Divorced & 5.1 & - & 14.0 \\
\hline Widowed & 52.6 & - & 6.0 \\
\hline Other & 5.1 & - & 14.0 \\
\hline Living alone (\%) & 52.6 & - & - \\
\hline \multicolumn{4}{|l|}{ Cognition } \\
\hline MoCA (mean, SD) & $21.1(4.7)^{3}$ & - & - \\
\hline \multicolumn{4}{|l|}{ Practice (\%) } \\
\hline Solo & - & 64.9 & - \\
\hline Duo & - & 12.3 & - \\
\hline Group & - & 22.8 & - \\
\hline \multicolumn{4}{|l|}{$\underline{\text { Relationship with older }}$} \\
\hline \multicolumn{4}{|l|}{ adult (\%) } \\
\hline Partner & - & - & 24.0 \\
\hline Child (in-law) & & - & 58.0 \\
\hline Grandchild & - & - & 2.0 \\
\hline Other family member & - & - & 8.0 \\
\hline Neighbour & - & - & 8.0 \\
\hline \multicolumn{4}{|l|}{ Frailty assessment } \\
\hline \multicolumn{4}{|l|}{ Frailty (mean, SD) } \\
\hline Environmental & $1.7(1.6)$ & & \\
\hline Physical & $4.8(3.5)$ & & \\
\hline Psychological & $2.6(2.4)$ & & \\
\hline Social & $3.9(1.9)$ & & \\
\hline Overall & $3.3(1.5)$ & & \\
\hline
\end{tabular}

Note: $\mathrm{MoCA}=$ Montreal Cognitive Assessment (range 0-30). Frailty: measured with the Comprehensive Frailty Assessment Instrument. Higher scores indicate higher levels of frailty (range 0-10).

${ }^{1} \mathrm{n}=77,{ }^{2} \mathrm{n}=55,{ }^{3} \mathrm{n}=69$ 


\section{Self-reported multidimensional frailty and proxy scores}

The lower part of Table 1 shows mean self-reported frailty scores. Scores ranged from 1.7 to 4.8 , with lowest scores for environmental frailty and highest for physical frailty. According to these self-reports, $14.1 \%$ of the respondents were environmentally frail, $19.2 \%$ physically, $20.5 \%$ psychologically, $12.8 \%$ socially and $30.8 \%$ overall (not tabulated).

Tables 2 and 3 show the mean scores and standard deviations for the frailty domains, and the correlations between self-reported frailty and proxy scores. Proxy scores ranged from 2.6 to 5.1, with lowest scores for environmental frailty and highest for physical frailty. There was a significant, moderate relationship between selfreported frailty and GPs' scores for physical frailty $(r=.366, p \leq .01)$, and a low correlation similarly for psychological frailty $(r=.230, \mathrm{p} \leq .05)$. In addition, a significant, moderate relationship between informal caregivers' scores of physical frailty and selfreported physical frailty, $(r=.305, p \leq .05)$, and a low correlation similarly for psychological frailty $(r=.254, p \leq .05)$ were found. No significant correlations were found for environmental, social or overall frailty.

After conducting correlation analyses separately for those aged 80 years and over $(n=39)$, and 79 years or younger $(n=36)$, differences in correlations were observed. Only in those aged 80 years and over a significant association between GPs' scores and self-reported physical frailty was found $(r=.663, p \leq .001)$, as well as a borderline significant association between informal caregivers' scores and selfreported physical frailty $(r=.296, p=.056)$ (findings not tabulated).

Table 2. Pearson correlations between older people's and GPs' frailty assessments $(n=57)$

\begin{tabular}{llll}
\hline & $\begin{array}{l}\text { Older people } \\
(\text { mean, SD) }\end{array}$ & $\begin{array}{l}\text { GPs } \\
(\text { mean, SD) }\end{array}$ & $\begin{array}{l}\text { Correlation } \\
(r, p \text {-value })\end{array}$ \\
\hline$\underline{\text { Frailty }}$ & $1.5(1.5)$ & $2.6(2.2)$ & $.093(.245)$ \\
Environmental & $4.8(3.3)$ & $4.2(2.4)$ & $.366(.003)$ \\
Physical & $2.7(2.3)$ & $3.6(2.7)$ & $.230(.043)$ \\
Psychological & $3.6(1.8)$ & $3.0(2.6)$ & $.177(.094)$ \\
Social & $3.2(1.4)$ & $4.2(2.6)$ & $.141(.148)$ \\
Overall & &
\end{tabular}

Note: Frailty: higher scores indicate higher levels of frailty (range 0-10). Older people: frailty measured with the Comprehensive Frailty Assessment Instrument; proxies: 1-item questions. 
Table 3. Pearson correlations between older people's and informal caregivers' frailty assessments $(n=50)$

\begin{tabular}{llll}
\hline & $\begin{array}{l}\text { Older people } \\
(\text { mean, SD) }\end{array}$ & $\begin{array}{l}\text { Informal caregivers } \\
\text { (mean, SD) }\end{array}$ & $\begin{array}{l}\text { Correlation } \\
(r, \mathrm{p} \text {-value })\end{array}$ \\
\hline Frailty & $1.8(1.7)$ & $2.6(0.7)$ & $.121(.202)$ \\
Environmental & $4.7(3.7)$ & $5.1(2.2)$ & $.305(.016)$ \\
Physical & $2.3(2.2)$ & $4.1(2.3)$ & $.254(.038)$ \\
Psychological & $3.9(1.9)$ & $3.5(2.7)$ & $.027(.427)$ \\
Social & $3.3(1.6)$ & $4.7(2.4)$ & $.127(.189)$ \\
Overall & & &
\end{tabular}

Note: Frailty: higher scores indicate higher levels of frailty (range 0-10). Older people: frailty measured with the Comprehensive Frailty Assessment Instrument; proxies: 1-item questions.

\section{Discussion}

This study assessed the associations between one-item proxy scores by GPs and informal caregivers, as a first screener, and self-reported multidimensional frailty in community-dwelling people aged 60 years and over. The results show that the relationship between proxy scores and self-reported frailty differs per domain, although proxy scores by GPs and informal caregivers were rather consistent. Whereas physical and psychological frailty scores by proxies and older people were significantly correlated, though only to a low (psychological frailty) to moderate (physical frailty) degree, no significant correlations were found for environmental, social and overall frailty. Thus, results suggest that proxy scores cannot completely replace self-reported multidimensional frailty. Nonetheless, for physical and psychological frailty, proxy scores might give an initial indication of whether further assessment is needed.

Our finding that physical frailty scores are moderately related might not be surprising as it corresponds with previous research on agreement levels [19,25], and might be due to the observable nature of physical frailty [18-19]. The low correlations between psychological frailty scores are comparable with previous research as well [25]. Nonetheless, for physical frailty, proxy assessments seem particularly useful at higher ages, as correlations only remained significant in those aged 80 years and over. This might be explained by the well-known relationship between higher age and physical frailty [1].

However, despite the observable nature of environmental frailty, such as housing condition, self-reported and proxy-assessed environmental frailty were not significantly related. This unexpected finding might be explained by proxies focusing on the need for adaptations in the house, in contrast to older people who prefer a home to which they are emotionally attached, even if it is 'suboptimal' [26]. Older people feel more purposeful when they are able to overcome difficulties, such as 
walking stairs [26]. Both could cause older people to self-report lower levels of environmental frailty.

Regarding social frailty, previous research has shown discrepancies between patient and GP scores on social aspects such as family relationships, possibly because these topics are not discussed during consultation [27]. However, while they also argued that assessments by family members are more similar to self-reports [27], we found no significant correlation with the scores of the informal caregivers either. Informal caregivers might feel that they are the ones on which the older people can rely when in difficulty, whereas older people might miss having people around them during the day.

However, other factors might explain our findings as well. First, proxies might have given a score based on their own perspective, rather than what they thought the older adult's perspective would be [28]. Second, frailty is still defined merely as a medical concept [29], which is not in line with our multidimensional approach. Third, sociodemographic characteristics might influence ratings, although findings on this differ between studies. While one study showed that neither gender, whether or not the patient and proxy live together, nor the closeness of the relationship influenced the association between scores [30], others argue that the amount of time spent together influences whether ratings are comparable [19], as does whether patients and proxies live together [31]. Fourth, people tend to rate themselves more favourably than is the case in reality [32] while proxies tend to report more difficulties [25], possibly due to higher levels of caregiver burden [25,33]. Lastly, previous research has shown that formal and informal proxies are usually equally (in)correct [31], which seems in line with our findings.

\section{Strengths and limitations}

This study has several strengths. First, it is the first study to assess formal and informal proxy scores of environmental, physical, psychological, social and overall frailty. Second, our inclusion rate of proxy scores by GPs (57.0\%) lies within the range of other studies [34]. However, some limitations should be mentioned as well. First, different frailty measures were applied in the different populations. Consequently, scores by the older people and their proxies were not directly comparable. Because there are no cutoffs for the proxy measures available, the number of false positives and false negatives could not be determined. Nonetheless, as both scores ranged from 'not frail at all' to 'severely frail', it was possible to examine correlations. Second, participants had relatively low scores on the MoCA, and cognitive impairment could cause denial of problems or reduced awareness of problems [35]. However, it is known that many participants score below the cut-off in population-based cohorts, and it has been argued that this threshold should be lower [36]. Yet, there is no consensus about an 
optimal cut-off score so far [36]. Third, the sample size was relatively low, partly due to the high number of missing values (i.e. on the frailty measures or because no proxy assessments were conducted). However, significant differences between those in- and excluded were only found for living arrangement and marital status, which might have merely influenced whether a spouse was available as an informal proxy.

\section{Conclusion and implications}

Proxy scores cannot be a substitute for self-reported frailty, although proxy scores of physical and psychological frailty might serve as a first step in the process of screening (i.e. as an indicator for the need of a more extended assessment). However, further research should be conducted to gain more insight into factors underlying these discrepancies.

First, future studies should include a larger number of older people and proxies, and should assess self-reported frailty with both a validated scale and a simple, one-item measure. In addition, factors that might influence correlation levels, such as contact frequency, should be taken into account. Furthermore, the potentially different perspectives of older people and their proxies could be investigated in more depth by means of a qualitative study. Moreover, longitudinal studies should take adverse outcomes into account, to be able to investigate the predictive value of proxy assessed frailty per domain, and if this differs compared with self-reported frailty. Lastly, whereas we aimed to compare proxy assessments with self-reported frailty, for clinical practice it might be necessary to gain insight into multiple perspectives (i.e. from the older people as well as from proxies) in order to develop a richer understanding of the actual frailty level of the older person [29], given that frailty is a multidimensional and complex construct.

\section{Acknowledgments}

The D-SCOPE Consortium is an international research group and is composed of researchers from University of Antwerp, Vrije Universiteit Brussel, University College Ghent, Catholic University of Leuven (Belgium), and Maastricht University (the Netherlands): Peter Paul De Deyn, Liesbeth De Donder, Jan De Lepeleire, Ellen De Roeck, Nico De Witte, Eva Dierckx, Daan Duppen, Sarah Dury, Sebastiaan Engelborghs, Bram Fret, Sylvia Hoens, Lieve Hoeyberghs, Tinie Kardol, Gertrudis I.J.M. Kempen, Deborah Lambotte, Birgitte Schoenmakers, Jos M.G.A. Schols, An-Sofie Smetcoren, Lise Switsers, Michaël Van Der Elst, Anne van der Vorst, Dominique Verté, G.A. Rixt Zijlstra.

The authors would like to thank all participating older people, GPs, and informal caregivers. 


\section{References}

1. Fried LP, Tangen CM, Walston J, et al. Frailty in older adults: evidence for a phenotype. J Gerontol A Biol Sci Med Sci 2001; 56(3): 146-57.

2. De Witte $N$, Gobbens $R$, De Donder $L$, et al. The comprehensive frailty assessment instrument: development, validity and reliability. Geriatr Nurs 2013;34(4):274-81

3. Collard RM, Boter H, Schoevers RA, Oude Voshaar RC. Prevalence of frailty in a community-dwelling older persons: a systematic review. J Am Geriatr Soc 2012;6o(8):1487-92

4. Dury $S$, De Roeck $E$, Duppen $D$, et al. Identifying frailty risk profiles of homedwelling older people: focus on sociodemographic and socioeconomic characteristics. Aging Ment Health 2017;21(10):1031-39

5. Gobbens RJ, van Assen MALM, Luijkx KG, Schols JMGA. The predictive validity of the Tilburg Frailty Indicator: disability, health care utilization, and quality of life in a population at risk. Gerontologist 2012;52(5):619-31

6. Wiles JL, Leibing A, Guberman N, Reeve J, Allen RES. The meaning of "aging in place" to older people. Gerontologist 2012;52(3):357-66

7. Scharlach A. Creating Aging-Friendly communities in the United States. Ageing Int 2011;37(1):25-38

8. European Commission. The 2015 ageing report (2014). Available:

http://ec.europa.eu/economy_finance/publications/european_economy/2014/pdf/ ee8_en.pdf. Accessed 8 December 2016

9. Bouillon K, Kivimaki M, Hamer M, et al. Measures of frailty in population-based studies: an overview. BMC Geriatr 2013;13(64). http://dx.doi.org/10.1186/14712318-13-64

10. De Lepeleire J, Degryse J, Illiffe S, Mann E, Buntinx F. Family physicians need easy instruments for frailty. Age Ageing 2008;37:484-85

11. Wang Y, Hunt K, Nazareth I, Freemantle N, Petersen I. Do men consult less than women? An analysis of routinely collected UK general practice data. BMJ Open. 2013 doi:10.1136/bmjopen-2013-003320

12. van Campen C. (ed) Kwetsbare ouderen. Sociaal en Cultureel Planbureau. 2011 [in Dutch]

13. Cès S, Flusin D, Schmitz O, et al. Mantelzorgers van thuiswonende ouderen in België: een cruciale en complexe rol. Data-onderzoek. Koning Boudewijnstichting. 2016. [in Dutch]

14. Verbeek-Oudijk D, Putman L, de Klerk M. Zorg en ondersteuning in Nederland: kerncijfers. 2015. [in Dutch] Available:

https://www.scp.nl/Publicaties/Alle_publicaties/Publicaties_2017/Zorg_en_onders teuning_in_Nederland_kerncijfers_2015. Accessed 8 February 2017 
15. Sadiraj K, Timmermans T, Ras M, de Boer A. De toekomst van de mantelzorg. Den Haag: Sociaal en Cultureel Planbureau. 2009. [in Dutch].

16. Salter ML, Gupta N, Massie AB, et al. Perceived frailty and measured frailty among adults undergoing hemodialysis: a cross-sectional analysis. BMC Geriatr 2015;15(1). doi:10.1186/s12877-015-0051-y

17. Hoogendijk EO, Van Der Horst HE, Deeg DJ, et al. The identification of frail older adults in primary care: comparing the accuracy of five simple instruments. Age Ageing 2013;42(2):262-5.

18. McPherson CJ, Addington-Hall JM. Judging the quality of care at the end of life: can proxies provide reliable information? Soc Sci Med. 2003;56(1):95-109

19. Snow AL, Cook KF, Lin PS, Morgan RO, Magaziner J. Proxies and Other External Raters: Methodological Considerations. Health Serv Res 2005;40:1676-93

20. Nasreddine ZS, Phillips NA, Bédirian V, et al. The Montreal Cognitive Assessment, MoCA: a brief screening tool for mild cognitive impairment. J Am Geriatr Soc 2005;53(4):695-9

21. Julayanont $P$, Hemrungrojn $S$, Tangwongchai. The effect of education and literacy on performance on the Montreal Cognitive Assessment among cognitively normal elderly. Alzheimers Dement 2013;9(4):793

22. Luis CA, Keegan AP, Mullan M. Cross validation of the Montreal Cognitive Assessment in community dwelling older adults residing in the Southeastern US. Int J Geriatr Psychiatry 2009;24(2): 197-201.

23. Magierska J, Magierski R, Fendler W, Kłoszewska I, Sobów TM. Clinical application of the Polish adaptation of the Montreal Cognitive Assessment (MoCA) test in screening for cognitive impairment. Neurologia i Neurochirurgia Polska 2012;46(2): 130-9.

24. Kim HY. Statistical notes for clinical researchers: assessing normal distribution (2) using skewness and kurtosis. Restor Dent Endod 2013;38(1):52-4

25. Neumann PJ, Araki SS, Gutterman EM. The use of proxy respondents in studies of older adults: lessons, challenges, and opportunities. J Am Geriatr Soc 2000;48(12):1646-54

26. Sixsmith J, Sixsmith A, Fänge AM, et al. Healthy ageing and home: the perspectives of very old people in five European countries. Soc Sci Med 2014;106:1-9

27. Wilson KA, Dowling AJ, Abdolell M, Tannock IF. Perception of quality of life by patients, partners and treating physicians. Qual Life Res 2000;9(10): 41-52.

28. Pickard AS, Knight SJ. Proxy evaluation of health-related quality of life. Med Care 2005;43(5):493-9.

29. Nicholson $C$, Gordon AL, Tinker A. Changing the way "we" view and talk about frailty. Age Ageing 2017;46(3):349-51. 


\section{CHAPTER 3}

30. Capuzzo M, Grasselli C, Carrer S, Gritti G, Alvisi R. Quality of life before intensive care admission: agreement between patient and relative assessment. Intensive Care Med 2000;26(9):1288-95

31. Sprangers MA, Aaronson NK. The role of health care providers and significant others in evaluating the quality of life of patients with chronic disease: a review. J Clin Epidemiol 1992;45(7):743-60

32. Layne C. Painful truths about depressives' cognitions. J Clin Psychol 1983;39: 84853.

33. Long K, Sudha S, Mutran EJ. Elder-proxy agreement concerning the functional status and medical history of the older person: the impact of caregiver burden and depressive symptomatology. J Am Geriatr Soc. 1998;46(9):1103-11.

34. Kellerman SE, Herold J. Physician Response to Surveys. Am J Prev Med 2001;20(1):61-7

35. Dillon C, Serrano CM, Castro D, Perez Leguizamón P, Heisecke, SL, Taragano FE. Behavioral symptoms related to cognitive impairment. Neuropsychiatr Dis Treat 2013;9: 1443-55.

36. Davis DHJ, Creavin ST, Yip JLY, Noel-Storr AH, Brayne C, Cullum S. Montreal Cognitive Assessment for the diagnosis of Alzheimer's disease and other dementias (review). Cochrane Database of Syst Rev 2015;10. 
$-56-$ 


\section{4}

\section{Limitations in activities of daily living in community-dwelling people aged 75 and over: a systematic literature review of risk and protective factors}

Published as

Van der Vorst, A., Zijlstra, G.A.R., De Witte, N., Duppen, D., Stuck, A.E., Kempen, G.I.J.M., Schols, J.M.G.A., D-SCOPE consortium (2016). Limitations in activities of daily living in community-dwelling people aged 75 and over: a systematic literature review of risk and protective factors. PLOS ONE, 11(10): e0165127. 


\section{Abstract}

Background: Most older people wish to age in place, for which functional status or being able to perform activities of daily living (ADLs) is an important precondition. However, along with the substantial growth of the (oldest) old, the number of people who develop limitations in ADLs or have functional decline dramatically increases in this part of the population. Therefore, it is important to gain insight into factors that can contribute to developing intervention strategies at older ages. As a first step, this systematic review was conducted to identify risk and protective factors as predictors for developing limitations in ADLs in community-dwelling people aged 75 and over.

Methods: Four electronic databases (CINAHL (EBSCO), EMBASE, PsycINFO and PubMed) were searched systematically for potentially relevant studies published between January 1998 and March 2016.

Results: After a careful selection process, 6,910 studies were identified and 25 were included. By far most factors were examined in one study only, and most were considered risk factors. Several factors do not seem to be able to predict the development of limitations in ADLs in people aged 75 years and over, and for some factors ambiguous associations were found. The following risk factors were found in at least two studies: higher age, female gender, diabetes, hypertension, and stroke. A high level of physical activity and being married were protective in multiple studies. Notwithstanding the fact that research in people aged 65 years and over is more extensive, risk and protective factors seem to differ between the 'younger' and 'older' olds.

Conclusion: Only a few risk and protective factors in community-dwelling people aged 75 years and over have been analysed in multiple studies. However, the identified factors could serve both detection and prevention purposes, and implications for future research are given as well. 


\section{Introduction}

In $2013,18 \%$ of the European Union (EU) population was aged 65 years or older, which is expected to increase to $28 \%$ in 2060 . However, those aged 80 years and over are the fastest growing group with an expected increase from $5 \%$ in 2013 to $12 \%$ in 2060 [1]. With this rising proportion of the (oldest) old, concepts as active ageing and ageing in place have gained more and more attention [2]. According to the WHO [3], active ageing "aims to extend healthy life expectancy and quality of life for all people as they age". Herewith, one of the key goals is maintaining independence, defined as, "the ability to perform functions related to daily living - i.e. the capacity of living independently in the community with no and/or little help from others" [3]. Indeed, delaying dependency is important to be able to live autonomously for as much and as long as possible [4], or in other words, to age in place. Ageing in place is not only important from a policy perspective (i.e. to reduce the high costs of institutionalisation; [5]), but is also the wish of most older people, even when significant health problems arise and they need care [6].

Early detection of risks associated with ageing is important to minimise or slow down negative consequences of ageing [e.g. 7], and therewith to facilitate ageing in place. Researchers have been focusing on the process leading from ill health to disability for many years. A prominent model is the disablement process model, in which the progressive worsening from pathology (biochemical or physiological abnormalities) to impairments (dysfunctions affecting physical, mental, and/or social functioning), functional limitations (restrictions in performing activities), and eventually disability (difficulty doing activities) is elaborated. Furthermore, this model describes personal capacities and demands created by the social and physical environment that speed up or slow down this process, which can be both intraindividual (i.e. coping) and extra-individual (i.e. medical care) [8].

In a previous review with functional status decline as outcome measure, different risk factors related to the disablement process have been identified [9]. Amongst others, impaired cognition, depression, comorbidity, low frequency of social contacts, low level of physical activity, poor self-perceived health, smoking, and vision impairment have been found to influence this process [9]. An update and broadening of this review might give new insights for several reasons. First, it is important to examine a more specific, homogenous outcome to be able to determine a causal pathway. The results of the earlier review of Stuck et al. [9] were based on a broad definition of functional status decline, encompassing ADLs, instrumental ADLs (IADLs), and upper and lower extremity function. In contrast, the purpose of the present review was to specifically analyse the predictors of decline in ADLs, which are essential for an independent life [10]. This makes it possible to give a more focused contribution to preventive actions. Second, since the development of limitations in 
ADLs are known to increase with age, and especially in those aged 80 years and over [e.g. 11], it seems more constructive to focus on the (oldest) old, while Stuck et al. [9] included studies with a broader age range $\left(25^{+}\right)$. For example, the need for help with ADLs was 3.5\% in 65-74 year old Americans, 7.4\% in those aged 75-84 years, and $18.1 \%$ in those aged 85 and over [12]. Since limitations in ADLs are most substantial in the oldest old, it is important to investigate whether it is possible to intervene in the slightly younger age group $\left(75^{+}\right)$to work prevention-driven. Third, the identification of both risk and protective factors is relevant. As a result, strategies not only to reduce the risk factors can be implemented, but also to strengthen protective factors [13]. Although risk and protective factors are often thought to be different sides of the same coin, previous research has revealed differences between predictors for ill-health and excellent health [14]. In addition, Kempen, Ranchor, van Sonderen, van Jaarsveld, and Sanderman [15] showed that risk factors for and protective factors against IADLs and ADLs are not always that closely related. However, Stuck et al. [9] mainly focused on risk factors. Lastly, since the previous review dates from 1999, an update indeed is useful.

To conclude, this systematic review aims to obtain insight into risk factors for and protective factors against developing limitations in ADLs in community-dwelling people aged 75 and over.

\section{Materials and methods}

This systematic review was conducted according to the PRISMA (Preferred Reporting Items for Systematic Reviews and Meta-Analyses) guidelines [16]. The study protocol was not preregistered.

\section{Database sources and search strategy}

Electronic databases CINAHL (EBSCO), EMBASE, PsycINFO and PubMed were searched on 7 March 2016 for manuscripts published between 1 January 1998 and 1 March 2016. Searches were tailored to the specific databases ( $\mathrm{S}_{1} \mathrm{Text}$ ), and included key words and MeSH terms related to risk factors for and/or protective factors against developing limitations in ADLs in community-dwelling people aged 75 and over.

\section{Definition key concepts}

ADLs were defined as activities essential for an independent life [10] or necessary for survival [8], representing common everyday tasks required for self-care [17]. Outcome measures needed to include at least three of the following activities: bathing, dressing, eating, toileting, and transferring [e.g. 17]. Risk factors were defined as factors that lead to limitations in ADLs, whereas protective factors are associated with prevention or alleviation. To be as comprehensive as possible, all factors measured as potential 
risk factors for and/or protective factors against developing limitations in ADLs in community-dwelling older people were taken into account.

\section{Inclusion and exclusion criteria}

Longitudinal, prospective studies, published in the public domain, written in English, and assessing risk factors for and/or protective factors against developing limitations in ADLs in community-dwelling people aged 75 and over were included. Studies in which all or part of the population was living in a long-term care facility at baseline were excluded as well, unless results for persons living at home at baseline were reported separately. Level of limitation in ADLs at baseline was no inclusion or exclusion criterion. Cross-sectional and intervention studies were excluded, as well as studies assessing subsamples of the population (e.g. people with sarcopenia), and case-control studies.

Studies evaluating IADLs, which are necessary for maintaining a dwelling in a given sociocultural setting (i.e. the ability to use the telephone; [8]), mobility, balance, gait performance, or lower and/or upper extremity function were excluded. Studies using combined measures of IADL and ADL were excluded as well, unless results were reported separately. In addition, studies in which people were defined as having developed limitations in ADLs when they were institutionalised, hospitalised or died at follow-up, were excluded.

\section{Selection and data extraction}

Bibliographic details of retrieved studies were stored in EndNote (version X6) and the selection process was tracked in Excel. After removing duplicate records, a random sample of $10 \%$ was assessed by two reviewers (authors AvdV and DD). Agreement for inclusion and exclusion was greater than 95\% (95.6\%), and therefore, the process was completed by one reviewer (author AvdV). To decide upon inclusion, a predefined order was used to screen titles, abstracts, and keywords in the first stage, and full-texts if necessary, namely: population, concept and measurement of ADLs, design, measurement of risk and/or protective factors, and report of quantitative data. When one of the domains was scored as 'exclude', the study was excluded without assessing the other domains. When all domains were scored as 'include' and/or 'unclear', the fulltext was screened using the same order. In case of doubt, the final decision was made after discussion with a third reviewer (author GARZ). Reference lists of included studies were reviewed to ensure inclusion of all relevant studies.

Data of a random selection of included studies (20\%) were extracted by two independent reviewers (authors AvdV and DD). Because agreement was equal to the prearranged level of $95 \%$, the data extraction was completed by one reviewer (author AvdV). A structured form with the following variables was used: (1) publication details 
(first author, year, country); (2) study details (baseline sample size, sample size in analyses, age, gender, length of follow-up, mortality rate); (3) concept and measurement of ADLs; (4) concept and measurement of risk and/or protective factors; and (5) quantitative results (If results were available for the entire sample, they were taken into account instead of subgroup analyses).

\section{Evaluation of studies and factors}

Data synthesis and analyses

To structure this review, a direct content analysis approach was used ([8], for an overview). All risk and protective factors from a random sample of the included studies $(n=10)$ were identified and grouped into major domains as initial coding categories. Next, the risk and protective factors in all included studies were identified and grouped under one of these domains. If necessary, a domain was added. Meta-analyses were not performed because the identified factors were too heterogeneous.

\section{Quality assessment and strength of evidence}

Since there is limited consensus on the quality assessment of prognostic studies, a modified version of checklists by [19-20] was used ( $\mathrm{S}_{1}$ Table). Selection, attrition, and measurement bias, confounding, and the risk of bias related to analyses and selective reporting of results were assessed. Two reviewers (authors AvdV and DD) independently assessed the quality of each study, and discussed disagreements. When not all the required information per domain was available, the item was scored as unclear.

The overall strength of evidence per factor (after grouping results) was determined using criteria based on the checklist used by Stuck et al. [9]. Studies with a quality assessment score of more than $50 \%$ (a score of $\geq 7$ out of 12 ), and excluding people with limitations in ADLs at baseline were classified as high quality studies. Studies with a quality assessment score of $50 \%$ or less and/or including people with limitations in ADLs at baseline were classified as low quality studies. Ratings for overall evidence per factor were as follows:

- Evidence in $\geq 3$ high quality studies: +++

- Evidence in 2 high or $\geq 3$ low quality studies: ++

- Evidence in 1 high or 2 low quality studies: +

- Evidence in 1 low quality study: +/- 


\section{Results}

\section{Search outcome}

Fig 1 shows the flowchart of the selection process. Once duplicates were removed, 6,910 potentially relevant studies were identified. After assessing title, abstract, and keywords, 574 full-texts needed further examination, which resulted in the inclusion of 20 studies. After screening their reference lists, another five were included, resulting in 25 included studies.

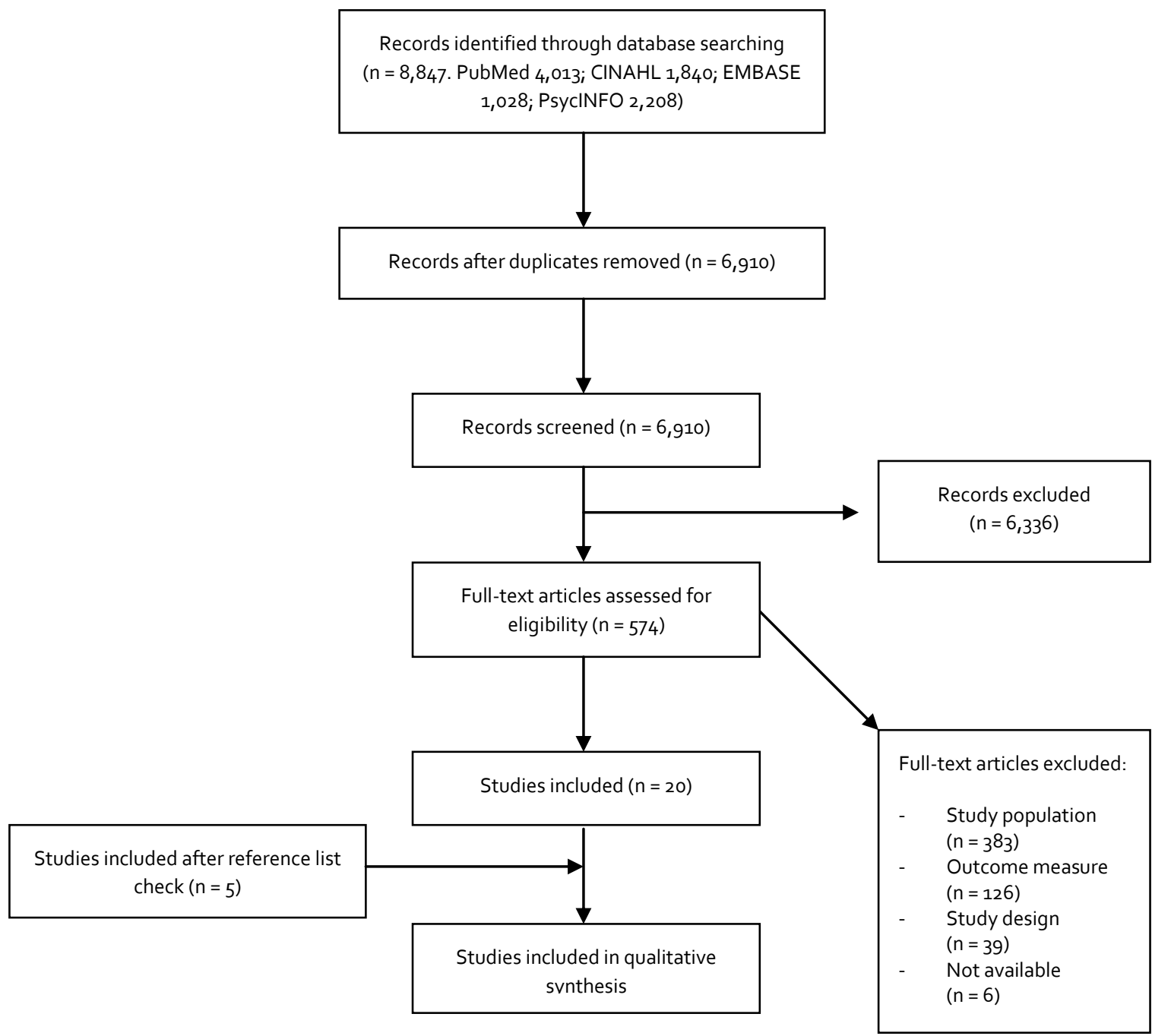

Figure 1. PRISMA flowchart

Figure credited from: Moher D, Liberati A, Tetzlaff J, Altman DG, The PRISMA Group (2009). Preferred Reporting Items for Systematic Reviews and Meta-Analyses: The PRISMA Statement. PLoS Med 6(7): e1000097. doi:10.1371/journal.pmed1000097 


\section{Description of included studies}

Characteristics of the included studies are presented in Table 1. Studies were conducted in a wide range of countries. The length of follow-up ranged from 2 to 20 years. Limitations in ADLs were measured with questionnaires only (no performancebased assessments), and included the items bathing and dressing in all studies. Gender distribution was variable, whereby two studies included women only.

Four studies met at least five of the six quality criteria, while for eight studies two criteria could not be judged because of a lack of information. In most cases, study participation and attrition could not be judged because it was not reported whether non-response was selective. Thirteen studies were classified as high quality (quality assessment score $\geq 7$ out of 12 , and excluding people with limitations in ADLs at baseline) ( $S_{2}$ Table for full details). 


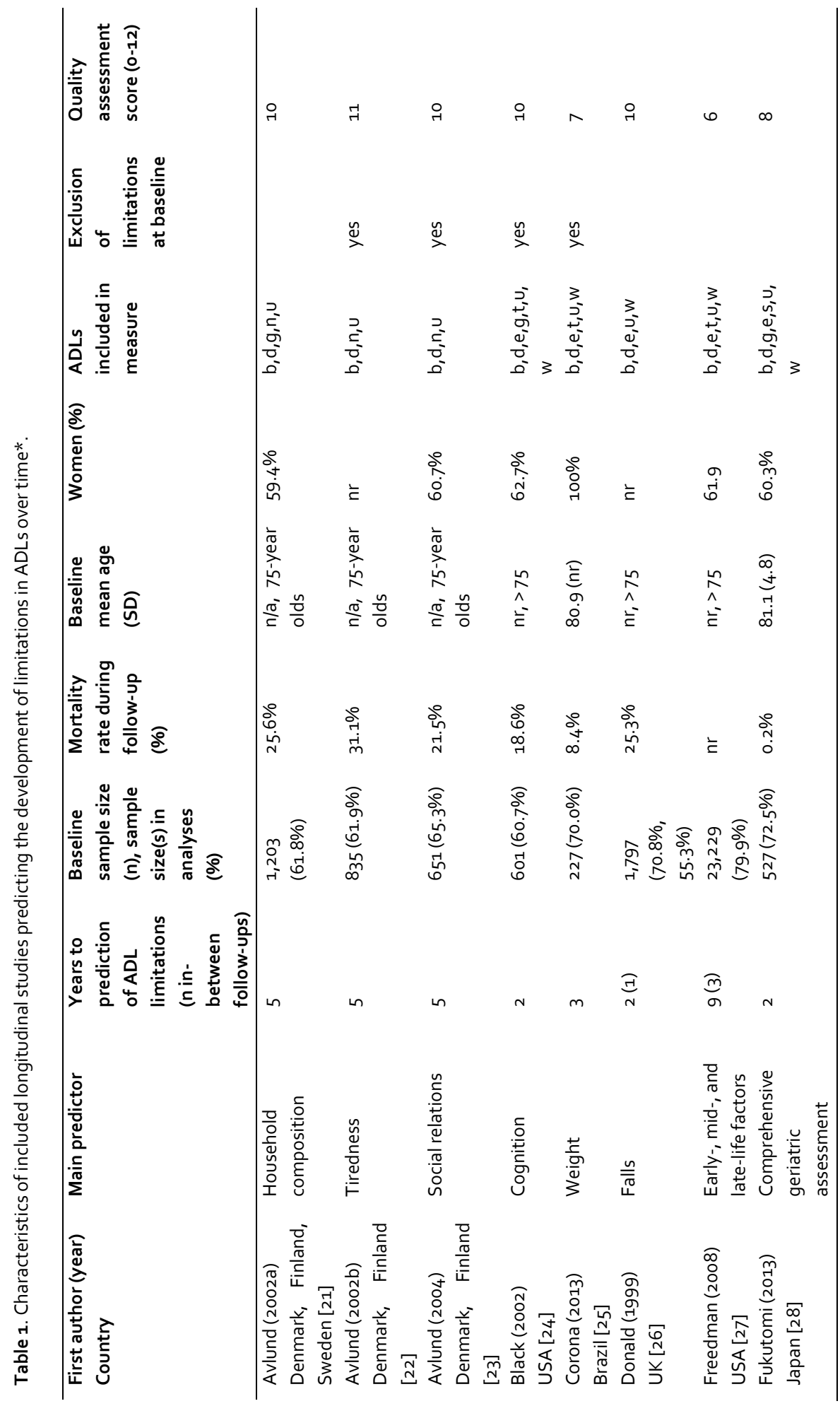




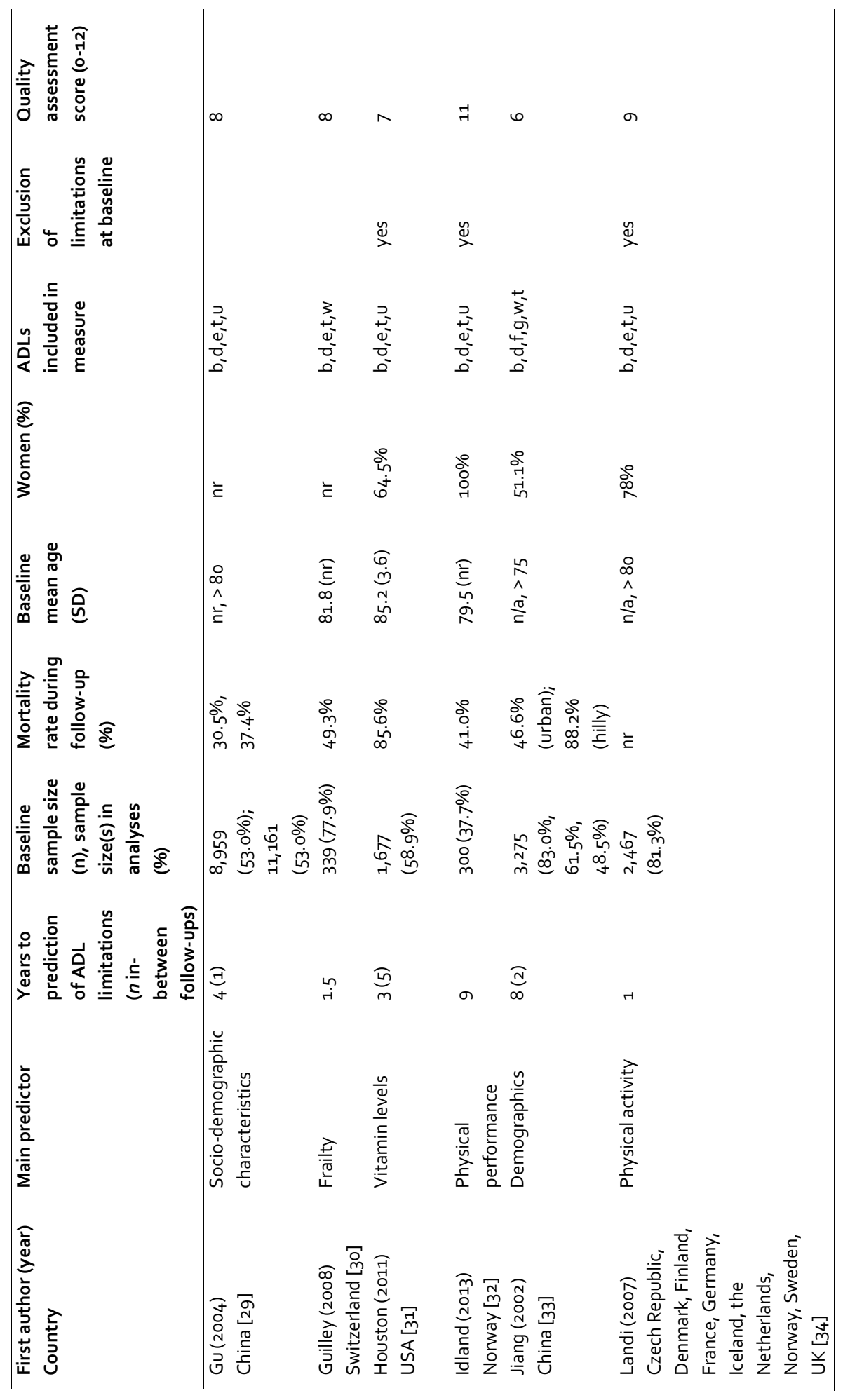


RISK \& PROTECTIVE FACTORS FOR LIMITATIONS IN ACTIVITIES OF DAILY LIVING

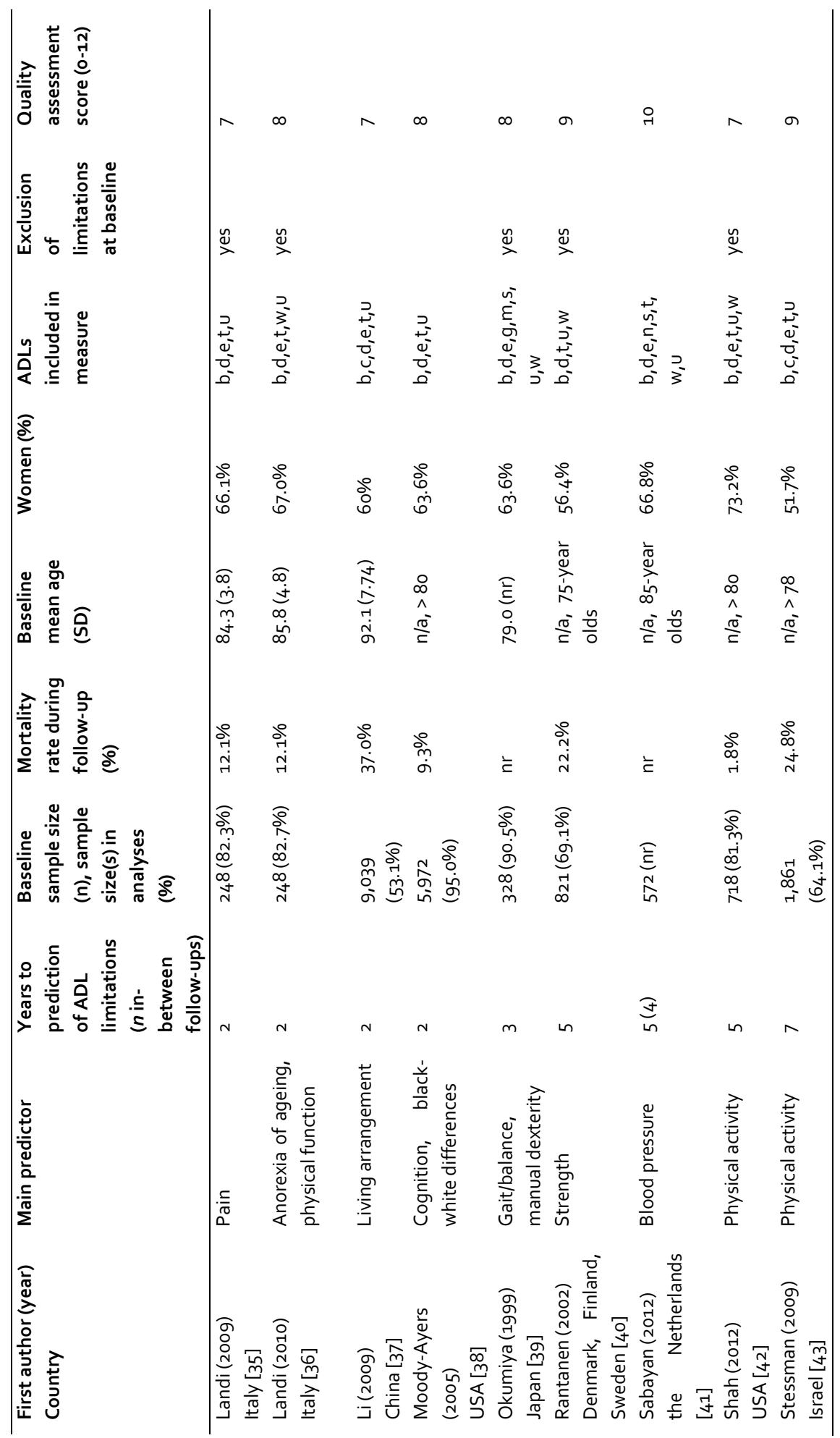




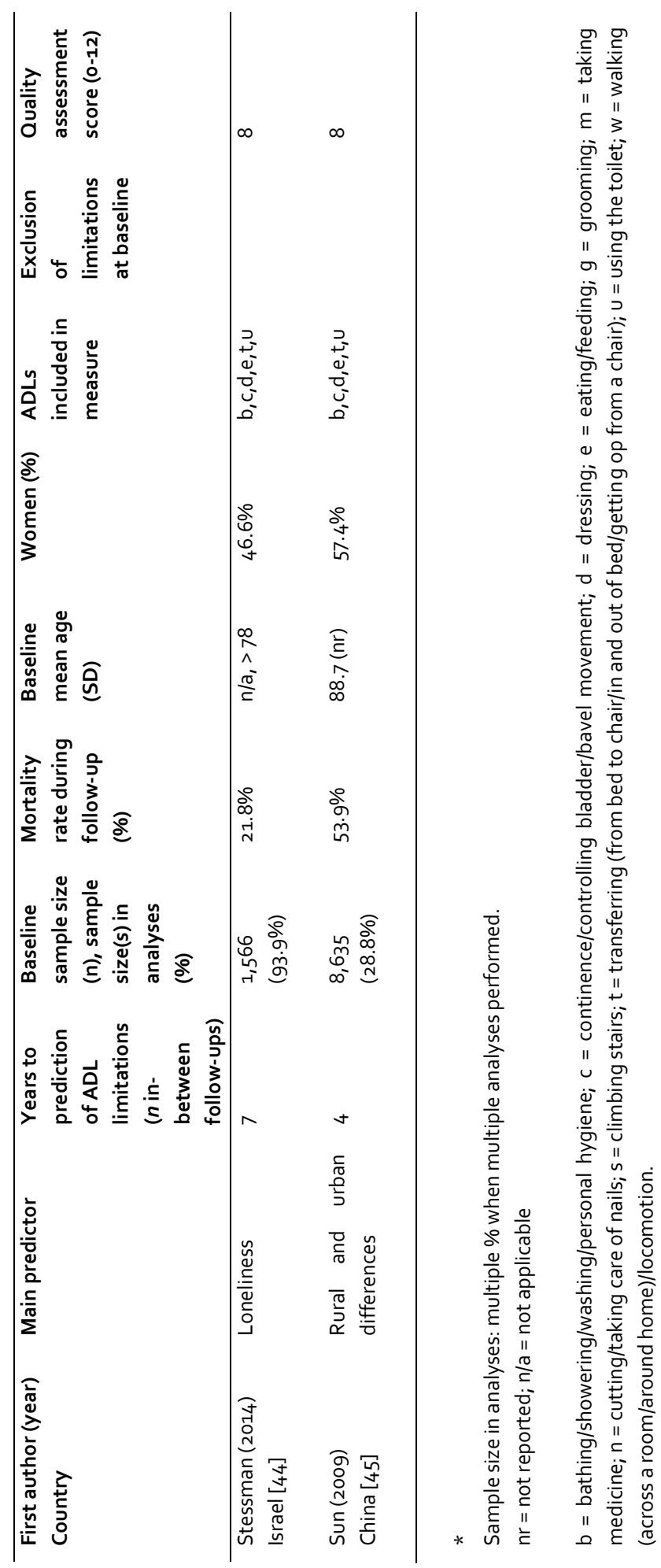




\section{Identified factors}

Table 2 shows the overall findings grouped by domain ( 33 Table for corresponding quantitative data). Factors that were associated with developing limitations in ADLs (irrespective of the quality score), or for which findings were ambiguous are described below. When evidence was found in at least two studies, it is mentioned explicitly.

\section{Socio-demographic characteristics}

Higher age was a risk factor in multiple studies, whereby it should be noted that two studies taking age into account used data from the Chinese Longitudinal Healthy Longevity Survey (CLHLS) [29, 45]. Being from a minor ethnicity/race was protective in women aged 90 years and over, and men in their eighties [e.g. 29], though once only after controlling for cognition [38]. Female gender was a risk in multiple studies. Findings regarding household composition were ambiguous. Studies using data from the Nordic Research on Ageing (NORA) study found that living alone was not statistically significant associated with developing limitations in ADLs [22-23], while sustained living alone was a risk factor [21]. Living with children and with those other than children and spouse were risk factors [37]. Living in a rural area was protective [45], and living in an urban area was a risk factor [29] (both used data from the CLHLS study). Living in the South of the USA was a risk factor [27]. Out of two studies that were based on the CLHLS, one performed subgroup analyses, and found that being married was a risk in women aged 90-99, but protective in men aged 90-99 (only unadjusted) [29]. In two other studies, being married was protective.

\section{Socio-economic characteristics}

Fewer years of education was a risk factor in multiple studies, although not in most adjusted models [e.g. 24, 27]. While two studies used data from the CLHLS study, education was an unadjusted risk factor only when performing subgroup analyses in those aged $80-89$ [29]. Fewer years of mother's education became nonsignificant after controlling for late-life factors (e.g. marital status, income, and chronic conditions) [27]. People with lower income levels ( < 19,999 dollars) and low total wealth $(<49,999$ dollars) were at risk for developing limitations in ADLs [27], whereas economic independence was protective in women in their nineties [29]. Females who were housewives had an increased risk for developing limitations in ADLs, as well as people without a lifetime occupation [29]. Poor socioeconomic status as a child was no longer a risk factor after correcting for late-life factors [27].

\section{Psychosocial factors}

Regarding social participation, not sewing for others was a risk factor in women [23]. 


\section{Health behaviour}

High levels of physical activity were protective in multiple studies [e.g. 24]. Smoking was a risk factor, while not smoking was protective [27, 45].

\section{Self-reported conditions}

Findings regarding arthritis were ambiguous. Cancer was a risk factor [27]. Diabetes was a risk in multiple studies [24, 27]. Having eye disorders was an unadjusted risk [32]. Selfreported hypertension was a risk in two out of three studies [24, 27]. Findings regarding lung disease were ambiguous. Having a psychiatric disorder was a risk factor [27], as well as stroke in two studies [24, 27].

\section{Observed health-related measures}

Cognition and depression were examined multiple times, but were statistically significant associated with developing limitations in ADLs only once, namely when examined with the Short Portable Mental Status Questionnaire (SPMSO) [24], respectively the Geriatric Depression Scale (GDS) [25]. No hypertension was a risk factor [39], while other blood pressure measures (e.g. high mean arterial pressure) were protective [41]. People with multiple impaired frailty domains (e.g. mobility capacities, and memory problems) were at risk for developing limitations in ADLs [30]. IADL disability was an unadjusted risk factor [25]. Impaired gait/balance [39] and low elbow flexion, knee extension, and trunk flexion strength were risk factors [40]. Findings regarding grip strength were ambiguous. Two studies examining chronic conditions used data from the NORA study took different confounding factors into account, and found different results [21-22]. Poor functional reach lost its significant association after controlling for step climbing and walking speed [32]. Low manual dexterity was a risk factor [39]. Step climbing lost its significant association after controlling for functional reach and walking speed [32]. Tiredness in activities was a risk factor in all models but one; the statistically significant association disappeared after controlling for health factors [22]. Low walking speed [32] and weight gain were risk factors. Weight loss was an unadjusted risk [25].

\section{Self-reported health-related measure}

Poor hearing was a risk factor [27]. Moderate to severe pain was a risk, as well as daily and multiple site pain, although the last two were only significant in unadjusted models [35]. Peak stature was no longer associated after controlling for mid- and late-life factors [27]. Findings regarding self-rated health were ambiguous. Less than excellent self-rated health as a child (recalled) was a risk factor, as well as vision less than excellent/very good [27]. Obesity [27] was a risk factor, whereas for weight loss 'anorexia of ageing' was an unadjusted risk factor [36]. 
RISK \& PROTECTIVE FACTORS FOR LIMITATIONS IN ACTIVITIES OF DAILY LIVING

\section{Other}

Response by a proxy was a risk factor [27]. 
CHAPTER 4

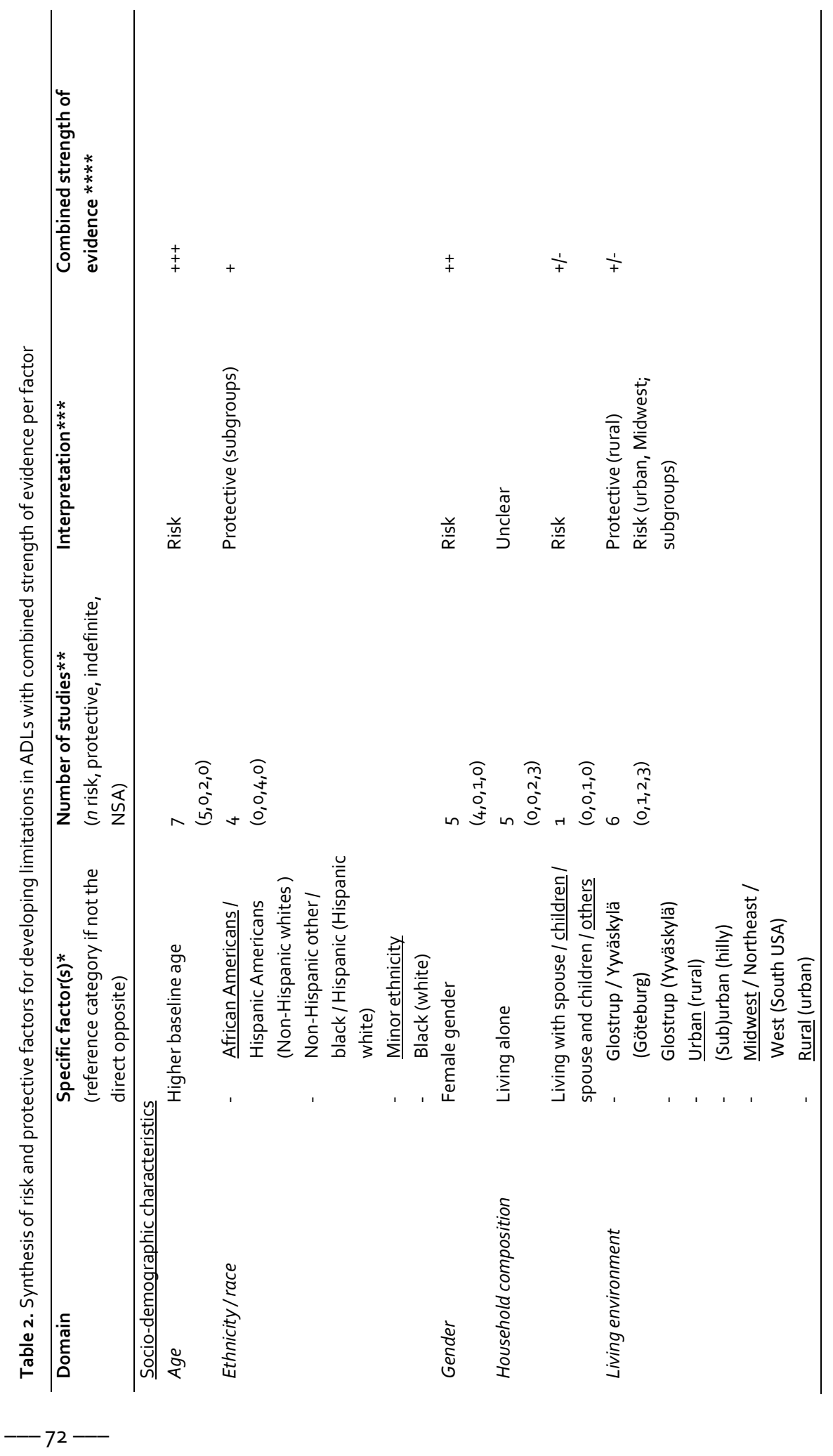


RISK \& PROTECTIVE FACTORS FOR LIMITATIONS IN ACTIVITIES OF DAILY LIVING

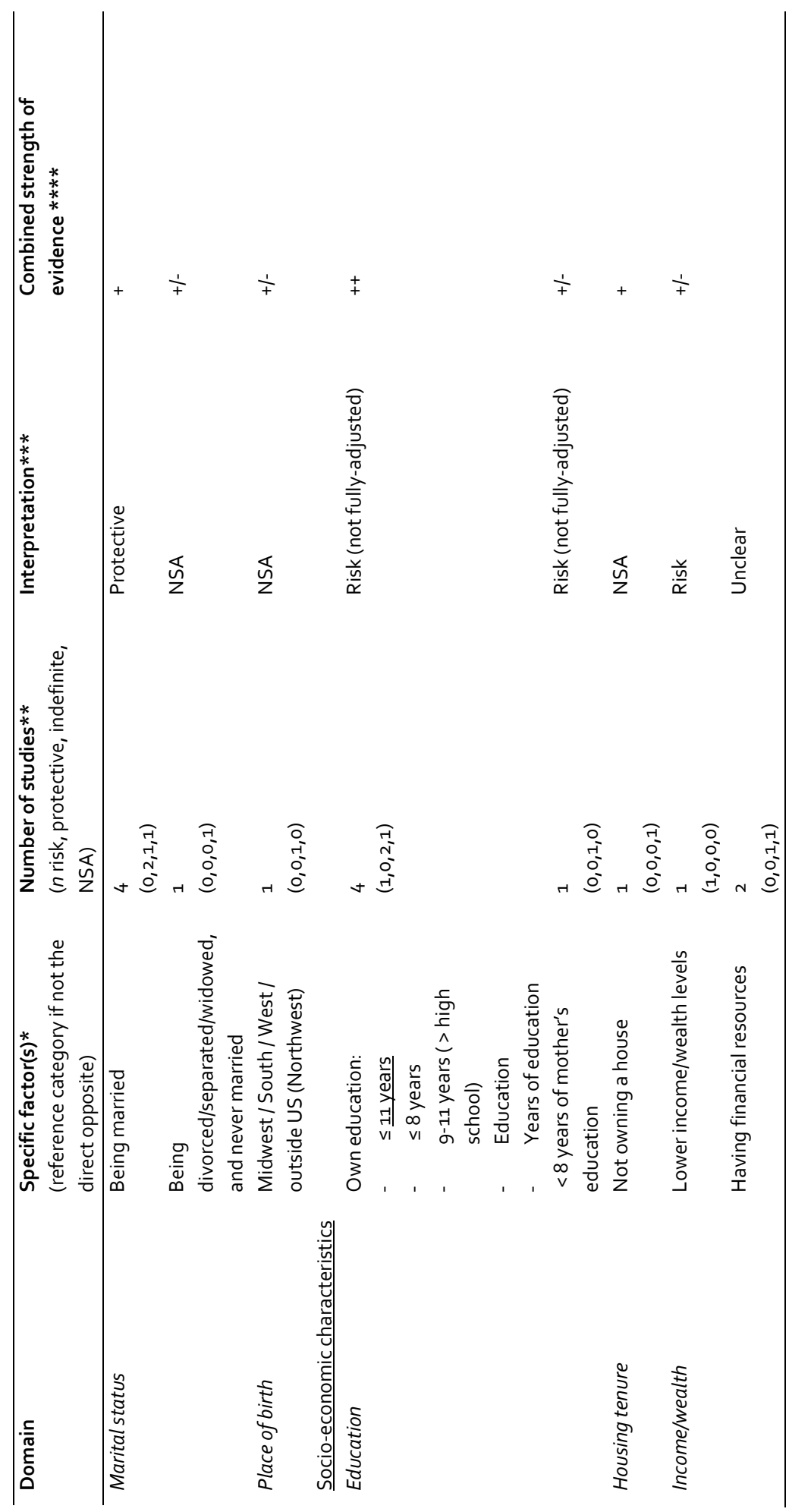




\section{CHAPTER 4}

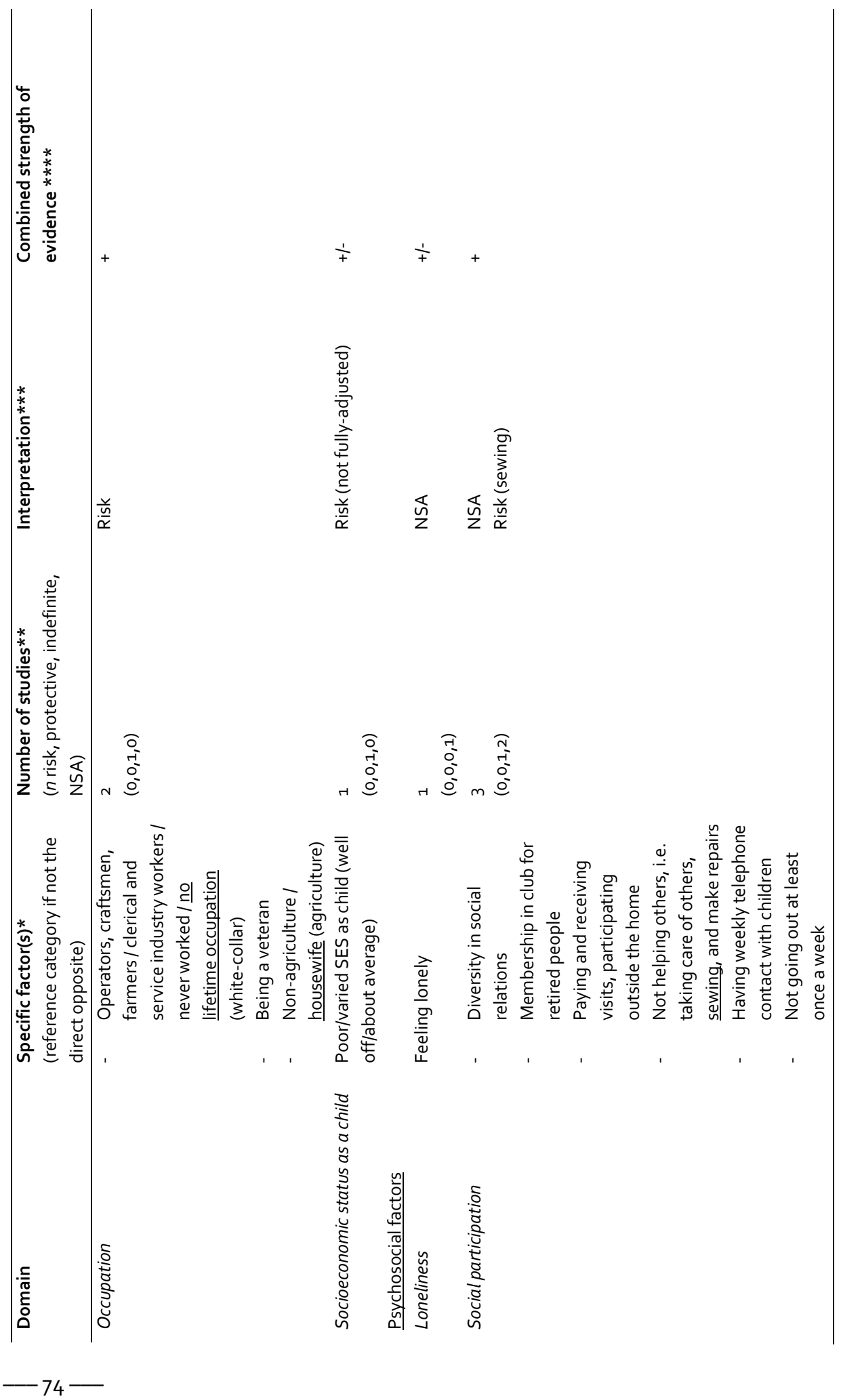


RISK \& PROTECTIVE FACTORS FOR LIMITATIONS IN ACTIVITIES OF DAILY LIVING

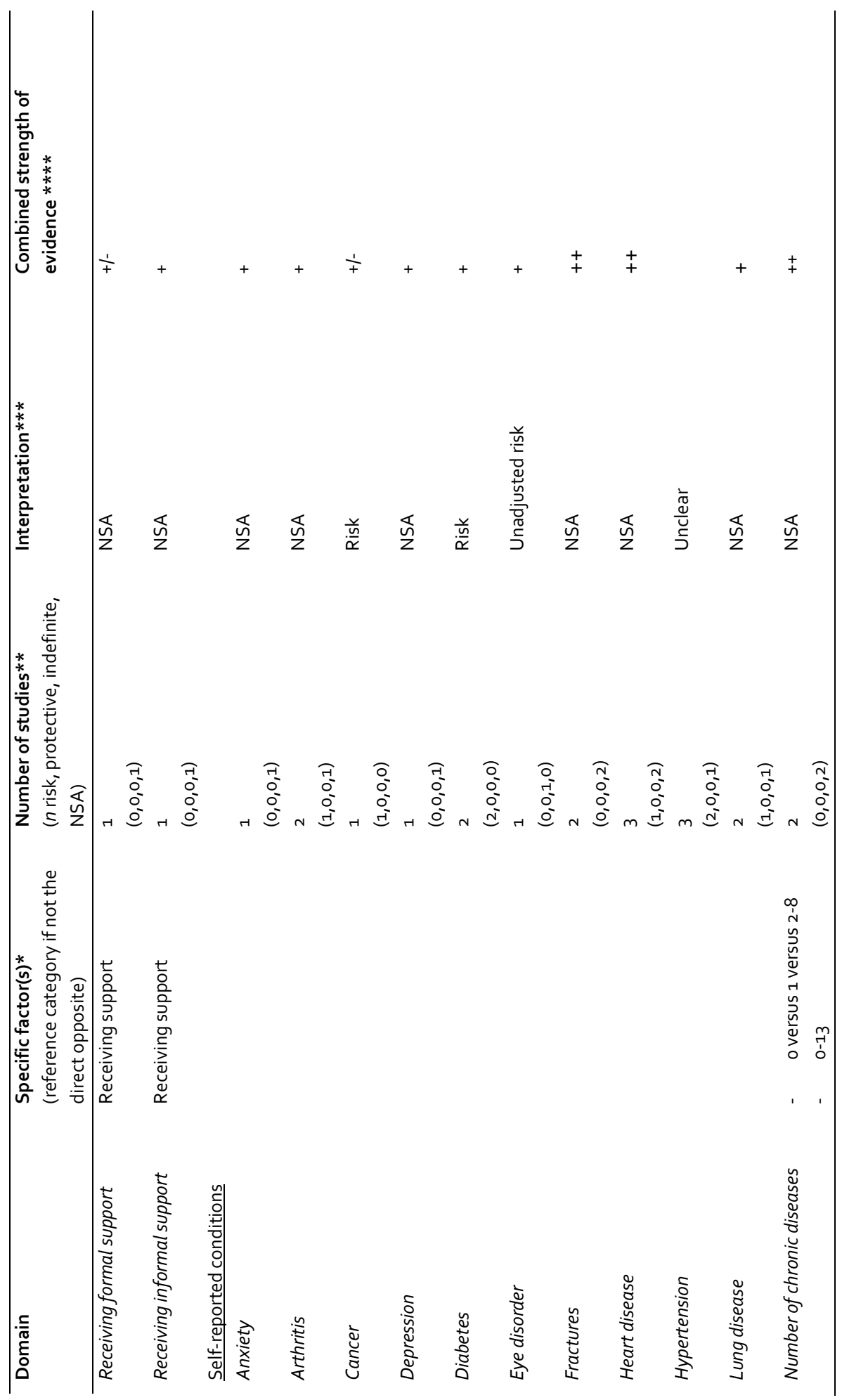




\section{CHAPTER 4}

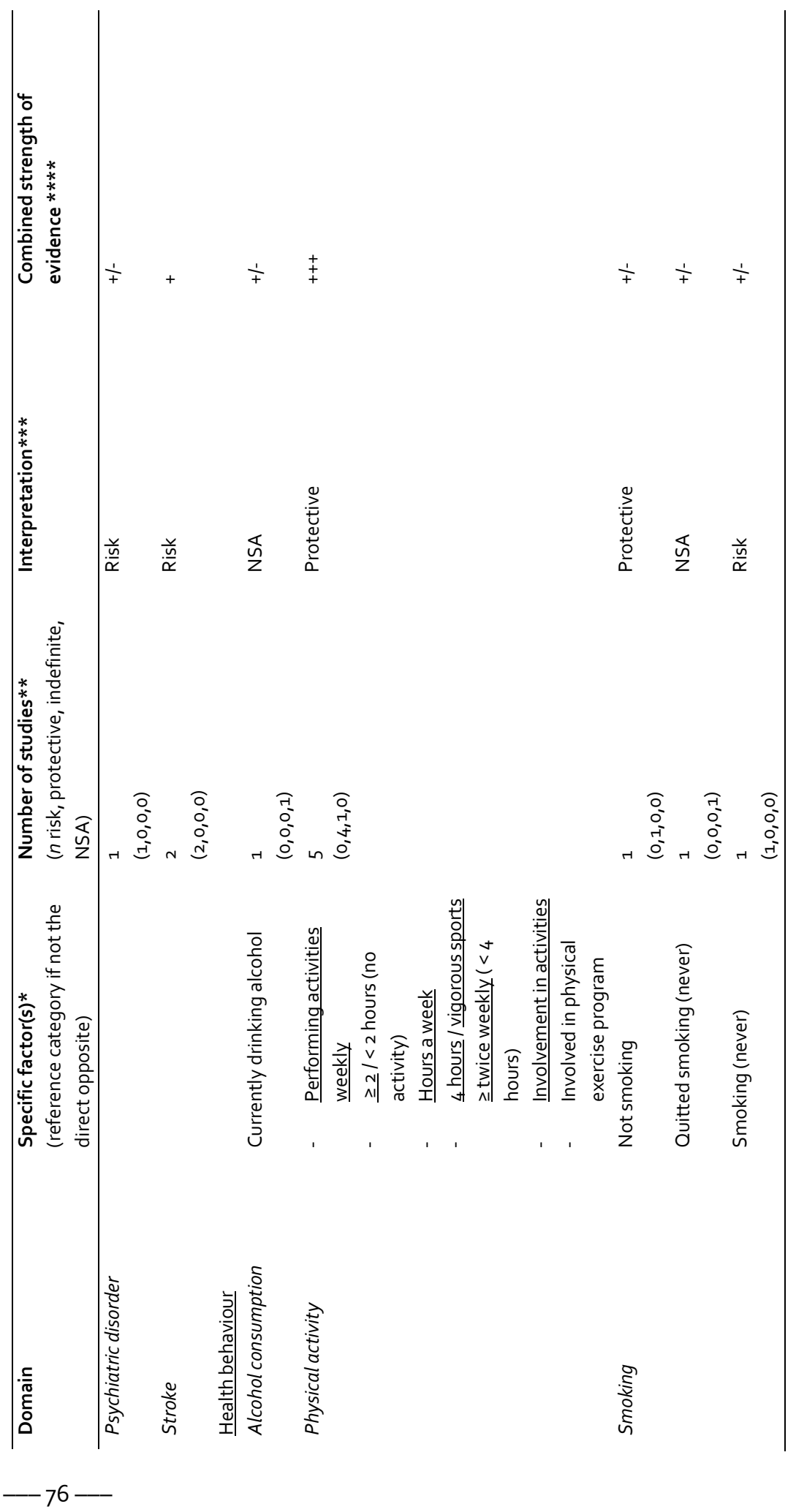


RISK \& PROTECTIVE FACTORS FOR LIMITATIONS IN ACTIVITIES OF DAILY LIVING

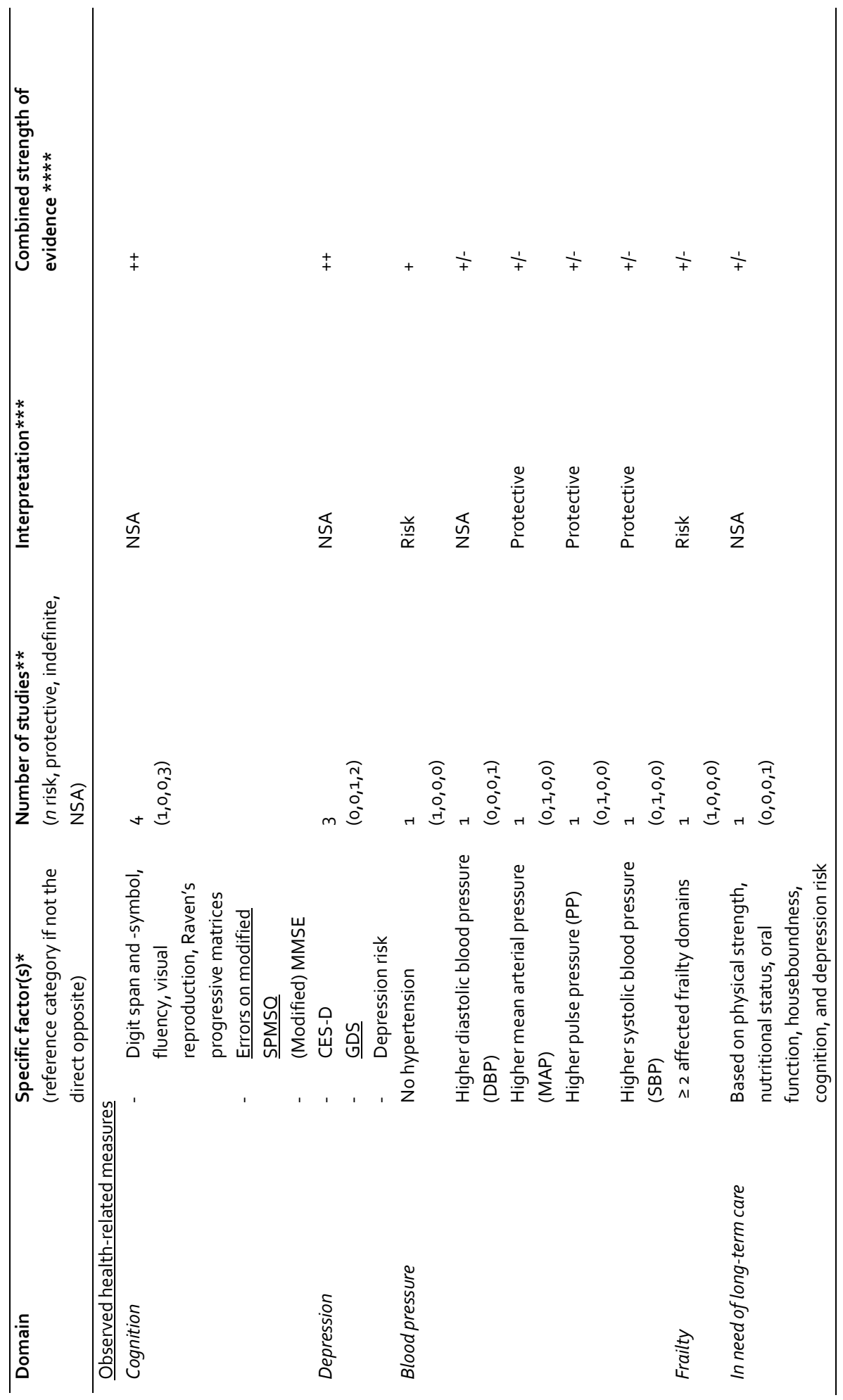


CHAPTER 4

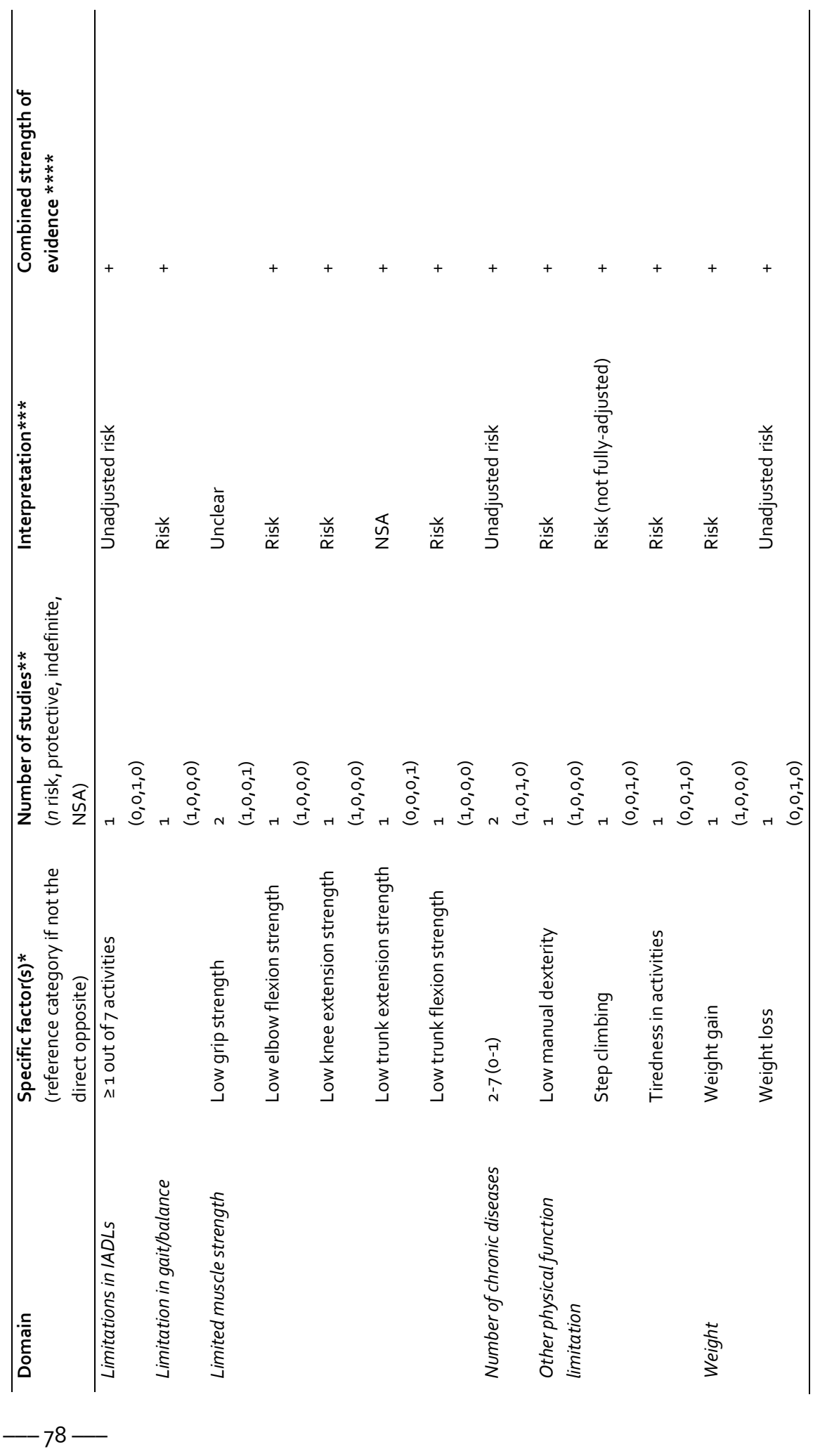


RISK \& PROTECTIVE FACTORS FOR LIMITATIONS IN ACTIVITIES OF DAILY LIVING

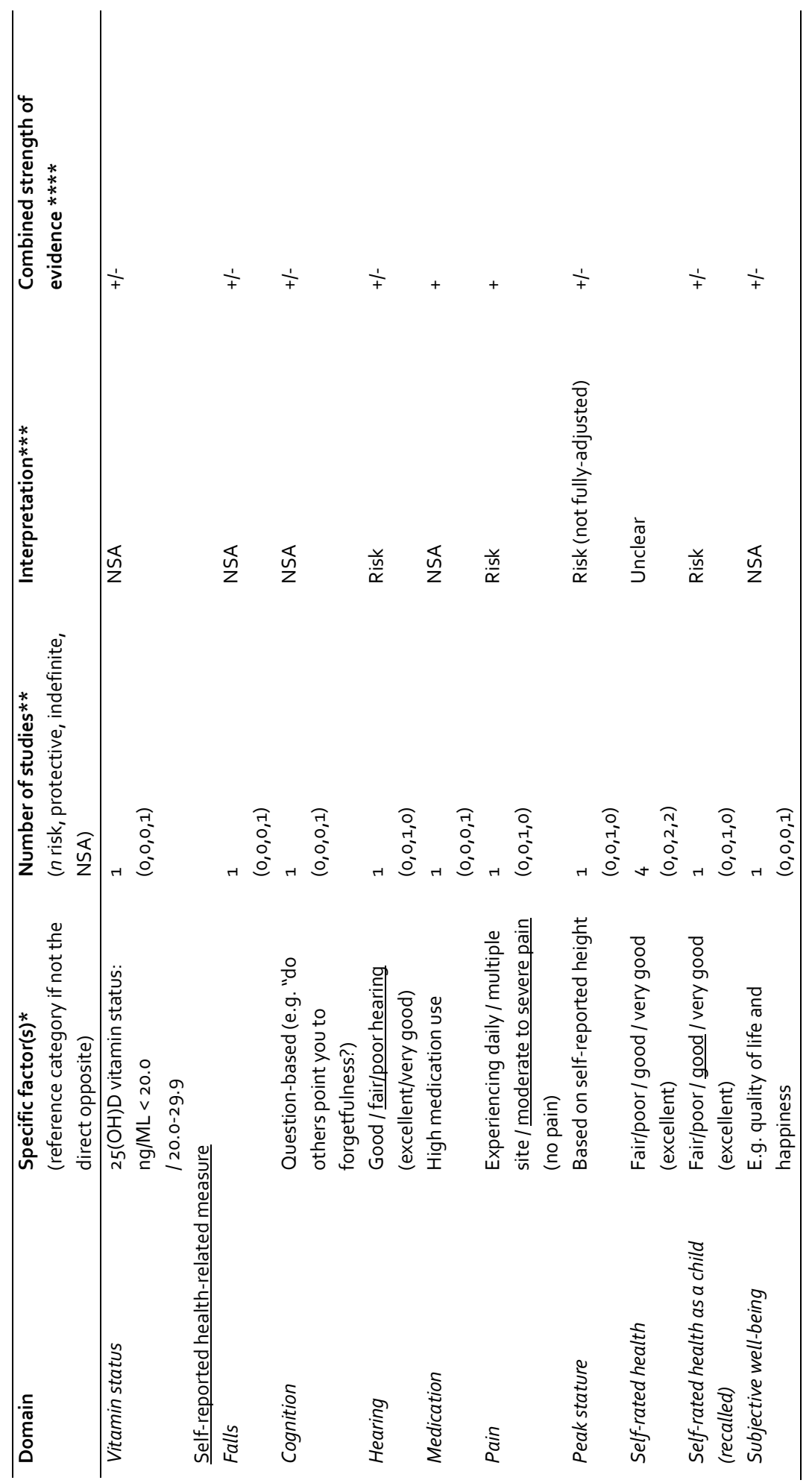




\section{CHAPTER 4}

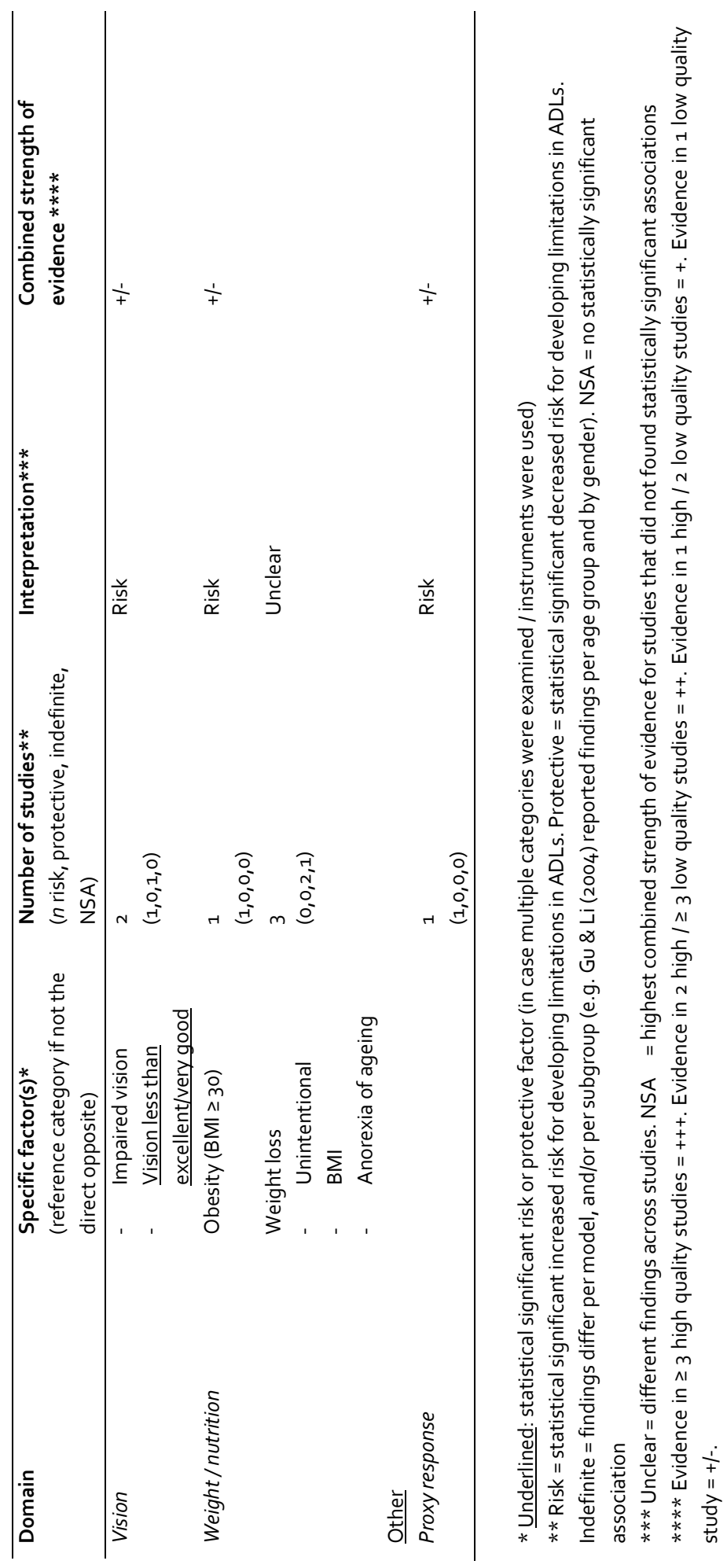




\section{Discussion}

This systematic review aimed to identify risk factors for and protective factors against developing limitations in ADLs in community-dwelling people aged 75 years and over. Higher age, female gender, diabetes, hypertension, and stroke were risk factors in at least two studies. In addition, quite a number of risk factors were supported by only one study (e.g. frailty). However, some risk factors were no longer associated in (fully) adjusted models (e.g. IADL disability). With respect to overall domains, lower socioeconomic status in old age seems to predict limitations in ADLs, more than socioeconomic status at younger ages [e.g. 27]. In addition, people with more self-reported clinical conditions, and more health-related problems, both observed (e.g. limited strength) and self-reported (e.g. pain), seem at risk for developing limitations in ADLs, although most sub-factors have been examined only once. A high level of physical activity and being married were found to be protective. In addition, some factors were protective in one study only (e.g. economic independence). When considering sociodemographic characteristics as a whole, being from a minor ethnicity/race seems to be protective. Although numerous factors have been examined, most do not seem to be able to predict the development of limitations in ADLs (e.g. never married, anxiety, and falls).

\section{Comparison with previous review}

When comparing the current findings with the outcomes of the review by Stuck et al. [9], it should be noted that different data was used (i.e. studies published prior to 1999 versus studies published since then). Furthermore, the previous review had a broader age range, as well as a broader outcome measure. Therefore, a substantial higher number of studies (78) were included in their review. In the review from 1999, substantial evidence (in at least two high quality studies) was found for associations between risk factors and functional decline that have not been found in the current review, but were examined in the studies that were part of the present review (e.g. depression, alcohol consumption, and cognition). Additionally, Stuck et al. [9] found substantial empirical evidence for risk factors for which we found evidence in one study only (e.g. high BMI and smoking), and for factors for which we found ambiguous results (e.g. poor self-rated health). These differences might be explained by the difference in age range and outcome measure.

\section{The 'oldest old' versus those aged 65 years and over}

Out of 25 included studies, six performed subgroup analyses across different age groups [33-34, 38, 42-44]. Some found differences, while others did not. For example, Moody-Ayers et al. [38] found that differences in developing limitations in ADLs between black and white people primarily disappeared in those aged 80 years and over 
compared to those aged 70-79, but did emerge after controlling for cognition. On the other hand, Landi et al. [34], who examined the effect of physical activity on limitations in ADLs, found no differences between those aged 65-79 and those 80 years and over. Overall, there seem to be some differences between age groups. Therewith, different prevention strategies might be needed for different age groups.

Since numerous studies in those aged 65 years and over emerged while including and excluding articles for the current review, it seemed reasonable to compare some of the studies in those aged 65 and over (including people aged 75 and over) with the findings of this review. It appears that there are factors that have been examined in those aged 65 years and over, but not in those aged 75 years and over. For example, performing volunteer or paid work [e.g. 46] and positive affect [e.g. 47] were found to be protective, and not being satisfied with your social network was a risk factor in those aged 65 years and over [e.g. 48].

\section{Ambiguous findings}

Some findings were different for different measurement methods. For example, cognition was no risk factor when measured with the Mini-Mental State Examination (MMSE) and as self-report, but was when examined with the SPMSO [24]. However, it is known that additional neuropsychological testing besides the MMSE is needed for diagnostics [49-50], and that self-reported cognition correlates poorly with actual neuropsychological performance [e.g. 51]. However, the use of different covariates might explain some of the contradictory results as well. For example, Gu and Yi [29] controlled for other and more variables than Black and Rush [24] while examining being married.

For some findings it might be important to examine possible underlying factors. For example, living with children and with those other than spouse or children was a risk factor [37], but sustained living alone was a risk factor as well [21]. One might argue that living alone may result in the maintenance of functioning because people are forced to perform all activities by themselves. However, previous research has shown that women who lost their spouse did not feel obliged to perform activities anymore and, consequently, became less active [52, in 21], while it is known that being physically active is important to prevent the development of limitations in ADLs [e.g. 36].

\section{Limitations and strengths}

This review has several limitations. First, it was difficult to determine the actual quality of each study since not all the necessary information was reported. Second, low ratings of strength of evidence must be interpreted with some caution because this was the result of a lack of data for some factors. In addition, inappropriate sample sizes might 
have influenced the results. For example, for weight loss, no statistically significant association was found, though the $95 \% \mathrm{Cl}$ ranged from 0.8 to 4.62 [25]. This may indicate underpowered, low quality studies. Lastly, since five studies could be included only after a reference check, it cannot be ruled out with certainty that all relevant studies have been included.

This review has several strengths as well. First, cross-sectional and retrospective studies were excluded. Factors that precede the development of limitations in ADLs could, therefore, be distinguished from factors that result from these limitations; and the natural course could be determined. Second, by examining a specific outcome (limitations in ADLs) in a specific population (people aged 75 years and over), the explanatory potential of the identified factors may be considered as higher. Although it can be argued that findings are not generalizable to the entire older population, this specific focus and knowledge is needed for prevention and intervention strategies that are more tailored to this specific vulnerable population. Lastly, by using strict criteria for strength of evidence, it was made certain that revealed factors were supported by multiple studies, which enlarged the strength of evidence.

\section{Conclusion}

Five risk (higher age, female gender, diabetes, hypertension, and stroke), and two protective factors (being married and being physical active) were empirically supported by at least two studies. However, most factors were examined in one study only, while some were associated only in unadjusted analyses, and for other factors ambiguous results or no statistically significant associations were found. Factors that may help to identify groups at risk (e.g. older women, people living with children) have been identified, as well as risk (e.g. obesity) and protective factors (e.g. physical activity) for which preventive actions can take place.

\section{Implications for future research}

More specific research in community-dwelling people aged 75 and over is needed (1) to investigate risk and protective factors that have not yet been examined in multiple studies but do appear to be related with developing limitations in ADLs; and (2) to examine factors that have been found to influence the development of limitations in ADLs in those aged 65 years and over. Factors that are useful to detect vulnerable groups of older people (e.g. related to potential risk factors such as income, and household composition), as well as those older people for which preventive actions can take place (e.g. the possible risk factor psychiatric disorder) should be further investigated. In addition, future research (1) could perform subgroup analyses to compare different age groups since we noticed that subgroup analyses did reveal 
differences between the 'younger' and 'older' olds; (2) could focus more on protective factors because this is a neglected area, and it is shown that they are not always the other side of the coin (e.g. being married was protective, but never married was not significantly associated); and (3) could examine the interaction between risk factors.

\section{Implications for clinical practice}

Several risk factors that have been identified could serve for the detection of groups at risk for developing limitations in ADLs. Thereafter, preventive actions need to take place. When it is possible to intervene on the risk factors itself, for example by trying to prevent the occurrence of adverse clinical conditions, or to cure them, this is preferable. However, some of the revealed risk factors cannot be influenced and therefore could serve detection purposes only (older age, and female gender). In that case, it is important to take preventive actions that are known to decrease the risk of developing limitations in ADLs. Being physically active is, to our knowledge, the best studied intervention, and found to be effective, whereby it can slow-down the process of disability as well [53, for an overview]. Such intervention is in line with our approach of not merely focusing on risk factors, but also looking at protective factors, which can be promoted, as the most prominent protective factor that appeared in this review was physical activity. Thus, promoting an active lifestyle in general is important. Less demanding physical activities, such as household chores, walking, and gardening might be attractive even for older people with (less severe) limitations. The WHO (2012) further notes the importance of having a motivating environment to support older people to actually play an active role. In this perspective, age-friendly cities might be important to make sure places are suitable for older people to perform leisure activities [54]. 


\section{References}

1. European Commission. The 2015 Ageing Report. 2014. Available:

http://ec.europa.eu/economy_finance/publications/european_economy/2014/pdf/ ee8_en.pdf

2. Walker A, Maltby T. Active ageing: A strategic policy solution to demographic ageing in the European Union. Int J Soc Welf. 2012; 21: 117-30.

3. WHO. Active ageing: a policy framework. 2001. Available: http://apps.who.int/iris/bitstream/10665/67215/1/WHO_NMH_NPH_02.8.pdf

4. European Council. Council conclusions on active ageing. $3019^{\text {th }}$ Employment, Social Policy, Health and Consumer Affairs Council meeting, Luxembourg, 7 June 2010.

5. Scharlach A. Creating Ageing-Friendly Communities in the United States. Ageing Int, 2011; 37(1): 25-38.

6. De Witte N, De Donder L, Dury S, Smetcoren A.-S, Brosens D, Buffel T, Dierckx E, Verté $D$. Together on the sidewalks: About social cohesion and older people. Gent: Oost-Vlaanderen. [In Dutch]; 2012

7. Beswick AD, Rees K, Dieppe P, Ayis S, Gooberman-Hill R, Horwood J, Ebrahim S. Complex interventions to improve physical function and maintain independent living in elderly people: a systematic review and meta-analysis. The Lancet. 2008; 371(9614), 725-35.

8. Verbrugge LM, Jette AM. The disablement process. Soc Sci Med. 1994; 38(1): 1-14.

9. Stuck AE, Walthert JM, Nikolaus T, Büla CJ, Hohmann C, Beck JC. Risk factors for functional status decline in community-living elderly people: a systematic literature review. Soc Sci Med. 1999; 48(4): 445-69.

10. WHO. International Classification of Functioning, Disability and Health. 2001b. Available: http://www.who.int/classifications/icf/icfbeginnersguide.pdf?ua = 1

11. Ostchega $Y$, Harris $T B$, Hirsch $R$, Parsons $V L$, Kington R. The prevalence of functional limitations and disability in older persons in the US: data from the National Health and Nutrition Examination Survey III. J Am Geriatr Soc. 2000; 48(9): 1132-5.

12. Center for Disease Control and Prevention. Early Release of Selected Estimates Based on Data From the National Health Interview Survey. 2014. Available: http://www.cdc.gov/nchs/data/nhis/earlyrelease/earlyrelease201506_12.pdf

13. National Public Health Partnership (2006). The Language of Prevention. Melbourne: NPHP.

14. Mackenbach JP., Van den Bos J, Joung IMA, Van de Mheen H, Stronks K. The determinants of excellent health: different from the determinants of ill-health? Int J Epidemiol. 1994; 23: 1273-81 
15. Kempen GIJM, Ranchor AV, van Sonderen E, van Jaarsveld CHM, Sanderman R. Risk and protective factors of different functional trajectories in older persons: are these the same? J Gerontol B Psychol Sci Soc Sci. 2006; 61B(2): 95-101.

16. Moher D, Liberati A, Tetzlaff J, Altman DG, PRISMA Group. Preferred reporting items for systematic reviews and meta-analyses: the PRISMA statement. Int J Surg. 2010; 8(5): 336-41.

17. Katz S, Ford AB, Moskowitz RW, Jackson BA, Jaffe MW. Studies of illness in the aged. The index of ADL: a standardized measure of biological and physiological function. Jama. 1963; 185: 914-9.

18. Hsieh HF, Shannon SE. Three approaches to qualitative content analysis. Qual Health Res. 2005; 15(9): 1277-88.

19. Hayden JA, Côté $P$, Bombardier, $C$. Evaluation of the quality of prognosis studies in systematic reviews. Ann Intern Med. 2006; 144: 427-37.

20. Kuijpers T, van der Windt DAWM, van der Heijden GJMG, Bouter LM. Systematic review of prognostic cohort studies on shoulder disorders. Pain. 2004; 109: 420-31

21. Avlund $K$, Due $P$, Holstein BE, Sonn $U$, Laukkanen P. Changes in household composition as determinant of changes in functional ability among old men and women. Ageing Clin Exp Res. 2002a; 14(3): 65-74

22. Avlund K., Damsgaard MT, Sakari-Rantala R, Laukkanen P, Schroll M. (2002b). Tiredness in daily activities among nondisabled old people as determinant of onset of disability. J Clin Epidemiol, 55(10), 965-73.

23. Avlund $K$, Lund $R$, Holstein BE, Due $P$, Sakari-Rantala $R$, Heikkinen RL. The Impact of Structural and Functional Characteristics of Social Relations as Determinants of Functional Decline. J Gerontol B Psychol Sci Soc Sci. 2004; 59(1): 44-51.

24. Black SA, Rush RD. Cognitive and functional decline in adults aged 75 and older. J Am Geriatr Soc. 2002; 50(12): 1978-86.

25. Corona LP., Nunes DP, Alexandre Tda S, Santos JL, Duarte YA, Lebrao ML. Weight gain among elderly women as risk factor for disability: Health, Well-being and Ageing Study (SABE Study). J Ageing Health. 2013; 25(1): 119-35. doi: $10.1177 / 0898264312466261$

26. Donald IP, Bulpitt CJ. The prognosis of falls in elderly people living at home. Age Ageing. 1999; 28(2): 121-25.

27. Freedman VA, Martin LG, Schoeni RF, Cornman JC. Decline in late-life disability: the role of early- and mid-life factors. Soc Sci Med. 2008; 66(7): 1588-602.

28. Fukutomi E, Okumiya K, Wada T, Sakamoto R, Ishimoto $Y$, Kimura $Y$, et al. Importance of cognitive assessment as part of the 'Kihon Checklist' developed by the Japanese Ministry of Health, Labor and Welfare for prediction of frailty at a 2-year follow up. Geriatr Gerontol Int. 2013; 13(3): 654-62. doi: 10.1111/j.14470594.2012.00959.x 
29. Gu D, Yi Z. Sociodemographic effects on the onset and recovery of ADL disability among Chinese oldest-old. Demographic Res. 2004; 11: 1-42

30. Guilley E, Ghisletta P, Armi F, Berchtold A, d'Epinay CL, Michel J-P, de Ribaupierre A. Dynamics of Frailty and ADL Dependence in a Five-Year Longitudinal Study of Octogenarians. Res Ageing. 2008; 30(3): 299-317. doi: 10.1177/0164027507312115

31. Houston DK, Tooze JA, Davis CC, Chaves PH, Hirsch CH, Robbins JA et al. Serum 25-hydroxyvitamin $D$ and physical function in older adults: the Cardiovascular Health Study All Stars. J Am Geriatr Soc. 2011; 59(10): 1793-1801. doi: 10.1111/j.1532-5415.2011.03601.x

32. Idland G, Pettersen $R$, Avlund $K$, Bergland A. Physical performance as long-term predictor of onset of activities of daily living (ADL) disability: a 9-year longitudinal study among community-dwelling older women. Arch Gerontol Geriatr. 2013; 56(3): 501-6. doi: 10.1016/j.archger.2012.12.005

33. Jiang J, Tang Z, Meng XJ, Futatsuka M. Demographic determinants for change in activities of daily living: a cohort study of the elderly people in Beijing. J Epidemiol, 12. $2002 ;$ (3): 280-6.

34. Landi F, Onder G, Carpenter I, Cesari M, Soldato M, Bernabei R. Physical activity prevented functional decline among frail community-living elderly subjects in an international observational study. J. Clin. Epidemiol. 2007; 6o(5): 518-24

35. Landi F, Russo A, Liperoti R, Danese P, Maiorana E, Pahor M et al. Daily pain and functional decline among old-old adults living in the community: results from the ilSIRENTE Study. J Pain Symptom Manage. 2009; 38(3): 350-7. doi: 10.1016/j.jpainsymman.2008.10.005

36. Landi F, Russo A, Liperoti R, Tosato M, Barillaro C, Pahor M et al. Anorexia, physical function, and incident disability among the frail elderly population: Results from the ilSIRENTEstudy. JAMDA. 2010; 11(4): 268-74.

37. Li LW, Zhang J, Liang J. Health among the oldest-old in China: which living arrangements make a difference? Soc Sci Med. 2009; 68(2): 220-7. doi: 10.1016/j.socscimed.2008.10.013

38. Moody-Ayers SY, Mehta KM, Lindquist K, Sands L, Covinsky KE. Black-white disparities in functional decline in older persons: the role of cognitive function. $J$ Gerontol A Biol Sci Med Sci. 2005; 60(7): 933-9.

39. Okumiya K, Matsubayashi K, Nakamura T, Fujisawa M, Osaki Y, Doi Y, Ozawa T. The timed 'Up \& Go' test and Manual Button score are useful predictors of functional decline in basic and instrumental ADL in community-dwelling older people. J Am Geriatr Soc. 1999; 47(4): 497-8.

40. Rantanen T, Avlund K, Suominen H, Schroll M, Frändin K, Era P. Muscle strength as a predictor of onset of ADL dependence in people aged 75 years. Ageing Clin Exp Res. 2002; 14(3): 10-5. 
41. Sabayan B, Oleksik AM, Maier AB, Buchem MA, Poortvliet RK, Ruijter W et al. High blood pressure and resilience to physical and cognitive decline in the oldest old: the Leiden 85-plus study. J Am Geriatr Soc. 2012; 60(11): 2014-9.

42. Shah RC, Buchman AS, Leurgans S, Boyle PA, Bennett DA. Association of total daily physical activity with disability in community-dwelling older persons: a prospective cohort study. BMC Geriat. 2012; 12(1). doi: 10.1186/1471-2318-12-63

43. Stessman J, Hammerman-Rozenberg R, Cohen A, Ein-Mor E, Jacobs JM. Physical activity, function, and longevity among the very old. Arch Intern Med. 2009; 169(16): 1476-83. doi: 10.1001/archinternmed.2009.248

44. Stessman J, Rottenberg Y, Shimshilashvili I, Ein-Mor E, Jacobs JM. Loneliness, health, and longevity. J Gerontol A Biol Sci Med Sci. 2014; 69(6): 744-50. doi: 10.1093/gerona/glt147

45. Sun F, Park NS, Klemmack DL, Roff LL, Li Z. Predictors of physical functioning trajectories among Chinese oldest old adults: rural and urban differences. Int J Ageing Hum Dev. 2009; 69(3): 181-99.

46. Luoh MC, Herzog AR. Individual consequences of volunteer and paid work in old age: health and mortality. J Health Soc Behav. 2002; 43(4): 490-509.

47. Díaz-Ramos JA, Navarrete-Reyes AP, Ávila-Funes JA. Positive affect in elderly Mexicans and its protective role against disability. J Am Geriatr Soc. 2012; 60(2): 384-385. doi: 10.1111/j.1532-5415.2011.03805.x

48. McLaughlin D, Leung J, Pachana N, Flicker L, Hankey G, Dobson A. Social support and subsequent disability: it is not the size of your network that counts. Age Ageing. 2012; 41(5): 674-7.

49. O'Bryant SE, Humphreys JD, Smith GE, Ivnik RJ, Graff-Radford NR, Petersen, RC, Lucas JA. Detecting dementia with the mini-mental state examination in highly educated individuals. Arch Neurol. 2008; 65(7): 963-7.

50. Simard M. The Mini-Mental State Examination: strengths and weaknesses of a clinical instrument. Can Alzheimer's Dis Rev. 1998; 12: 10-2.

51. Gagnon M, Dartigues JF, Mazaux, JM, Dequae L, Letenneur L, Giroire JM, Barberger-Gateaup P. Self-reported memory complaints and memory performance in elderly French community residents: Results of the PAQUID research program. Neuroepidemiology. 1994; 13(4): 145-54.

52. Due P. "You get what you want to when you are alone". Life course and health among old, single-living women in Denmark. In Helset, A., ed. For good and worse. The life-situation among old women with minimum pension in Denmark, Norway, and Sweden. Oslo: Norwegian Gerontological Institute; 1993.

53. Tak E, Kuiper R, Chorus A, \& Hopman-Rock M. Prevention of onset and progression of basic ADL disability by physical activity in community dwelling older adults: a meta-analysis. Ageing Res Rev. 2013; 12(1): 329-38. 
54. WHO. Global Age-Friendly Cities Project. 2016. Available:

http://www.who.int/ageing/projects/age_friendly_cities/en/ 
CHAPTER 4

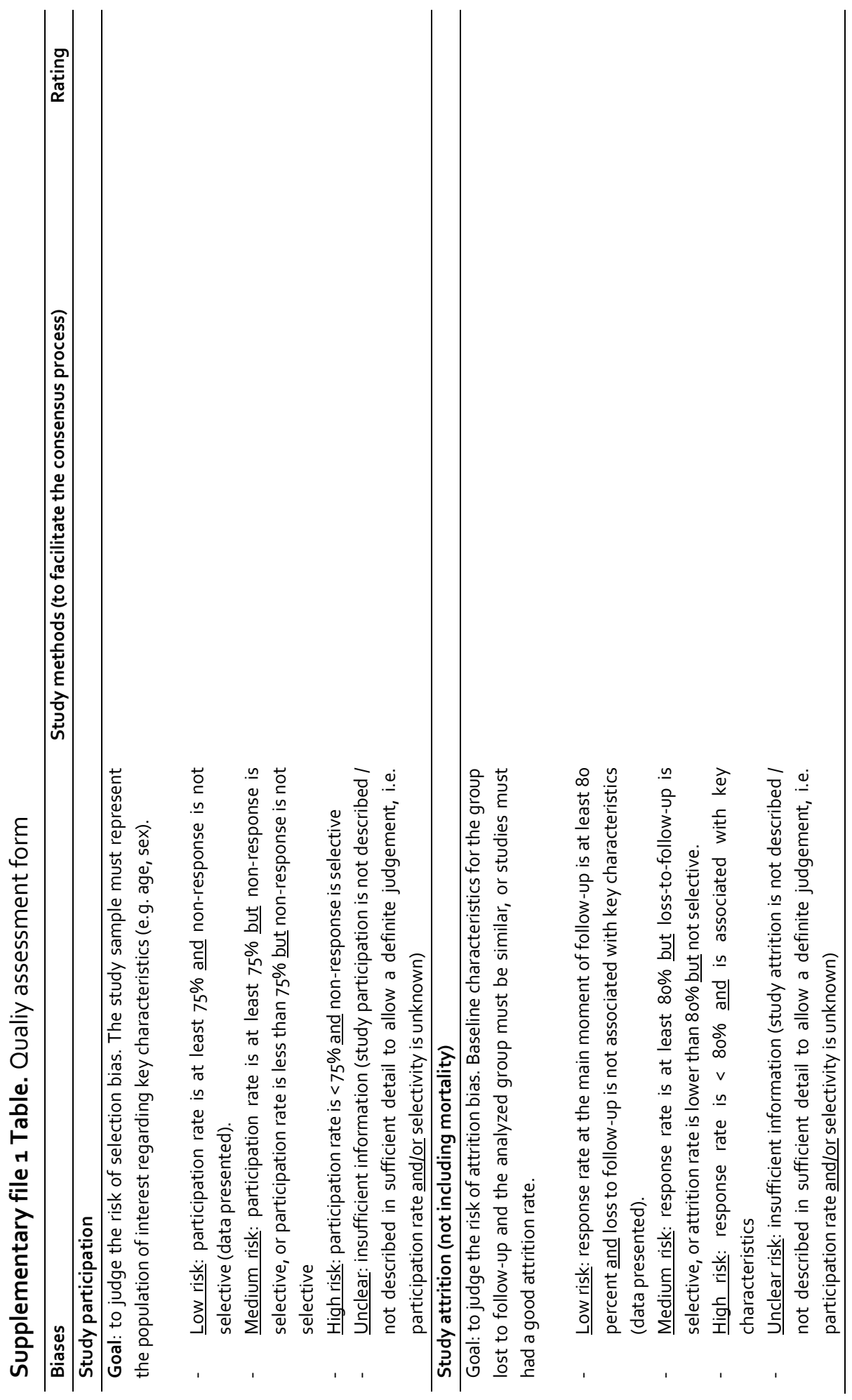




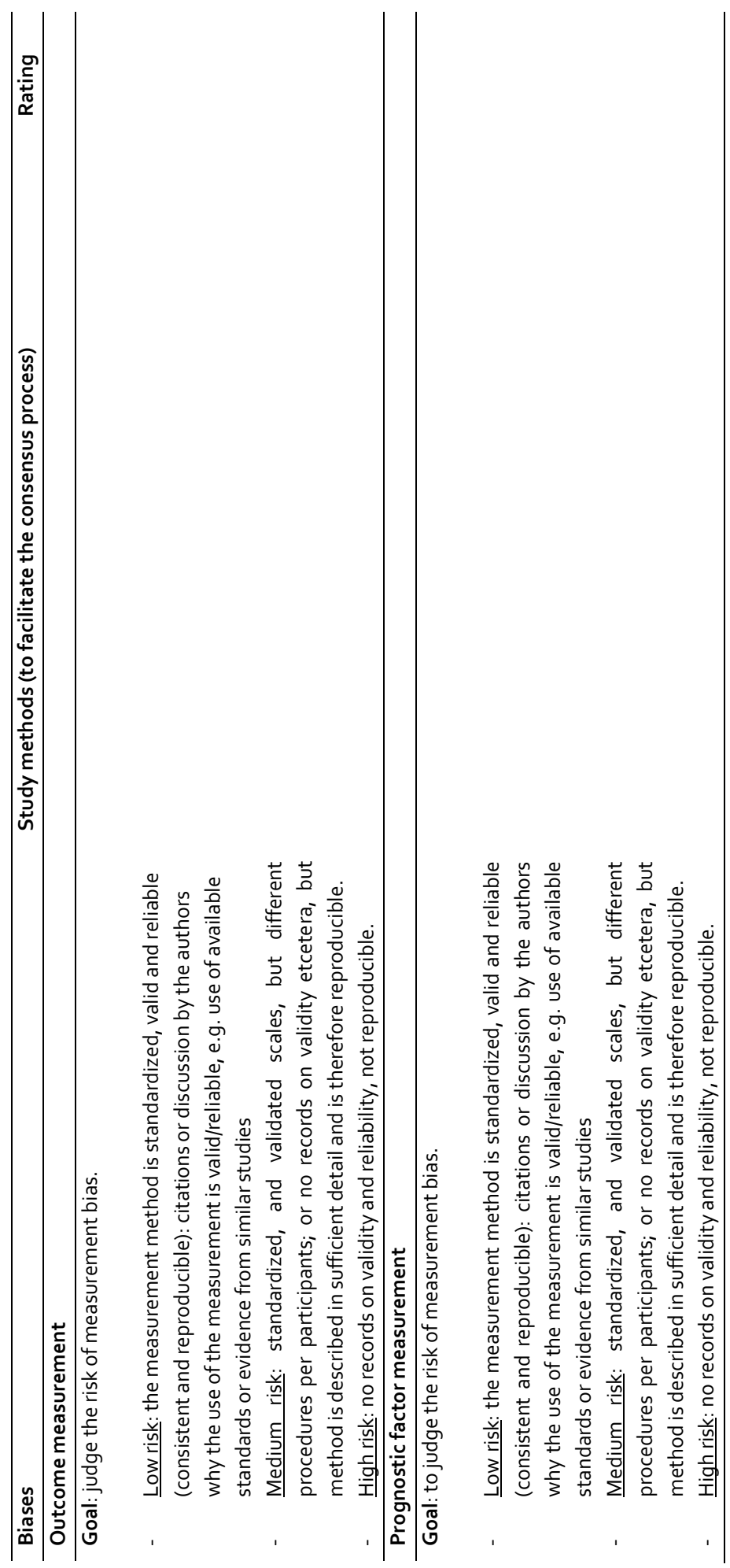


CHAPTER 4

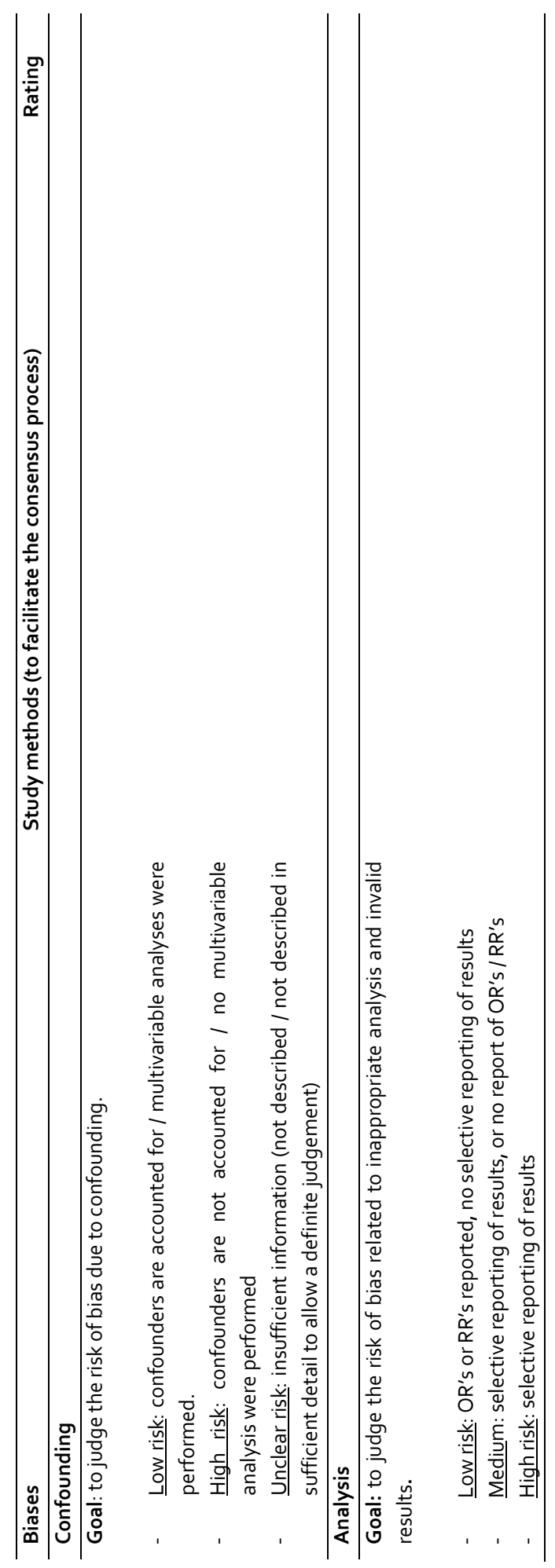


Supplementary file 1 Text. Search strategy per database

\section{CINAHL (EBSCO)}

((MH "Risk Assessment") OR (MH "Prognosis") OR (protective factors) OR (protecting) OR (protective) OR (protects) OR (risk factors) OR (risk) OR (factor) OR (predictor) OR (predictors) OR (predicts) OR (predicting) OR (association) OR (associations) OR (associated) OR (correlation) OR (correlations) OR (correlated) OR (correlates) OR (relation) OR (related) OR (relationship) OR (relates) OR (causal) OR (causality) OR (change) OR (changes) OR (changing) OR (life-course)) AND ((MH "Disabled") OR (MH "Activities of Daily Living") OR (MH "Instrumental Activities of Daily Living (Saba CCC)") OR (MH "Instrumental Activities of Daily Living Alteration (Saba CCC)") OR (MH "Activities of Daily Living Alteration (Saba CCC)") OR (MH "Activities of Daily Living (Saba CCC)") OR (MH "Functional Status") OR (disabled persons) OR (disability) OR (daily living activity) OR (instrumental activities of daily living) OR (instrumental activity of daily living) OR (ADL) OR (IADL) OR (functional status) OR (functional abilities) OR ((impaired) OR (limited) OR (decline) AND (function)) ((MH "Community Living") OR (community dwelling) OR (home living) OR (ageing in place)) NOT ((MH "Cross Sectional Studies" OR (MH "Experimental Studies"))

Limiters: language: Dutch/Flemish, English, German. Age: Aged: 65+ years, Aged, 80 and over. Human.

\section{EMBASE}

((protection/ or protecting.mp. or protective.mp. or protects.mp. or risk factors/ or risk/ or factor.mp. or predictor.mp. or predictors.mp. or predicts.mp. or predicting.mp. or association.mp. or associations.mp. or associated.mp. or correlation.mp. or correlations.mp. or correlated.mp. or correlates.mp. or relation.mp. or related.mp. or relationship.mp. or relates.mp. or causal.mp. or causality.mp. or change.mp. or changes.mp. or changing.mp. or life-course.mp.) and (disabled person/ or daily life activity/ or disability.mp. or disabled.mp. or daily living activity.mp. or instrumental activities of daily living.mp. or instrumental activity of daily living.mp. or ADL.mp. or IADL.mp. or functional status.mp. or functional abilities.mp. or ((impaired or limited or decline) and function).mp.) and (independent living/ or community dwelling.mp or home living.mp or community living.mp or ageing in place.mp) and (cohort analysis/ or prospective study/ or observational study/ or follow up/ or retrospective study/)) not (cross-sectional study/ or intervention study/)

Limits: human, Dutch or English or German, and aged $<65+$ years 


\section{PsycINFO}

((DE "Risk Factors") OR (DE "Protective Factors") OR (protective factors) OR (protecting) ("protective") OR (protects) OR (risk factors) OR (risk) OR (factor) OR (predictor) OR (predictors) OR (predicts) OR (predicting) OR (association) OR (associations) OR (associated) OR (correlation) OR (correlations) OR (correlated) OR (correlates) OR (relation) OR (related) OR (relationship) OR (relates) OR (causal) OR (causality) OR (change) OR (changes) OR (changing) OR (life-course)) AND ((disabled) OR (disabled persons) OR (disability) OR (DE "Activities of Daily Living") OR (DE "Daily Activities") OR (instrumental activities of daily living) OR (DE "Ability Level") OR (daily living activity) OR (instrumental activities of daily living) OR (instrumental activity of daily living) OR (ADL) OR (IADL) OR (functional status) OR (functional abilities) OR ((impaired) OR (limited) OR (decline) AND (function))) AND ((community living) OR (community dwelling) OR (home living) OR (ageing in place))

Limiters: language: Dutch, English German. Age: 65 years and older, 85 years and older. Population: human, (fe)male. Source types: academic journals

\section{PubMed}

((protective factors [Majr]) OR (protect* [Tiab]) OR (risk factors [Majr]) OR (risk[MeSH]) OR (risk* [Tiab]) OR (factor) OR (predictor) OR (predictors) OR (predicts) OR (predicting) OR (association) OR (associations) OR (associated) OR (correlation) OR (correlations) OR (correlated) OR (correlates) OR (relation) OR (related) OR (relationship) OR (relates) OR (causal) OR (causality) OR (change) OR (changes) OR (changing) OR (life-course)) AND ((disabled persons [MeSH:NoExp]) OR (activities of daily living[MeSH]) OR (disabled) OR (disability) OR (daily living activity) OR (instrumental activities of daily living) OR (instrumental activity of daily living) OR (ADL) OR (IADL) OR (functional status) OR (functional abilities) OR ((impaired) OR (limited) OR (decline) AND (function))) AND ((community dwelling) OR (home living) OR (community living) OR (ageing in place)) AND ((cohort studies [MesH]) OR (prospective Studies[MesH) OR (observational study [Publication type]) OR (follow-up studies [MesH]) OR (retrospective studies[MesH]))

NOT ((cross-sectional studies [MesH]) OR (intervention studies[MesH]))

Filters activated: Humans, Dutch, English, German, Aged: $65^{+}$years, 80 and over: $80+$ years. 


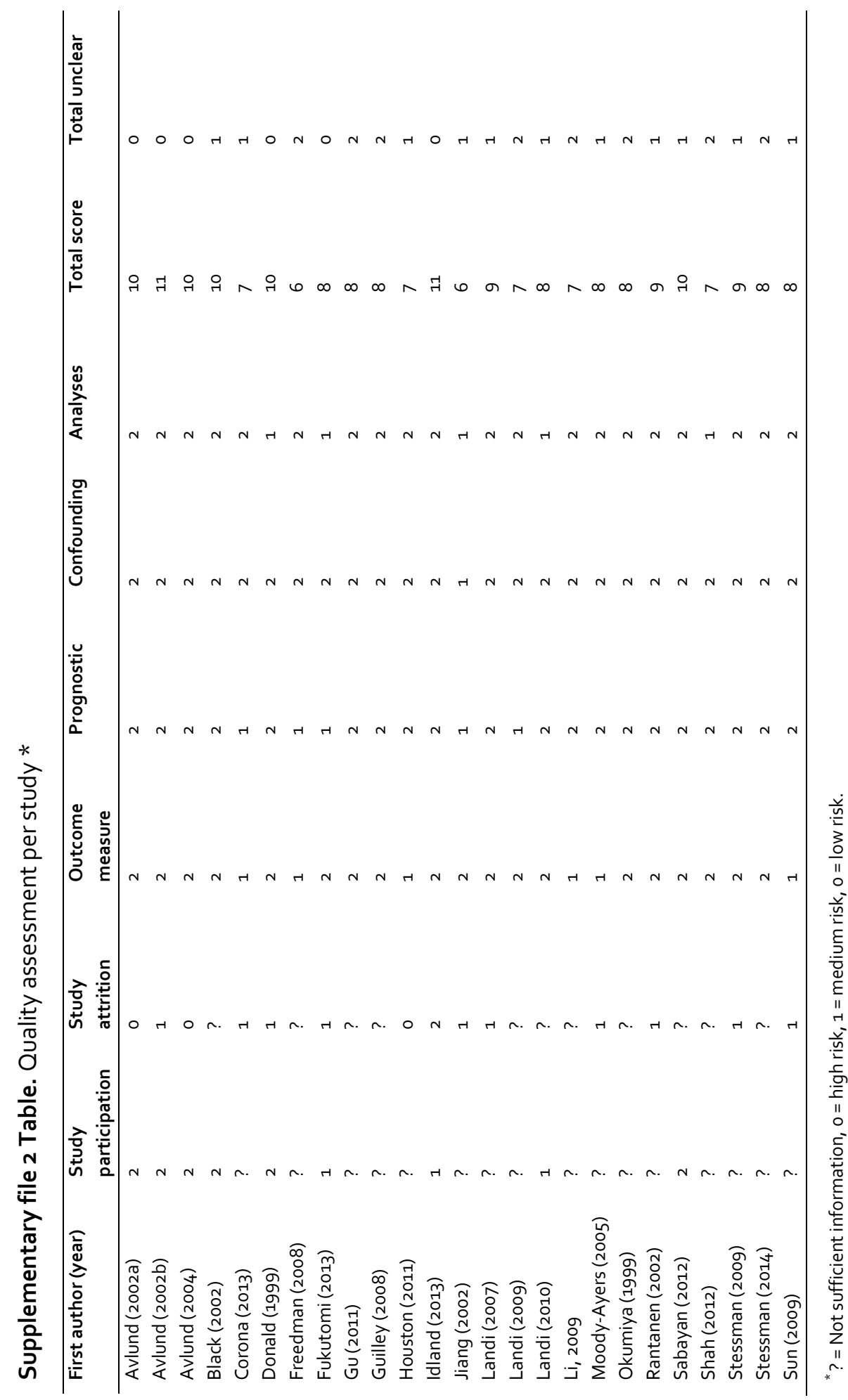




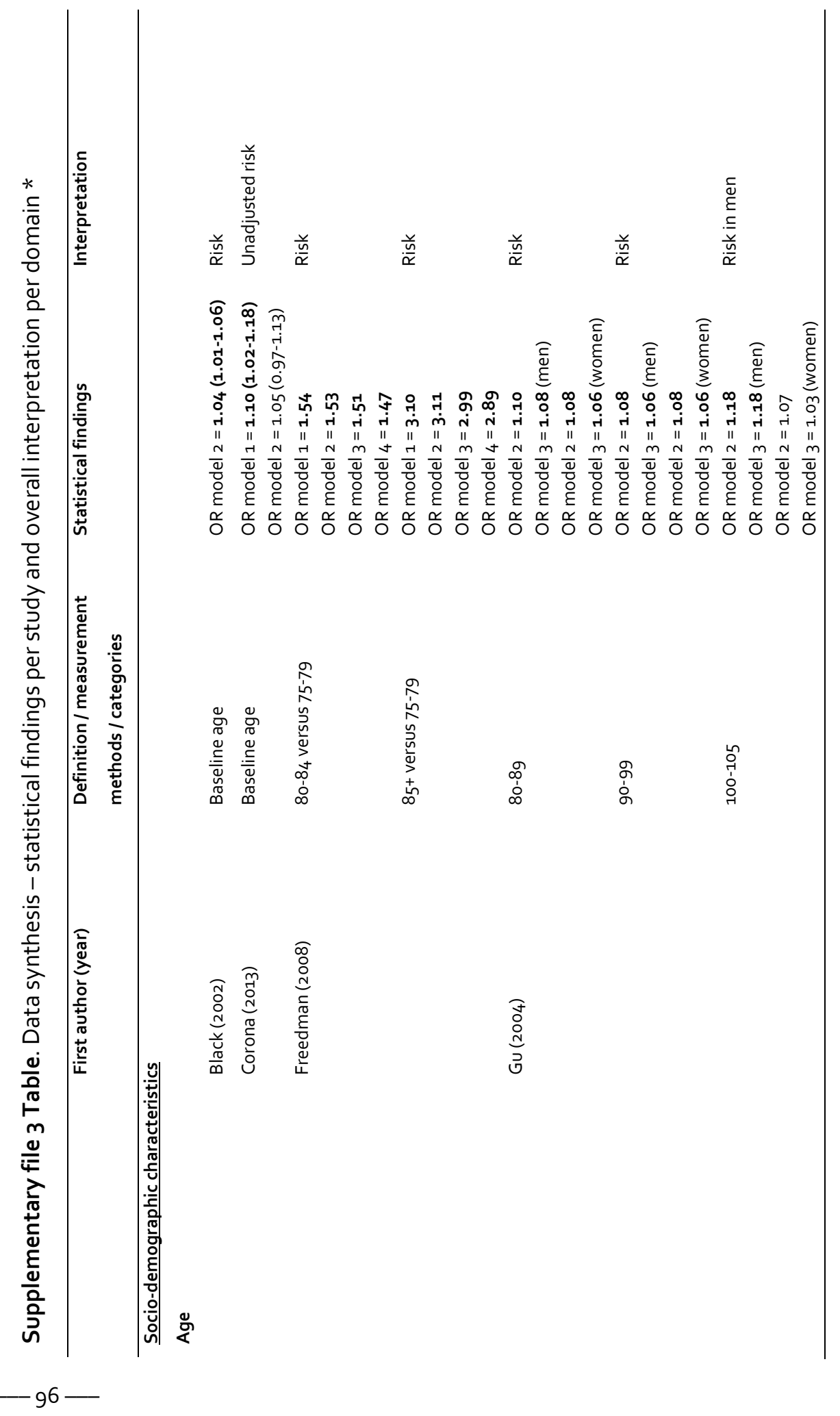




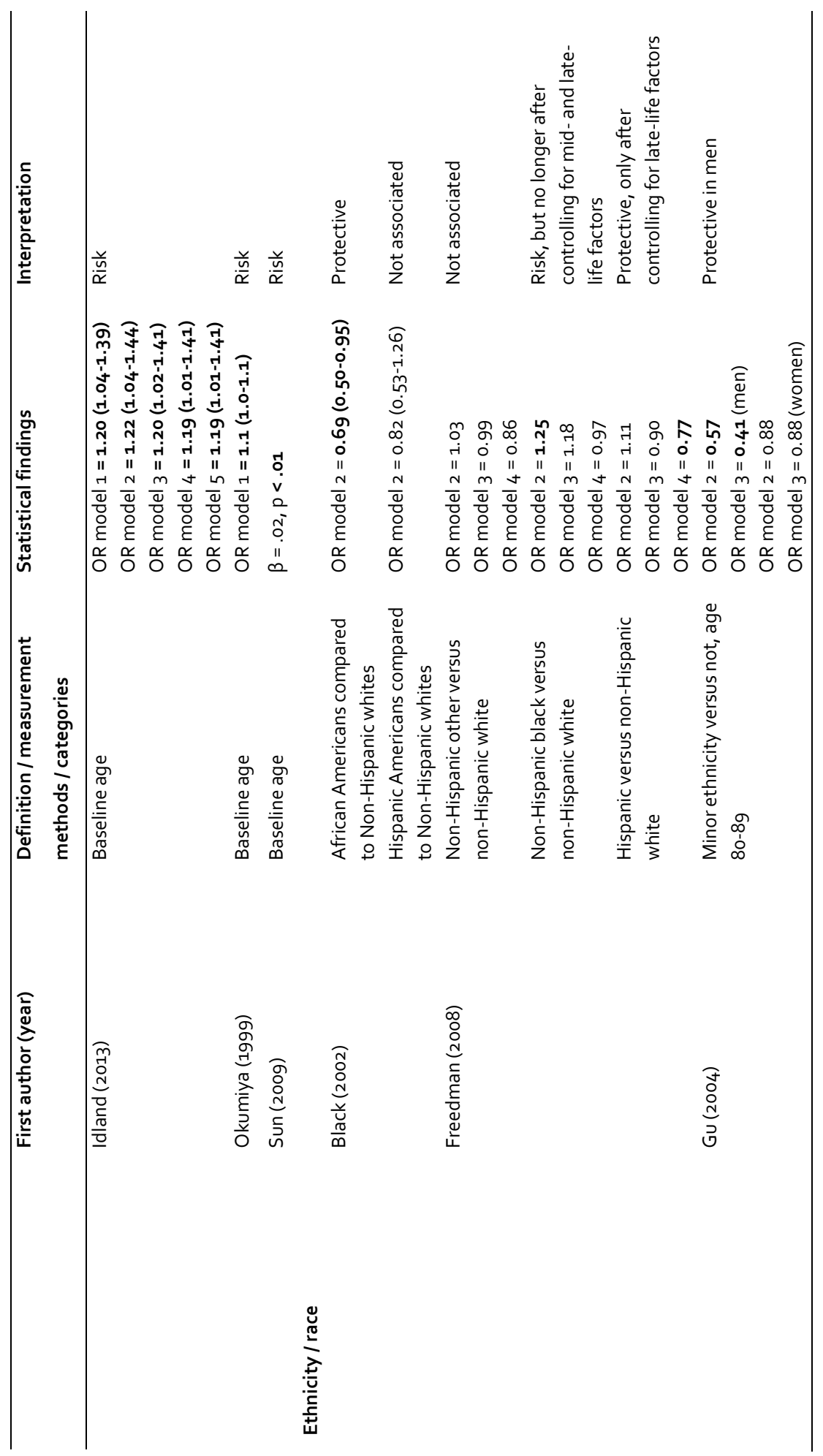




\section{CHAPTER 4}

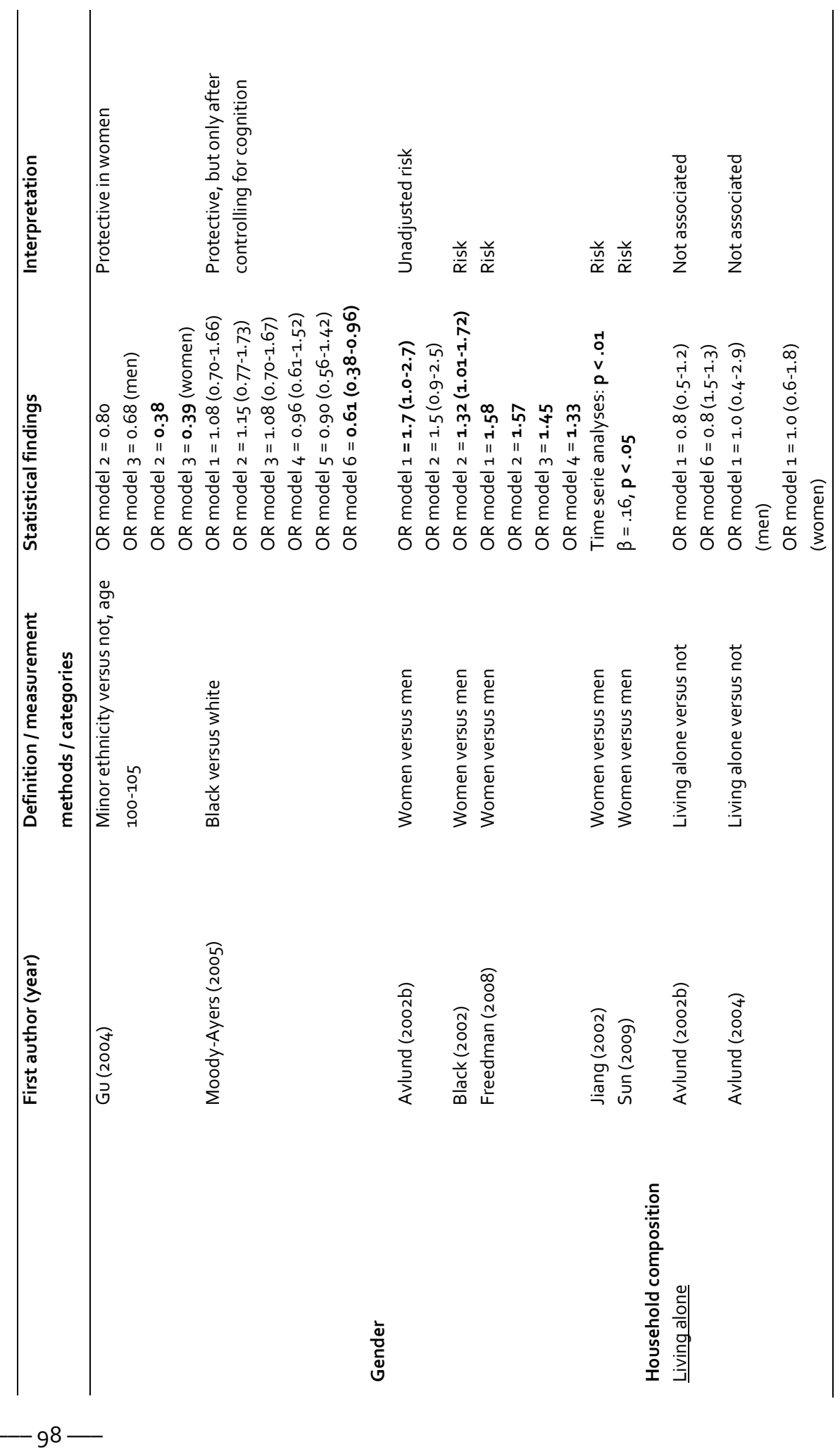




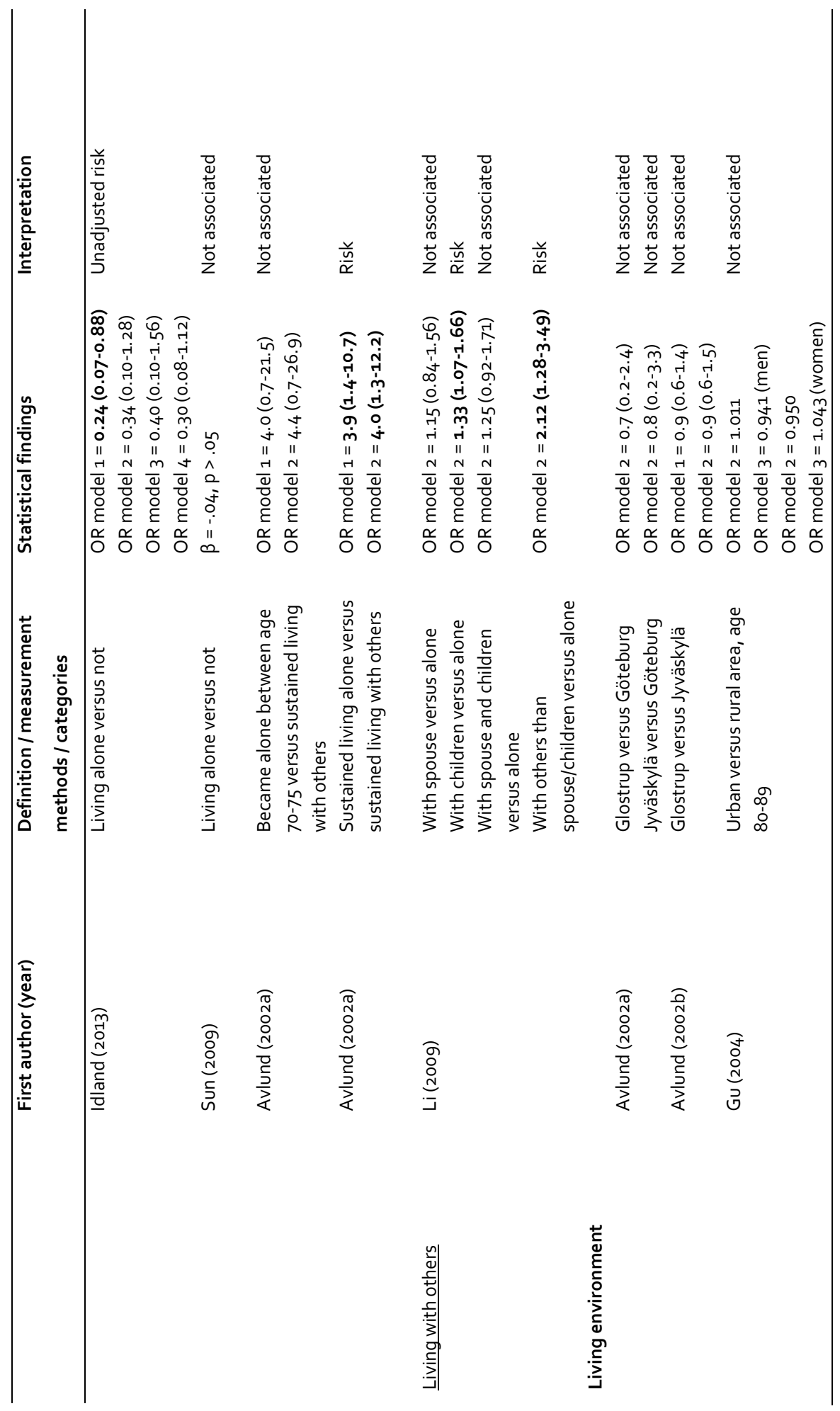




\section{CHAPTER 4}

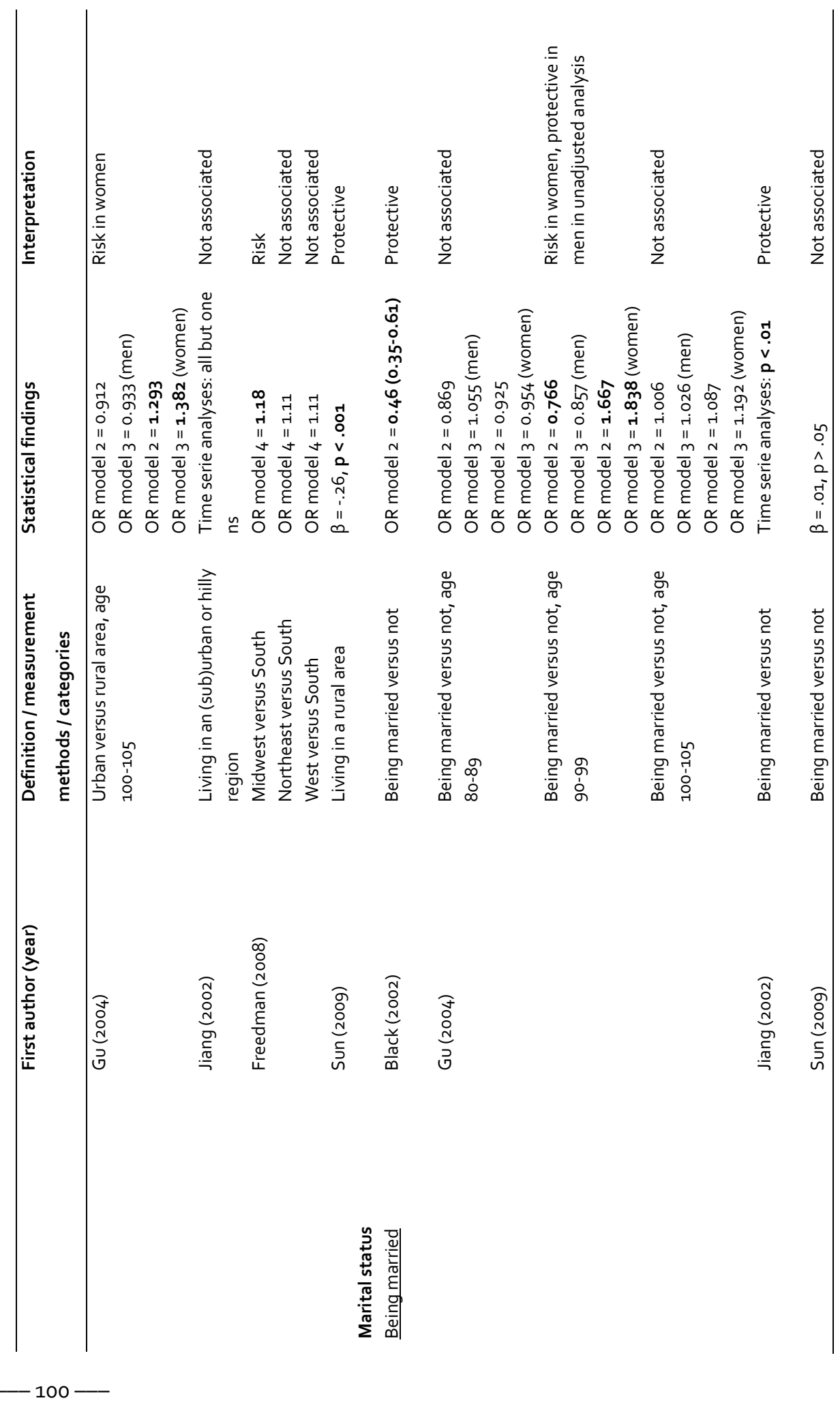


RISK \& PROTECTIVE FACTORS FOR LIMITATIONS IN ACTIVITIES OF DAILY LIVING

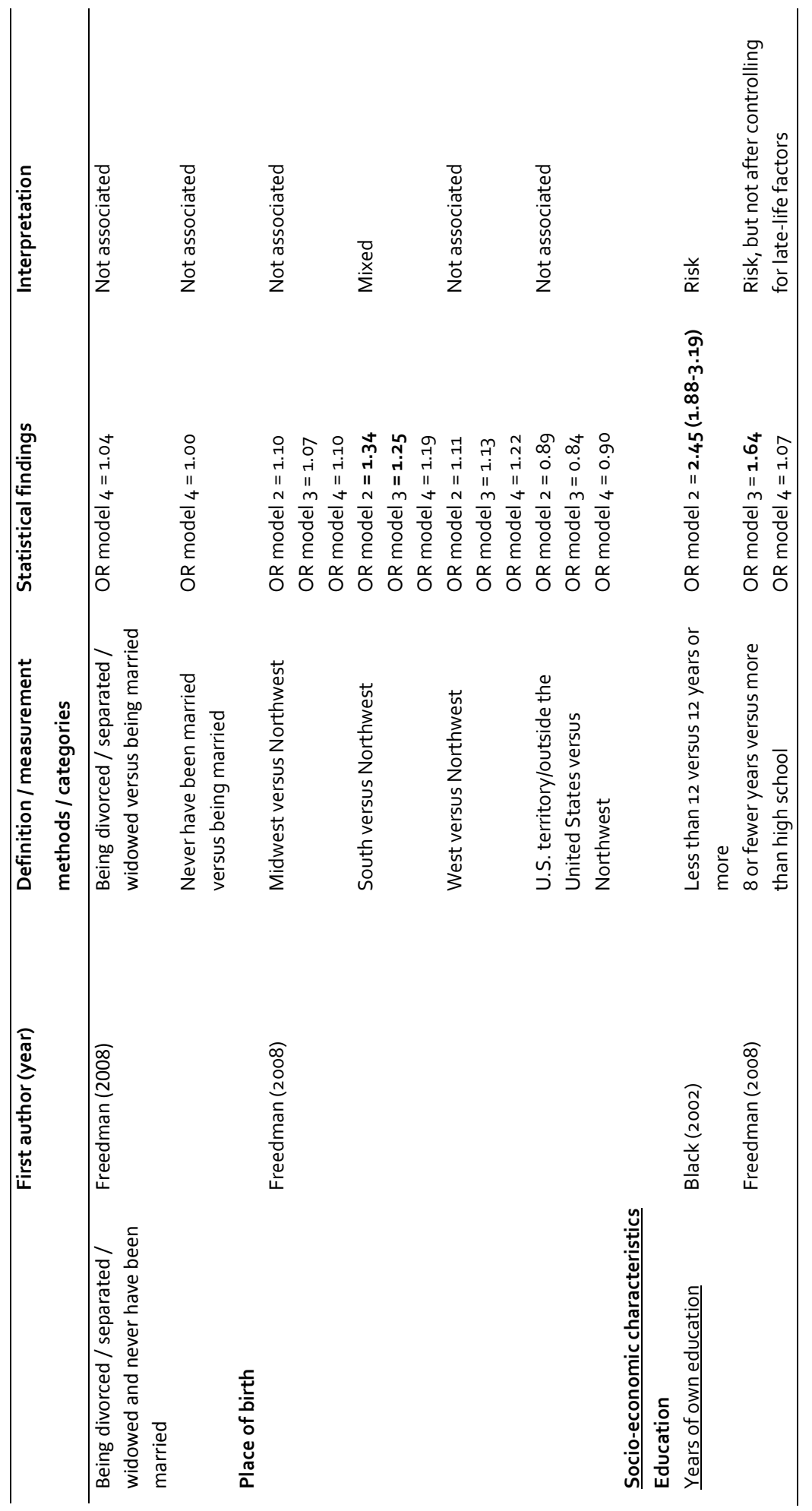




\section{CHAPTER 4}

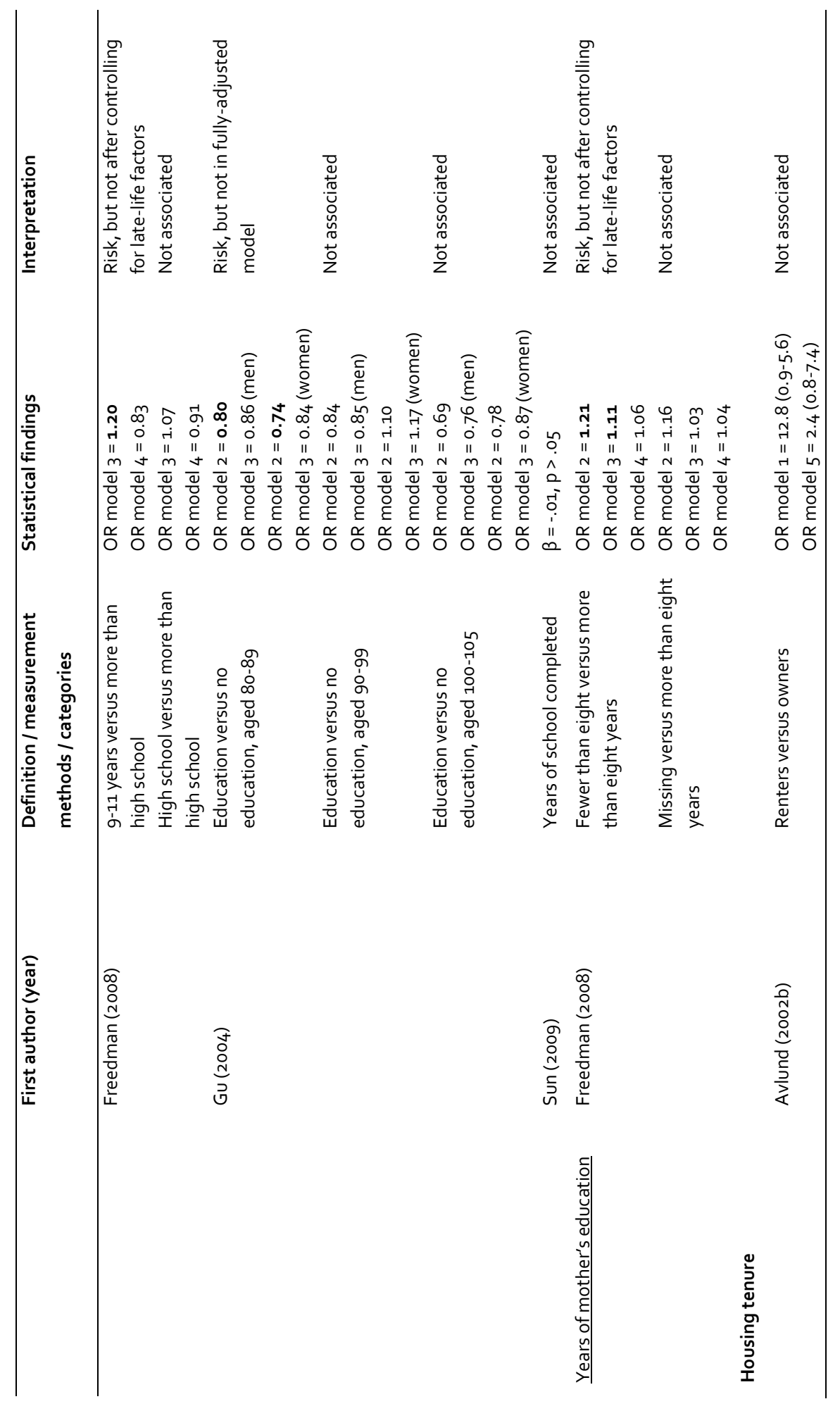


RISK \& PROTECTIVE FACTORS FOR LIMITATIONS IN ACTIVITIES OF DAILY LIVING

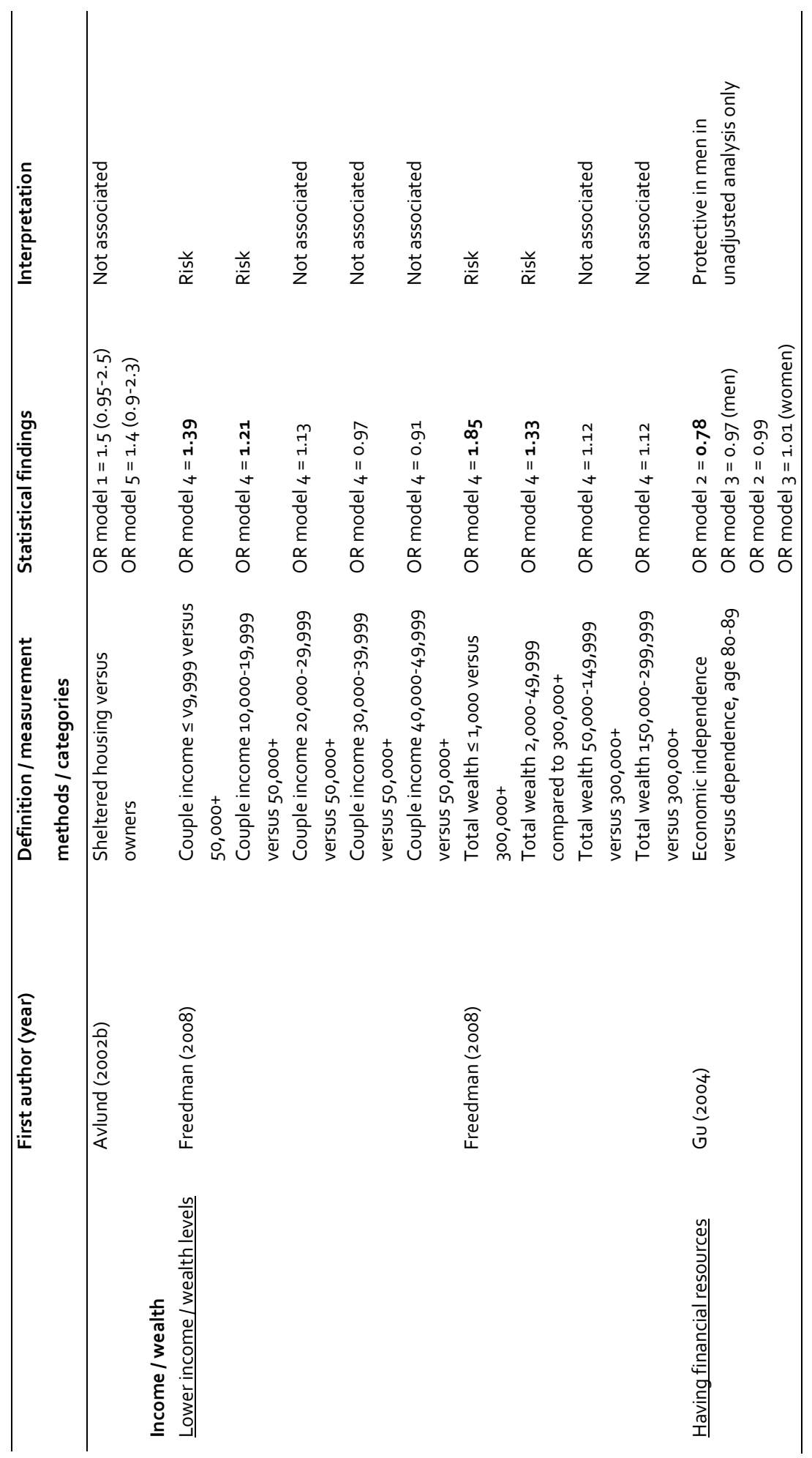




\section{CHAPTER 4}

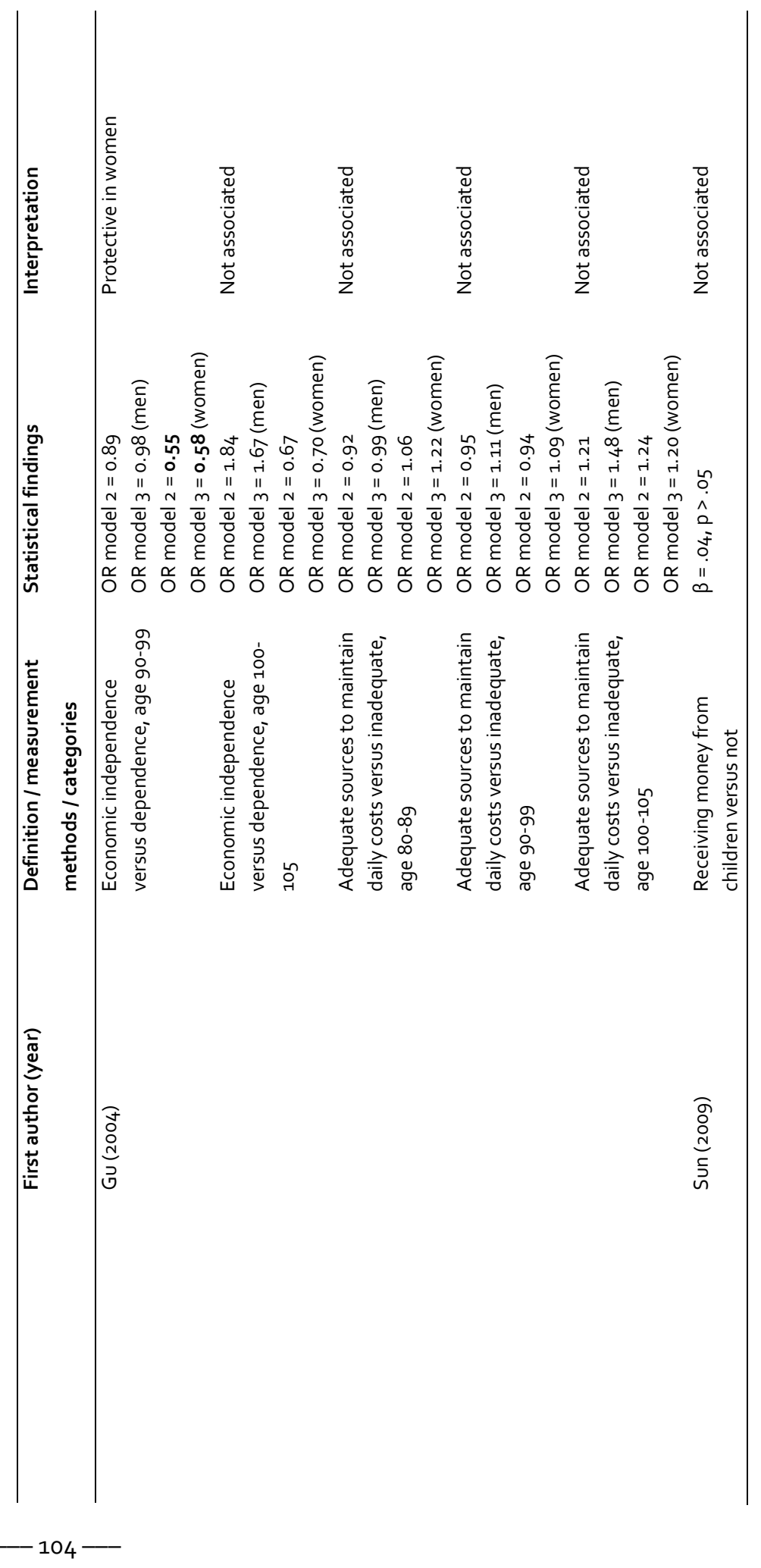


RISK \& PROTECTIVE FACTORS FOR LIMITATIONS IN ACTIVITIES OF DAILY LIVING

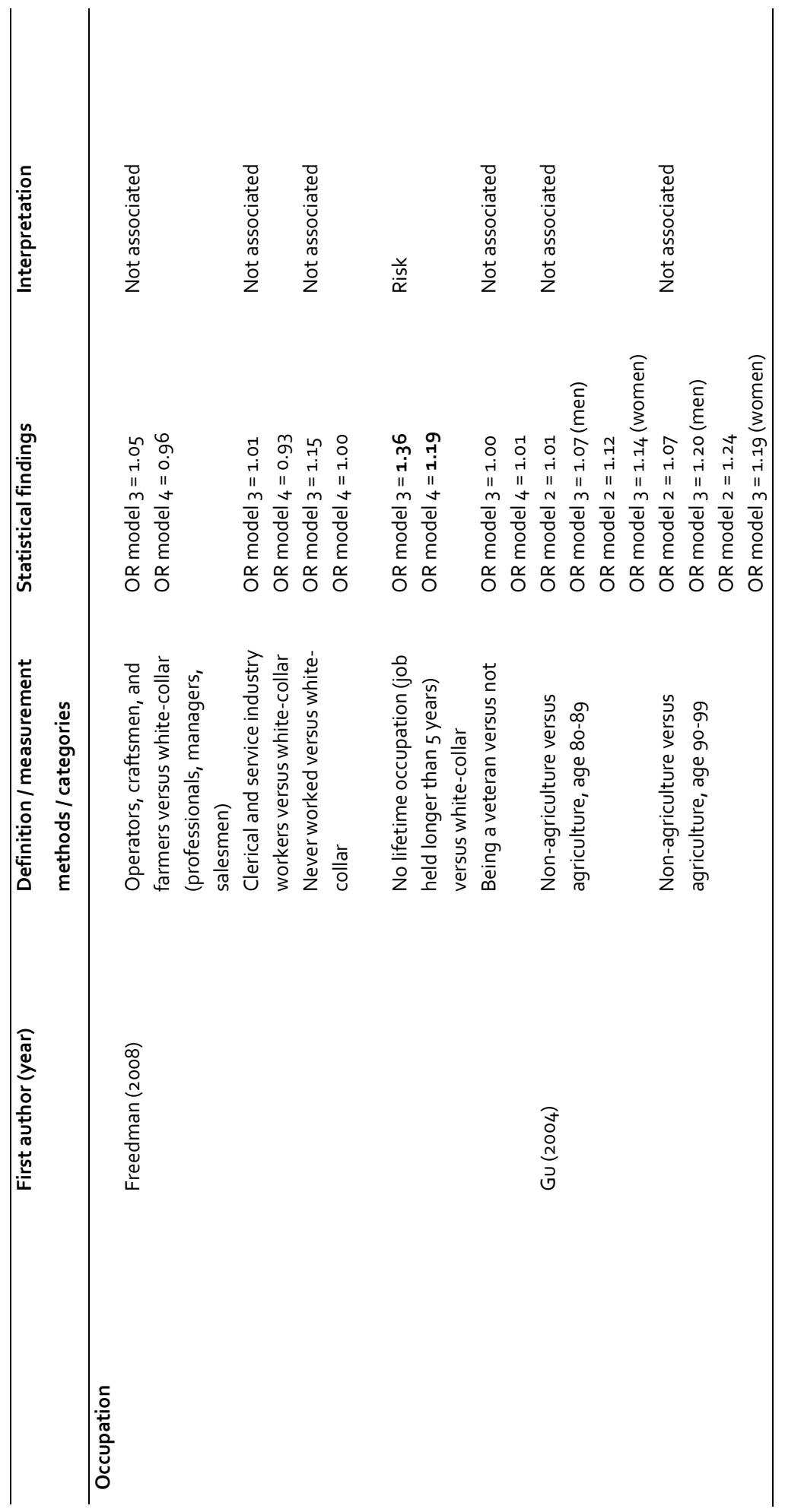




\section{CHAPTER 4}

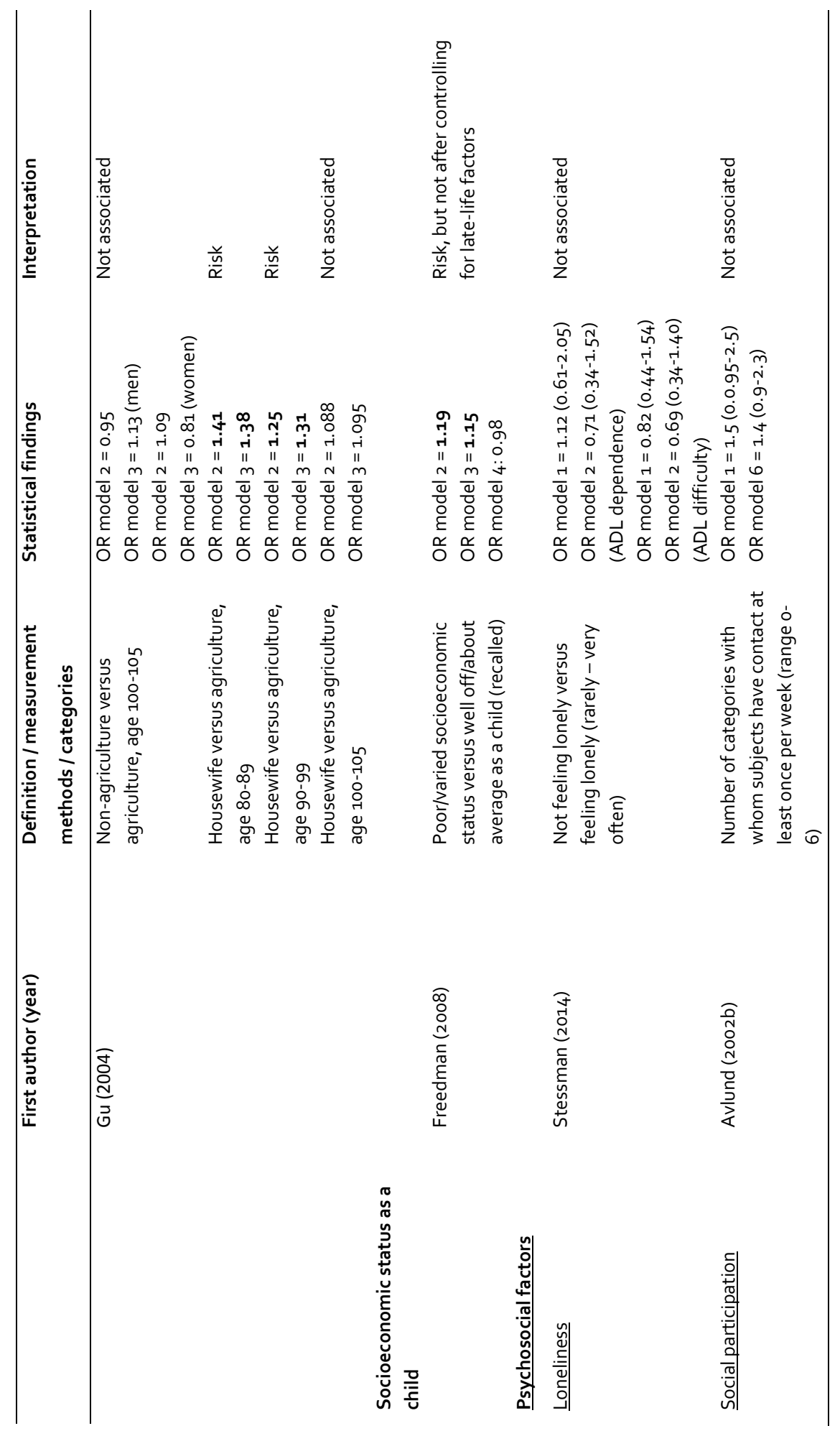



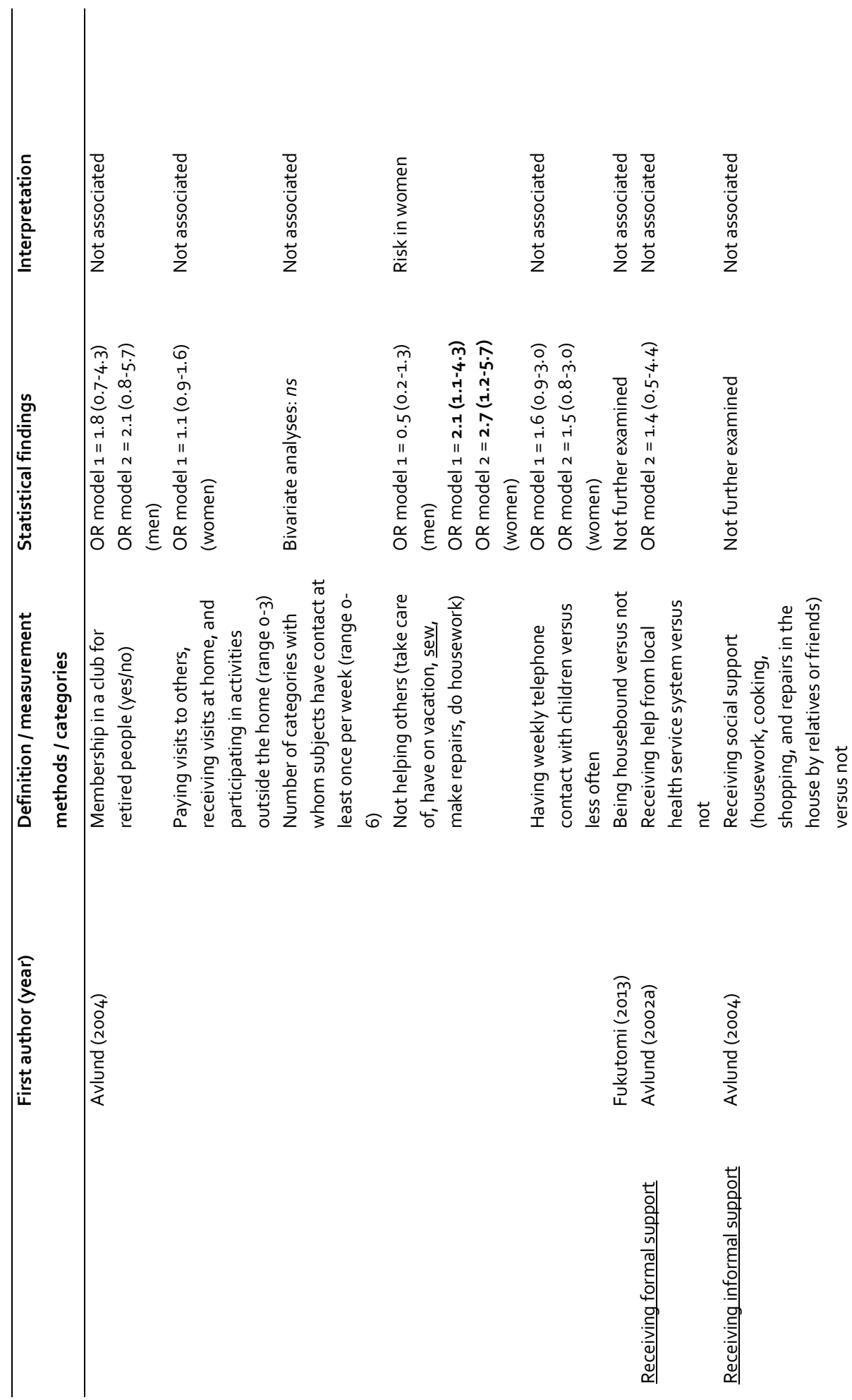


\section{CHAPTER 4}

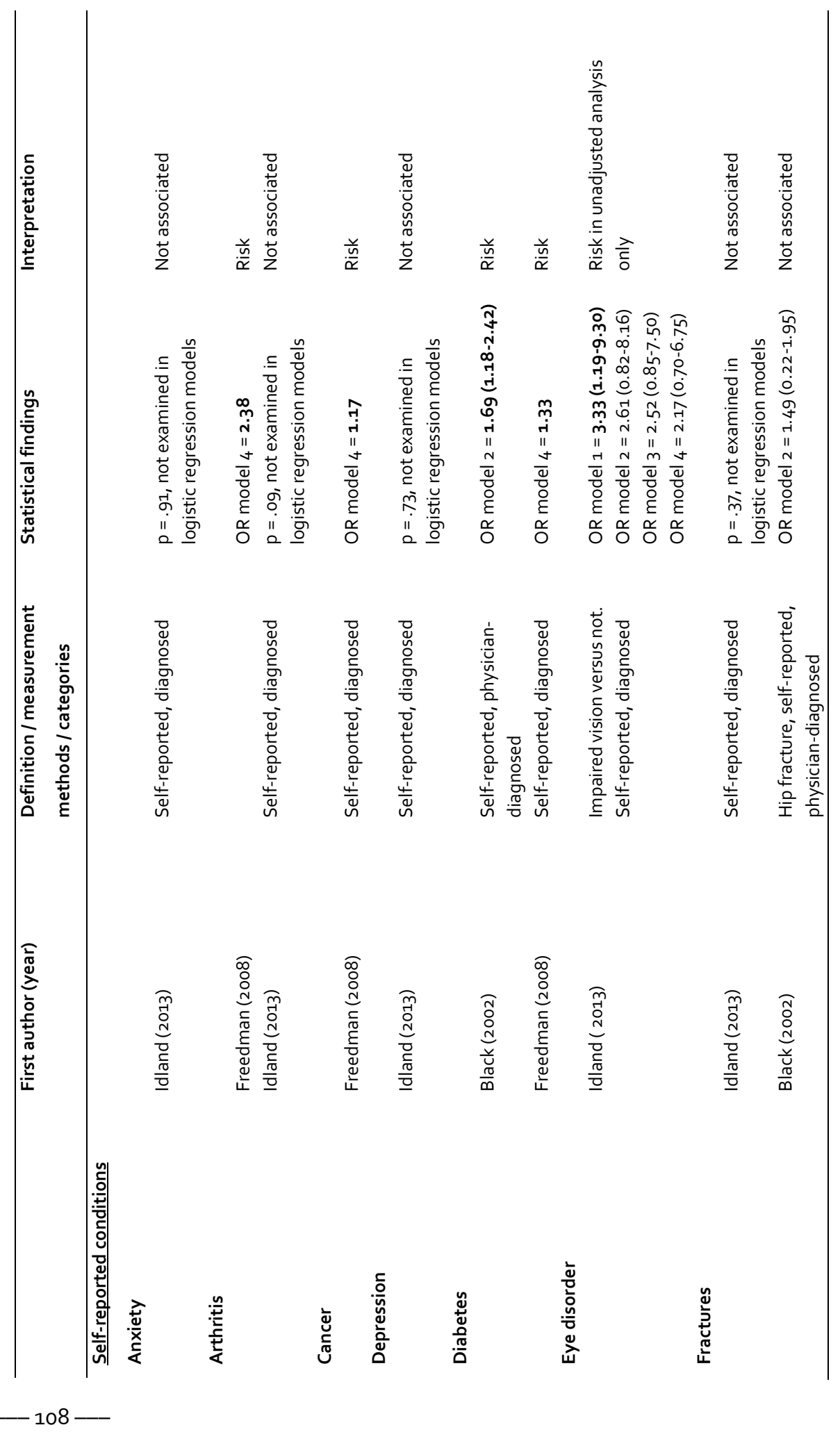




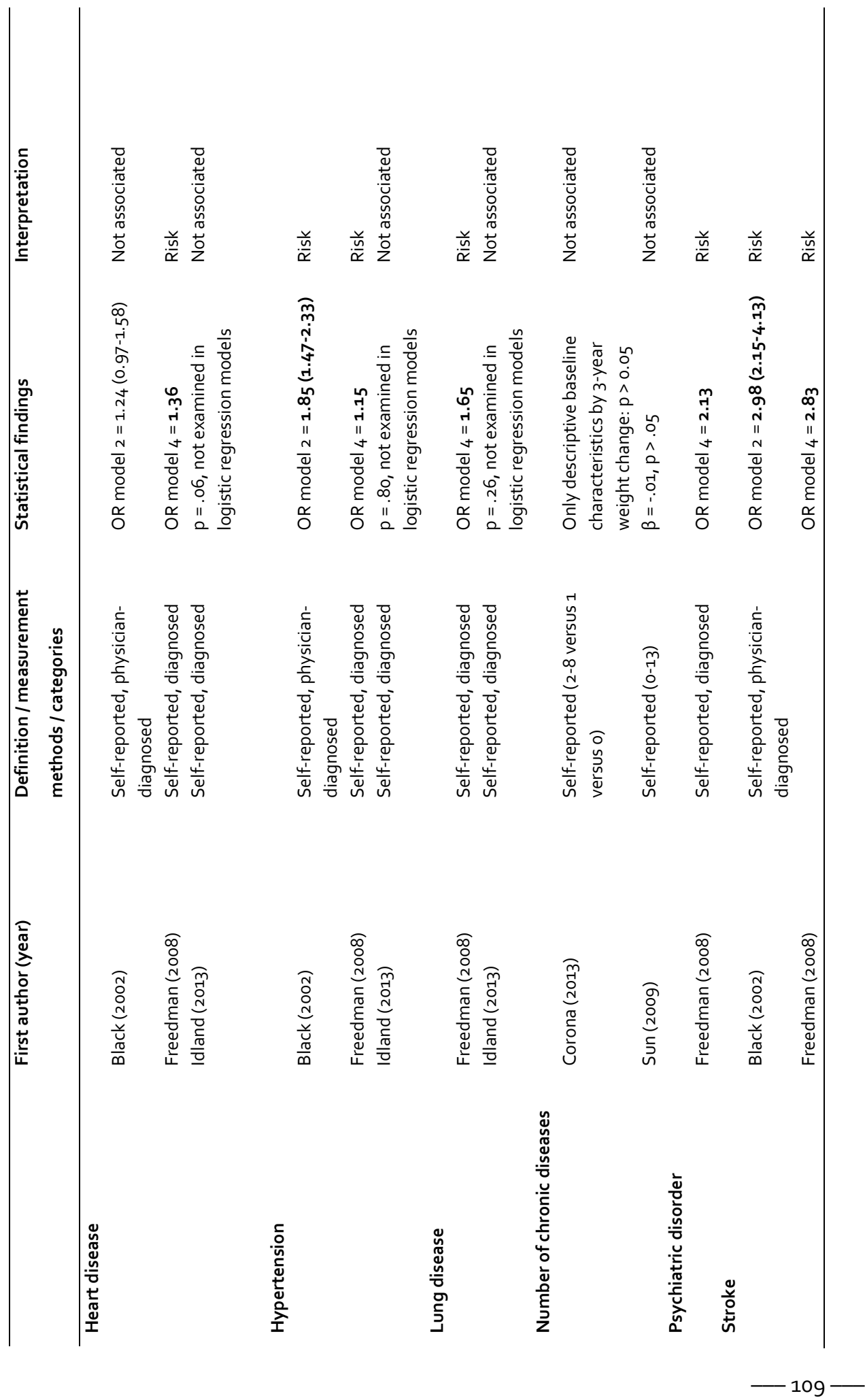




\section{CHAPTER 4}

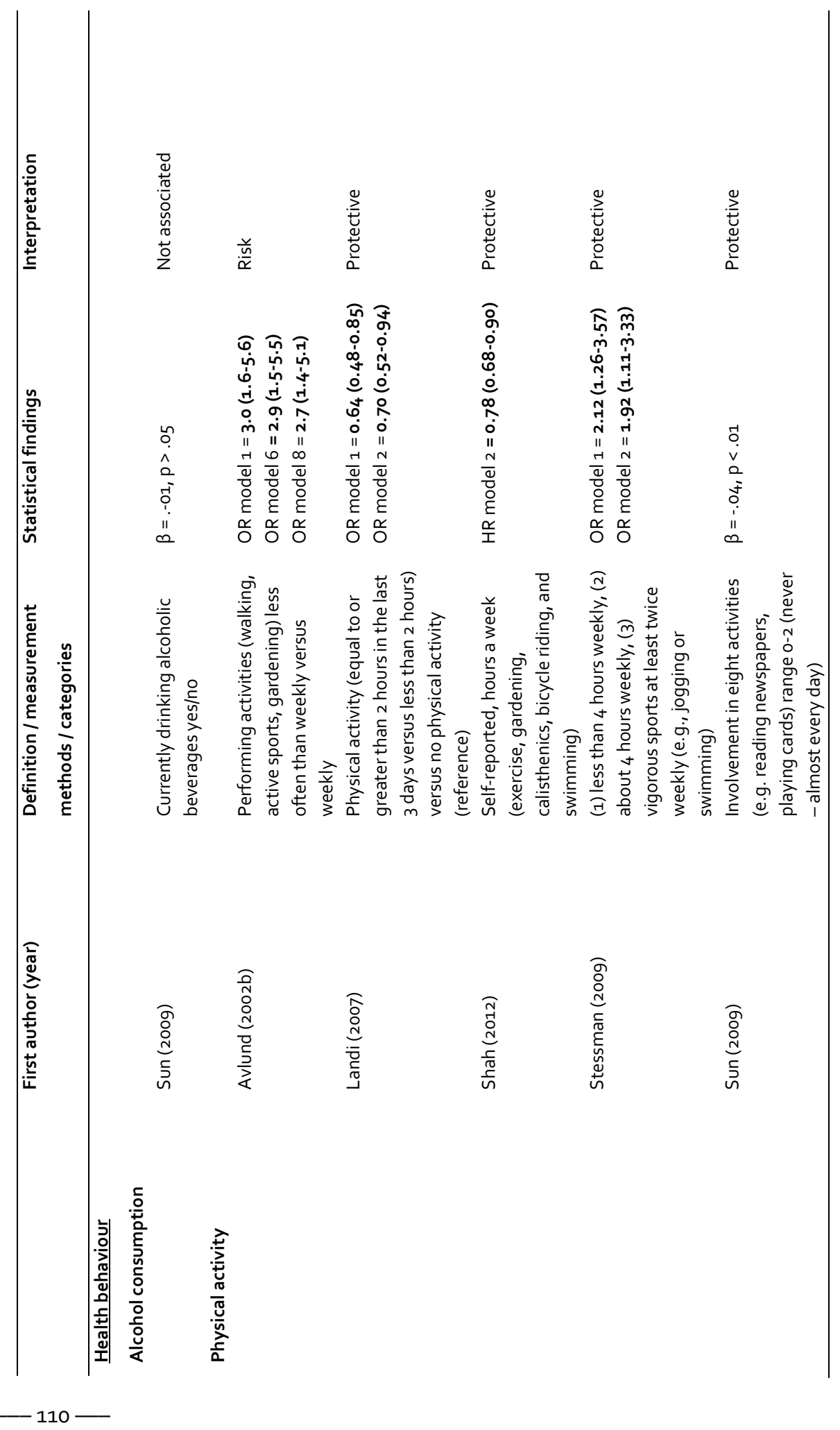




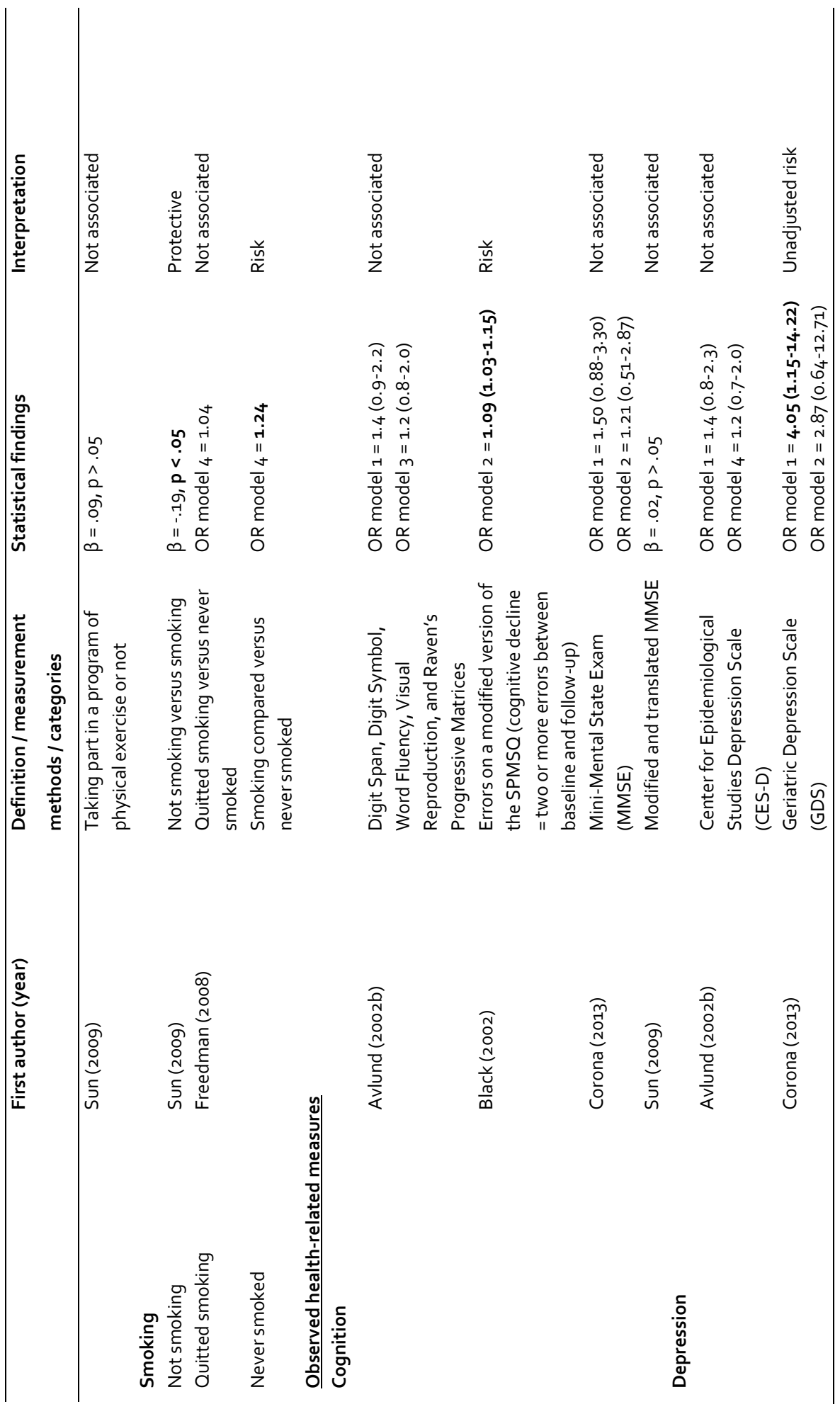




\section{CHAPTER 4}

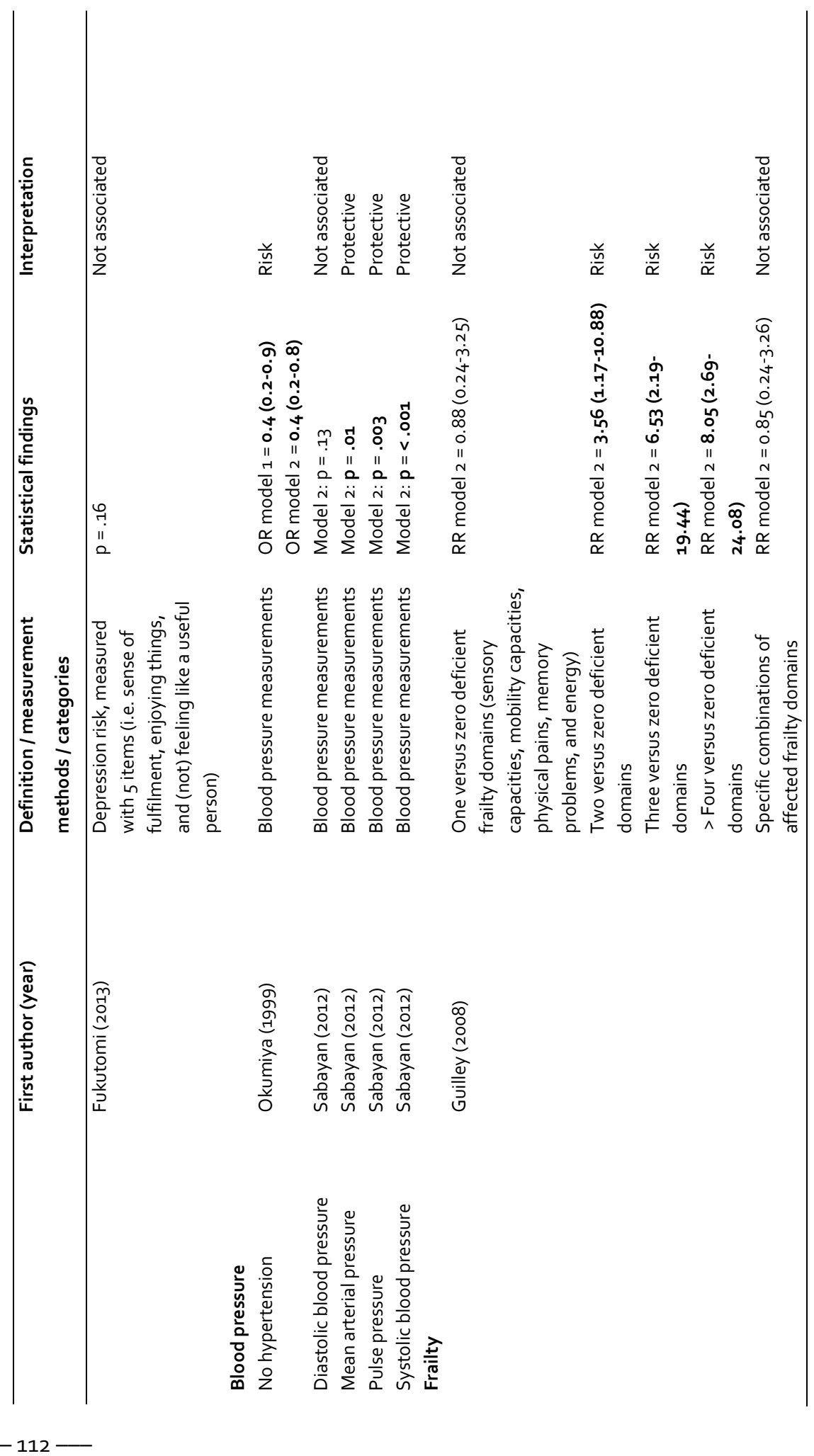




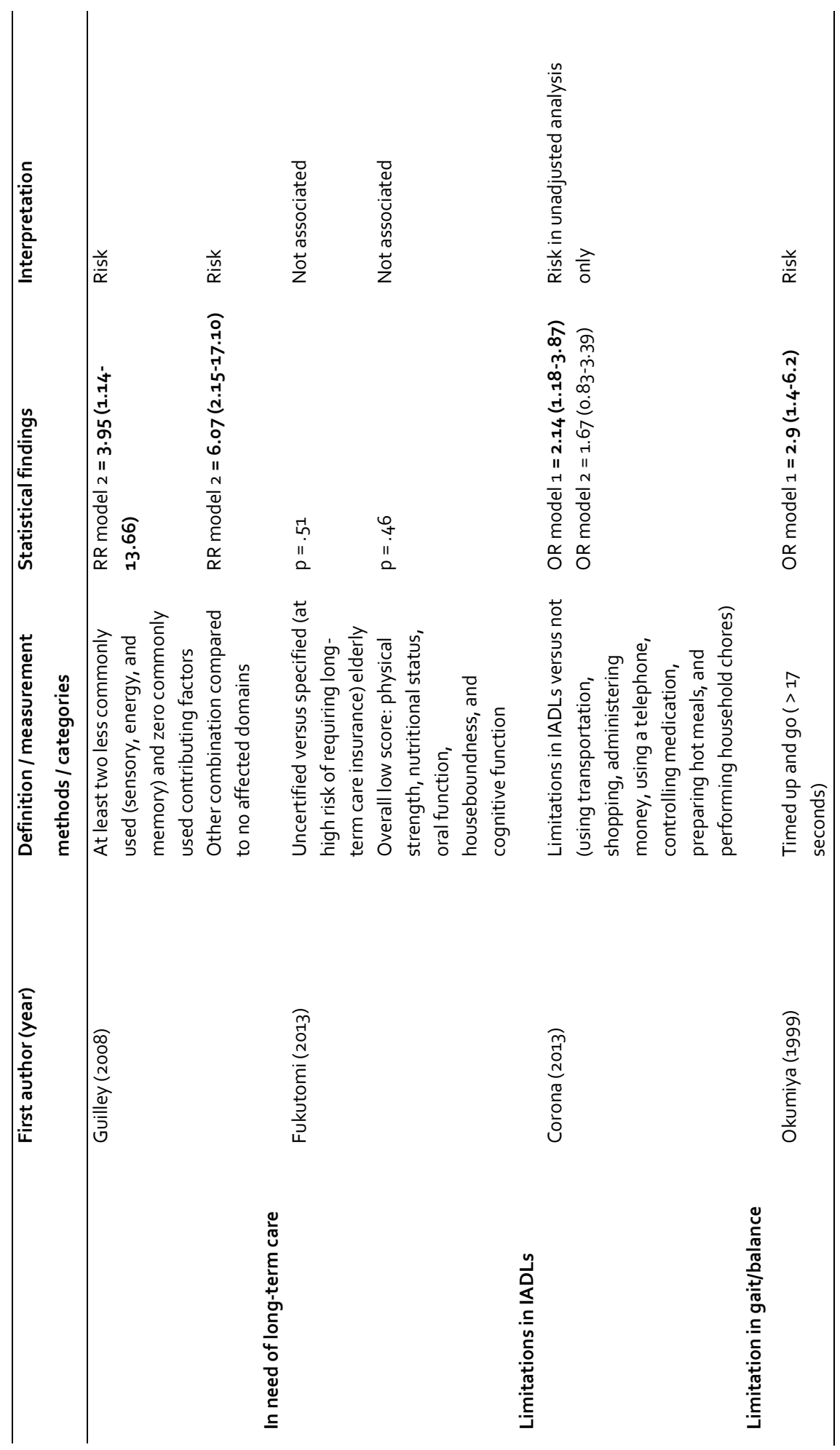




\section{CHAPTER 4}

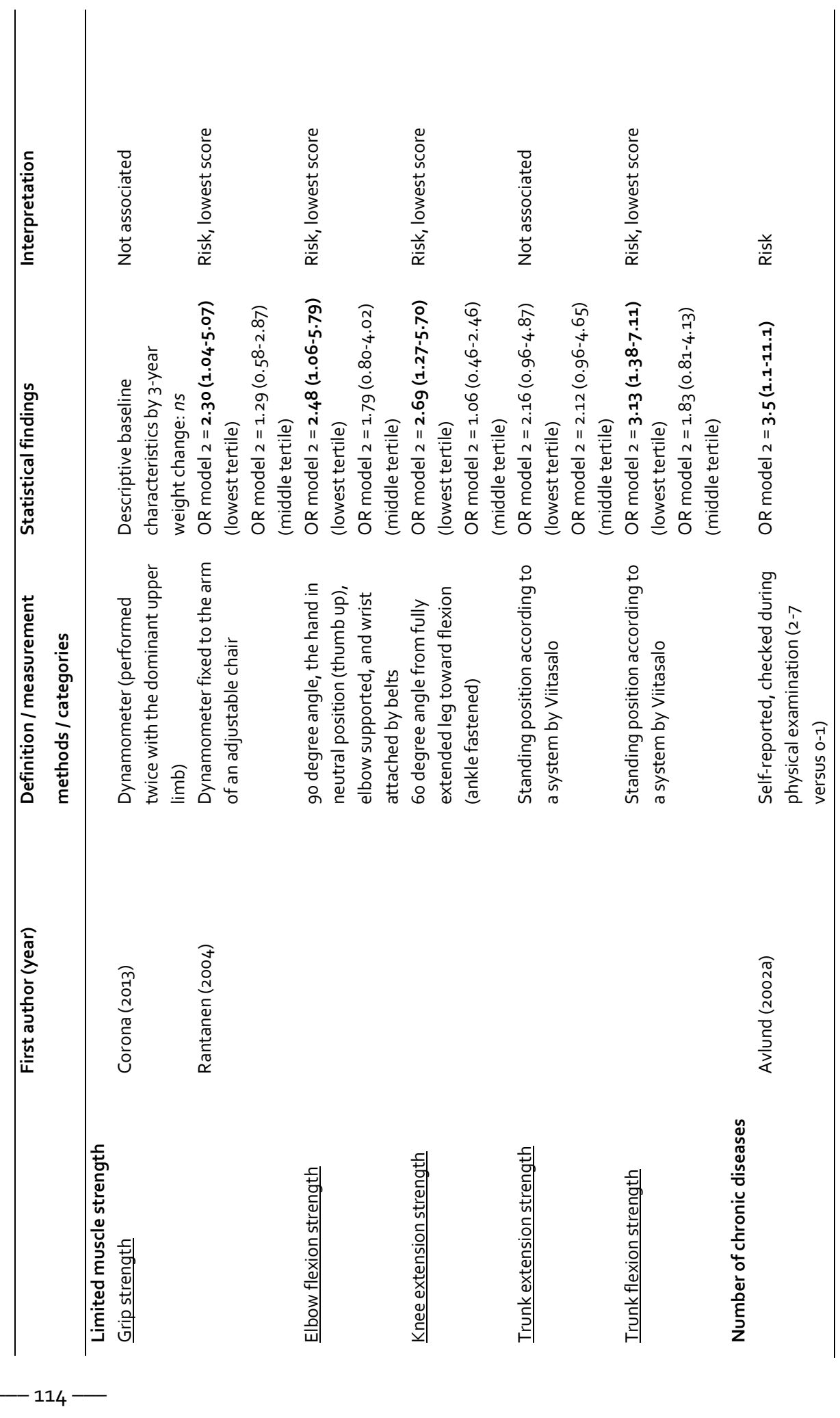




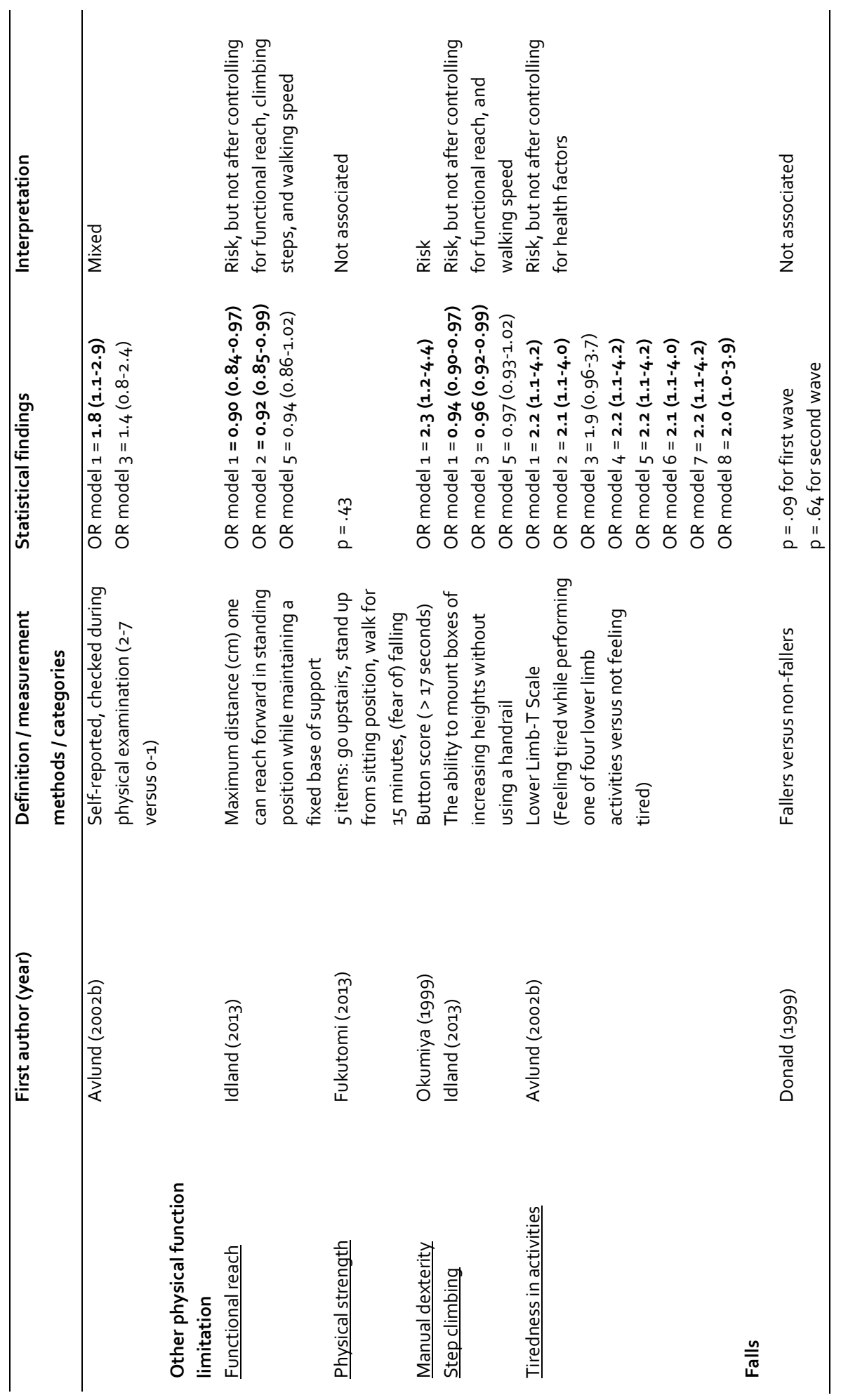




\section{CHAPTER 4}

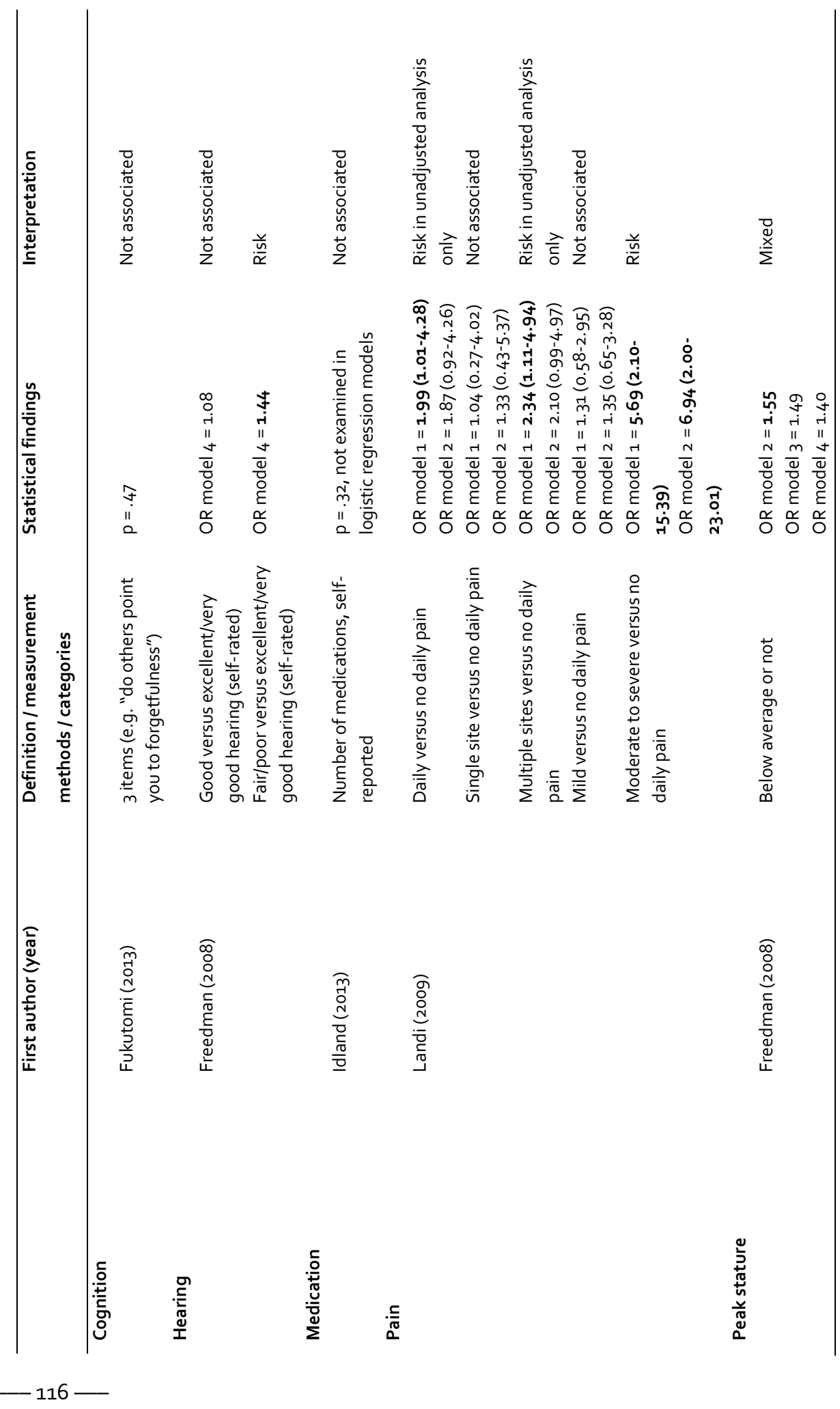




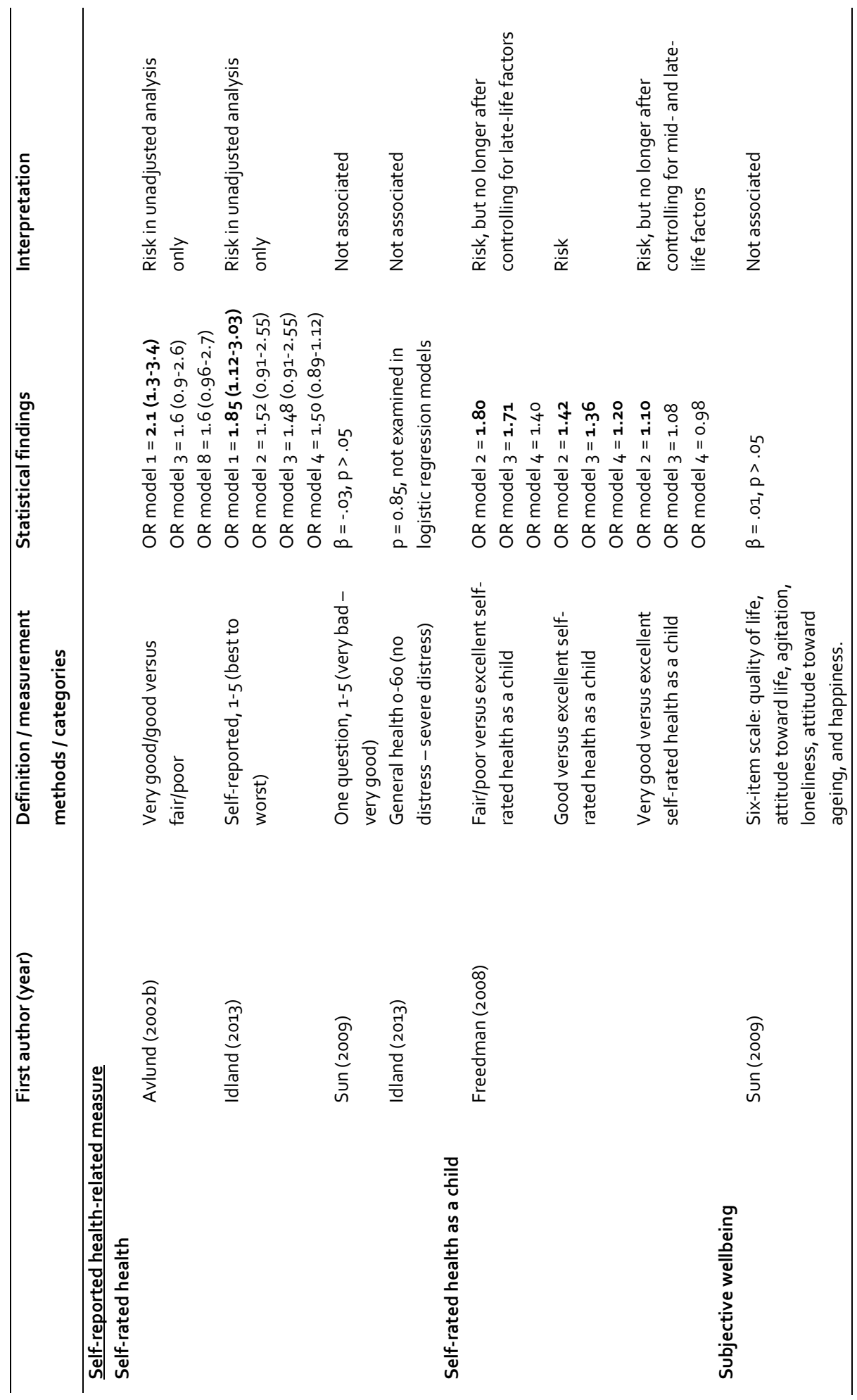




\section{CHAPTER 4}

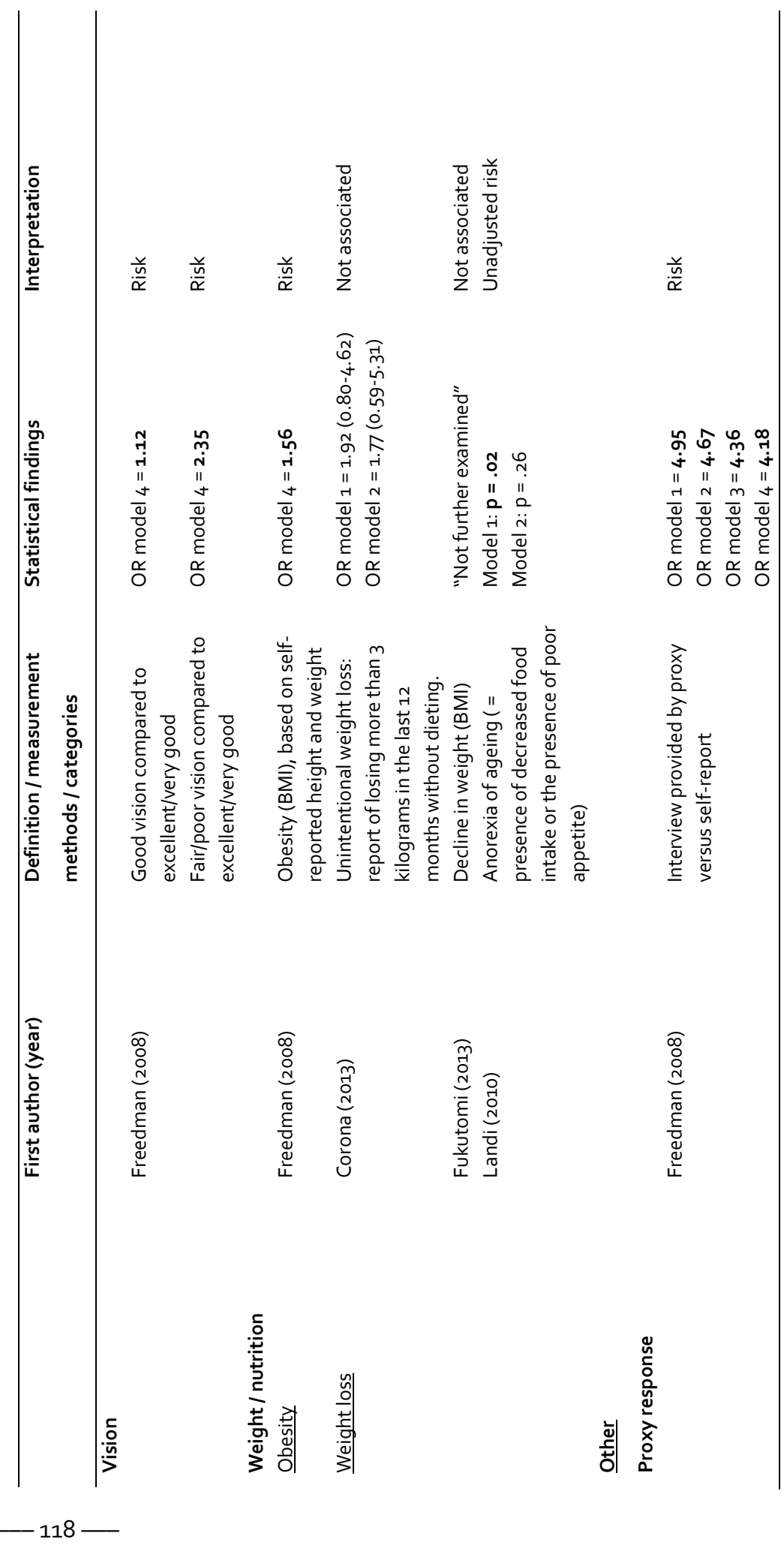


* Model 1 = unadjusted analyses for all studies. For the specification of other models per study, see below:

\begin{tabular}{|c|c|}
\hline First author (year) & Adjusted models \\
\hline Avlund (2002a) & Chronic diseases, home help, and locality \\
\hline \multirow[t]{7}{*}{ Avlund (2002b) } & Sex and locality \\
\hline & 3. Health factors \\
\hline & 4. Depressive symptoms \\
\hline & 5. Housing tenure \\
\hline & 6. Social relations \\
\hline & 7. Physical activity \\
\hline & $\begin{array}{l}\text { 8. Physical activity or self-rated health (final } \\
\text { model) }\end{array}$ \\
\hline \multirow[t]{4}{*}{ Avlund (2004) } & $\begin{array}{l}\text { 2. Social relations variables that were related to } \\
\text { the specific outcome measures in the } \\
\text { unadjusted analyses }\end{array}$ \\
\hline & $\begin{array}{l}\text { 3. Social relations variables that were related to } \\
\text { the specific outcome measures in model } 2\end{array}$ \\
\hline & 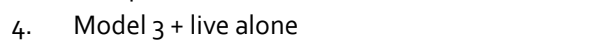 \\
\hline & $\begin{array}{l}\text { 5. Variables model } 4 \text { if related to outcome, and } \\
\text { chronic diseases, cognitive function, } \\
\text { depressive symptoms, and locality }\end{array}$ \\
\hline Black (2002) & $\begin{array}{l}\text { 2. Sociodemographics, chronic health conditions, } \\
\text { cognitive status and functional decline }\end{array}$ \\
\hline Corona (2013) & $\begin{array}{l}\text { 2. Factors significant in unadjusted analyses (age, } \\
\text { IADL, cognition, depression, unintentional } \\
\text { weight loss) }\end{array}$ \\
\hline Donald (1999) & 2. Unclear \\
\hline \multirow[t]{3}{*}{ Freedman (2008) } & $\begin{array}{l}\text { 2. Early-life factors (race/ethnicity, region of } \\
\text { birth, mother's education, childhood SES, } \\
\text { childhood self-rated health and low peak } \\
\text { stature) }\end{array}$ \\
\hline & $\begin{array}{l}\text { 3. Plus mid-life factors (education, veteran, } \\
\text { lifetime occupation) }\end{array}$ \\
\hline & $\begin{array}{l}\text { 4. Plus late-life factors (marital status, region of } \\
\text { residence, income, assets, smokers, chronic } \\
\text { conditions, obesity, vision and hearing) }\end{array}$ \\
\hline \multicolumn{2}{|l|}{ Fukutomi (2013) } \\
\hline \multirow[t]{2}{*}{ Gu (2011) } & 2. Socio-demographic variables \\
\hline & $\begin{array}{l}\text { 3. Socio-demographic variables and "all other } \\
\text { controlling variables" (family and social } \\
\text { support/connections, alcohol consumption, } \\
\text { smoking, diet, exercise, cognition, self- } \\
\text { reported health, depression, chronic disease, } \\
\text { hearing and visual impairment, lower and } \\
\text { upper extremities, survivors verses decedents) }\end{array}$ \\
\hline Guilley (2008) & $\begin{array}{l}\text { 2. Controlled for age, gender, socioeconomic } \\
\text { status, and geographical area }\end{array}$ \\
\hline
\end{tabular}




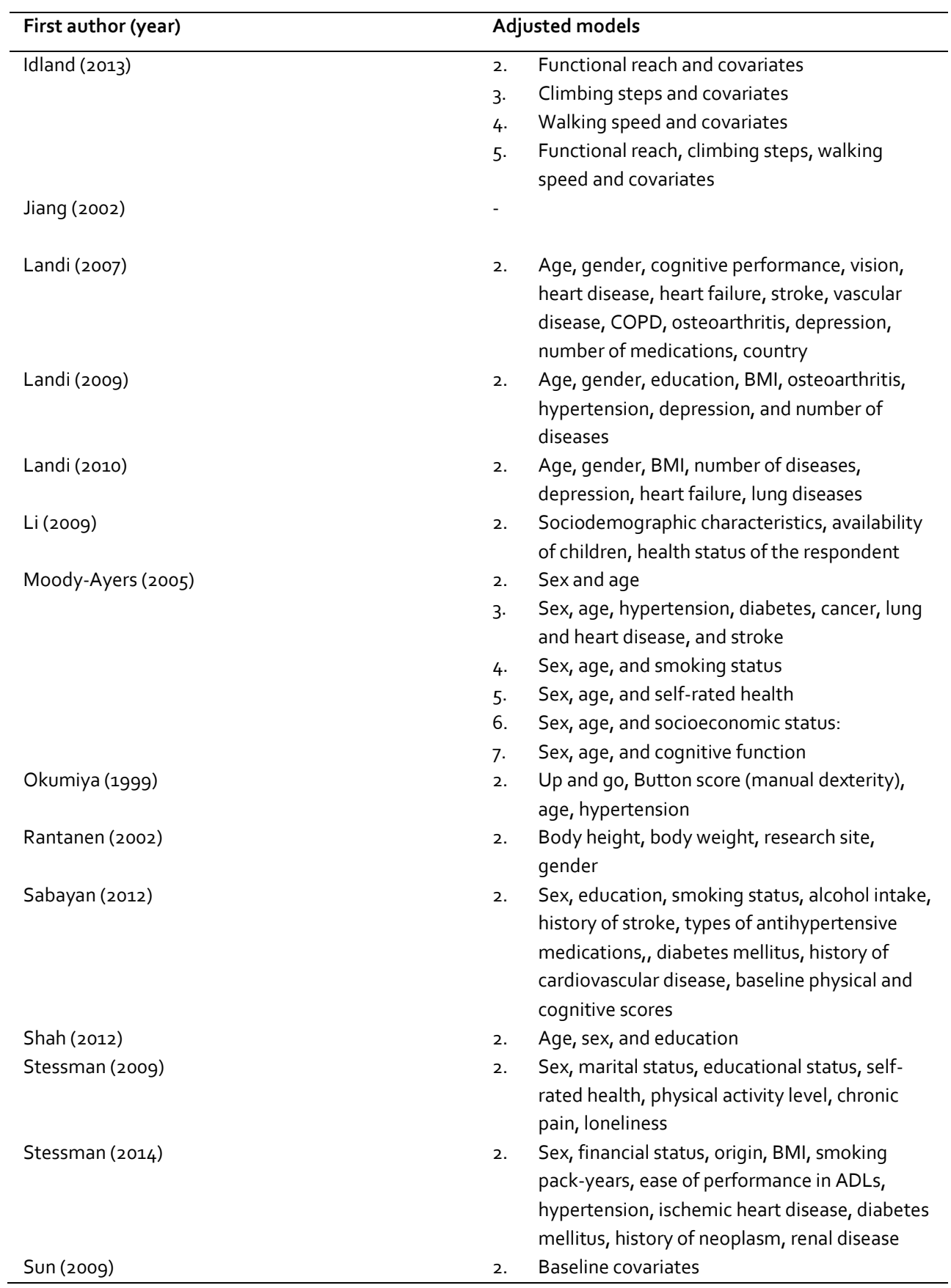


$-121-$ 
$-122-$ 


\section{The impact of multidimensional frailty on dependency in activities of daily living and the moderating effects of protective factors}

\section{Published as}

van der Vorst, A., Op het Veld, L.P.M., De Witte, N., Schols, J.M.G.A., Kempen, G.I.J.M., Zijlstra, G.A.R. (2018). The impact of multidimensional frailty on dependency in activities of daily living and the moderating effects of protective factors. Archives of Gerontology and Geriatrics. 78: 255-260. DOI: 10.1016/j.archger.2018.06.017. 


\section{Abstract}

Background: Dependency in activities of daily living (ADL) might be caused by multidimensional frailty. Prevention is important as ADL dependency might threaten the ability to age in place. Therefore, this study aimed to assess whether protective factors, derived from a systematic literature review, moderate the relationship between multidimensional frailty and ADL dependency, and whether this differs across age groups.

Methods: A longitudinal study with a follow-up after 24 months was conducted among 1027 community-dwelling people aged $\geq 65$ years. Multidimensional frailty was measured with the Tilburg Frailty Indicator, and ADL dependency with the ADL subscale from the Groningen Activity Restriction Scale. Other measures included socio-demographic characteristics and seven protective factors against ADL dependency, such as physical activity and non-smoking. Logistic regression analyses with interaction terms were conducted.

Results: Frail older people had a twofold risk of developing ADL dependency after 24 months in comparison to non-frail older people ( $O R=2.12,95 \% \mathrm{Cl}=1.45-3.00$ ). The selected protective factors against ADL dependency did not significantly moderate this relationship. Nonetheless, higher levels of physical activity decreased the risk of becoming $A D L$ dependent $(O R=0.67,95 \% \mathrm{Cl}=0.46-0.98)$, as well as having sufficient financial resources $(\mathrm{OR}=0.49,95 \% \mathrm{Cl}=0.35-0.71)$.

Conclusions: Multidimensional frail older people have a higher risk of developing ADL dependency. The studied protective factors against ADL dependency did not significantly moderate this relationship. 


\section{Introduction}

With the ageing population, frailty has become an increasingly relevant construct. However, consensus about the definition is lacking. It is defined as a merely physical construct [1], and a multidimensional construct, including physical, psychological, social, and environmental aspects [2-4]. Prevalence rates vary accordingly [5]. Nonetheless, it is well-known that frailty is associated with adverse outcomes, of which one is disability in activities of daily living (ADLs) [6]. Most older people desire to age in place [7]. However, "the ability to perform functions related to daily living" is needed to remain independently living in the community [8], and thus is ADL disability likely to diminish the ability to age in place. Indeed, negative consequences of ADL disability may be hospitalisation [9], mortality [10], and lower levels of quality of life [11], amongst others. Therefore, it is important to prevent (frail) older people from becoming disabled in ADL.

Although multiple studies on physical frailty in relation to ADL disability have been performed [12, for an overview], literature on multidimensional frailty and ADL disability is relatively sparse. Nonetheless, Teo et al. [13] recently reported that social frailty is associated with an increased risk of ADL disability, irrespective of physical frailty. In addition, Mulasso et al. [14] showed that both physical frailty and psychosocial factors influence the level of ADL disability. Given these findings, it seems important to investigate $A D L$ disability as an adverse outcome in multidimensional frailty. However, instead of merely focusing on the risk of ADL disability, it is also of value to identify protective factors. In this way, interventions can concentrate on factors that may prevent frail older people from becoming disabled in ADLs, which makes it possible to intervene in a more positive way, as preferred by older people [15].

In their recent systematic review, van der Vorst et al. [16] identified several protective factors against ADL disability in community-dwelling people aged $\geq 75$. With regards to intervening factors, strong evidence was found for higher levels of physical activity as a protective factor against developing ADL disability [17-21]. In addition, not smoking was found to be protective in one study [21]. Regarding protective factors that could serve detection purposes only, being married was found to be a protective factor in multiple studies [22-24]. In addition, being from a minor ethnicity [22-23, 25-26], living in a rural area [21], and having sufficient financial resources [23] were found to be potential protective factors. Lastly, and perhaps surprisingly, the review by van der Vorst et al. [16] identified hypertension as a potential protective factor. This was reported in one of the included studies, conducted in people aged $\geq 85$ years [27].

However, it is unclear whether these factors are still protective in communitydwelling older people with multidimensional frailty. For clinical practice, it is particularly important to know which factors moderate the effect of frailty on ADL 
disability, and which frail older people have a reduced risk of developing ADL disability. Herewith, it is necessary to take into account the possible differences across age groups, as van der Vorst et al. [16] mentioned that predictive factors for developing ADL disability were likely to differ across age groups. While some studies focus on increasing levels of ADL disability as an adverse outcome, this study focuses on ADL dependency (i.e. whether or not people could independently perform ADL) - as this seems the biggest threat to remaining living independently at home [8]. We aimed to investigate the following: (i) the main effect of multidimensional frailty on ADL dependency (arrow a, Figure 1); (ii) whether this relationship is moderated by the aforementioned protective factors (arrow b, Figure 1); (iii) the main effects of the selected protective factors on ADL dependency (arrow c, Figure 1); and (iv) if there are differences across age groups (for all relationships). It is hypothesised that (i) multidimensional frailty is associated with an increased risk of ADL dependency; and (ii) older people with protective factors against ADL dependency are less likely to become dependent on others, even when they suffer from multidimensional frailty.

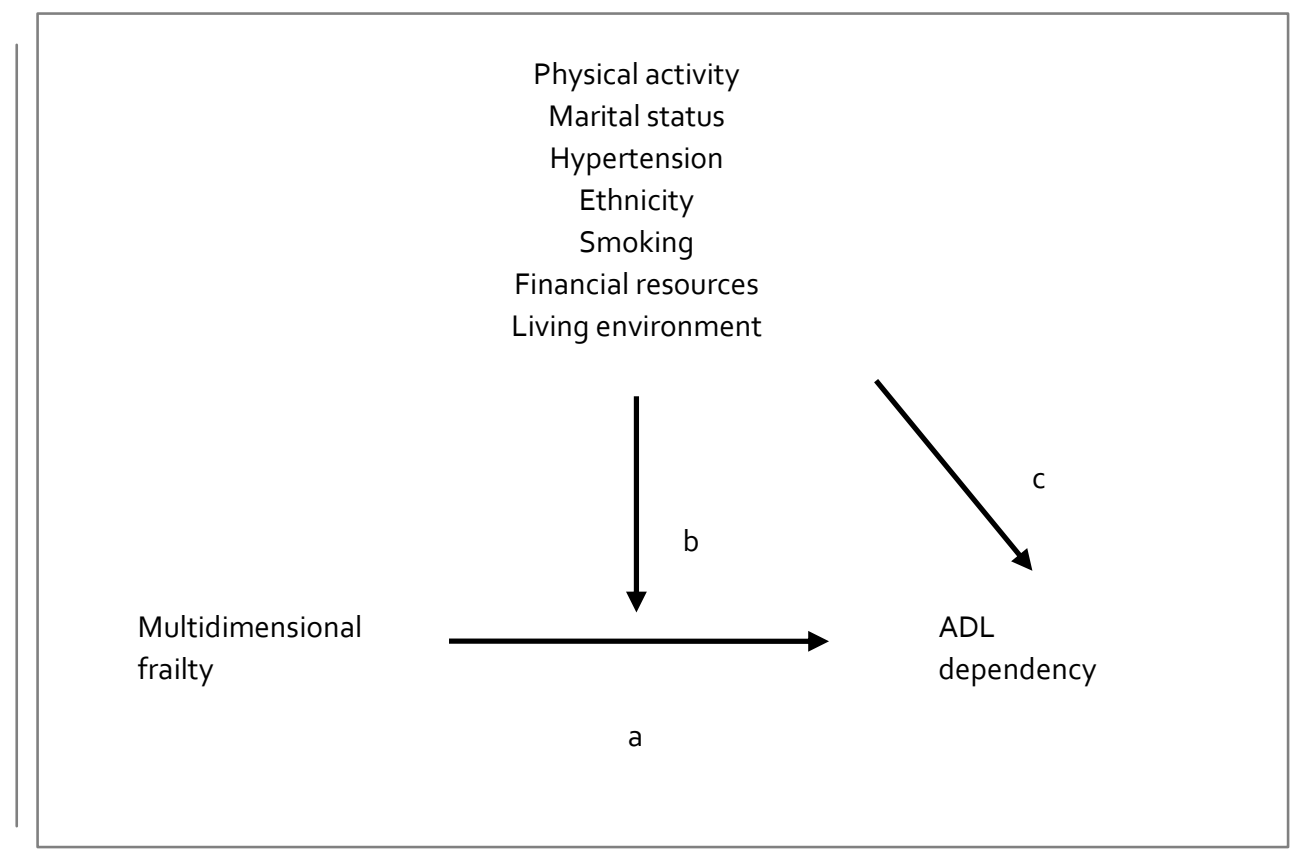

Figure 1. Hypothesized model with seven protective factors as moderators 


\section{Methods}

\section{Study design and participants}

Data used in this study was from a longitudinal study conducted by the Community Health Services Limburg in collaboration with Zuyd University of Applied Sciences (Heerlen, the Netherlands). The study was conducted in 2420 community-dwelling people aged $\geq 65$ years. All participants were pre-frail or frail, according to Fried's criteria [1], and lived in the southern part of the Netherlands. The medical ethic committee of Zuyderland and Zuyd University of Applied Sciences approved the study (METC $Z, 12-N-129)$, and informed consent was obtained from all participants. A more extensive description of the study has been published elsewhere [28-29].

For the current study, participants were included when they completed both the frailty and ADL measure at baseline, and reported no dependency in ADL at baseline (i.e. they were not dependent on others for 11 selected ADL from the Groningen Activity Restriction Scale (GARS) [30-31], which is described in more detail in the Measurements section of this paper, below). This resulted in a sample of 1027 participants.

\section{Measurements}

\section{Independent and outcome measure}

\section{Frailty}

Frailty, as an independent measure, was assessed at baseline with the Tilburg Frailty Indicator (TFI) [2]. This 15-item questionnaire includes physical (8 items: physical health, weight loss, walking difficulties, balance, hearing, vision, strength in hands, and physical tiredness), social (3 items: living alone, miss having people around, and receiving support from others), and psychological frailty (4 items: cognition, depression, anxiety, and coping) [2]. The total score ranges from 0-15, with higher scores indicating a higher level of frailty. A cut-off $\geq 5$ is used to distinguish frail from non-frail respondents [2].

\section{Dependency in activities of daily living}

ADL dependency, as the outcome measure, was assessed after 24 months with the ADL subscale from the GARS [30-31], which is a valid and reliable instrument [31]. The ADL subscale includes 11 items measuring, amongst others, bathing and transferring (e.g. 'Can you, fully independently, wash and dry your whole body?', and 'Can you, fully independently, get around in the house (if necessary with a cane)?'). The answer options are measured on the following 4-point scale: 1 = 'Yes, I can do it fully independently without any difficulty', 2 = 'Yes, I can do it fully independently but with some difficulty', 3 = 'Yes, I can do it fully independently but with great difficulty', and 4 $=$ 'No, I cannot do it fully independently; I can only do it with someone's help'. 
For the current study, scores on the ADL subscale from the GARS were dichotomised into two groups $(1=$ yes; $O=$ no). Those needing help with one or more of the 11 ADL activities were defined as ADL dependent (i.e. those who scored answer option 4 on $\geq 1 \mathrm{ADL}$ received a score of 1 on dependency). Those who were able to conduct all ADL activities independently were defined as non-dependent (i.e. without needing to rely on someone else; answer option 1-3 on all items and score o on dependency) [32].People who were not dependent on others for performing all ADL at baseline (i.e. answer option 1-3 on all items) were included.

\section{Protective factors}

Physical activity

For physical activity, three main categories were assessed at baseline: vigorous household activities (e.g. mopping the floor), leisure activities (e.g. walking and riding a bike), and sport activities (e.g. running and fitness). For each activity, participants had to report how many days per week they performed the activity, and for how many hours per day. People who were involved in these activities for at least 30 minutes per day on 5 or more days per week were categorised as physically active [33].

\section{Marital status}

At baseline, participants were asked to define their relationship status in one of the following terms: currently married, in a registered partnership, cohabiting, never married, divorced, or widowed. Answers were dichotomised into currently married (includes having a registered partnership) versus not married.

\section{Hypertension}

Self-reported overall blood pressure was measured at baseline with the following question: 'Did you have a high blood pressure in the past 12 months?', which was answered with yes or no.

\section{Ethnicity}

As participants from minor ethnicity groups were sparse $(n=5 ; 0.5 \%)$, people who were not born in the Netherlands were compared to people who were born in the Netherlands.

\section{Smoking behaviour}

At baseline, participants were asked whether they currently smoked or if they had ever smoked. Answers were divided in those who currently smoked compared to those who did not. 


\section{Financial resources}

Respondents were asked, 'Did you have any trouble making ends meet with your income in the last 12 months?' to which they could answer on a 4-point scale ranging from 'no, no difficulties at all' to 'yes, great difficulties'. Answers were separated into those with no difficulties at all versus people with at least some difficulties, including having to take care of expenses.

\section{Living environment}

Statistics Netherlands (CBS) labels each municipality in the Netherlands with one of the following categories: (a) very strongly urbanized; (b) highly urbanized; (c) moderately urbanized; (d) not having a particularly urban character; or (e) not urbanized at all [34]. These categories were dichotomized into urban (categories a-c) and rural (categories d-e).

\section{Sample characteristics}

The following sociodemographic characteristics were assessed at baseline: age, gender, education level, marital status, and living situation. In addition, the level of ADL disability was measured by means of the ADL subscale from the GARS [32] at baseline. As we excluded people with ADL dependency at baseline (i.e. GARS answer option 4 on $\geq 1$ item), baseline scores theoretically ranged from 11 to 33 (rather than 1144), with higher scores indicating higher levels of disability.

\section{Statistical analyses}

Firstly, to assess selection bias due to loss to follow up, people who did and did not complete the ADL subscale after 24 months were compared using Mann-Whitney and Chi-Square tests. Secondly, descriptive statistics were calculated to describe the study sample regarding socio-demographic characteristics, frailty level, ADL disability level, and the presence of protective factors. Thirdly, people aged 65-74 and $\geq 75$ were compared for each characteristic using Mann-Whitney and Chi-Square tests, as well as participants who did and did not develop ADL dependency after 24 months. Fourthly, logistic regression analyses were performed to investigate the following: (i) the main effect of multidimensional frailty at baseline on ADL dependency after 24 months; (ii) if this association can be influenced by each protective factor, by adding interaction terms; (iii) the main effect of each protective factor on ADL dependency; and (iv) if associations were influenced by age, by adding interaction terms. Regression analyses were adjusted for age and gender, and were conducted separately for those aged 6574 and $\geq 75$. In the case of significant interaction effects, regression analyses were conducted separately to be able to assess differences in odds ratio (OR) per group. 
Analyses were performed in SPSS Statistics for Windows, version 24.0 (Armonk, NY: IBM Corp). Statistical significance was set at $p<0.05$.

\section{Results}

Out of 1027 participants, 859 completed the ADL measure after 24 months. Those who completed the measure differed significantly at baseline from those who did not ( $n=$ 168 ), in terms of age (mean age 73.9 (SD = 5.9) compared to $75.6(S D=6.8) ; p=.003$ ), and level of ADL disability (mean score 13.3 (SD = 3.0) compared to 14.6 (SD = 4.3); $\mathrm{p} \leq$ .001). In addition, those who completed the measure were less likely to be frail $(50.1 \%$ versus $64.9 \%$; $p \leq .001$ ), more likely to have sufficient financial resources ( $45.8 \%$ versus $38.7 \% ; p=.015)$, and more likely to be physically active at baseline (39.3\% versus 27.9\%; $p=.008$ ) (findings not tabulated).

\section{Sample characteristics}

Socio-demographic characteristics of the participants are shown in Table 1. Their mean age was 74.2 years (range $=65-93$ ). 55.1\% were female, 52.5\% suffered from multidimensional frailty, and $21.7 \%(n=186)$ of the older people who completed the follow-up measure $(n=859)$ developed ADLs dependency after 24 months.

People aged 65-74 were less likely to be frail at baseline, had lower levels of ADL disability at baseline, and were more likely to be physically active, married, and have sufficient financial resources compared to people aged $\geq 75$. The same applied to people who did not develop ADL dependency after 24 months compared to those who did. In addition, people aged 65-74 were mostly female and less likely to smoke, compared to people aged $\geq 75$. Lastly, people who did not develop ADL dependency after 24 months were younger compared to those who did. 


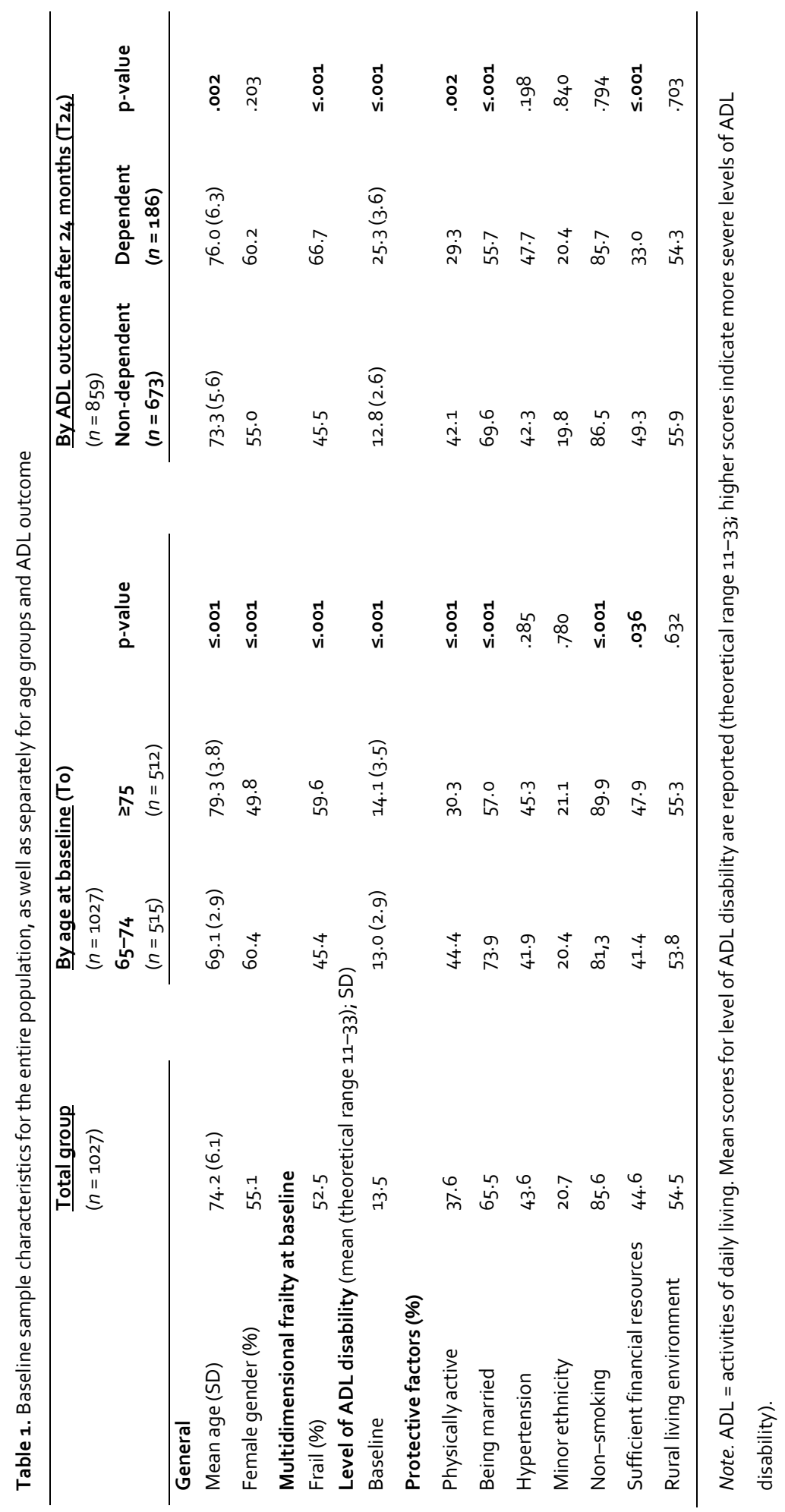




\section{Frailty and protective factors in relation to ADL dependency}

Table 2 shows the results of the logistic regression analyses. Frail older people had a twofold increased risk of ADL dependency compared to non-frail older people $(O R=$ $2.12,95 \% \mathrm{Cl}=1.50-3.00)$. This risk seemed slightly higher in those aged $\geq 75$ (OR = $2.70,95 \% \mathrm{Cl}=1.64-4.42)$ compared to those aged $65-74(\mathrm{OR}=1.62,95 \% \mathrm{Cl}=0.98-$ 2.68). However, this observed difference was not statistically significant ( $p$-value interaction term $=.151$, not tabulated). Interaction terms between frailty and the protective factors were not statistically significant in the entire sample, or in the two age groups.

Table 2. Association between frailty and ADL dependency, and interaction terms with each protective factor for the total sample and per age group

\begin{tabular}{|c|c|c|c|}
\hline & ADL dependency & $\begin{array}{l}\text { ADL dependency in } \\
\text { those aged } 65-74\end{array}$ & $\begin{array}{l}\text { ADL dependency in } \\
\text { those aged } \geq 75\end{array}$ \\
\hline \multicolumn{4}{|c|}{ OR of frailty on ADL dependency $(95 \% \mathrm{Cl})$} \\
\hline $\begin{array}{l}\text { Frailty (frail versus non- } \\
\text { frail) }\end{array}$ & $2.12(1.50-3.00)$ & $1.62(0.98-2.68)$ & $2.70(1.64-4.42)$ \\
\hline \multicolumn{4}{|c|}{ Interaction terms between frailty and each protective factor ( $p$-values) } \\
\hline Physical activity & .139 & .331 & .505 \\
\hline Marital status & .974 & .942 & .757 \\
\hline Hypertension & .459 & .948 & .270 \\
\hline $\begin{array}{l}\text { Being from a minor } \\
\text { ethnicity }\end{array}$ & .849 & .901 & .952 \\
\hline Non-smoking & .563 & .402 & .998 \\
\hline $\begin{array}{l}\text { Sufficient financial } \\
\text { resources }\end{array}$ & .802 & .540 & .551 \\
\hline Rural living environment & 912 & .842 & .769 \\
\hline
\end{tabular}

Note. $A D L=$ activities of daily living. Models were adjusted for age and gender.

When assessing the main effects of each protective factor, it was found that higher levels of physical activity (OR $=0.67,95 \% \mathrm{Cl}=0.46-0.98)$, and having sufficient financial resources $(\mathrm{OR}=0.49,95 \% \mathrm{Cl}=0.35-0.71)$ were protective against developing ADL dependency (Table 3). The impact of physical activity on ADL dependency did not differ significantly between the two age groups, although the impact of physical activity on $A D L$ dependency only remained statistically significant in those aged $\geq 75$ $(\mathrm{OR}=0.48,95 \% \mathrm{Cl}=0.27-0.85)$. Having sufficient financial resources only remained a significant protective factor in those aged $65-74$ years $(O R=0.31,95 \% \mathrm{Cl}=0.17-0.56)$, although there was only found a trend while comparing the age groups ( $p$-value interaction term $=.059$ ). Lastly, there was a significant interaction effect regarding marital status. Nonetheless, findings were not statistically significant in both age groups: $\mathrm{OR}=1.18(95 \% \mathrm{Cl}=0.66-2.14)$ in those aged $65-74$, compared to $\mathrm{OR}=0.62$ $(95 \% \mathrm{Cl}=0.38-1.01)$ in those aged $\geq 75$. 
Table 3. Main effects of each protective factor on ADL dependency for the total sample and per age group, and interaction terms between each protective factor and the age groups.

\begin{tabular}{|c|c|c|c|}
\hline & ADL dependency & $\begin{array}{l}\text { ADL dependency in } \\
\text { those aged } 65-74\end{array}$ & $\begin{array}{l}\text { ADL dependency in } \\
\text { those aged } \geq 75\end{array}$ \\
\hline & \multicolumn{3}{|c|}{ OR of each protective factor on ADL dependency $(95 \% \mathrm{CI})$} \\
\hline High levels of physical activity & $0.67(0.46-0.98)$ & $0.88(0.53-1.49)$ & $0.48(0.27-0.85)$ \\
\hline Interaction ( $p$-value) & & .105 & \\
\hline Married & $0.81(0.56-1.17)$ & $1.18(0.66-2.14)$ & $0.62(0.38-1.01)$ \\
\hline Interaction ( $p$-value) & & 0.047 & \\
\hline Hypertension & $1.13(0.80-1.59)$ & $1.11(.066-1.86)$ & $1.11(0.68-1.79)$ \\
\hline Interaction ( $p$-value) & & .946 & \\
\hline Being from a minor ethnicity & $1.09(0.72-1.66)$ & $1.17(0.64-2.14)$ & $1.02(0.57-1.82)$ \\
\hline Interaction (p-value) & & .719 & \\
\hline Non-smoking & $0.80(0.49-1.31)$ & $0.88(0.46-1.68)$ & $0.72(0.34-1.54)$ \\
\hline Interaction (p-value) & & .702 & \\
\hline$\underline{\text { Sufficient financial resources }}$ & $0.49(0.35-0.71)$ & $0.31(0.17-0.56)$ & $0.67(0.42-1.07)$ \\
\hline Interaction (p-value) & & 0.059 & \\
\hline$\underline{\text { Rural living environment }}$ & $0.95(0.68-1.33)$ & $0.95\left(0.5^{8-1.56)}\right.$ & $0.98(0.62-1.56)$ \\
\hline Interaction ( $p$-value) & & .945 & \\
\hline
\end{tabular}

\section{Discussion}

The aim of this longitudinal study was to assess whether factors that have been found to be protective against ADL disability [16, for an overview] in previous studies, moderate the relationship between multidimensional frailty and ADL dependency. This study shows that older people who suffer from multidimensional frailty have an increased risk of developing ADL dependency, which is in line with previous research [6]. However, no moderating effects were found for the seven factors that have previously been shown to decrease the risk of developing ADL disability in communitydwelling people aged $\geq 75$. Nonetheless, higher levels of physical activity were protective against future ADL dependency, as well as having sufficient financial resources.

Although all the factors included in this study were found to be protective against ADL disability in one or more previous studies [16], these factors were not yet studied as moderating factors in the relationship between multidimensional frailty and ADL dependency. Nonetheless, income has been found to moderate the effect of physical frailty on ADL disability [28]. However, while we found that people with sufficient financial resources were less likely to become dependent in ADL after 24 months, the previous study showed that physically frail older people with higher levels of income were more likely to develop ADL disability compared to physically frail older people with lower income levels [28]. Our findings seem contradictory; however, while Op het Veld et al. [28] assessed the disposable income, we assessed whether people 
had sufficient financial resources, which differs on a conceptual level (i.e. we asked if they are able to make ends meet). In addition, Op het Veld et al. [28] only took physical frailty into account, while we followed a multidimensional approach.

Although we have not found physical activity to have an interaction effect, we found a main effect of physical activity on ADL dependency, irrespective of the fact that all participants were at least pre-frail, according to Fried's criteria [1]. This might seem surprising, as presumably all participants were physically limited to some extent [1]. However, it could be hypothesized that physical activity is more influential than physical frailty with regards to ADL dependency. In this study, the protective effect of physical activity does not significantly differ across age groups, which is comparable with previous research [18].

Regarding marital status, no main effect was found. However, there was a significant interaction effect of age, and there was found a trend for being married as a protective factor against future ADL dependency in those aged $\geq 75$. Thus, marital status seems to have a stronger effect in older age, which is in line with the findings of the systematic literature review by van der Vorst et al. [16]. This might also be partially related to physical activity, as it is known that women who lose their spouse often become less active, as they do not feel obliged to perform certain activities any longer [35-36]. Therefore, older people who are married may be more active, i.e. to take care of each other.

Nonetheless, there was no interaction or main effect for having hypertension, being from a minor ethnicity, non-smoking or living in a rural area. This might be due to the specific sample, i.e. physically (pre)frail older people. In addition, while we only included people without ADL dependency at baseline, most of the studies investigating the aforementioned factors did include people with ADL dependency. Moreover, we included people aged $\geq 65$, while all the studies upon which the protective were selected were conducted with participants aged $\geq 75$. However, other factors may have also influenced our findings. We did not found an effect of hypertension. While Sabayan et al. [27] conducted their study in the oldest old (i.e. people aged 285 ), used an objective measure, and specified different blood pressure types; we measured it with only one question, which seems less reliable. In addition, the previous studies [22-23, 25-26] assessed whether people belonged to a minor ethnicity or not, however only $0.5 \%$ of our participants belonged to a minor ethnicity. Therefore, we compared people with and without a migration background, which is likely to have influenced our results. Lastly, while we did not found an effect of living environment, Sun et al. [21] argued that the protective effect of living in a rural area could be due to the fact that these people have to walk more to perform activities such as running errands. While differences between rural and urban areas occur to a lesser 
extent in the Netherlands, their argument is in line with our finding that physical activity is protective against ADL dependency.

\section{Strengths and limitations}

This study has several strengths. Research on multidimensional frailty and ADL dependency is relatively sparse, as is research on moderating effects. This is the first study to empirically verify all the factors that were previously found to be protective against $A D L$ disability [16, for an overview] in one study sample. However, some limitations should also be mentioned. Firstly, a relatively large number of ADL measurements were missing after 24 months. Non-completers were more likely to be frail, less likely to have sufficient financial resources, and less likely to be physically active at baseline. All these factors were found to be associated with an increased risk of developing ADL dependency, and therefore the missing data might have influenced the strength of our findings. Secondly, the generalizability of our findings is limited to community-dwelling physically (pre)frail older people according to Fried's phenotype of frailty [1]. Moreover, a consequence of this selection criterion might be that older people with only psychological and social frailty were excluded at baseline, and people who were multidimensional frail according to the TFI [2] might therefore still have been primarily physically frail. Thirdly, our measures of hypertension (self-reported), and migration background (rather than ethnicity) were less suitable.

\section{Implications for clinical practice and research}

Even in a physically (pre)frail population, physical activity and financial resources are protective against developing ADL dependency. Although it may not always be possible to help people financially, an active lifestyle can be promoted, for example, by supporting household chores and walking. In addition, age-friendly cities, with places that enable older people to perform leisure activities, might support preventing older people from becoming dependent in ADL [37]. Subsequently, this might give them the opportunity to be involved in social interactions. However, early detection and prevention of multidimensional frailty are important as well, particularly because physical activity, financial resources, and being married are no longer protective when a person has multidimensional frailty. Therefore, future research, clinical practice, and policy should focus on prevention strategies to prevent older people from becoming (pre)frail.

Future research could specify the moderating effect of protective factors for each domain of multidimensional frailty, as some factors did have a protective effect in this physically (pre)frail population. In addition, factors that have been found to be protective against ADL disability in community-dwelling people aged $\geq 65$, such as 


\section{CHAPTER 5}

performing volunteer or paid work [38], and positive affect [39], should be taken into account.

\section{Conclusion}

People who suffer from multidimensional frailty have an increased risk of developing ADL dependency compared to people who are not frail. This relationship cannot be moderated by physical activity, marital status, hypertension, ethnicity, (non-)smoking, financial resources, and living environment. However, even in physically (pre)frail older people, physical activity was found to be protective against developing ADL dependency, as was having sufficient financial resources in people aged 65-74, and being married in people aged $\geq 75$.

\section{Acknowledgments}

The authors would like to thank all participants for filling out the questionnaires.

The Community Health Services in Limburg are acknowledged for providing baseline data and making it possible to form the cohort, and Zuyd University of Applied Sciences is acknowledged for providing follow-up data. 


\section{References}

1. Fried LP, Tangen CM, Walston J, et al. Frailty in older adults: evidence for a phenotype. J Gerontol A Biol Sci Med Sci. 2001;56:146-56.

2. Gobbens RJJ, van Assen MALM, Luijkx KG, Wijnen-Sponselee MT, Schols JMGA. The Tilburg Frailty Indicator: psychometric properties. JAMDA. 2010;11(5):344-55.

3. De Witte N, Gobbens R, De Donder L, et al. The Comprehensive Frailty Assessment Instrument: development, validity and reliability. Geriatr Nurs. 2013;34(4):274-81.

4. Rockwood K, Mitnitski A. Frailty in relation to accumulation of deficits as a proxy measure of ageing. J Gerontol A Biol Sci Med Sci. 2007;62:722-7.

5. Collard RM, Boter H, Schoevers RA, Oude Voshaar RC. Prevalence of frailty in community-dwelling older persons: a systematic review. J Am Geriatr Soc. 2012;60(8):1487-92.

6. Coelho T, Paúl C, Fernandes L. Physical, psychological and social frailty in prediction of disability and quality of life. Eur Psychiatry. 2015;30: 447.

7. De Witte N, De Donder L, Dury S, et al. Together on the Side-Walks: About Social Cohesion and Older People. Gent: Oost-Vlaanderen [In Dutch]; 2012.

8. WHO. Active ageing: a policy framework. 2001. Available: http://apps.who.int/iris/bitstream/10665/67215/1/WHO_NMH_NPH_02.8.pdf

9. Gill TM, Robison JT, Tinetti ME. Difficulty and dependence: two components of the disability continuum among community-living older persons. Ann Intern Med. 1998;128:96-101.

10. Stineman MG, Xie D, Pan $Q$, et al All-cause 1-, 5-, and 10-year mortality in elderly people according to activities of daily living stage. J Am Geriatr Soc. 2012;60:485492. doi:10.1111/j.1532-5415.2011.03867.x

11. Unsar S, Dindar I, Kurt S. Activities of daily living, quality of life, social support and depression levels of elderly individuals in Turkish society. Group, 2015;11:14.

12. Vermeulen J, Neysens JC, van Rossum E, Spreeuwenberg MD, De Witte LP. Predicting ADL disability in community-dwelling elderly people using physical frailty indicators: a systematic review. BMC Geriatr. 2011;11(1):33

13. Teo N, Gao Q, Nyunt MSZ, Wee SL, Ng TP. Social frailty and functional disability: findings from the Singapore longitudinal ageing studies. JAMDA. 2017;18(7):637e13.

14. Mulasso A, Roppolo M, Giannotta F, Rabaglietti E. Associations of frailty and psychosocial factors with autonomy in daily activities: a cross-sectional study in Italian community-dwelling older adults. Clin Interv Ageing. 2016;11:37-45

15. Lette M, Baan CA, van den Berg M, de Bruin SR. Initiatives on early detection and intervention to proactively identify health and social problems in older people: 
experiences from the Netherlands. BMC Geriatr. 2015;15:143. http://dx.doi.org/10.1186/s12877-015-0131-z

16. van der Vorst A, Zijlstra GAR, De Witte $N$, et al. Limitations in activities of daily living in community-dwelling people aged 75 and over: a systematic literature review of risk and protective factors. PloS One. 2016;11(10), e0165127.

17. Avlund K, Damsgaard MT, Sakari-Rantala R, Laukkanen $P$, Schroll M. Tiredness in daily activities among nondisabled old people as determinant of onset of disability. J Clin Epidemiol. 2002;55(10):965-73.

18. Landi F, Onder G, Carpenter I, Cesari M, Soldato M, Bernabei R. Physical activity prevented functional decline among frail community-living elderly subjects in an international observational study. J Clin Epidemiol. 2007;60(5):518-24. doi: 10.1016/j.jclinepi.2006.09.010.

19. Shah RC, Buchman AS, Leurgans S, Boyle PA, Bennett DA. Association of total daily physical activity with disability in community-dwelling older persons: a prospective cohort study. BMC Geriat. 2012;12(1). doi: 10.1186/1471-2318-12-63.

20. Stessman J, Hammerman-Rozenberg R, Cohen A, Ein-Mor E, Jacobs JM. Physical activity, function, and longevity among the very old. Arch Intern Med. 2009;169(16):1476-83. doi: 10.1001/archinternmed.2009.248.

21. Sun F, Park NS, Klemmack DL, Roff LL, Li Z. Predictors of physical functioning trajectories among Chinese oldest old adults: rural and urban differences. Int $J$ Ageing Hum Dev. 2009;69(3):181-99..

22. Black SA, Rush RD. Cognitive and functional decline in adults aged 75 and older. J Am Geriatr Soc. 2002;50(12):1978-86.

23. Gu D, Yi Z. Sociodemographic effects on the onset and recovery of ADL disability among Chinese oldest-old. Demographic Res. 2004;11:1-42.

24. Jiang J, Tang Z, Meng XJ, Futatsuka M. Demographic determinants for change in activities of daily living: a cohort study of the elderly people in Beijing. J Epidemiol. 2002;12(3):280-6.

25. Freedman VA, Martin LG, Schoeni RF, Cornman JC. Decline in late-life disability: the role of early- and mid-life factors. Soc Sci Med. 2008;66(7):1588-1602. doi: 10.1016/j.socscimed.2007.11.037.

26. Moody-Ayers SY, Mehta KM, Lindquist K, Sands L, Covinsky KE. Black-white disparities in functional decline in older persons: the role of cognitive function. $J$ Gerontol A Biol Sci Med Sci. 2005;60(7):933-9.

27. Sabayan B, Oleksik AM, Maier AB, et al. High blood pressure and resilience to physical and cognitive decline in the oldest old: the Leiden 85-plus study. J Am Geriatr Soc. 2012;60(11):2014-9. doi: 10.1111/j.1532-5415.2012.04203.x

28. Op het Veld LPM, Ament BHL, van Rossum E, Kempen GIJM, de Vet HCW, Hajema $\mathrm{KJ}$, Beurskens AJHM. Can resources moderate the impact of levels of frailty on 
adverse outcomes among (pre-)frail older people? A longitudinal study. BMC Geriatr. 2017;17. doi: 10.1186/s12877-017-0583-4

29. Terstegge $C$, Houben $T$, Schefman $S$, et al. Onderzoeksprotocol Limburgse monitor volwassenen en ouderen. GGD Limburg [in Dutch]; 2012.

30. Kempen GIJM, Miedema I, Ormel J, Molenaar W. The assessment of disability with the Groningen Activity Restriction Scale. Conceptual framework and psychometric properties. Soc Sci Med. 1996;43(11):1601-10.

31. Suurmeijer TP, Doeglas DM, Moum T, et al. The Groningen Activity Restriction Scale for measuring disability: its utility in international comparisons. Am J Public Health. 1994;84(8):1270-3.

32. Kempen GIJM, Miedema I, Ormel J, Molenaar W. The assessment of disability with the Groningen Activity Restriction Scale. Conceptual framework and psychometric properties. So Sci Med. 1996;43(11): 1601-10.

33. Broekhuizen K, de Gelder J, Wijsman CA, et al. An internet-based physical activity intervention to improve quality of life of inactive older adults: a randomized controlled trial. J Med Internet Res. 2016;18(4).

34. CBS, 2015. Demografische kerncijfers per gemeente [In Dutch]; 2015.

35. Avlund K, Due P, Holstein BE, Sonn U, Laukkanen P. Changes in household composition as determinant of changes in functional ability among old men and women. Ageing Clin Exp Res. 2002;14(3):65-74.

36. Due P. You get what you want to when you are alone. Life course and health among old, single-living women in Denmark. In: Helset A, ed. For Good and Worse. The Life-Situation Among Old Women with Minimum Pension in Denmark, Norway, and Sweden. Oslo: Norwegian Gerontological Institute; 1993.

37. WHO. Global Age-Friendly Cities Project. 2016. Available: http://www.who.int/ageing/projects/age_friendly_cities/en/.

38. Luoh MC, Herzog AR. Individual consequences of volunteer and paid work in old age: health and mortality. J Health Soc Behav. 2002;43(4): 490-509.

39. Diaz-Ramos JA, Navarrete-Reyes AP, Avila-Funes JA. Positive affect in elderly Mexicans and its protective role against disability. J Am Geriatr Soc. 2012;60(2):384-385. doi:10.1111/j.1532-5415.2011.03805.x 
$-140-$ 


\section{6}

\section{Explaining discrepancies in self-}

reported quality of life in frail older people: a mixed-methods study

\section{Published as}

van der Vorst, A., Zijlstra, G.A.R., De Witte, N., Vogel, R.G.M., Schols, J.M.G.A., Kempen, G.I.J.M., D-SCOPE Consortium. (2017). Explaining Discrepancies in Self-Reported Quality of Life in Frail Older People. BMC Geriatrics, DOI: 10.1186/s12877-017-0641-y. 


\section{Abstract}

Background: Most research on multidimensional frailty focuses on deficits and risks of adverse outcomes. However, although some frail older people report a low quality of life $(\mathrm{QoL})$, others still report a relatively high $\mathrm{QoL}$. More knowledge about these discrepancies might give new insight into developing frailty prevention strategies. Therefore, this mixed-method study aimed (a) to identify characteristics related to QoL among frail older people; and (b) to explain discrepancies between higher and lower levels of QoL, with a specific interest in identifying strengths frail older people with a higher QoL still have.

Methods: Semi-structured interviews were held with community-dwelling, frail older people with higher $(n=16)$ and lower levels of QoL $(n=18)$. Frailty was assessed with the Comprehensive Frailty Assessment Instrument, which measures environmental, physical, psychological, and social frailty. Other quantitative measures included sociodemographic characteristics, overall QoL, meaning in life, and mastery. The qualitative part focused on the meaning and maintenance of QoL (among other factors), despite being frail. Possible explanations for discrepancies in QoL were explored.

Results: Frail older people with a higher QoL were older, had lower levels of psychological frailty, and reported higher meaning in life compared to those with a lower QoL. Outcomes of qualitative analysis showed that participants in the high QoL subgroup adapted more effectively to difficulties, had more things in prospect, performed more activities, and were more satisfied with their social network compared to the low QoL subgroup.

Conclusion: This exploratory study suggests possibilities to promote and improve QoL by strengthening specific resources among frail older people. 


\section{Introduction}

Although frailty is often described as merely a physical construct [1], there is a growing tendency to conceptualise frailty from a multidimensional perspective, where environmental, psychological, and social factors are taken into account as well [2]. Prevalence rates of multidimensional frailty vary between 4.2-59.1\% across studies, depending on the definition and the population included [3]. Multidimensional frailty is associated with higher age [3-4] and may lead to disability, hospitalisation, early institutionalisation, and death [5-6]. Hence, it might threaten the wish most older people have to age in place [7]. Moreover, ageing in place is stimulated from a policy perspective, for example to reduce the overall costs of institutionalisation [8]. Early detection and prevention of frailty are important topics for research, policy, and clinical practice because of the growing number of people aged 65 years and over [9], the negative consequences of frailty, and the necessity of enabling ageing in place.

Current approaches on frailty seem to be dominated by a "deficit approach." They mainly focus on things people cannot do any longer and the risks of adverse outcomes [5-6], or define frailty as an accumulation of deficits [10]. Despite this deficit approach in research, older people themselves seem less focused on shortages. A recent qualitative study showed that older people favour receiving support that improves their autonomy and well-being, instead of interventions which focus on diseases and dysfunctions [11-12]. Besides, older people dislike an approach in which every older adult is perceived as someone with (a risk of) deficits [11]. Furthermore, qualitative studies revealed negative consequences of stereotyping. For example, when people were labelled as frail by others, this actually made them feel frail, and they behaved accordingly [13]. This suggests that a strengths-based approach, which offers the opportunity to get a better understanding of people's strengths and abilities [14-15], might be of value for frailty prevention strategies.

As frail older people still can have a good perceived quality of life (QoL), this might be an important entry for such a strengths-based approach. For example, previous research has shown that nearly $50 \%$ of the participants who were frail at least on the physical domain still reported a good to excellent QoL [16]. In another study, $46 \%$ of physically frail older women reported a good QoL [17], while in a qualitative study 8 out of 11 frail participants reported a satisfactory to good OoL [18]. Qualitative studies that have investigated what QoL means to (frail) older people revealed several important factors: social contacts, (physical) health, psychological well-being, being able to perform activities, and having enough facilities at home and in the neighbourhood [18]. Nonetheless, little is known about factors that may actually contribute to a high $\mathrm{QoL}$ in frail older people. Although it has been found that frail older people with a higher age report higher levels of QoL [19], as well as those who compare themselves with people in a worse situation [18], the focus of these studies 
was not to identify strengths in frail older people. However, that is exactly what is important while aiming for a strengths-based approach.

The aim of this mixed-methods study was twofold: (1) to identify characteristics of community-dwelling, frail older people with higher and lower levels of QoL, respectively; and (2) to explain discrepancies in self-reported $\mathrm{OoL}$, with a specific interest in identifying strengths that community-dwelling, frail older people with a higher QoL still have. Herewith, the focus was not on investigating associations between frailty and QoL, but on investigating which factors might explain differences in QoL among frail older people, as it seems particularly important to make (strengthbased) interventions more tailored in this vulnerable population. While some studies assess multiple domains of $\mathrm{QoL}$, this study focuses on overall $\mathrm{QoL}$, which is defined as 'an individual's overall satisfaction with life and general sense of well-being' [20], and for which one question seems to be a particular adequate measure [21].

\section{Methods}

\section{Study design and participants}

This study included a subsample of a larger mixed-methods study within the D-SCOPE project (Detection, Support and Care for Older people: Prevention and Empowerment, www.d-scope.be), which was conducted between November, 2015 and April, 2016. The D-SCOPE project aims at early detection and prevention of multidimensional frailty to enable ageing in place, focusing on deficits as well as strengths older people have. Participants needed to be 60 years and over, and living in the community. Exclusion criteria were as follows: hospitalisation, institutionalisation, and not being able to answer simple questions. In total, 121 community-dwelling people aged 60 years and over were recruited. Purposeful sampling was used to oversample community-dwelling older people at risk for frailty [4]. Healthcare organizations in West Flanders, Belgium, selected potential participants from their client database, based on risk profiles for frailty [4], and provided information about the study. For instance, they oversampled people aged 75 years and over, people without a partner, people with a migration background, and people who had moved in the past ten years [4]. When older people approved to participate in the study, the healthcare organization provided the research team with their contact details. In addition, snowball sampling was used (i.e. participants contacted friends, family members and/or relatives and asked if they would like to participate. If yes: the participant provided the researcher with their contact details). The 121 older people gave their consent. The Ethics Commission in Humane Sciences of the Vrije Universiteit Brussel (Belgium) approved the study [reference ECHW_031].

For the current study, only frail older people with higher $(\geq 8, n=16)$ and lower levels of $\operatorname{QoL}(\leq 6, n=18)$ were included. These cut-offs were based on tertiles to be 
able to compare sufficiently contrasting and nearly equally sized groups. "Frail" was defined as a combined score between 38.76 and 100 on the Comprehensive Frailty Assessment Instrument (CFAl, [22]) (explained in more detail under the heading Measures and data collection). The cut-off was based on a two-step cluster analysis that was conducted for each frailty domain, as well as for overall frailty. This analysis resulted in cut-offs for no-mild, mild, and high frailty (De Witte et al., available upon request). Six researchers (including author $A v d V ;$ all $P h D$ students, 3 female) conducted the interviews, twice in the presence of an interpreter due to language barriers.

\section{Measures and data collection}

A concurrent mixed-methods design was used. Both quantitative and qualitative data were assessed at once, in person, at the homes of the participants. First, the following socio-demographic characteristics were collected: age, gender, nationality, place of birth, marital status, and living arrangement. Next, overall cognition was measured in the D-SCOPE study using the Montreal Cognitive Assessment (MoCA) [23], which has been found to be a valid measure [24]. For the current study, MoCA scores were used to describe the overall sample as well as the high and low OoL subgroups. The MoCA assesses multiple cognitive domains, including short-term memory, visuospatial abilities (e.g., clock drawing), executive functioning, fluency, attention, concentration, working memory, language, and orientation. Third, multidimensional frailty was measured by administering the previously validated CFAI [2, 22], which comprises environmental (e.g., condition of the house), physical (e.g., walking difficulties), psychological (mood disorders and emotional loneliness), and social frailty (social loneliness and social support network). Fourth, participants were asked to rate their QoL ("On a scale from o to 10, how would you rate your QoL? By this, we mean how you feel about your life. Whether you are satisfied with your life and enjoy your life, for instance, and whether you find satisfaction in the life you live."), meaning in life ("On a scale from o to 10, to what extent do you feel that your life is meaningful (e.g. worthwhile, purposeful, that you look forward to something or strive for something)?"), and mastery ("On a scale from o to 10, to what extent do you feel in control of what happens in your life?") by means of Numeric Rating Scales ranging from 0-10, with lowest and highest scores as extreme values [25]. As we aimed to gain insight into overall $\mathrm{CoL}$ we asked for one general evaluation, which has been measured on a scale from o (lowest QoL) to 10 (highest $\mathrm{QoL}$ ) in previous research as well [17]. For meaning in life and mastery, we aimed to measure the overall constructs as well. As we were dealing with a vulnerable population, one-item questions were used to measure these constructs. Similar approaches have been used previously [26- 
27], though for comparability with the QoL measure, we chose to measure these constructs on a scale from o-10 as well.

The topic list of the qualitative interview included perceptions and experiences of the older people regarding the meaning of frailty, aspects of life that are important for $\mathrm{QoL}$, the influence of frailty on QoL, factors that may help to maintain QoL despite being frail, positive and negative life events, and future perspective. An additional file shows an overview of the questions that were proposed during the qualitative survey [see Additional file 1]. The researchers received a 6 -hour theoretical and practical training on interview techniques in qualitative research. The interviews lasted between one and two-and-a-half hours, and were recorded with Audacity. Participants were informed that the aim of the interview was to gain insight into factors that enable older people to age in place. The interviews were fully transcribed, including words, speech particles, and expressions of feelings (e.g., laughter). Transcripts were not returned to participants for correction purposes.

\section{Data analyses}

Initial analysis of quantitative and qualitative data was conducted independently. Regarding the quantitative data, descriptive statistics were calculated for sociodemographic characteristics, and MoCA and CFAI scores. To examine differences between the low $(\leq 6)$ and high $(\geq 8)$ OoL subgroups, Chi-square tests (categorical data; e.g. gender), and independent samples t-tests (scale data; age, MoCA, meaning in life, and multidimensional frailty) or Mann-Whitney $U$ tests ( $O L L$ and mastery, due to non-normality of the data) were performed in SPSS Statistics for Windows, version 24.0 (Armonk, NY: IBM Corp).

Regarding the qualitative data, the six researchers who conducted the interviews analysed the data using MAXODA (version 12 Standard, student license), based on the Qualitative Analysis Guide of Leuven [28]. To enhance the trustworthiness, each individual interview was analysed and coded by two researchers independently. The two researchers were educated in different disciplines (e.g., educational sciences, gerontology, psychology, and nursing) to ensure that different perspectives were taken into account during the analyses. Most themes were derived in advance, matching the interview scheme. In addition, author AvdV read the full transcriptions of all 34 qualitative interviews and author RV independently read a random sample of five interviews from each QoL subgroup. Both authors were blinded for QoL scores. Summaries were made in order to obtain a conceptual framework per participant by (re)reading the interviews, trying to find the essential characteristics of each interview, and describing these findings conceptually [28]. Codes in MAXODA as well as the conceptual frameworks were taken into account to perform an overall content analysis per subgroup. Thereafter, groups were compared. Finally, findings 
from both researchers (authors AvdV and RV) were compared and discussed to reach agreement. Figure 1 displays the process of the qualitative analyses. A professional translator was consulted to translate quotes into English. Thereafter, the English quotes were compared with the original citations by author AvdV to ensure that the meaning of the quotes was preserved [29].

During the interpretation stage, findings from quantitative and qualitative results were compared, although emphasis was on the qualitative findings due to the exploratory design of the study.

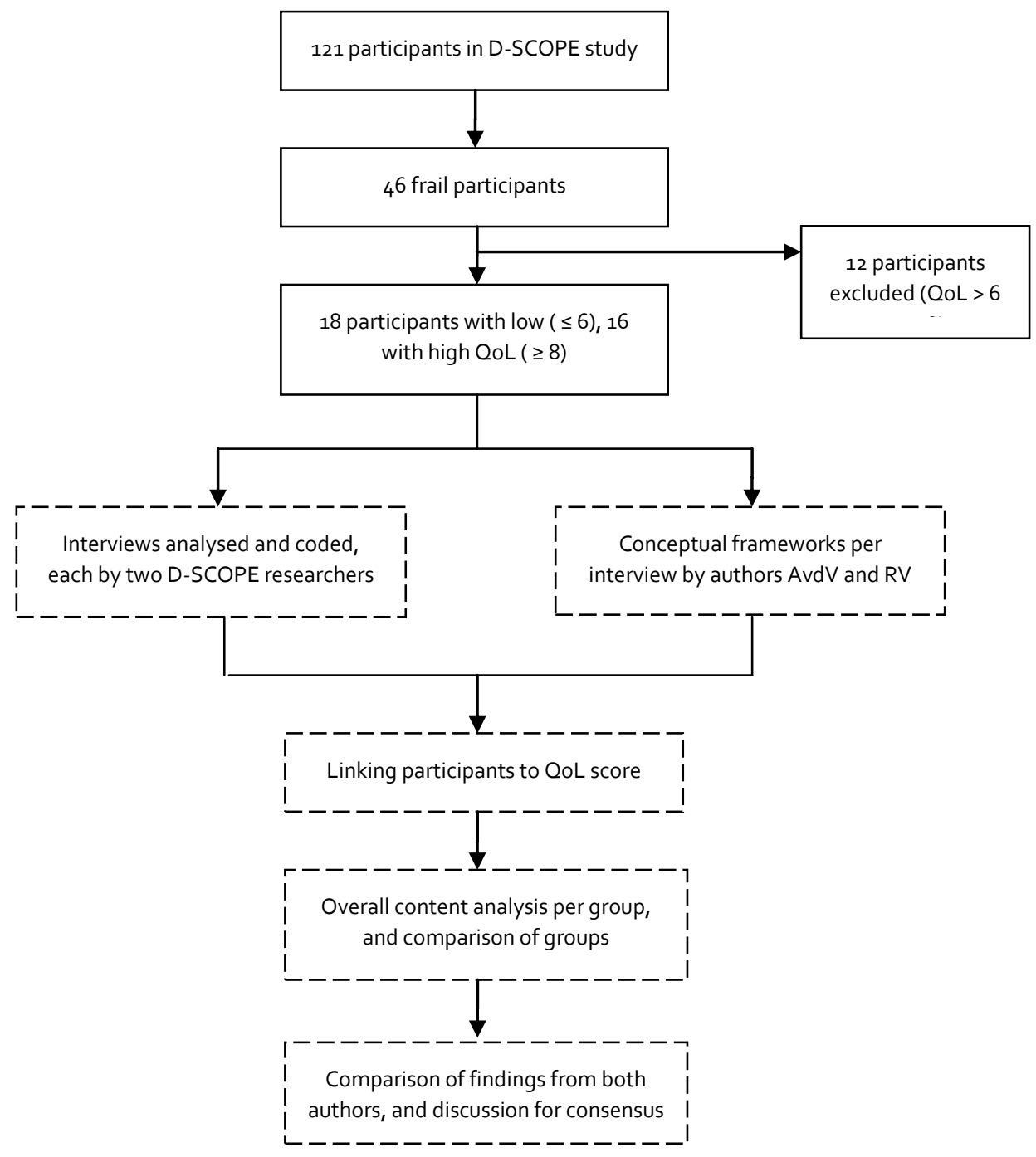

Figure 1. Flow chart of the selection process (-) and qualitative analysis procedure (----) 


\section{Results}

\section{Sample characteristics}

The mean age of the study sample was 80.7 years (range $66-94$ ); 61.8\% were female, $8.8 \%$ had a migration background, $61.8 \%$ were widowed, and $67.6 \%$ lived alone (Table 1).

Table 1. Characteristics of the sample, and comparisons per QoL subgroup

\begin{tabular}{|c|c|c|c|c|c|c|c|}
\hline & $\begin{array}{l}\text { Sample } \\
(n=34)\end{array}$ & & $\begin{array}{l}\text { Low QoL } \\
(n=18)\end{array}$ & & $\begin{array}{l}\text { High OoL } \\
(n=16)\end{array}$ & & $\begin{array}{l}\text { Group } \\
\text { differences }\end{array}$ \\
\hline \multicolumn{8}{|l|}{ Socio-demographics } \\
\hline Age (mean) (SD) & $80.7(7.3)$ & & $78.1(6.5)$ & & $83.9(7.0)^{a}$ & & * \\
\hline Females (\%) (n) & 61.8 & 21 & 61.1 & 11 & 62.5 & 10 & \\
\hline $\begin{array}{l}\text { Migration background (\%) } \\
(\mathrm{n})\end{array}$ & 8.8 & 3 & 11.1 & 2 & 6.3 & 1 & \\
\hline \multicolumn{8}{|l|}{ Marital status (\%) (n) } \\
\hline Married & 11.8 & 4 & 16.7 & 3 & 6.3 & 1 & \\
\hline Never married & 11.8 & 4 & 5.6 & 1 & 18.8 & 3 & \\
\hline Divorced & 14.7 & 5 & 27.8 & 5 & - & o & \\
\hline Widowed & 61.8 & 21 & 50.0 & 9 & 75.0 & 12 & \\
\hline \multicolumn{8}{|l|}{ Living arrangement (\%) (n) } \\
\hline Alone & 67.6 & 23 & 72.2 & 13 & 62.5 & 10 & \\
\hline With partner & 11.8 & 4 & 16.7 & 3 & 6.3 & 1 & \\
\hline With child(ren) & 17.6 & 6 & 11.1 & 2 & 25.0 & 4 & \\
\hline With others & 2.9 & 1 & - & o & 6.3 & 1 & \\
\hline \multicolumn{8}{|l|}{ Cognition } \\
\hline MoCA (mean, SD) & $19.9(4.1)$ & & $18.8(4.4)^{b}$ & - & $21.2(3.3)^{c}$ & & \\
\hline \multicolumn{8}{|l|}{ Frailty (mean, SD) } \\
\hline Overall & $50.4(8.6)$ & & $53.1(8.3)$ & & $47.3(8.3)$ & & \\
\hline Environmental & $31.3(17.7)$ & & $26.7(19.2)$ & & $36.6(14.7)$ & & \\
\hline Physical & $81.3(22.5)$ & & $82.0(21.1)$ & & $80.5(24.6)$ & & \\
\hline Psychological & $40.0(22.9)$ & & $52.0(16.2)$ & & $26.6(19.7)$ & & ** \\
\hline Social & $52.3(18.6)$ & & $52.9(15.1)$ & & $51.6(22.4)$ & & \\
\hline \multicolumn{8}{|l|}{ Quality of life } \\
\hline VAS-scale (median) & 6 & & 6 & & 9 & & ** \\
\hline \multicolumn{8}{|l|}{ Meaning in life } \\
\hline VAS-scale (mean, SD) & $7.6(1.9)$ & & $6.9(2.1)$ & & $8.4(1.3)$ & & * \\
\hline \multicolumn{8}{|l|}{ Mastery } \\
\hline VAS-scale (median) & 8 & & 8 & & 8.5 & & \\
\hline \multicolumn{8}{|c|}{ Note: $\mathrm{Low}$ QoL $=\leq 6$. High $\mathrm{QoL}=\geq 8 . \mathrm{SD}=$ Standard Deviation. MoCA $=$ Montreal Cognitive Assessment. } \\
\hline \multicolumn{8}{|c|}{ QoL = Quality of Life. VAS = Visual Analogue Scale. Cognition (MoCA): range o-30, cut-off for Mild Cognitive } \\
\hline \multicolumn{8}{|c|}{ Impairment is $\leq 26$. Frailty (Comprehensive Frailty Assessment Instrument): range o-100 per domain, with } \\
\hline \multicolumn{8}{|c|}{ higher scores indicating more severe levels of frailty. } \\
\hline$* p<.05 . * * p<.001$ & & & & & & & \\
\hline${ }^{a} n=15 \cdot{ }^{b} n=17 \cdot{ }^{c} n=13$. & & & & & & & \\
\hline
\end{tabular}




\section{Quantitative comparison}

The outcomes of the quantitative analyses showed that participants in the high OoL subgroup ( $\geq 8 ; n=16$ ) were significantly older, had lower (less severe) levels of psychological frailty, and reported higher scores on meaning in life compared to the low OoL subgroup $(\leq 6 ; n=18$ ) (Table 1 ).

\section{Qualitative comparison}

The following five main themes were covered during the interviews: frailty, well-being, dealing with problems, life events, and future perspective.

\section{Theme 1: Multidimensional frailty.}

The majority of participants in both subgroups did not identify themselves as frail. However, most reported physical health problems, and difficulties in at least one of the following domains: social relations, psychological functioning, the home environment, and cognition. Some examples of physical problems were loss of strength, mobility problems, and limited vision or hearing. Consequences of limited physical abilities were mentioned as well, such as losing confidence due to previous falls. A male participant (aged > 75) mentioned: "I used to love going fishing. I had to get rid of everything. I couldn't see my float anymore." Regarding social relations, participants in both subgroups mentioned feelings of loneliness or losing social contacts, for example due to death or health problems of friends and family members. Concerning psychological functioning, participants felt more vulnerable, worried more often, and were more sensitive to things other people said compared to before. For example, a female participant (aged > 80) told: "In the past, I would have said 'hey, don't worry about it.' But when you're old, you don't do that anymore. That's strange, isn't it? You just don't have the strength anymore." Two participants reported a history of depression, and a male participant (aged > 75) said: "Maybe, after you leave, I'll simply fall to bits this evening. Sometimes I get so sad all of a sudden that she's no longer with me [late wife]." Regarding their living environment, some participants needed adaptations (e.g., a shower instead of bathtub), or had difficulties walking the stairs. Negative aspects about the home environment were lack of shops in the neighbourhood, not having as much contact with neighbours as preferred, new neighbours who were less likely to help, or losing interactions. For example: "The first generation of people to live here were all friends. We'd go to concerts together, we did things with one another. The second generation, they were friendly folks, but they weren't really friends like before. And now there are a few older people living here, who don't get around as well as they used to, and who are pretty isolated too, actually. Plus a number of young people, a bunch of foreigners who don't even say 'good morning' when you see them... time was, you wouldn't dream of not doing that" (woman, aged > 70). Some participants reported 
(being confronted with) memory problems, while others feared developing cognitive problems. In addition, trouble keeping up in today's society was mentioned a couple of times in both subgroups.

A few discrepancies regarding multidimensional frailty between both QoL subgroups were observed. Some participants in the high QoL subgroup mentioned positive stories about their social relations. For example, a male participant (aged $>85$ ) never felt lonely because he always had dinner together with his children. However, in contrast to the high QoL subgroup, participants in the low QoL subgroup mentioned a couple of times that they did not have enough financial resources to be able to perform desired activities.

\section{Theme 2: Well-being.}

Subtheme 1: Quality of life. In both QoL subgroups, participants mentioned the following aspects as important for their QoL: activities (e.g., gardening); autonomy/independence; sufficient financial resources; (physical) health; optimism; pets; social contacts with their partner, family members, neighbours, and/or friends; and traveling.

By comparing both subgroups, it appeared that only participants in the high QoL subgroup mentioned that having something in prospect and being of value to and/or helping others was important for their QoL. For example: "I have to say, no matter how low you're feeling, when you do that [help others, ed.] and they give you that look... It just makes your whole day, doesn't it? It's amazing how that works" (man, aged > 75). In contrast, in the low QoL subgroup, "unmet needs" were revealed. Participants mentioned feelings of loneliness, insufficient contact with family members, or inability to perform the activities they would like to do. In addition, a female participant (aged > 65) told: "Um, to have a good quality of life and to live with purpose, it's primarily important to have good health. So you need to be healthy, and to have financial resources as well. You need those, too-because when you can't afford the things you want...," while she also said: "That's something else I find exhausting. I mean, because I'm constantly having to pinch pennies."

Subtheme 2: Meaning in life. Regarding meaning in life, the following was mentioned to be important in both subgroups: ageing in place, family bonds, going out, pets, having social contacts, and being of meaning to others. For example, a male participant (aged > 85) told: "If the children weren't around any longer, I wouldn't care a thing about living. Not a thing. Then I might as well just come right out and say I want to die, in that case. That's something that I'm quite satisfied with, something that keeps me busy. Ah, yes, of course. Today I'm going to make soup." 
When comparing both subgroups, having something to look forward to (e.g., seeing grandchildren grow up or going out with a friend each Saturday) was mainly mentioned in the high QoL subgroup. Once again, unmet needs were mentioned in the low QoL subgroup. For example, a female participant (aged > 65) told that her children and grandchildren, who were important to her meaning in life, lived abroad. As a consequence she had not much to look forward to.

\section{Theme 3: Dealing with problems.}

Subtheme 1: Individual factors. Participants in both subgroups mentioned acceptance, active problem-solving, expressing emotions/feelings, optimism, religion, seeking distraction (e.g., performing hobbies) and comparing themselves with those in a worse situation as important factors to deal with problems. Examples of active problemsolving were memory training and remaining physically active despite limitations.

However, some strategies to deal with problems seemed more prevalent in the high QoL subgroup. For example, participants replaced activities (e.g., "I used to still be able to go for bike rides, now I visit comrades, friends and family"; man, aged > 80 ), and actively sought social support from friends and family members, which was less pronounced in the low QoL subgroup. In addition, participants with higher levels of QoL tried not to dwell in the past or on things they were no longer able to do. Instead, they focused on positive aspects (e.g., things they still could do), or tried to change the situation they were in. Furthermore, they seemed more convincing in how they dealt with problems. For example, a male participant (aged $>80$ ) responded as follows to the question, "And you tried to solve the problem?": "I didn't try to - that's what I did." In contrast, strategies to deal with problems applied by participants with lower levels of QoL, such as optimism, did not always seem to be effective and long-lasting. For example, a female participant (aged > 80) responded to the question, "What do you think an older person should do in order to preserve their quality of life?" with: "Stay optimistic. Keep being an optimist. ... That gets harder as you go on. Then you ask yourself: 'What's left for me?' I'm pretty much left to my own devices ... Why am I still here?" Additionally, passive reacting was mentioned in the low OoL subgroup, although this did not always seem to be effective. For example, a female participant (aged > 65) told: "And that I'm coming here alone, too. And then the emptiness, the loneliness especially. And then I just watch TV, whatever's on, and kind of zone out. And then it's exactly like my brain has been numbed, just a little." Moreover, she passively waited until her friends called her, even during times when she needed social contact.

Subtheme 2: Neighbourhood and living environment. In both subgroups, some participants who lived together with a child mentioned that this enabled them to age in place. Other positive aspects about the home environment were having a one-story 
house, receiving help from neighbours, living near all facilities, and feeling attached (e.g., a female participant (aged > 70) was emotionally attached to her house because her deceased husband had built everything). No noticeable discrepancies were observed when comparing the high and low QoL subgroup.

Subtheme 3: (In)formal care and social support. The majority of participants in both subgroups received informal care from family members, neighbours, and one participant even from her former son-in-law (woman, aged > 85). Most participants were positive about the help they received. Regarding formal care, participants mentioned the importance of social support (i.e., being able to tell someone about problems, and having a trustworthy relationship), and that it was reassuring to have someone to rely on, more than the actual care they received. A female participant (aged > 80) told: "I'm happy whenever I see her. Because I see her as-l'd never say, 'the hired help.' No, no-l always say 'my friend."' Negative aspects about receiving help included being confronted with things they could not do any longer, as well as (the fear of) becoming dependent: "I'd really like to be able to dine out from time to time. But I can't do that by myself. I always have to have someone else go with me. I went [to a restaurant] once with the carer, but then she has to ask for permission from her, uh, company and also, well, I can't pay for her meal all the time. So you see, that's gone too." (woman, aged > 85). In addition, some participants preferred to arrange things themselves. For instance, male participant (aged > 80) stated: "We do everything ourselves, because I was sick of it. No, no, no... The children think they can do a better job than we can. No, we can take care of it on our own." Lastly, some negative experiences with formal care were mentioned, such as feeling treated like a number.

Some discrepancies appeared between both subgroups. In the high QoL subgroup, more participants used assisting aids compared to the low QoL subgroup, and this actually enabled them to do the things they wanted. For example, a female participant (aged > 85) told: "And when the weather's fair I can walk to my fence and back 10 times in an afternoon, with my little rolly-car [rollator], and that makes me feel good. Someone's bound to walk by so you can have a bit of chit chat." In addition, participants in the high OoL subgroup were more involved in activities offered by welfare organizations, which gave them something to look forward to. Regarding social support, positive stories were mentioned more often in the high QoL subgroup compared to the low QoL subgroup. For example, having social contacts with and feeling supported by others really helped participants, and provided comfort: "Sometimes just getting a hold of someone by phone, or that I just finished talking with somebody and I think, 'So, I feel worlds better'." (woman, aged > 75). Although less often, a few participants in the low QoL subgroup explicitly mentioned positive aspects 
about social contacts as well: "That's a real comfort to me, getting out of the house and sitting at a table with those guys and drinking coffee and such." (man, aged > 80).

Theme 4: Life events. Participants in both subgroups mainly experienced negative life events, such as changes in their (physical) health, losses of people around them, or troubles within their families. For example, a female participant (aged > 85) recently lost her youngest brother, who was like a son to her because she raised him. However, some positive life events were mentioned as well, such as an improvement of health after stopping smoking and the birth of great-grandchildren: "It feels as though I'm stronger and healthier, like I used to be, because of those children [birth of grandchildren]. Like I won the lottery" (woman, aged > 85). In the low QoL subgroup, changes in living situation were mentioned, which were positive in most cases, sometimes due to a higher comfort level. However, the house of a female participant (aged > 80) burnt down, which caused her to lose tangible memories: "And then the house having burnt down. That's my lot in life, I can't do anything to fix that misfortune. Those are all my memories and what have you, and they're all gone. And yes... I still miss that. That's over now. It can't be brought back. No. I fully understand that." Lastly, a female participant (aged > 75) in the low QoL subgroup recently lost her job due to illness, and as a consequence also lost social contacts.

No clear discrepancies were observed between the two subgroups.

Theme 5: Future perspective. Some participants still had really specific dreams, such as going out for dinner once again, winning the lottery, swimming with dolphins, remaining independent, or going back to their place of birth.

When comparing both subgroups, it appeared that wishes regarding the future were more often pronounced in the high QoL subgroup. In contrast, in the low QoL subgroup it was more common that participants did not dare to dream or did not have any expectations, and they said things like: "What am I still doing here?" (man, aged > 85), or even feared the future. In response to the question, "Do you think your life might change within a year?" a male participant (aged > 80) replied, "I hope not, but I worry it will. I might get more of the shakes [i.e., Parkinson's disease]."

\section{Discussion}

This mixed-methods study is the first aimed at identifying discrepancies between community-dwelling, frail older people with higher and lower levels of self-reported, overall QoL, focusing on potential strengths frail older people with higher levels of $\mathrm{OoL}$ still have. Despite similarities regarding perceived frailty or vulnerabilities according to the qualitative data, the quantitative data showed that people in the high $\mathrm{OoL}$ subgroup had lower levels of psychological frailty. In addition, higher age, higher levels 
of meaning in life (both quantitative data), having things in prospect, being of value/meaning to others, being able to cope with or adapt to difficulties, performing activities, and satisfaction with social network appeared to be factors that can distinguish frail older people with a higher QoL from those with a lower QoL. In addition, in the low QoL subgroup more unmet needs were experienced regarding factors important for QoL and meaning in life.

Participants in the high QoL subgroup seemed to have more effective ways of coping with and/or adapting to difficulties. For example, they focused on things they still were able to do, or replaced activities they were no longer able to perform. Indeed, previous research has shown that being able to cope with difficulties was important for life satisfaction in people aged 80 years and over who were assessed during and after rehabilitation [30]. In addition, it has been found that disabled persons who were able to adapt reported higher levels of QoL compared to those who did not [31], which is in line with our findings. Furthermore, both our quantitative and qualitative findings indicate that meaning in life is associated with QoL in frailty, along with having things in prospect. Related to this, previous research has shown that meaning in life contributes to QoL in people with chronic diseases [32], while not having a purpose in life has been found to be associated with lower levels of QoL [31]. Nonetheless, being able to cope and meaning in life have been found to be associated as well [33]. Therefore, it could be argued that meaning in life is a part of the relationship between coping and QoL.

Although no clear differences were found in the qualitative interviews regarding the experienced level of frailty, while exploring the other quantitative findings, lower levels of psychological frailty were observed in the high OoL subgroup. Indeed, previous research has shown that feeling down, which is an important aspect of psychological frailty, is associated with lower levels of environmental, social, physical, and psychological QoL [34]. In addition, psychological frailty has been found to predict past, present, and future activities [35]. This could be related to our qualitative finding that frail older people with a higher QoL performed activities more often, while this was mentioned to be important for QoL in both subgroups. With regard to the finding that age might play an important role, previous research has found that being older was associated with a higher QoL in frailty as well [19]. They argued that this could be due to the fact that older people had been able to adapt to their frailty. However, for the current study it is unknown whether participants in the high QoL subgroup indeed had been frail for a longer period of time than participants in the low QoL subgroup. Nonetheless, being able to adapt (e.g., by replacing activities one was no longer able to do) has been found to be important for higher levels of QoL.

Regarding QoL itself, previous research has already shown that psychological well-being, social contacts, and being able to perform activities are important aspects 
of QoL in older people [18]. Indeed, these factors were mentioned to be important for QoL in this study as well. However, our findings add that these factors might actually be related to higher levels of QoL in frailty, as more unmet needs were mentioned in the low QoL subgroup. Whereas previous research has already shown that unmet needs are associated with lower levels of OoL [36], this study identified specific unmet needs in frail older people with a lower QoL. For example, not having enough financial resources was only mentioned in the low QoL subgroup. While previous research has shown that financial resources had no significant effect on the association between frailty and well-being [37], they have not investigated whether income actually fitted the needs of the older people, while this seems to be what is important according to our qualitative findings.

An unexpected finding might be that the majority of participants in both subgroups received (in)formal care as previous research has shown that support from informal caregivers enabled frail older people to maintain their well-being [38]. We therefore would expect to see lower levels of (in)formal care in the low OoL subgroup. However, although both subgroups mentioned the social aspect to be important rather than the actual care they received from (in)formal caregivers, the low QoL subgroup less often pronounced that they actually felt supported by their social network, while this was one of the important aspects for higher levels of well-being in the previous study [38].

\section{Strengths and limitations}

This study has several strengths. First of all, we adopted a mixed-methods design, and with the qualitative part we were able to explore experiences of frail older people more in-depth, taking a lot of different individual perspectives into account. Second, to reduce the risk of bias in personal interpretation, all interviews were coded independently by two researchers with different educational backgrounds, and group analyses were performed independently by two researchers as well. While author AvdV was involved in conducting the interviews and analysing them in the first stage, author RV was an independent researcher who did not conduct any interviews nor was involved in the research project, to enable the trustworthiness of the findings. Lastly, by providing quotes in the results section, readers are enabled to interpret findings themselves.

However, this study has several limitations as well. First, the small sample size might have influenced quantitative findings, as the statistical power was relatively low. Second, only five participants in the low QoL subgroup $(\leq 6)$ scored 5 or lower on $\mathrm{OoL}$, and none below 4, whereas five participants in the high OoL subgroup $(\geq 8)$ scored a 10. Therefore, the contrast between subgroups might be not as large as needed to distinguish substantial differences in people with lower and higher QoL levels. Third, 
QoL might fluctuate from day to day [39], which was mentioned by one of the participants in the high QoL subgroup as well, but no repeated measures were conducted. Fourth, by assessing overall OoL with one overarching question, it could be argued that participants had different operationalisations in mind [40]. Nonetheless, overall QoL can be defined as 'an individual's overall satisfaction with life, and one's general sense of personal wellbeing' [20-21]. Fifth, informal caregivers were present during three interviews in the high QoL subgroup and during one interview in the low QoL subgroup, which might have influenced participants' responses as they might have given socially desirable responses. Linked to this, an interpreter joined the interview in the case of language barriers (once in both subgroups), which might have affected the results as well [41]. In addition, generalisability of findings is limited as only frail older people were included, although the frailest might have refused to take part. Lastly, participants in both subgroups had relatively low scores on the MoCA. However, a systematic review showed that in population-based cohorts many participants score below the cut-off of 26 for $\mathrm{MCl}$, and it is argued that the threshold should be lower [40]. In addition, we intended to include people at risk for frailty, which might explain these cognitive vulnerabilities.

\section{Conclusion}

Frail older people with a higher QoL seem to have better and more effective ways to cope with and/or adapt to difficulties. In addition, they report higher levels of meaning in life, seem to have more things in prospect, are older, have lower levels of psychological frailty, perform more activities, and are more satisfied with their social relationships compared to frail older people with a lower QoL. On the contrary, frail older people with lower levels of QoL report more unmet needs regarding their QoL and meaning in life.

\section{Implications for future research}

While this study aimed to identify individual perspectives and therefore was explorative, by means of a quantitative study approach it will be possible to examine whether for example coping strategies, having something in prospect, and meaning in life actually contribute to QoL in frailty on a larger scale. Hereby, a longitudinal study with repeated measures might be needed as QoL might change over time. Furthermore, future research should explicitly ask whether or not participants feel frail. Previous research has shown that older people who were classified as frail do not always perceive themselves as frail [43], and "experienced frailty" may influence their self-reported QoL as well. 


\section{Implications for clinical practice}

While current clinical practice in frailty mainly focuses on the prevention of negative outcomes, such as delaying functional decline [44] or institutionalisation [45], results from this study suggest possibilities to promote and improve OoL by strengthening specific resources among frail older people. As older people indicate that they wish to focus on things they still can do [11], such a strengths-based approach seems to be a promising way to work more preventatively. Therewith, clinical practice should focus on improving ways older people adapt to or cope with problems, psychological wellbeing, improving their meaning in life, making sure that people have something in prospect, and social contacts, as these factors contribute to QoL even in frailty. It is expected that this will contribute to ageing in place with a good OoL.

\section{Acknowledgments}

The D-SCOPE consortium is an international research group and is composed of researchers from University of Antwerp, Vrije Universiteit Brussel, University College Ghent, Catholic University of Leuven, Belgium, and Maastricht University, the Netherlands: Peter Paul De Deyn, Liesbeth De Donder, Jan De Lepeleire, Ellen De Roeck, Nico De Witte, Eva Dierckx, Daan Duppen, Sarah Dury, Sebastiaan Engelborghs, Bram Fret, Lieve Hoeyberghs, Tinie Kardol, Gertrudis I.J.M. Kempen, Deborah Lambotte, Birgitte Schoenmakers, Jos M.G.A. Schols, An-Sofie Smetcoren, Michaël Van Der Elst, Anne van der Vorst, Dominique Verté, G.A. Rixt Zijlstra.

The authors would like to thank all people who participated in the study. 


\section{References}

1. Fried LP, Tangen CM, Walston J, Newman AB, Hirsch C, Gottdiener J, et al. Frailty in Older Adults: Evidence for a Phenotype. J Gerontol A Biol Sci Med Sci. 2001;56(3):146-57.

2. De Witte N, Gobbens R, De Donder L, Dury S, Buffel T, Schols J.M.G.A, Verté D. The comprehensive frailty assessment instrument: Development, validity and reliability. Geriatr Nurs. 2013;34(4):274-81.

3. Collard RM, Boter H, Schoevers RA, Oude Voshaar RC. Prevalence of Frailty in Community-Dwelling Older Persons: A Systematic Review. J Am Geriatr Soc. 2012;60(8):1487-92.

4. Dury S, De Roeck E, Duppen D, Fret B, Hoeyberghs L, Lambotte D et al (2016). Identifying frailty risk profiles of home-dwelling older people: Focus on sociodemographic and socioeconomic characteristics. Aging Ment Health. 2016; http://dx.doi.org/10.1080/13607863.2016.1193120

5. Gobbens, RJJ, van Assen MALM, Luijkx KG, Schols JMGA. The Predictive Validity of the Tilburg Frailty Indicator: Disability, Health Care Utilization, and Quality of Life in a Population at Risk. Gerontologist. 2012;52(5):619-31.

6. Song X, Mitnitski A, Rockwood K. Prevalence and 10-Year Outcomes of Frailty in Older Adults in Relation to Deficit Accumulation. J Am Geriatr Soc. 2010;58(4):681-7.

7. Wiles JL, Leibing A, Guberman N, Reeve J, Allen RES. The Meaning of "Ageing in Place" to Older People. Gerontologist. 2012;52(3):357-66. http://dx.doi.org/10.1093/geront/gnrog8

8. Scharlach A. Creating Ageing-Friendly Communities in the United States. Ageing Int. 2011;37(1):25-38.

9. European Commission. The 2015 Ageing Report. 2014. Available: http://ec.europa.eu/economy_finance/publications/european_economy/2014/pdf/ ee8_en.pdf. Accessed 15 March 2017

10. Rockwood K, Mitnitski A. Frailty in relation to the accumulation of deficits. J Gerontol A Biol Sci Med Sci. 2007;62a(7):722-7.

11. Lette $M$, Baan CA, van den Berg M, de Bruin SR. Initiatives on early detection and intervention to proactively identify health and social problems in older people: Experiences from the Netherlands. BMC Geriatr. 2015;15:143. http://dx.doi.org/10.1186/s12877-015-0131-z

12. van Kempen JAL, Robben SHM, Zuidema SU, Olde Rikkert MGM, Melis RJF, Schers HJ. Home visits for frail older people: A qualitative study on the needs and preferences of frail older people and their informal caregivers. Br J Gen Pract. 2012;62(601):554-6o. 
13. Warmoth K, Lang IA, Phoenix C, Abraham C, Andrew MK, Hubbard RE, Tarrant M. "Thinking you're old and frail": A qualitative study of frailty in older adults. Ageing Soc. 2015;(36):1483-1500.

14. Graybeal C. Strengths-Based Social Work Assessment: Transforming the Dominant Paradigm. Fam Soc. 2001;82(3):233-42.

15. Minimol K. Risk Assessment and Strengths Based Case Management in Elderly Care-Scope of Social Work Practice. Artha-Journal of Social Sciences, 2016;15(2):121-33.

16. Ament $\mathrm{BHL}$, de Vugt ME, Verhey FRJ, Kempen GIJM .Are physically frail older persons more at risk of adverse outcomes if they also suffer from cognitive, social, and psychological frailty? Eur J Ageing. 2014;11(3):213-9.

17. Zaslavsky O, Woods NF, LaCroix AZ, Cauley JA, Johnson KC, Cochrane BB, Sagi SZ. Identification of Risk Factors for Mortality and Poor-Quality-of-Life Survival in Frail Older Women Participating in the Women's Health Initiative Observational Study. J Am Geriatr Soc. 2016;64(4):831-7.

18. Puts MTE, Shekary N, Widdershoven G, Heldens J, Lips P, Deeg DJH. What does quality of life mean to older frail and non-frail community-dwelling adults in the Netherlands? Qual Life Res. 2007;16(2):263-77. http://dx.doi.org/10.1007/s11136006-9121-0

19. Bilotta C, Bowling A, Casè A, Nicolini P, Mauri S, Castelli M, Vergani C. Dimensions and correlates of quality of life according to frailty status: A cross-sectional study on community-dwelling older adults referred to an outpatient geriatric service in Italy. Health Qual Life Outcomes. 2010;8(56):1-10.

20. Spilker B, Revicki DA. Taxonomy of quality of life. In Spilker B, ed. Quality of Life and Pharmacoeconomics in Clinical Trials. Philadelphia: Lippincott-Raven Publishers; 1996. p. 25-31.

21. Arnold R, Ranchor AV, Sanderman R, Kempen GIJM, Ormel J, Suurmeijer TPBM. The relative contribution of domains of quality of life to overall quality of life for different chronic diseases. Qual Life Res. 2004;13: 883-96.

22. De Witte N, Gobbens R, De Donder L, Dury S, Buffel T, Verté D, Schols, JMGA. Validation of the Comprehensive Frailty Assessment Instrument against the Tilburg Frailty Indicator. Eur Geriatr Med. 2013;4(4):248-54. http://dx.doi.org/10.1016/j.eurger.2013.03.001

23. Nasreddine ZS, Phillips NA, Bédirian V, Charbonneau S, Whitehead V, Collin I, Cummings $\mathrm{J}$, Chertkow $\mathrm{H}$. The Montreal Cognitive Assessment, MoCA: a brief screening tool for mild cognitive impairment. J Am Geriatr Soc. 2005; (53)4: 695-9.

24. Lam B, Middleton LE, Masellis M, Stuss DT, Harry RD, Kiss A, Black SE. Criterion and Convergent Validity of the Montreal Cognitive Assessment with Screening 
and Standardized Neuropsychological Testing. J Am Geriatr Soc. 2013;61:2181-5 http://dx.doi.org/10.1111/jgs.12541

25. Polit DF, Beck CT. Nursing Research. Generating and Assessing Evidence for Nursing Practice. Philadelphia: Wolters Kluwer Health/ Lippincott Williams \& Wilkins. 2008

26. Takkinen S, Ruoppila I. Meaning in Life as an Important Component of Functioning in Old Age. I nt J Ageing Hum Dev. 2001;53(3):211-31.

27. Borneman T, Ferrell B, Puchalski CM. Evaluation of the FICA tool for spiritual assessment. J Pain Symptom Manage. 2010;40(2):163-73

28. Dierckx de Casterlé B, Gastmans C, Bryon E, Denier Y. QUAGOL: A guide for qualitative data analysis. Int J Nurs Stud. 2012;49(3):360-71.

29. van Nes F, Abma T, Jonsson $H$, Deeg $D$. Language differences in qualitative research: Is meaning lost in translation? Eur J Ageing. 2010;7:313. http://dx.doi.org/ 10.1007/s10433-010-0168-y

30. Aberg AC, Sidenvall B, Hepworth M, O'Reilly K, Lithell H. On loss of activity and independence, adaptation improves life satisfaction in old age-a qualitative study of patients' perceptions. Qual Life Res. 2005;14(4):1111-25.

31. Albrecht GL, Devlieger PJ. The disability paradox: high quality of life against all odds. Soc Sci Med. 1999;48(8):977-88.

32. Bernard M, Braunschweig G, Fegg MJ, Borasio GD. Meaning in life and perceived quality of life in Switzerland: results of a representative survey in the German, French and Italian regions. Health Qual Life Outcomes. 2015;13:160. http://dx.doi.org/10.1186/s12955-015-0353-y

33. Park CL, Malone MR, Suresh DP, Bliss D, Rosen RI. Coping, meaning in life, and quality of life in congestive heart failure patients. Qual Life Res. 2008;17:21 http://dx.doi.org/10.1007/s11136-007-9279-0

34. Gobbens RJJ, Luijkx KG, van Assen MALM. Explaining quality of life of older people in the Netherlands using a multidimensional assessment of frailty. Qual Life Res. 2013;22: 2051-61. http://dx.doi.org/10.1007/s11136-012-0341-1

35. Coelho T, Paúl C, Fernandes L. Physical, Psychological and Social Frailty in Prediction of Disability and Quality of Life. Eur Psychiatry. 2015;30(1):447.

36. Hansen DG, Larsen PV, Holm LV, Rottmann N, Bergholdt SH, Søndergaard J. Association between unmet needs and quality of life of cancer patients: $A$ population-based study. Acta. Oncol. 2013;52(2):391-9.

37. Hubbard RE, Goodwin VA, Llewellyn DJ, Warmoth K, Lang, IA. Frailty, financial resources and subjective well-being in later life. Arch Gerontol Geriatr. 2014;58(3):364-9.

38. Lloyd A, Kendall M, Starr JM, Murray SA. Physical, social, psychological and existential trajectories of loss and adaptation towards the end of life for older 
people living with frailty: A serial interview study. BMC Geriatr. 2016;16:176 http://dx.doi.org/10.1186/s12877-016-0350-y

39. Moons $P$, Budts W, De Geest $S$. Critique on the conceptualisation of quality of life: A review and evaluation of different conceptual approaches. Int J Nurs Stud. 2006;43:891-901. http://dx.doi.org/10.1016/j.ijnurstu.2006.03.015

40. Rogerson RJ. Environmental and health-related Quality of Life: Conceptual and methodological similarities. Soc Sci Med. 1995;41:1373-82

41. Squires A. Methodological Challenges in Cross-Language Qualitative Research: $A$ Research Review. Int J Nurs Stud. 2009;46: 277-87.

42. Davis DHJ, Creavin ST, Yip JLY, Noel-Storr AH, Brayne C, Cullum S. Montreal Cognitive Assessment for the diagnosis of Alzheimer's disease and other dementias (Review). Cochrane Database Syst Rev. 2015;10. http://dx.doi.org/10.1002/14651858.CDo10775.pub2

43. Puts MTE, Shekary N, Widdershoven G, Heldens J, Deeg, DJH. The meaning of frailty according to Dutch older frail and non-frail persons. J Ageing Stud. 2009;23(4):258-66.

44. Ruikes FGH, Zuidema SU, Akkermans RP, Assendelft WJJ, Schers HJ, Koopmans, RTCM. Multicomponent Program to Reduce Functional Decline in Frail Elderly People: A Cluster Controlled Trial. J Am Board Fam Med. 2016;29(2): 209-17.

45. de Almeida Mello J, Declercq A, Cès S, Van Durme T, Van Audenhove C, Macq J. Exploring Home Care Interventions for Frail Older People in Belgium: A Comparative Effectiveness Study. J Am Geriatr Soc, 2016;64(11):2251-6. 
Appendix. Overview quantitative and qualitative survey

Table 1. Overview quantitative survey

\begin{tabular}{|c|c|c|}
\hline Domains & $\begin{array}{l}\text { Specific variables / } \\
\text { measurement instrument }\end{array}$ & Description \\
\hline \multicolumn{3}{|c|}{ Socio-demographic characteristics } \\
\hline & Age & \\
\hline & Gender & \\
\hline & Nationality & \\
\hline & Country of birth & \\
\hline & Marital status & \\
\hline & Living arrangement & \\
\hline \multicolumn{3}{|l|}{ Cognition } \\
\hline & $\begin{array}{l}\text { Montreal Cognitive Assessment } \\
\text { (MoCA) (Nasreddine et al., 2005) }\end{array}$ & $\begin{array}{l}\text { Multiple cognitive domains, } \\
\text { including, amongst others, short- } \\
\text { term memory, executive } \\
\text { functioning, and orientation }\end{array}$ \\
\hline \multicolumn{3}{|l|}{ Frailty } \\
\hline & Comprehensive Frailty & Environmental, physical, \\
\hline & $\begin{array}{l}\text { Assessment Instrument (CFAl; De } \\
\text { Witte et al., 2013) }\end{array}$ & psychological, and social frailty \\
\hline Quality of life & & 1-item, 10-point scale \\
\hline Meaning in life & & 1-item, 10-point scale \\
\hline Mastery & & 1-item, 10-point scale \\
\hline
\end{tabular}


Table 2. Overview semi-structured qualitative survey

\begin{tabular}{|c|c|}
\hline Topics & Questions \\
\hline Frailty & $\begin{array}{l}\text { - It is often said that people become frail as they age. How do you } \\
\text { experience this yourself? } \\
\text { - What does frailty mean to you? } \\
\text { - Do you feel more or less frail than other people your age? (Do } \\
\text { they feel frail?) }\end{array}$ \\
\hline $\begin{array}{l}\text { Quality of life, meaning in } \\
\text { life }\end{array}$ & $\begin{array}{l}\text { Do you believe that frailty affects the quality of life and meaning of } \\
\text { life? } \\
\text { - What is your view on that? Do you experience that yourself? } \\
\text { - What are things that contribute to your quality of life, despite } \\
\text { being frail? } \\
\text { - What makes your life meaningful (worthwhile, purposeful)? } \\
\text { quality, meaningful life? }\end{array}$ \\
\hline Mastery & $\begin{array}{l}\text { - Do you feel like you have control over the things that happen in your } \\
\text { life? } \\
\text { - To what extent do you feel able to make your own decisions } \\
\text { regarding what happens in your life? } \\
\text { require? }\end{array}$ \\
\hline Dealing with problems & $\begin{array}{l}\text { - What should an older person do to maintain his/her quality of life / } \\
\text { mastery / meaning in life when becoming frail? } \\
\text { - What is your own experience in that respect? How do you see } \\
\text { that, in your own case? } \\
\text { What factors influence this, do you think? (Individual aspects, } \\
\text { what part do (in)formal caregivers, the } \\
\text { environment/neighbourhood,... play?) }\end{array}$ \\
\hline Life-events & $\begin{array}{l}\text { - Looking back on the last year, have there been any significant changes } \\
\text { in your life? } \\
\text { - Can you describe important positive and negative changes that } \\
\text { - Wave happened in the past year? } \\
\text { - In contrast to the high, did you perhaps also experience a low } \\
\text { point during the last year? }\end{array}$ \\
\hline Future perspective & $\begin{array}{l}\text { - Do you expect your life to have changed in a year's time? } \\
\text { - Do you have any specific expectations for the future? } \\
\text { - What dreams do you have? Are there dreams you want to } \\
\text { accomplish? } \\
\text { (Do they think that they will have a quality life? That they will } \\
\text { become frail?) }\end{array}$ \\
\hline
\end{tabular}


$-164$ 
GENERAL DISCUSSION 
The objectives of this dissertation were threefold: (1) to expand the knowledge about the strength of the associations between the different multidimensional frailty domains; (2) to examine whether one-item proxy assessments by GPs and informal caregivers can serve as a first screener of multidimensional frailty; and (3) to identify countervailing strengths older people have despite frailty, by identifying contributors to daily functioning and wellbeing. This chapter summarises the main findings, reflects on theoretical considerations, and discusses several methodological issues. In the end, implications for clinical practice, future research, and policy are given.

\section{Summary of the main findings}

\section{Conceptualisation of multidimensional frailty}

In general terms, two approaches to frailty can be distinguished. Frailty is either defined as a unidimensional construct including merely physical aspects of functioning, or as a multidimensional construct, including domains such as psychological and social functioning as well. While in unidimensional approaches important determinants of functioning may be overlooked, leading to fragmentation of care [1-3], multidimensional approaches give more insight into the person as a whole [4]. Therefore, and especially in the home environment, multidimensional approaches seem preferable. However, for the development of individually-tailored strategies, it may be helpful to know the strength of the association between the different multidimensional frailty domains, or 'patterns of frailty'. Therefore, as a first step, we studied the (strength of the) associations between cognitive frailty on the one hand, and other frailty domains on the other hand. We examined if this differs for (1) randomly selected community-dwelling older people ( $n=353)$; (2) community-dwelling older people at increased risk of frailty $(n=95)$; and (3) community-dwelling people with cognitive problems visiting a memory clinic $(n=73)$; Chapter 2). Cognitive frailty was most common in the memory clinic group, and least common in the randomly selected community sample. A robust association (i.e. in all three groups) was observed between cognitive frailty and mood disorder symptoms (sub-domain of psychological frailty). However, associations between cognitive frailty and environmental, physical, and social frailty differed between the samples. Therefore, it seems relevant to also study the strength of the mutual associations between the other frailty domains, as our study implies that some associations are more robust than others. By knowing interrelationships between the different frailty domains, more individually tailored interventions could be developed-for example by integrating the different, interrelated domains of functioning [5]. In addition, it is relevant to take sample characteristics into account, as findings differed between the three groups. 


\section{(Pre)screening}

Prevention of risks associated with ageing, such as multidimensional frailty, is important. Therefore, early detection methods are needed. Especially in light of ageing in place, perspectives of (in)formal proxies could be relevant for early detection purposes. These proxies are likely among the first to notice initial signals signs of changed functioning in the older person. Proxy measures then could serve as a first indicator of whether a more comprehensive assessment is needed. Therefore, we examined whether ratings by general practitioners (GPs; $n=57$ ) and informal caregivers $(n=50)$ correspond with the level of frailty as perceived by older people themselves ( $n=78$; Chapter 3 ). One-item proxy assessments on a scale from o-10 were compared with self-reported frailty according to the Comprehensive Frailty Assessment Instrument (CFAI) [6]. Physical and psychological frailty ratings by older people and both proxies were associated, although not very strongly. No significant associations were shown for the other domains (i.e. environmental and social frailty), nor for overall frailty. Therefore, the addressed proxy measures cannot serve as a first screener for detecting frailty. Nonetheless, proxy scores might be of value as a first sign of something being wrong regarding physical and psychological functioning, but this needs further exploration.

\section{Towards a strengths-based approach in multidimensional frailty}

Frailty has previously been described as a complex interplay between deficits and losses on one side, and support and resources on the other side [7-8]. However, most research on frailty still focuses merely on the deficits and losses. In order to move towards a strengths-based approach, which is the preference of older people themselves [9], this dissertation focuses on contributors to daily functioning and wellbeing in several ways. First, we aimed to identify protective factors against developing disability in activities of daily living (ADLs) despite frailty. To begin with, a systematic literature review (Chapter 4 ) was conducted on studies aimed at identifying predictors for ADL disability in community-dwelling people aged $\geq 75$ years. Evidence for higher age, female gender, diabetes, hypertension and stroke as risk factors for ADL disability were reported in at least two studies. Being physically active and being married showed protection against ADL disability in multiple studies. In addition, not smoking, living in a rural area, having enough financial resources, and hypertension were protective in one study. Moreover, results from different studies pointed in the direction of being from a minor ethnicity as a potential protective factor. To conclude, this systematic review identified factors that could serve detection purposes for people at risk of ADL disability (e.g. older women), as well as factors that could serve for prevention purposes (e.g. stimulating physical activity). 
Subsequently, the impact of the seven identified protective factors from the literature review was empirically verified in a longitudinal study (Chapter 5 ). This study was conducted in 1,027 community-dwelling people aged $\geq 65$ years, and all participants were (pre)frail according to Fried's phenotype of frailty [10], which is a purely physical approach to frailty. Multidimensional frail older people had a twofold risk of developing $A D L$ dependency compared to non-frail older people after a period of two years, for which there was no significant difference across age groups (i.e. people aged $65-74$ versus $\geq 75$ ). No significant moderating effects were found for any of the selected protective factors. However, in the overall sample, higher levels of physical activity and having enough financial resources showed protective against ADL dependency.

Lastly, contributors to wellbeing in frailty were examined. By means of a mixed-methods study, factors contributing to quality of life ( $\mathrm{QoL})$ in multidimensional frailty were explored (Chapter 6). Quantitative data showed that frail older people with higher levels of QoL $(n=16)$ were older, had lower levels of psychological frailty, and reported higher meaning in life compared to those with lower levels of QoL ( $n=$ 18). Qualitative analyses showed that frail older people with higher levels of OoL had better and more effective ways of coping with and/or adapting to difficulties, had more things in prospect, performed more activities such as visiting friends, and were more satisfied with their social relationships compared to frail older people with lower levels of QoL. This study suggests possibilities for promoting and improving QoL by strengthening specific capacities and/or resources, even when people are frail.

\section{Theoretical considerations}

\section{Operationalisation frailty}

Consensus about the definition of frailty is lacking. In general, two approaches can be distinguished. First, frailty is conceptualised as a merely physical construct. For example, according to the frailty phenotype as defined by Fried et al. [10], a person is frail when he or she meets at least three of the following criteria: unintentional weight loss $\geq 5$ kilograms in the past year, self-reported exhaustion in the past week, low levels of physical activity, low grip strength and/or slow walking speed. Secondly, approaches conceptualise frailty as a multidimensional construct, and they also include other domains of functioning. For example, in the Frailty Index, as developed by Rockwood et al. [11], frailty is conceptualised as an accumulation of deficits, in which a non-fixed set of clinical deficits is taken into account. In addition, the Tilburg Frailty Indicator (TFI) includes physical (e.g. difficulties in walking), psychological (e.g. depressive symptoms) and social frailty (e.g. living alone) [12], while the Comprehensive Frailty Assessment Instrument (CFAl) [6] also examines environmental frailty (e.g. housing conditions). According to the CFAl, a person is 'overall' frail when experiencing 
problems in two or more frailty domains, although domain-specific frailty can be identified by the CFAI as well (De Witte et al., available upon request).

The choice for a particular conceptualisation of frailty depends on the setting and aim, amongst other factors [13]. In light of ageing in place, the studies in this dissertation all focus on community-dwelling older people, for whom it is particularly important to examine domains other than just physical frailty. Taking multiple domains of functioning into account is relevant from a clinical perspective as it gives more insight into the person as a whole [4] and the needs people have in specific domains. In addition, focusing on just one domain of functioning may lead to fragmentation of care [2-3], and important features may be overlooked [1]. Therefore, in the current dissertation, the multidimensional conceptualisation of frailty has been used.

\section{Moving towards a strengths-based approach}

A strong point of this dissertation is that it aimed to work towards a strengths-based approach to frailty by focusing on positive aspects, in contrast to a large amount of literature on frailty. This approach is in line with the needs and wishes of older people. They prefer a focus on autonomy and wellbeing, rather than on deficits [9]. In addition, merely focusing on things people can no longer do can be stigmatising. When people are labelled as frail, this often makes them behave accordingly [14]. Our aim of working towards a strengths-based approach in frailty has been achieved in several ways throughout this dissertation. First, protective factors against ADL disability as an adverse outcome were identified. Although it could be argued that risk factors are the direct opposite of protective factors, previous studies have shown that this is not always the case [15-16]. In addition, our systematic literature review (Chapter 4) showed that, in community-dwelling people aged $\geq 75$ years, being married was protective against becoming dependent in ADLs, whereas never having been married was not significantly associated with future ADL disability. Therefore, while protective factors are often neglected, this dissertation confirms that they are not always the direct opposite of risk factors. Second, we aimed to identify resources related to higher levels of QoL (i.e. a positive outcome; Chapter 6), rather than trying to explain why frail older people might experience lower levels of QoL. This seems to be the ideal way of working towards a strengths-based approach, in which the focus is on things people can still do and/or the resources they have [17-18].

Our findings are in line with research in other disciplines, which is also promising regarding opportunities to work according to a strengths-based approach. For example, optimism has been proven to reduce pain intensity [19], and a task focusing on positive emotions (i.e. the 'Best Possible Self') actually reduced pain intensity [19]. In addition to research focusing on protective factors to reduce the risk 
of negative outcomes, other scholars have also examined favourable ways of working towards positive outcomes. For example, physical activity can be best stimulated by focusing on the benefits, rather than on the negative consequences of not being physically active [20]. The same principle applies to fall prevention methods. A qualitative study on perspectives on fall prevention methods showed that older people prefer a focus on the positive benefits of the intervention program, rather than on the fall prevention itself [21]. The latter was perceived as patronising [21]. In addition, initiatives such as 'reablement', focusing on competences and opportunities to enable older people to perform certain activities again [22], are promising and they also correspond to our strengths-based approach. Complementary, the 'Stay Active at Home' programme focuses on 'doing with' rather than 'doing for' [23], and this also focuses on competences and resources. Moreover, a focus on self-perceived, positive health as a basis for interventions is currently taken within initiatives in different parts of the Netherlands [24-25], and first experiences are promising.

\section{Physical frailty as opposed to disability or dependency in activities of daily living}

Reflections should be made with regard to ADL functioning as an outcome measure in Chapters 4-5, because ADL disability is highly prevalent in people with frailty [26], and the two concepts might be overlapping [27]. Nonetheless, multidimensional frailty increases the risk of ADL disability [28] and ADL dependency (Chapter 5), which subsequently may threaten the wishes of most older people to age in place [29] Therefore, it is important to examine how to prevent (frail) older people from becoming disabled or dependent in ADLs. Some frailty measures, such as the Groningen Frailty Indicator (GFI) [30], actually address ADL activities such as dressing and toileting. However, Fried's phenotype of frailty [10] and the TFI [12] (i.e. the measures that were part of our study on ADL functioning in frailty; Chapter 5) measure physical capacities, rather than ADL activities as such. Nevertheless, about half of the baseline participants in the study sample, who were all (pre)frail according to Fried's frailty phenotype, were dependent in at least one ADL. Therefore, the concepts indeed seem related. However, because of our longitudinal design, we were also able to explore the pathway between frailty and ADL dependency. It was shown that multidimensional frailty increases the risk of becoming dependent in ADLs, corresponding with previous research defining frailty as a pre-disability state [31].

\section{Methodological considerations}

\section{Measurement methods}

Regarding the measurement methods, several concerns should be taken into account. First, in all studies, merely self-reported measures were used, while for both physical 
frailty and ADL functioning performance-based assessments also exist. In some cases, performance-based assessments seem advantageous as these findings are less influenced by factors such as cognition, culture, educational level, and language [32]. For instance, regarding ADL functioning, older people may underestimate their own performance in specific circumstances, for example they report more difficulties than are shown by performance-based assessments if they suffer from depressive symptoms or experience lower levels of perceived control [33]. However, performancebased assessments do not necessarily reflect what people can do in their own living environment [34]. Rather than indicating the potential capabilities of an individual, self-reported measures give an implication of the usual performance [35], which might be more important in light of ageing in place. In addition, self-reported measures seem particularly suitable when investigating a more broad perspective [36], and are easier to administer in a research setting, i.e. to study a larger group of participants. To conclude, both self-reported and performance-based measures have their pros and cons. Nonetheless, self-reported measures are especially applicable in research settings, and they reflect actual performance, rather than potential capabilities [34], which is important to take into account in light of ageing in place.

Second, numerous multidimensional frailty measurement instruments exist, taking different items and domains into account. For example, the TFI measures physical, psychological and social frailty [12], while the GFI [30] includes cognitive, physical, psychological and social frailty. Moreover, the CFAI [6] takes environmental, physical, psychological and social frailty into account, to which the cognitive domain has recently been added (i.e. CFAI-Plus) [37]. The CFAI is thus distinct from other measures because of the inclusion of environmental frailty. In addition, the CFAI-Plus measures several components of cognitive functioning, such as learning abilities and attention, in contrast to the specific focus on (merely) memory problems in both the GFI and TFI (i.e. in the TFI as a component of psychological frailty). The CFAI-Plus thus seems the most comprehensive measurement. Nonetheless, the choice for a specific instrument, or for the specific domains of frailty that should be examined, always depends on the setting and aim, among other things [13]. Especially in light of ageing in place, it is important to gain insight into the person as a whole, so multiple domains should be taken into account [4]. Environmental frailty is especially important to take into account in light of ageing in place, as people need to be able to perform the necessary and desired activities at home. In addition, regarding cognition, it could be argued that learning abilities are important when older people become physically disabled and need rehabilitation, or need to learn how to adjust to adaptations in their home. Thus, to conclude, it seems justified that in most studies in this dissertation (i.e. Chapters 2-3, 6) the CFAI or CFAI-Plus was used. 
A third concern might be that we measured overall QoL with one overarching question, which might not seem the ideal measure for this construct. For example, it could be argued that participants had different operationalisations in mind [38]. In addition, numerous QoL instruments actually differentiate between specific OoL domains. For example, physical health, psychological wellbeing, and social relationships are discerned [39], but these different domains were not part of our research. However, QoL has been defined as "an individual's overall satisfaction with life, and one's general sense of personal wellbeing" [40-41], for which it seems particularly important to examine subjective experiences, rather than to try to measure objective aspects [42]. Related to this, Hendry \& McVittie [43] showed that a multidomain QoL questionnaire does not necessarily reflect personal experiences. For older people themselves, some $\mathrm{QoL}$ domains are less important than others, but this is not reflected in such questionnaires, as each domain is given equal weight [43]. Therefore, one overarching question seems an adequate measure, particularly for measuring subjective experiences. In patients with cystic fibrosis, a one-item OoL measure (on a scale from 0-10) was shown to be reliable and valid [44], and one-item, global OoL measures have also been used in previous research [45].

\section{Study designs}

In the current dissertation, three out of four empirical studies had a cross-sectional design. Although this design may enable us to answer specific research questions, for example, to identify associations between the frailty domains (Chapter 2) and between (in)formal proxy measures and self-reported frailty (Chapter 3), some limitations should be mentioned. Cross-sectional studies generally do not provide the opportunity to assess the direction of associations. For example, Chapter 6 showed that frail older people with higher levels of QoL were older compared to frail older people with lower levels of QoL. It was hypothesised that these older people had been frail for a longer period of time, and therewith had been able to adapt to their frailty. However, because of the cross-sectional design, this could not be tested. Nonetheless, as little was known about contributors to QoL in frailty, this study had an exploratory character, for which a cross-sectional mixed-methods design is deemed an adequate method [46]. A mixed-methods study includes a separate quantitative and qualitative part [47]. We used a concurrent design; that is quantitative and qualitative data were assessed at the same time. Using the qualitative methods we gained in-depth understanding of the strengths that older people experience. This had not been explored as such before; therefore, more emphasis was put on the qualitative part [48]. Nonetheless, in the end, quantitative and qualitative data were combined and built upon each other, improving the strength of the evidence of our findings. For example, both quantitative and qualitative findings indicated that meaning in life in frail older 
people is associated with QoL. To conclude, without the qualitative part, our findings would not have been as comprehensive. Nonetheless, the quantitative part added value by providing the possibility to assess the statistical significance of some factors. Therefore, combining quantitative and qualitative methods enabled us to give a more detailed understanding of the contributors to QoL despite frailty. Thus, the crosssectional mixed-methods design was the most adequate design for our exploratory study. Moreover, the cross-sectional study designs in Chapters 2 and 3 also sufficed (i.e. as we did not aim to describe causal relationships, but rather to perform descriptive analyses).

In addition to the cross-sectional studies, a systematic literature review (Chapter 4) and longitudinal study (Chapter 5) were performed, which can be reviewed critically from a methodological perspective. A limitation of our systematic review might be that the articles included were heterogeneous in their sampling- and analyses methods. One of the limitations of longitudinal study designs is loss to followup, which is likely to be selective (i.e. participants who complete the follow-up measures are often more healthy compared to non-completers). In our study, noncompleters were more likely to be frail and dependent in performing ADL activities at baseline, for example. However, several strengths should be mentioned as well. The systematic review resulted in an overview of risk factors for and protective factors against developing ADL disability in community-dwelling people aged $\geq 75$ years. By including merely longitudinal studies, the factors that precede the development of ADL disability could be distinguished from the factors that result from these limitations. In addition, by using strict criteria for strength of evidence, we made certain that the factors revealed were supported by multiple studies, which added to the strength of evidence. Subsequently, findings from these different studies and samples in the literature were empirically verified in one longitudinal study. Due to the longitudinal design, Chapter 5 provides evidence for a causal pathway between multidimensional frailty and ADL dependency. In addition, moderating variables were studied in more detail. A moderator is a variable that influences the causal pathway between an independent and a dependent variable, but is not influenced by the independent variable itself [49], and for which a longitudinal design is needed.

\section{Study samples}

Our study samples should be taken into account when interpreting the results because generalisability might be somewhat limited. Our main aim was to gain insight into wellbeing and daily functioning despite frailty, as a first step of working towards a strengths-based approach, rather than shedding light on factors that are important in preventing older people from becoming frail. Therefore, we mainly focused on people with (an increased risk of) frailty, making generalisability to the general community- 
dwelling older population limited. However, it could be argued that the focus on specific populations is needed in order to be able to develop detection and intervention strategies that match this vulnerable group. Indeed, Chapters 2 and 5 show that findings vary across different groups, justifying our sampling methods. First, the association between the different frailty domains was examined in three different groups (Chapter 2). Apart from community-dwelling older people with an increased risk of frailty and community-dwelling people visiting a memory clinic, a third sample was randomly selected from the community. The study showed that associations between the frailty domains differed across the groups, indicating that sample characteristics and tailoring are relevant in frailty studies. Related to this, recent studies showed that risk profiles for frailty differ across the different domains [50], and that older people differ in the exact combination of domains in which they experience frailty [51], and thus that frail older people are a heterogeneous group. Moreover, Looman et al. [52] recently identified six frailty profiles, each with specific care needs. Therefore, tailoring within frailty research appears vital. Second, the findings of our systematic literature review that included studies on community-dwelling people aged $\geq 75$ years (Chapter 4 ) were verified in a longitudinal study in community-dwelling people aged $\geq 65$ years (Chapter 5 ). Findings were specified per age group (i.e. $65-74$ and $\geq 75$ ), and differences between these groups were also detected, indicating that it is important to assess specific groups again.

\section{Implications}

\section{Future research}

This dissertation covers three important areas in frailty research: (1) interrelationships between cognitive frailty and the other frailty domains as a first step in identifying 'patterns of frailty'; (2) early detection of frailty by (in)formal proxies; and (3) the identification of factors that might enable frail older people to experience positive health outcomes despite frailty (i.e. not becoming dependent in ADLs, or experiencing higher levels of $\mathrm{QoL}$ ). Despite the current studies, further research concerning early detection methods, 'patterns' within multidimensional frailty, and strengths-based approaches in frailty are needed.

Early detection. Chapter $\mathbf{5}$ shows that factors that were protective against ADL disability in our sample of community-dwelling people aged $\geq 65$ years could not moderate the pathway from multidimensional frailty to ADL dependency. This implies that timely detection of people at risk for frailty is important for prevention purposes as the factors were no longer protective when a person had become multidimensional frail. Although the suggested proxy measures could not serve as a first screener for multidimensional frailty (Chapter 3), the value of the perspectives of (in)formal proxies is not yet fully understood and requires further examination. Implications can be made 
regarding the study designs, the study samples, as well as the measurements that should be included in future research. First, longitudinal studies could take the predictive value of proxy assessments into account, in comparison to the predictive value of self-reported frailty. In addition, qualitative studies would allow for a more indepth examination of the potentially different perspectives of older people and their proxies. Furthermore, a larger number of older people and proxies should be included to obtain more statistical power, and self-reported frailty should be assessed with both validated scales and a simple, one-item measure. Moreover, factors that might influence comparability, and/or explain discrepancies between ratings, of proxy and self-reported measures, such as caregiver burden [53] and contact frequency [54], should be taken into account. However, other initiatives, such as the risk profiles for frailty as identified by Dury et al. [50] also seem promising for early detection, and they should be further validated. For example, selecting people for a frailty assessment based on these risk profiles could be examined to see if it is an effective way of identifying people at early stages of frailty who might benefit from preventive actions.

Multidimensional frailty. This dissertation shows that it is important to gain insight into the strength of the associations between all frailty domains, or in other words: 'frailty patterns'. Chapter 2 points out that some frailty domains have a stronger connection with each other than others, and that these associations may depend on specific characteristics of the population. The only robust association (i.e. in three different samples) between cognitive frailty and any of the other domains was identified for mood-disorder symptoms (subdomain psychological frailty). Further insight into the (strength of the) associations between all multidimensional frailty domains in different samples of community-dwelling older people is needed to be able to develop tailored interventions. Only by knowing interrelationships, can more individually tailored interventions be developed. In other words, interventions should focus on those domains of functioning in which there are difficulties [5]. Numerous 'frailty patterns', or combinations of frailty in specific domains, exist. By knowing which domains have strong interrelationships, interventions could be made more specific compared to current practices (i.e. which focus on the 'general' frail population). Because frail older people are a heterogeneous group [52] it is important to examine all mutual interrelationships for the other domains (i.e. environmental, physical, psychological and social frailty). Recently, Looman et al. [52] identified six frailty profiles, each with different health care needs. While their findings are important, future research should also include environmental frailty. In addition, sample characteristics need to be taken into account, as findings in Chapter 2 differed between the samples.

Strengths-based approach. Chapters 4-6 identified countervailing strengths in old age in different areas; (1) on an individual/micro level (e.g. coping and physical 
activity); (2) on the meso level (e.g. social contacts and/or support); and (3) on the macro level (e.g. financial resources). These strengths may contribute to the daily functioning and wellbeing of an older person, despite their frailty, and could therefore be defined as 'balancing factors'. Currently, research on protective factors that might positively influence the pathway from frailty to adverse outcomes is relatively sparse. Nonetheless, this dissertation confirms that protective factors are not always the direct opposite of risk factors (Chapter 4), and therefore must be taken into account more often. It seems reasonable that there are other 'balancing factors' that have not yet been taken into account as such in frailty research. For example, in samples of community-dwelling people aged $\geq 65$ years performing volunteer or paid work [55] and positive affect [56] were protective against ADL disability. In addition, factors such as resilience have been shown to contribute to wellbeing despite illness [57], and thus seem important to examine as a potential 'balancing factor'. Moreover, factors that contributed to higher levels of QoL in frailty (Chapter 6) should be re-examined on a larger scale by means of a quantitative study. Therefore, longitudinal data would be useful in order to study causal associations. To conclude, more research is needed regarding both protective factors against adverse outcomes, as well as contributors to positive outcomes, not least because older people themselves prefer a more positive approach [9].

\section{Clinical practice}

Several implications for clinical practice can be derived from the results of this dissertation. Regarding early detection methods, Chapter 3 showed that the assessed one-item proxy measures cannot serve as a first screener to identify people at risk of multidimensional frailty. However, for clinical practice, it might be useful to gain insight into multiple perspectives. By getting information from older people as well as from (in)formal proxies, a multifaceted understanding of the actual frailty level of the older person could be developed. Both the perspective of proxies (e.g. due to caregiver burden) and of older people themselves (e.g. due to a lack of insight) can be biased [58]. However, insight into these different perspectives could serve as a basis for a conversation between these different actors, mutual understanding, and awareness, and could possibly give direction for interventions. Moreover, self-perceived frailty is also important in this respect. Previously, it has been shown that people who are labelled as frail, do not always identify themselves as such [59]. A focus on selfperceived health as a basis for interventions is currently taken within initiatives in different parts of the Netherlands that focus on positive health [23-24], and results are promising.

Moreover, the multidimensional nature of frailty is important for intervention purposes Chapter $\mathbf{2}$ shows that it is important to gain insight into frailty in the different 
domains, rather than aiming for unidimensional approaches. Older people often experience difficulties in more than one domain of functioning, and focusing on merely physical aspects may cause important determinants of functioning to be overlooked [1], and prevention opportunities to be lost. Indeed, interventions must take the different domains of functioning into account. For example, Chapter 2 shows that cognitive frailty is often accompanied by mood-disorder symptoms in communitydwelling older people. Previous research suggested that the presence of both cognitive and psychological deficits might be early signs of future dementia [6o]. Therefore, especially people who suffer from cognitive and psychological frailty might benefit from early interventions that integrate these domains of functioning. For example, interventions aimed at emotional, functional and social aspects can improve psychological well-being despite cognitive difficulties [61]. In addition, 'cognitive rehabilitation' (focused on coping with cognitive changes or learning skills, for example), cognitive stimulation, and movement therapy have been shown to be promising in the early stages of cognitive difficulties [62].

Lastly, a strengths-based approach in clinical practice is recommended. Currently, health care professionals focus mainly on deficits, or things people can no longer do such as walking difficulties [9]. However, it seems of value to also incorporate the strengths that older people have into their care and support. Older people often suffer from functional limitations or diseases, but with the right care and support, they are still capable of performing valuable activities. This dissertation shows that it may be of value to focus on improving positive outcomes, and suggests possibilities for promoting and improving daily functioning and wellbeing by strengthening specific resources among frail older people. Rather than (merely) trying to diminish the level of frailty, interventions can also focus on promoting meaningful activities, or strengthening resources. For example, being physically active (Chapters 4-6) and having social contacts (Chapter 6) were shown to be beneficial for daily functioning and wellbeing, as well as being able to adapt to difficulties (Chapter 6). Therefore, it seems promising to integrate the strengths older people have in some domains of functioning into interventions or care, for example by involving the social support network to enable physically and/or psychologically frail older people to perform desired activities. Questions such as 'What would improve your QoL?' could be part of the interaction between health care professionals and older people. This will not only contribute to working towards a strengths-based approach, but it will also work towards a demand-driven, rather than a supply-driven approach. Nonetheless, ultimately, with this end in mind, evidence-based practices should be developed, applied and evaluated (i.e. a strengths-based, demand-driven approach). In the current dissertation, only factors that could potentially contribute to such a strengths-based approach were identified, meaning that no interventions were tested. Nonetheless, as 
mentioned before, findings in other research disciplines regarding strengths-based approaches are promising [19, 21-22].

\section{Policy}

With the ageing population, society and policy-makers are facing numerous challenges. From a policy perspective [63-64], ageing in place is encouraged to reduce the costs of institutionalisation [65-66], and to meet the wishes of most older people [30]. Consequently, it is expected that the number of (frail) older people who will age in place is going to increase. This leads to an increasing demand for care provided at home, as well as the need to create age-friendly environments. In turn, this presents new challenges. Several implications for policy making can be derived from current knowledge, including the results of this dissertation. First, it is advised that the multidimensional nature of frailty must be taken into account, instead of merely focusing on physical (dis)abilities, as for example environmental and psychological aspects are important in light of ageing in place as well [1-5]. A recent systematic review showed limited evidence for the effectiveness of integrated care (i.e. on a functional, normative and/or organisational level) aimed at frail older people [67]. It was hypothesised that this could be caused by the fact that specific, personal characteristics were not taken into account while developing these intervention strategies [67]. This is in line with our results. Indeed, Chapter 2 showed that frail older people are a heterogeneous group, and that attention must be paid to 'frailty patterns'. Interventions should focus on all domains of functioning in which difficulties are present [5]. Otherwise, it is likely that fragmentation of care will occur [2-3], because important determinants of functioning may be overlooked [1]. Thus, policy makers on a local and national level, but also within care organisations, should go beyond unidimensional views of frailty. It seems valuable to promote interdisciplinary collaboration, for example by setting up multidisciplinary care teams, or establishing regional health care networks.

Second, a stronger focus on things older people can still do despite frailty seems valuable. In policy-making, there are often two points of view: those who view older people as dependent and in need of care, and those who merely focus on healthy ageing and positive aspects [68]. We would argue that a combination of both would be worthwhile in frailty, meaning focusing on strengths of older people in (or despite) frailty. Several suggestions can be made for ways to bring this about. To start with, policy makers could facilitate adequate training to guide professionals towards adopting a strengths-based approach, and/or ensure that such initiatives are financially supported. It might not always be possible to intervene in frailty, for example when someone is physically frail due to a chronic disease. However, it might be possible to improve older people's wellbeing, by 'intervening' in other domains of functioning, 
strengthening resources, or enabling the older adult to perform desired activities. Frail older people should also be enabled to live independently and to participate in society, and it is important to focus on opportunities for improving their wellbeing. A recently published systematic review showed promising results for the effectiveness of interventions on outcomes such as wellbeing and life satisfaction, rather than on diminishing the level of frailty [67]. In addition, Chapters 4-6 can give guidance for how to improve daily functioning and wellbeing. Based on Chapter 6, it seems worthwhile to focus on inclusion in society and on enabling older people to be of value to others, as this was associated with higher levels of QoL despite frailty. In addition, physical activity was an important contributor to daily functioning (Chapters 4-6). Therefore, designing age-friendly cities [69], with places that enable older people to perform leisure activities and meet each other might help to improve wellbeing despite frailty. Local policy initiatives such as 'Manchester: A great place to grow older' could serve as an example. This initiative works at including older people in all aspects of society, leading, among other things, to a sense of belonging and ownership. Practical aspects, such as affordable and appropriate housing, accessibility of pavements, involving the perspective of older people in policy-making, and well-organised public transport, are important in this respect. Moreover, it seems important to change the somewhat negative stereotypes about old age, as stereotyping has negative consequences. For example, when people are labelled as frail by others, this makes them feel frail, and they behave accordingly [14]. Policy also has its share in this, as due to a "compassionate ageism" [70] point of view, initiatives of policy makers focus on providing specific assistance to older people, which reinforces the negative stereotypes. Instead, policy campaigns should focus on creating a more positive view of older people, for example by emphasising contributions older people can make to society. In addition, older people should be pro-actively informed about things they can still do, meaning that older people can also change their own view of ageing, and they can gain an insight into their own potential. Overarching, stimulating a focus on support (e.g. enabling older people to perform desired activities), rather than merely on care (e.g. nursing tasks, or taking over tasks people can no longer do rather than helping them perform the tasks) is important.

To conclude, this dissertation offers tools for current health care policy makers who focus on ageing in place [63-64] and positive health [24-25]. However, it is likely that health care funding models should also be adapted as the current focus, including financial compensation models, is on treating diseases, rather than on improving wellbeing. 


\section{CHAPTER 7}

\section{Overall conclusion}

Overall, this dissertation provides evidence that (1) the strength of the associations between the different multidimensional frailty domains varies, or in other words: that there are different 'frailty patterns'-this is important for the development of tailored intervention strategies; (2) one-item proxy measures on a scale from 0-10 do not reflect the outcome on a comprehensive self-reported frailty assessment; and (3) older people still possess strengths, even when they are frail. The latter makes it possible to intervene in a more positive way, namely by strengthening resources. Therefore, this dissertation contributes to moving towards a strengths-based approach to frailty in which the 'frailty balance' is key, or in other words, in which older people's deficits as well as strengths are taken into account. While diminishing the level of frailty might not always be possible, interventions can still contribute to improving daily functioning. This can be achieved by promoting protective factors against adverse outcomes (e.g. Chapters 4-5), or strengthening resources to improve wellbeing (e.g. Chapter 6). 


\section{References}

1. Clarfield AM, Bergman $\mathrm{H}$, Kane R. Fragmentation of care for frail older people-an international problem. Experience from three countries: Israel, Canada, and the United States. JAGS. 2001;49: 1714-21.

2. Gobbens RJ, Luijkx KG, Wijnen-Sponselee MT, Schols JMGA. Towards an integral conceptual model of frailty. J Nutr Health Aging. 2010; 14: 175-181.

3. Markle-Reid M, Browne $G$. Conceptualizations of frailty in relation to older adults. J Adv Nurs. 2003; 44: 58-68

4. Collard RM, Boter $H$, Schoevers RA, Oude Voshaar RC. Prevalence of Frailty in Community-Dwelling Older Persons: A Systematic Review. J Am Geriatr Soc. 2012;60(8):1487-92.

5. Arts $\mathrm{MH}$, Collard RM, Comijs $\mathrm{HC}$, et al. Physical frailty and cognitive functioning in depressed older adults: Findings from the NESDO Study. JAMDA. 2016; 17: 36-43. DOI: 10.1016/j.jamda.2015.07.016

6. De Witte N, Gobbens R, De Donder L, et al. The Comprehensive Frailty Assessment Instrument: development, validity and reliability. Geriatr Nurs. 2013;34(4):274-81.

7. Brocklehurst JC (ed): The day hospital. In Textbook of Geriatric Medicin7e and Gerontology. 3rd ed. Churchill. London, England. 1985: p. 982-995.

8. Sipsma DH. Modellen en paradigma's in de geriatrie. Medisch Contact. 1993; 48(8):1229-31.[in Dutch].

9. Lette $M$, Baan CA, van den Berg M, de Bruin SR. Initiatives on early detection and intervention to proactively identify health and social problems in older people: Experiences from the Netherlands. BMC Geriatr. 2015;15:143. http://dx.doi.org/10.1186/s12877-015-0131-z

10. Fried LP, Tangen CM, Walston J, et al. Frailty in older adults: evidence for a phenotype. J Gerontol A Biol Sci Med Sci. 2001;56:146-56.

11. Rockwood K, Mitnitski A (2007). Frailty in relation to accumulation of deficits as a proxy measure of ageing. J Gerontol A Biol Sci Med Sci. 2007;62: 722-7

12. Gobbens RJJ, van Assen MALM, Luijkx KG, Wijnen-Sponselee MT, Schols JMGA. The Tilburg Frailty Indicator: Psychometric Properties. JAMDA. 2010;11(5):344-55.

13. De Vries NM, Staal JB, Van Ravensberg CD, Hobbelen JS M., Olde Rikkert MMG, Nijhuis-Van der Sanden MWG. Outcome instruments to measure frailty: a systematic review. Ageing Res Rev. 2011;10(1): 104-14.

14. Warmoth K, Lang IA, Phoenix C, Abraham C, Andrew MK, Hubbard RE, Tarrant M. "Thinking you're old and frail": a qualitative study of frailty in older adults. Ageing Soc. 2015;36: 1483-500. 
15. Kempen GIJM, Ranchor AV, Sonderen E van, Jaarsveld CHM van, Sanderman R. Risk and protective factors of different functional trajectories in older persons. Are these the same? J Gerontol Psy Sci Soc Sci. 2006; 61B: 95-101

16. Mackenbach JP, Van den Bos J, Joung IMA, Van de Mheen H, Stronks K. The determinants of excellent health: different from the determinants of ill-health? Int J Epidemiol. 1994;23: 1273-81.

17. Graybeal C. Strengths-based social work assessment: transforming the dominant paradigm. Fam Soc. 2001;82(3): 233-42.

18. Minimol K. Risk assessment and strengths based case Management in Elderly Care-Scope of social work practice. Artha-J Soc Sci. 2016;15(2):121-33.

19. Hanssen MM, Peters ML, Vlaeyen JW, Meevissen YM, Vancleef LM. Optimism lowers pain: evidence of the causal status and underlying mechanisms. Pain. 2013;154(1): 53-58.

20. Notthoff N, Carstensen LL. Positive messaging promotes walking in older adults. Psychol Aging. 2014;29(2): 329.

21. Yardley L, Donovan-Hall M, Francis K, Todd C. Older people's views of advice about falls prevention: a qualitative study. Health Educ Res. 2006;21(4): 508-17.

22. Aalbers T, Qin L, Baars MA, de Lange A, Kessels RP, Olde Rikkert MMG. Changing behavioral lifestyle risk factors related to cognitive decline in later life using a selfmotivated eHealth intervention in Dutch adults. JMIR. 2016;18(6).

23. Metzelthin SF, Zijlstra GAR, van Rossum E, et al. 'Doing with...'rather than 'doing for...'older adults: rationale and content of the 'Stay Active at Home'programme. Clin Rehabil. 2017;31(11): 1419-30.

24. Institute for Positive Health. [Internet] Available: www.iph.nl [in Dutch]

25. Limburg Positief Gezond. [Internet] Available: www.limburgpositiefgezond.nl [in Dutch]

26. Lutomski JE, Baars MA, Boter $\mathrm{H}$., et al. Frailty, disability and multi-morbidity: the relationship with quality of life and healthcare costs in elderly people. NTvG. 2014;158: 7297.

27. Fried LP, Ferrucci L, Darer J, Williamson JD, Anderson G. Untangling the concepts of disability, frailty, and comorbidity: implications for improved targeting and care. J Gerontol A Biol Sci Med Sci. 2004; 59(3): M255-M263.

28. Coelho T, Paúl C, Fernandes L. Physical, Psychological and Social Frailty in Prediction of Disability and Quality of Life. Eur Psychiatry. 2015;30:447

29. De Witte N, De Donder L, Dury S, et al. Together on the Side-Walks: About Social Cohesion and Older People. Gent: Oost-Vlaanderen [In Dutch]; 2012.

30. Steverink N, Slaets JPJ, Schuurmans H, van Lis M: Measuring frailty: Development and testing of the Groningen Frailty Indicator (GFI). Gerontologist. 2001, 41 (special issue 1): 236-7. 
31. Abellan van Kan G, Rolland YM, Morley JE, Vellas B. Frailty: Toward a clinical definition. J Am Med Dir Assoc 2008;9: 71-72

32. VanSwearingen JM, Brach JS. Making geriatric assessment work: selecting useful measures. PhysTher. 2001;81(6):1233-52.

33. Kempen GIJM, Steverink N, Ormel J, Deeg DJ. The assessment of ADL among frail elderly in an interview survey: self-report versus performance-based tests and determinants of discrepancies. J Gerontol B Psychol Sci Soc Sci. 1996;51(5): P254P26o.

34. Guralnik JM, Branch LG, Cummings SR, Curb JD. Physical performance measures in aging research. J Gerontol.1989; 44:M141-M146.

35. Kane RA, Kane RL. Assessing the Elderly: A Guide to Practical Measurement . Lexington, Mass: Lexington Books. 1981.

36. Martin FC, Brighton P. Frailty: different tools for different purposes? Age Ageing. 2008;37(2): 129-31

37. De Roeck EE, Dury $\mathrm{S}$, De Witte, $\mathrm{N}$ et al. CFAl-Plus: Adding cognitive frailty as a new domain to the comprehensive frailty assessment instrument. Int J Geriatr Psychiatry. 2018. https://doi.org/10.1002/gps.4875

38. Rogerson RJ. Environmental and health-related quality of life: conceptual and methodological similarities. Soc Sci Med. 1995;41: 1373-82.

39. WHOQOL Group. The World Health Organizatioppn WHOQOL: Tests of the universality of quality of life in 15 different cultural groups worldwide. Health Psychology. 1999; 18(5): 495-505

40. Arnold R, Ranchor AV, Sanderman R, GIJM K, Ormel J, TPBM S. The relative contribution of domains of quality of life to overall quality of life for different chronic diseases. Qual Life Res. 2004;13: 883-96.

41. Spilker B, Revicki DA. Taxonomy of quality of life. In: Spilker B, editor. Quality of life and Pharmacoeconomics in clinical trials. Philadelphia: Lippincott-Raven Publishers; 1996. p. 25-31.

42. Addington-Hall J, Kalra L. Who should measure quality of life? BMJ. 2001; 322: 1417-20.

43. Hendry F, McVittie C. Is quality of life a healthy concept? Measuring and understanding life expectancies of older people. Qual Health Res. 2004; 14: 96175.

44. Yohannes AM, Dodd M, Morris J, Webb K. Reliability and validity of a single item measure of quality of life scale for adult patients with cystic fibrosis. Health Qual Life Outcomes. 2011;9(1): 105.

45. Zaslavsky O, Woods NF, LaCroix AZ, Cauley JA, Johnson KC, Cochrane BB, Sagi $S Z$. Identification of risk factors for mortality and poor-quality-of-life survival in 
frail older women participating in the Women's Health Initiative observational study. J Am Geriatr Soc. 2016;64(4): 831-7.

46. Polit DF, Beck CT. Nursing Research. Generating and Assessing Evidence for Nursing Practice. Philadelphia: Wolters Kluwer Health/ Lippincott Williams \& Wilkins. 2008. p. 208

47. Johnson RN, Onwuegbuzie AJ. Mixed methods research: A research paradigm whose time has come. ER. 2004; 33(7): 14-26.

48. Creswell JW, Fetters MD, Ivankova, NV. Designing a mixed methods study in primary care. The Ann Fam Med. 2004; 2(1): 7-12.

49. Polit DF, Beck CT. Nursing Research. Generating and Assessing Evidence for Nursing Practice. Philadelphia: Wolters Kluwer Health/ Lippincott Williams \& Wilkins. 2008. p. $75^{8}$

50. Dury $S$, De Roeck $E$, Duppen $D$, et al. Identifying frailty risk profiles of homedwelling older people: focus on sociodemographic and socioeconomic characteristics. Aging Ment Health 2017; 21(10): 1031-9.

51. Smetcoren AS, Dury $S$, De Donder $L$, et al. Detectie en preventie van kwetsbaarheid: Op zoek naar risicoprofielen voor fysieke, psychische, sociale en omgevingskwetsbaarheid. Tijdschr Gerontol Geriatr. 2018;49(1): 1-11 [in Dutch].

52. Looman WM, Fabbricotti IN, Blom JW, Jansen APD, Lutomski JE, Metzelthin SF, Huijsman R. The frail older person does not exist: development of frailty profiles with latent class analysis. BMC Geriatr. 2018;18(1): 84.

53. Snow AL, Cook KF, Lin PS, Morgan RO, Magaziner J. Proxies and Other External Raters: Methodological Considerations. Health Serv Res 2005;40: 1676-93

54. Nasreddine ZS, Phillips NA, Bédirian V, et al. The Montreal Cognitive Assessment, MoCA: a brief screening tool for mild cognitive impairment. J Am Geriatr Soc 2005;53(4): 695-9

55. Luoh MC, Herzog AR. Individual consequences of volunteer and paid work in old age: health and mortality. J Health Soc Behav. 2002; 43(4): 490-509.

56. Díaz-Ramos JA, Navarrete-Reyes AP, Ávila-Funes JA. Positive affect in elderly Mexicans and its protective role against disability. J Am Geriatr Soc. 2012; 60(2): 384-5. doi: 10.1111/j.1532-5415.2011.03805.x

57. Wiles $\mathrm{J}$, Wild K, Kerse N, Allen RE. Resilience from the point of view of older people:'There's still life beyond a funny knee'. Soc Sci Med. 2012; 74(3): 416-24.

58. Arlt S, Hornung J, Eichenlaub M, Jahn H, Bullinger M, Petersen C. The patient with dementia, the caregiver and the doctor: cognition, depression and quality of life from three perspectives. Int J Geriatr Psychiatry. 2008;23(6): 604-10.

59. Grenier A. The distinction between being and feeling frail: exploring emotional experiences in health and social care. Journal of Social Work Practice. 2006;20(3): 299-313. 
6o. Seo EH, Kim H, Choi KY, Lee KH, Choo IH. Association of subjective memory complaint and depressive symptoms with objective cognitive functions in prodromal Alzheimer's disease including pre-mild cognitive impairment. J Affect Disord. 2017; 1: 217:24-8. doi:10.1016/j.jad.2017.03.062.

61. Gates N, Valenzuela M, Sachdev PS, Singh MAF. Psychological well-being in individuals with mild cognitive impairment. Clin Interv Aging. 2014; 9: 779 .

62. Dröes RM, Van Der Roest HG, Van Mierlo L, Meiland FJ. Memory problems in dementia: adaptation and coping strategies and psychosocial treatments. Expert Rev Neurother. 2011;11(12): 1769-82.

63. Ministerie van Volksgezondheid, Welzijn en Sport. De maatschappij verandert. Verandert de zorg mee? 2014. Available:

http://vwshuisstijl.nl/uploads/2014/07/vws-veranderingzorg-web.pdf

64. Vlaamse Regering. Conceptnota Vlaams welzijns- en zorgbeleid voor ouderen. Dichtbij en integraal. Visie en veranderagenda. 2016. Available:

https://www.zorgneticuro.be/sites/default/files/general/160205_Conceptnota_Vla ams\%2owelzijns-\%2oen\%2ozorgbeleid\%2ovoor\%2oouderen_o.pdf

65. Marek KD, Stetzer F, Adams SJ, Popejoy LL, Rantz M. Aging in place versus nursing home care: Comparison of costs to Medicare and Medicaid. Res Gerontol Nurs. 2012;5(2): 123-9.

66. Rantz M, Popejoy LL, Galambos C, et al. The continued success of registered nurse care coordination in a state evaluation of aging in place in senior housing. Nurs Outlook. 2014;62(4): 237-46.

67. Looman WM, Huijsman R, Fabbricotti IN. The (cost-)effectiveness of preventive, integrated care for community-dwelling frail older people: A systematic review. Health Soc Care Community. 2018. https://doi.org/10.1111/hsc.12571

68. Angus J, Reeve P. Ageism: a threat to 'aging well' in the 21st century. J Appl Gerontol. 2006;25(2): 137-52.

69. WHO. A glossary of terms for community health care and services for older persons. 2004. Available:

http://www.who.int/kobe_centre/ageing/ahp_vol5_glossary.pdf

70. Binstock RH. From compassionate ageism to intergenerational conflict? Gerontologist. 2010;50(5): 574-85 
$-186$ 


\section{ADDENDA}

Summary

Samenvatting

Valorisation

Dankwoord

About the author

Publications and conference contributions

D-SCOPE 
$-188$ 


\section{SUMMARY}

With the increasing number of older people, more and more attention is paid to concepts such as 'active and healthy ageing' and 'ageing in place'. However, chronic and acute conditions associated with ageing, might threaten the need and wish to age in place. Frailty is such a condition and although different approaches to frailty exist, an increasing number of experts operationalise frailty as a multidimensional concept. This implies that it is not only the physical aspects of functioning that are taken into account, but also the cognitive, psychological and social aspects, as well as the home environment. However, associations between these different domains are not yet fully understood. Insights into such 'frailty patterns' may be important for making interventions more individually tailored. In addition, timely detection of frailty is important for prevention purposes. However, current detection methods are rather time consuming. A two-step approach, with a short first screener as a first step to identify those in need of a more comprehensive assessment, might be favourable. Another area of concern is that existing detection instruments do not endorse the needs, wishes and strengths of older people. Detection instruments focus merely on things people can no longer do and on adverse outcomes, while older people prefer a more positive approach. Linked with this, older people might feel stigmatised and might behave accordingly when they are labelled as frail. Therefore, a strengths-based approach, which aims to gain understanding of people's strengths and abilities despite frailty, also seems important. Therefore, the aims of this dissertation were threefold: (1) to gain more insight into the associations between frailty domains; (2) to assess the value of one-item proxy measures as a first screener for identifying people at risk for multidimensional frailty; and (3) to identify determinants of daily functioning and wellbeing in order to move towards a strengths-based approach to frailty.

Chapter 1 provides information about the significance of enabling older people to age in place, the concept of frailty, the importance of early detection and the importance of working towards a strengths-based approach. The chapter ends with the main objectives and an outline of this dissertation.

During the last decades, many conceptualisations of frailty have been proposed. While initially merely biomedical aspects were taken into account, an increasing number of approaches assess multiple domains of functioning. However, associations between cognitive frailty and the other frailty domains (i.e. environmental, physical, psychological and social frailty) still remain mainly unclear. Therefore, Chapter 2 
discusses the association between cognitive frailty and the other domains in three populations with increasing levels of objective cognitive impairment: a random sample of community-dwelling older people $(n=353)$, community-dwelling older people with an increased risk of frailty $(n=95)$, and community-dwelling older people visiting a memory clinic $(n=73)$. Associations between cognitive frailty and mood disorder symptoms, which is a sub-domain of psychological frailty, were observed in all three groups. However, the relationship between cognitive frailty and the other domains varied with the level of cognitive functioning and cognitive frailty. For example, cognitive and environmental frailty were only associated in people visiting a memory clinic, while physical and social frailty were only significantly associated with cognitive frailty in the random selected sample. This study implies that the strength of the associations between the different frailty domains might differ, and that it is important to discover this for all domains in order to develop 'frailty patterns'.

Timely detection is important in reducing negative consequences associated with frailty. Although numerous frailty instruments have been developed, their administration might take up to 30 minutes. A short first screener, as a 'rule of thumb', might be useful in identifying those older people in need of a more comprehensive assessment. Especially in light of ageing in place, the perspective of (in)formal caregivers might be of value as a first screener. Therefore, a cross-sectional study was conducted in 78 community-dwelling older people, their general practitioners $(n=57)$ and informal caregivers $(n=50)$ (Chapter 3). One-item proxy measures of environmental, physical, psychological and social frailty were compared with selfreported outcomes on the Comprehensive Frailty Assessment Instrument (CFAI). Physical and psychological frailty scores by proxies and older people were significantly correlated, though only to a low (psychological frailty) to moderate (physical frailty) degree. No significant correlations were found for environmental, social and overall frailty. Based on our findings, global, one-item proxy scores cannot replace comprehensive self-reported frailty. Nonetheless, proxy scores on psychological and physical frailty might be a first indication of something being wrong in these domains of functioning. This calls for further investigation.

In Chapter 4, we present a systematic literature review on identifying risk factors for and protective factors against developing disability in activities of daily living (ADLs), which is an adverse outcome of frailty. Twenty-five longitudinal studies in communitydwelling people aged $\geq 75$ years were included. Higher age, female gender, diabetes, hypertension and stroke were risk factors for ADL disability in $\geq 2$ studies, while physical activity and being married were protective in $\geq 2$ studies. In addition, some factors were associated with future ADL disability in one study. The identified factors 
can serve both detection (e.g. older women) and prevention (e.g. physical activity) purposes.

Chapter 5 describes the results of a longitudinal study in 1,027 community-dwelling people aged $\geq 65$ years in which the findings of the systematic literature review were empirically tested. This study aimed to examine (1) the main effect of multidimensional frailty on ADL dependency; (2) whether this relation could be moderated by the protective factors that were identified in the systematic literature review; (3) the main effects of the selected protective factors on ADL dependency; and (4) whether there are differences across age groups (65-74 and $\geq 75$ years, respectively). The outcomes showed that multidimensional frail older people had a twofold risk of developing ADL dependency after 24 months as compared to non-frail older people. This did not differ significantly between the two age groups. The selected protective factors against ADL dependency did not significantly moderate this relationship either. Nonetheless, in the overall sample, higher levels of physical activity decreased the risk of becoming dependent in ADLs, as well as having enough financial resources.

In a mixed-methods study (Chapter 6), differences between frail older people with higher $(n=18)$ and lower $(n=16)$ levels of quality of life (QoL) were explored. Quantitative measures included socio-demographic characteristics, overall QoL, meaning in life and mastery. The qualitative part focused on the meaning and maintenance of QoL, among other factors, despite being frail. Quantitative analyses showed that frail older people with higher levels of QoL were older, had lower levels of psychological frailty, and higher levels of meaning in life compared to frail older people with lower levels of QoL. Qualitative analyses showed that frail older people with a higher QoL had more things in prospect, adapted more effectively to difficulties, performed more activities, and were more satisfied with their social network compared to those with a lower QoL. In addition, people with higher levels of QoL reported that they were of value or meaning to others. This study provides possibilities to promote and improve QoL by strengthening specific resources, even in frail older people.

Chapter 7 summarises and discusses the main findings. In addition, implications for clinical practice and future research are given. Overall, this dissertation provides evidence that associations between frailty domains vary, that one-item proxy measures do not reflect self-reported frailty, and that older people still possess strengths. The latter makes it possible to intervene in a more positive way, for example by strengthening resources. Therefore, this dissertation contributes to moving towards a strengths-based approach to frailty. 
$-192-$

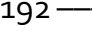




\section{SAMENVATTING}

Door het toenemend aantal ouderen krijgen concepten als 'actief en gezond ouder worden' en 'oud worden in de eigen woonomgeving' steeds meer aandacht. Chronische en acute problemen, welke nu eenmaal gepaard gaan met ouder worden, kunnen de wens om 'oud te worden in de eigen woonomgeving' echter in gevaar brengen. Kwetsbaarheid is een van deze mogelijke problemen. In het onderzoek en de zorgpraktijk wordt kwetsbaarheid in toenemende mate geconceptualiseerd als een multidimensionaal construct. Dit betekent dat niet enkel de fysieke domeinen van het functioneren in kaart worden gebracht, maar ook cognitieve, psychische en sociale aspecten, evenals (in enkele gevallen) aspecten van de leefomgeving. Tot op heden is echter nog weinig bekend over de onderlinge relaties tussen deze verschillende kwetsbaarheidsdomeinen, terwijl inzicht in de samenhang tussen de kwetsbaarheidsdomeinen van belang is om interventies gericht op kwetsbaarheid meer 'op maat' te kunnen maken.

In het kader van preventie is het daarnaast van belang om mensen met een verhoogd risico op kwetsbaarheid tijdig te detecteren. De meeste instrumenten die hier momenteel voor gebruikt worden, zijn tijdrovend. Een stapsgewijze aanpak, met een kort screeningsinstrument als eerste stap om na te gaan of uitgebreidere diagnostiek nodig is, lijkt daarom van toegevoegde waarde. Een ander aandachtspunt binnen het onderzoek rondom kwetsbaarheid is dat bestaande instrumenten niet (voldoende) inspelen op de noden, wensen en competenties van ouderen. Detectie instrumenten zijn vrijwel enkel gericht op dingen die mensen niet meer kunnen en de daaraan gekoppelde negatieve uitkomsten, terwijl veel ouderen zelf de voorkeur geven aan een meer positieve aanpak. Hieraan gerelateerd zien we ook dat wanneer ouderen als kwetsbaar bestempeld worden, dit stigmatiserend kan werken en zij zich hierdoor soms ook kwetsbaar gaan gedragen. Een zogenaamde 'strengths-based approach', waarbij getracht wordt inzicht te krijgen in competenties en sterktes, of draagkracht, die mensen hebben, ondanks hun kwetsbaarheid, biedt mogelijkheden om dit veelal negatieve perspectief te veranderen.

Uitgaande van bovenstaande aandachtspunten waren de doelen van dit proefschrift drievoudig, te weten:

(1) het verkrijgen van meer inzicht in de relatie tussen de verschillende kwetsbaarheidsdomeinen;

(2) het onderzoeken of het perspectief van huisartsen en mantelzorgers, gemeten door middel van één vraag per kwetsbaarheidsdomein, kan bijdragen aan het identificeren van ouderen met een verhoogd risico op kwetsbaarheid; en 
(3) het in kaart brengen van factoren die (positief) bijdragen aan het dagelijks functioneren en welzijn om zo uiteindelijk tot een 'strengths-based approach' met betrekking tot de omgang met kwetsbaarheid te kunnen komen.

Hoofdstuk 1 geeft achtergrondinformatie. Hierbij komen achtereenvolgens het belang om mensen in de vertrouwde woonomgeving zelfstandig 'oud te laten worden', het begrip kwetsbaarheid en het belang van vroegdetectie als ook van het werken volgens een 'strengths-based approach' aan bod. Aan het einde van het hoofdstuk wordt het doel en de onderzoeksvragen als ook de opbouw van dit proefschrift weergeven.

Gedurende de laatste jaren is kwetsbaarheid op veel verschillende manieren geconceptualiseerd. In eerste instantie werd voornamelijk naar biomedische en fysieke aspecten gekeken. De laatste jaren worden problemen in andere domeinen van functioneren steeds vaker hierbij betrokken. Over de sterkte en de richting van associaties tussen cognitieve kwetsbaarheid en andere domeinen (te weten: omgevings-, fysieke, psychische en sociale kwetsbaarheid) is echter nog weinig bekend. In Hoofdstuk $\mathbf{2}$ is daarom gekeken naar de associatie tussen cognitieve kwetsbaarheid en de andere kwetsbaarheidsdomeinen in drie verschillende onderzoekspopulaties. Deze onderzoekspopulaties hadden in toenemende mate (objectief vastgestelde) cognitieve beperkingen en betroffen (1) een willekeurige steekproef van thuiswonende ouderen $(\mathrm{N}=353)$; (2) thuiswonende ouderen met een verhoogd risico op kwetsbaarheid ( $N=95)$; en (3) thuiswonende ouderen die een geheugenpoli bezochten $(\mathrm{N}=73$ ). In alle groepen werd een associatie gevonden tussen cognitieve kwetsbaarheid en stemmingsproblemen - een subdomein van psychische kwetsbaarheid. De associatie tussen cognitieve kwetsbaarheid en de andere domeinen verschilde daarentegen tussen de drie groepen, oftewel: er was een verschil naar gelang de mate van objectief vastgestelde cognitieve beperkingen en cognitieve kwetsbaarheid. Cognitieve en omgevingskwetsbaarheid waren bijvoorbeeld enkel significant geassocieerd in de groep die een geheugenpoli bezocht, terwijl fysieke en sociale kwetsbaarheid enkel significant geassocieerd waren met cognitieve kwetsbaarheid in de willekeurige getrokken steekproef. Daarmee laat deze studie zien dat de (sterkte van de) associaties tussen de kwetsbaarheidsdomeinen al naar gelang de onderzochte groep kan verschillen. In toekomstig onderzoek is het van belang deze onderlinge associaties ook voor de andere domeinen te onderzoeken, om zo te komen tot groepen ouderen met verschillende 'kwetsbaarheidsprofielen'.

Tijdige detectie van kwetsbaarheid is van belang om negatieve gevolgen te voorkomen. In de laatste jaren zijn daarom meerdere kwetsbaarheidsinstrumenten ontwikkeld. De afnameduur hiervan kan echter tot wel 30 minuten bedragen. Een kort, 
globaal screeningsinstrument, als een eerste indicator om na te gaan of meer uitgebreide diagnostiek nodig is, lijkt derhalve zinvol. Daarnaast is er de veronderstelling dat personen uit de directe nabijheid van ouderen (zoals formele en informele zorgverleners) van waarde kunnen zijn bij het vroegtijdig signaleren van kwetsbaarheid, ook omdat steeds meer mensen 'zelfstandig in de eigen woonomgeving oud worden'. Daarom werd een cross-sectionele studie uitgevoerd, waaraan 78 thuiswonende ouderen, 57 huisartsen en 50 mantelzorgers deelnamen (Hoofdstuk 3). Aan de huisarts en mantelzorger werd over de betreffende oudere één vraag gesteld die algehele kwetsbaarheid omvatte, als ook één vraag per kwetsbaarheidsdomein (te weten omgevings-, fysieke, psychische en sociale kwetsbaarheid). Daarnaast werd multidimensionale kwetsbaarheid bij de oudere zelf gemeten met de CFAI (Comprehensive Frailty Assessment Instrument), een zelfrapportage lijst. De CFAI scores betreffende fysieke en psychische kwetsbaarheid waren significant geassocieerd met de scores die de huisartsen en mantelzorgers gaven op deze domeinen. Er werd echter geen significant verband gevonden tussen de verschillende scores met betrekking tot omgevings-, sociale en algehele kwetsbaarheid. Op basis van deze studie kan geconcludeerd worden dat 1-item kwetsbaarheidsscores gegeven door huisartsen en mantelzorgers over een oudere een meer uitgebreid kwetsbaarheidsinstrument niet kunnen vervangen als het gaat om het signaleren van kwetsbaarheid bij thuiswonende ouderen. Het perspectief van huisartsen en mantelzorgers op de mate van fysieke en psychische kwetsbaarheid zou echter wel een eerste indicatie kunnen geven of mogelijk iets mis is voor wat betreft deze domeinen van functioneren. Verder onderzoek hiernaar wordt aanbevolen.

In hoofdstuk 4 wordt een systematisch literatuuronderzoek gepresenteerd waarin risicofactoren voor en protectieve factoren tegen het ontwikkelen van beperkingen in de algemene dagelijkse activiteiten (ADL) in kaart worden gebracht. ADL beperkingen worden immers beschouwd als een negatief gevolg van kwetsbaarheid. Er werden 25 longitudinale studies geïncludeerd, allen vitgevoerd bij thuiswonende ouderen met een minimale leeftijd van 75 jaar. Een hogere leeftijd, het vrouwelijke geslacht, diabetes, hypertensie en beroerte werden in minstens twee van de geïncludeerde studies gerapporteerd als risicofactor voor ADL beperkingen. Daarnaast werden fysieke activiteit en gehuwd zijn geïdentificeerd als protectieve factor in minstens twee studies. Ook waren er nog enkele factoren waarvoor de associatie met ADL beperkingen maar in één studie werd gevonden. De geïdentificeerde factoren kunnen enerzijds bijdragen aan het detecteren van ouderen met een verhoogd risico op ADL beperkingen (bijvoorbeeld oudere vrouwen) en geven anderzijds indicaties voor preventieve interventies die van belang zijn (bijvoorbeeld het stimuleren van verandering in gedrag zoals fysieke activiteit). 
Hoofdstuk 5 beschrijft de resultaten van een longitudinale studie, welke werd uitgevoerd bij 1027 thuiswonende ouderen met een minimale leeftijd van 65 jaar. In deze studie zijn de bevindingen uit het voorgaande systematische literatuuronderzoek empirisch getoetst. Het doel was om te onderzoeken (1) wat het (hoofd)effect van multidimensionale kwetsbaarheid op afhankelijkheid in ADL functioneren is; (2) of deze relatie gemodereerd wordt door de protectieve factoren die naar voren zijn gekomen uit het literatuuronderzoek; (3) wat het (hoofd)effect van iedere protectieve factor op afhankelijkheid in ADL functioneren is; en (4) of er verschillen zijn in de associaties tussen leeftijdsgroepen (65-74 versus $\geq 75$ jaar). De resultaten toonden dat multidimensionaal kwetsbare ouderen na 24 maanden een twee keer zo hoog risico hadden om afhankelijk te worden van anderen voor ADL activiteiten in vergelijking met ouderen die niet multidimensionaal kwetsbaar waren. Hierbij waren er geen significante verschillen tussen de twee leeftijdsgroepen. De effecten van kwetsbaarheid op afhankelijkheid in ADL functioneren werd niet beïnvloed door de geselecteerde protectieve factoren.

Door middel van een mixed-method studie (Hoofdstuk 6) zijn verschillen tussen kwetsbare ouderen met een 'hoge' $(\mathrm{N}=18)$ en 'lage' $(\mathrm{N}=16)$ kwaliteit van leven $(\mathrm{KvL})$ onderzocht. Beoogd werd na te gaan welke factoren het verschil in KvL bij aanwezige kwetsbaarheid kunnen verklaren. Het kwantitatieve gedeelte bestond onder andere uit socio-demografische karakteristieken, globale $\mathrm{KvL}$, zingeving en zelfregie. Het kwalitatieve gedeelte richtte zich op de betekenis en het behouden van de KvL ondanks kwetsbaarheid. De kwantitatieve analyses lieten zien dat kwetsbare ouderen in de 'hoge' KvL groep ouder en in mindere mate psychisch kwetsbaar waren, en ook meer zingeving ervaarden dan de ouderen in de 'lage' KvL groep. Daarnaast bleek uit de kwalitatieve analyses dat kwetsbare ouderen in de 'hoge' KvL groep meer gebeurtenissen (bijvoorbeeld activiteiten) in het vooruitzicht hadden, gemakkelijker met moeilijkheden konden omgaan, meer activiteiten ondernamen en meer tevreden waren over hun sociale netwerk in vergelijking met de ouderen in de 'lage' KvL groep. Verder rapporteerden enkel ouderen in de 'hoge' KvL groep dat zij nog van betekenis konden zijn voor anderen. De resultaten van deze studie bieden aanknopingspunten om de KvL van ouderen ondanks kwetsbaarheid te vergroten door in te spelen op specifieke competenties en sterktes.

Hoofdstuk 7 vat de belangrijkste bevindingen van het proefschrift samen en plaatst deze in een breder perspectief. In dit hoofdstuk worden ook aanbevelingen gegeven voor zowel toekomstig onderzoek, de klinische praktijk als beleid. Samenvattend laat dit proefschrift zien dat de associaties tussen de verschillende kwetsbaarheidsdomeinen verschillen al naar gelang de cognitieve status van de 
onderzoekspopulatie, dat het globale perspectief van huisartsen en mantelzorgers niet geheel overeenkomt met de mate van kwetsbaarheid zoals ervaren door thuiswonende ouderen zelf, en dat ook kwetsbare ouderen sterktes hebben waardoor zij hun kwaliteit van leven als adequaat ervaren. Dit laatste maakt het mogelijk om op een meer positieve wijze te interveniëren, bijvoorbeeld door het versterken van competenties die ouderen hebben. Daarmee draagt dit proefschrift bij aan de verandering van een 'deficit-based approach' naar een meer 'strengths-based approach' in kwetsbaarheid. 
$-198$ 


\section{VALORISATION}

This dissertation describes studies that aimed (1) to increase the knowledge about the associations among different frailty domains, or 'frailty patterns' in older people, which may contribute to the development of individually tailored interventions; (2) to assess the added value of the perspective of general practitioners and informal caregivers by means of a short first screener for the identification of people at risk for multidimensional frailty; and (3) to identify factors that contribute to daily functioning and wellbeing despite frailty in order to work towards a strengths-based approach. Although the value of our work for clinical practice has been described in each study, this chapter focuses on the positioning of our findings in a broader, societal framework. This chapter therefore discusses (1) the societal relevance; (2) the innovativeness of our findings; (3) target groups to whom our findings are relevant; (4) how our findings can be translated into specific products or activities; and (5) how valorisation actually can be realised, or in other words, how the products can be implemented.

\section{Societal relevance}

Within the ageing population, policymakers are focusing more and more on stimulating 'ageing in place'. This is not only the wish older people have, it also is important to reduce the high costs of institutionalisation. However, chronic and acute conditions associated with ageing, such as multidimensional frailty, threaten the ability to age in place. It is well-known that frailty increases the risk of disability, hospitalisation and institutionalisation, amongst other consequences. Thus, early detection of frailty and prevention of frailty and its adverse outcomes are important.

Therefore, regarding detection methods, we explored if a one-item proxy measure could serve as a short, first screener for identifying people at risk for multidimensional frailty (Chapter 3). We found, however, that the outcome on a self-reported frailty measure and the perspectives (in)formal proxies differ. This might indicate that (in)formal caregivers lack knowledge about multidimensional frailty as perceived by older persons. Nonetheless, as our work highlights the importance of assessing frailty as a multidimensional construct (Chapter 2), it is likely that this increases their awareness. Eventually, this might result in multidimensional frailty to be recognised in an earlier stage.

In addition, findings from Chapters 2 and 4-6 are relevant for developing interventions. First, we identified interrelationships between the different multidimensional frailty domains (Chapter 2). Knowledge about such 'frailty patterns' 
may contribute to tailoring interventions to individuals. For example, cognitive and psychological frailty were found to be rather strongly associated, indicating a need to develop interventions focused on these domains of functioning.

Indeed, although most of the existing intervention strategies focus on the 'general' frail older population, it seems important to tailor interventions to subgroups or specific individuals, depending on the domains in which problems are encountered. It is likely that matching interventions to a person's specific needs will result in more effective intervention strategies.

Second, we identified factors that contribute to daily functioning (Chapters 4-5) and wellbeing (Chapter 6) despite frailty. By identifying and focusing on factors that contribute to positive outcomes in old age, negative stereotypes might be countered. In addition, this provides new insights for the development of interventions which may better match the needs, goals and preferences older people have themselves as they prefer a focus on improving their wellbeing rather than on intervening on diseases.

To conclude, findings of this dissertation are relevant for early recognition of multidimensional frailty, and give directions for the development of new intervention strategies. This is of societal relevance because frailty is highly prevalent in old age and increases the risk of adverse outcomes.

\section{Innovativeness}

Until now, most research on frailty has focused merely on deficits and losses. The innovativeness of our work lies in the fact that we aimed to identify strengths (frail) older people have and focused on things people still can do or strengths they possess. Moreover, we aimed to work towards a strengths-based approach in two ways.

First, our main focus was on identifying protective factors against disability or dependency in activities of daily living (ADL) rather than on identifying risk factors for developing ADL disability or dependency. Although it might not always be possible to diminish the level of frailty, it might be possible to reduce adverse consequences and to sustain or even to improve daily functioning by strengthening strong points (i.e. such protective factors).

Second, we aimed to contribute towards an approach in which the focus could be on improving wellbeing, rather than diminishing the risk of adverse outcomes, despite being frail. Although previous studies argued that frailty reduces the quality of life $(\mathrm{OoL})$, in most of those studies, at least $50 \%$ of the participants had a good-toexcellent QoL. Therefore, we argued that it is important and relevant to investigate which factors contribute to higher levels of QoL despite being frail. This is likely to contribute to knowledge about older people's strengths and abilities. 


\section{Target groups}

Findings from this dissertation are relevant not only for older people but also for their informal caregivers, healthcare professionals and policymakers with an interest in enabling older people to age in place and/or focusing on positive health. First, this dissertation shows that it is important to conceptualise frailty from a multidimensional perspective (Chapter 2). Therewith, our work increases the awareness that different domains of functioning (i.e. cognitive, environmental, physical, psychological, social) are important to take into account in light of ageing in place. Knowing what frailty is about, and that it is highly prevalent in old age, might increase the likelihood that older people will communicate about difficulties in different domains of functioning and/or will seek help when they experience such difficulties.

In addition, by increasing the awareness of informal caregivers and healthcare professionals about the need to consider the different domains of functioning, this might result in the detection of frailty in earlier stages. Moreover, it is likely that interventions will become more tailormade and therewith, probably, more effective. This is beneficial for older people as well as their (in)formal caregivers.

Moreover, it is important that the multidimensional nature of frailty is taken into account by policymakers. Based on our findings, policymakers should, for example, promote interdisciplinary collaboration by setting up multidisciplinary care teams or establishing regional healthcare networks. It is likely that the inclusion of different perspectives (i.e. of different healthcare professionals) will lead to a more holistic view of the older person.

Second, this dissertation shows that (in)formal caregivers have a different perspective on the level of frailty than older people themselves. An increased awareness of these different perspectives (Chapter 2 ) could serve as a basis for a conversation between the different actors and mutual understanding.

Third, this dissertation shows the importance of adopting a strengths-based approach in managing frailty and that it can be of value to focus on improving positive outcomes rather than only on diminishing the risk of adverse outcomes. We suggest possibilities for promoting and improving daily functioning and wellbeing by strengthening specific resources among frail older people. In addition, in line with such a strengths-based approach, it is recommended that questions such as 'What would improve your OoL?' should be part of the interaction between healthcare professionals and older people. This will not only contribute to working towards a strengths-based approach, but it also will work towards a demand-driven, rather than a supply-driven, approach. It is likely that this is beneficial for the wellbeing of the older people, as well as their informal caregivers.

Related hereto, our findings regarding the strengths-based approach might contribute to a reduction of negative stereotypes about ageing and instead contribute to a more 
positive view of older people. For example, policymakers could use our findings to increase awareness of the strengths older people have, for instance, by emphasising in campaigns the contributions older people can make to society. Moreover, when older people are being proactively informed about things they can still do, they might change their own view of their ageing as well as they gain insight into their own potential. This might empower them to perform certain activities they would like to do but thought of as 'not appropriate' at their age.

\section{Products and activities}

This dissertation was part of the Detection, Support and Care for Older people: Prevention and Empowerment (D-SCOPE) project (www.d-scope.be), on behalf of which several activities will be organised and products will be developed. Although the D-SCOPE project covers many aspects, the focus in this section is on activities and products that are related to the work presented in this dissertation.

With regard to the products, a 'frailty balance instrument', together with an Information Communication Technology (ICT) tool, will be developed starting in September 2018. In this instrument, strengths and resources are considered in addition to frailty. The aim of this instrument is to more easily detect people in need of care. For example, some older people with multidimensional frailty already receive appropriate care and support and/or have the right coping strategies to deal with their frailty, while others do not. In light of interventions, it seems most important to visit the latter group as they are 'out of balance', while the first group already has found ways to adapt to or cope with their frailty. It is expected that groups with different care needs can be detected more easily and faster with such a frailty balance instrument.

To develop this instrument, a longitudinal randomised controlled trial of 870 community-dwelling older people was conducted within the D-SCOPE project between March 2017 and April 2018. Their level of frailty, possible resources and strengths (based on Chapters 4-6, amongst other studies), and positive outcomes such as QoL were assessed. While Chapter 6, for example, had a more explorative character, this large-scale quantitative study makes it possible to empirically verify the factors that seemed important for higher levels of QoL despite being frail. Thus, we next will analyse which factors are most important to experience positive outcomes (such as QoL) despite being frail.

After the frailty balance instrument has been developed, an ICT tool will be developed to enhance the practical implementability. In this tool, the questionnaire can be completed and results can be obtained. Then, results can be used, for example, in personalised action plans. Furthermore, a guideline on how to use the instrument and interpret results will be developed. 
Lastly, a short movie about the D-SCOPE project will be produced. Related to the findings of our work, it will include the importance of considering different domains of functioning while assessing frailty (Chapter 2), as well as the importance of assessing strengths and resources, or in other words, what older people still can do (e.g. Chapter 6).

Regarding activities, a 1-day conference will be held in November 2018. Results from the D-SCOPE project will be presented to the researchers, healthcare professionals, and volunteers and older people who participated in our study, among other people. The presentations will include our approach to multidimensional frailty and use of the frailty balance instrument. In addition, workshops about different frailty measurement instruments and how they complement each other will be given, and an expert meeting will be organised on how to link findings of the D-SCOPE project to policy and clinical practice.

Aside, findings of this dissertation have been disseminated in the past 3.5 years in several ways. First, findings were presented during national and international conferences. They also have been disseminated among healthcare professionals who participated in the D-SCOPE project. For example, meetings were organised, newsletters were sent to healthcare professionals and participants in the project, and information about the D-SCOPE project is available on the website (www.d-scope.be). In addition, scientific articles that have been published (Chapter 2, 4 and 6) are freely available (open access); one of the articles (Chapter 6) will be translated into Dutch for publication to make our findings more accessible to healthcare professionals working in the Netherlands and Belgium.

\section{Implementation}

The frailty balance instrument and the accompanying ICT tool, as described in Products and activities, will be developed starting in September 2018. Thereafter, the actual implementation will take place. One of the partners within the D-SCOPE project, the Socialist Community Health Insurance ('Socialistische Mutualiteiten' in Dutch), will test and implement the use of the instrument in four municipalities in Belgium. The Socialist Community Health Insurance covers medical costs and disability allowances, provides home care services and lends equipment to community-dwelling people in need of care, amongst others.

The first training sessions and workshops will include, for example, an explanation of the meaning and use of the instrument and the ICT tool. Thereafter, the social workers of the Socialist Community Health Insurance will use the frailty balance instrument during the home visits they conduct in community-dwelling older people. Researchers involved in the D-SCOPE project will monitor this process and, if needed, will give extra training sessions tailored to the needs of the social workers. Moreover, focus groups 
will be held to gain insight into their experiences, including questions on positive aspects and suggestions for improvement.

Thereafter, and based on the needs and barriers the social workers experience, we will develop practical guidelines to facilitate other healthcare professionals who want to make use of the D-SCOPE methodology. In the end, the partners involved in the DSCOPE project will no longer be able to provide training sessions and/or workshops (as funding will end by December 2018). Nonetheless, the tools, including the frailty balance instrument and practical guidelines, will be made freely accessible upon request. The Vrije Universiteit Brussel, as the coordination centre of the project, will own all instruments. This also means that whenever healthcare organisations want to work with the tools or require further assistance, de Vrije Universiteit Brussel is the first point of call. 
$-206-$ 


\section{DANKWOORD}

Op jonge leeftijd schreef ik al graag verhalen, en nu is het dan zover: een 'echt' boek op mijn naam $(-)$. Ik wil dan ook graag een aantal mensen die hier op enigerlei wijze aan hebben bijgedragen, bedanken.

Mijn begeleidingsteam, bestaande uit prof. dr. Schols, prof. dr. Kempen, prof. dr. De Witte en dr. Zijlstra. Jullie vormen een mooie aanvulling op elkaar en het was fijn om met jullie samen te werken. Gelukkig blijven we dit nog even voortzetten! Bedankt voor het delen van jullie inhoudelijke kennis, het geven van constructieve feedback en jullie betrokkenheid, maar vooral voor jullie vertrouwen in mij. Ook dank dat jullie mij hielpen om de focus te bewaren - omdat ik soms met iets te veel dingen tegelijkertijd aan de slag wilde.

Jos, ik waardeer je enthousiasme en dat je bijna iedere week wel even binnen bent gelopen om te informeren hoe het ervoor stond, of voor een positief woordje. Jij was bij uitstek degene die tijdens overleggen benadrukte wat er allemaal goed ging en de moed erin hield. Daarnaast kon ik vaak een paar uur nadat ik een stuk had opgestuurd alweer verder met je feedback, hetgeen heel fijn werkt.

Ruud, ook voor jou geldt dat je snel en kritisch naar mijn stukken keek. Ik heb bewondering voor hoe je dat doet, ook omdat ik me altijd welkom voelde om tussendoor even binnen te lopen. Daarnaast waardeer ik het dat je me stimuleerde om zelf na te denken - door in plaats van mijn vragen meteen te beantwoorden, de juiste vragen terug te stellen.

Nico, ondanks de fysiek toch vaak grote afstand was ook jij erg betrokken. Het was altijd fijn om samen te overleggen. Bedankt voor de keren dat je bent afgereisd naar Maastricht, maar ook dat je per mail, skype of sms altijd bereikbaar was.

Rixt, dank voor je kritische blik op mijn stukken, waarbij zo nu en dan ook ruimte was voor een grapje tussendoor $(-)$. Jos zei eens dat hij een kleine Rixt herkende in hoe ik bepaalde werkzaamheden uitvoer; een mooi compliment én een teken dat ik veel geleerd heb de afgelopen jaren! Het was leuk om Oslo samen te verkennen wandelend in de stromende regen en fietsend in het zonnetje.

De beoordelingscommissie, bestaande uit prof. dr. F.R.J. Verhey als voorzitter en dr. R.M.M. Crutzen, prof. dr. E. Gorus, prof. dr. K. Lombaerts, prof. dr. M.M.G. Olde Rikkert en prof. dr. B.J.M. Steverink. Hartelijk dank voor het lezen en beoordelen van mijn manuscript. Ook dank aan dr. M. van den Akker voor het deelnemen aan de oppositie tijdens mijn verdediging. 
ledereen die betrokken was bij het D-SCOPE onderzoek, en dan natuurlijk allereerst alle (in totaal bijna 100o!) deelnemers. Zonder jullie zou dit proefschrift er nooit geweest zijn. Een speciaal woord van dank aan de deelnemers die mij als Hollandse (hetgeen vaak al snel 'gecorrigeerd' werd in Nederlandse) binnen hebben gelaten. Bedankt dat jullie je verhaal met mij hebben durven en willen delen. Ik waardeer jullie openheid en hoop dat ook jullie positief terugkijken op mijn bezoekjes.

Ook dank aan de vrijwilligers die hebben geholpen met de dataverzameling. Ik waardeer jullie betrokkenheid bij de respondenten en jullie vastberadenheid, want na een aantal weigeringen was het soms lastig om de moed erin te houden. Het was altijd fijn om samen te komen en onze ervaringen te bespreken.

Daarnaast dank aan het voltallige D-SCOPE consortium, naast mijn begeleiders bestaande vit prof. dr. De Donder en prof. dr. Dierckx als projectcoördinatoren; prof. dr. Verté, prof. dr. Kardol, prof. dr. De Deyn, prof. dr. Engelborghs, prof. dr. De Lepeleire en prof. dr. Schoenmakers als leden van de stuurgroep; dr. Sarah Dury, dr. An-Sofie Smetcoren en Sylvia als (oud) valorisatiecoördinatoren; en, last but not least, de onderzoekers: Bram, Daan, Deborah, dr. (!) Ellen, Lieve en Michaël die vanaf het eerste moment betrokken waren, maar ook Eva Pattyn en Lise die later (deels) zijn aangesloten. Aan iedereen: bedankt voor jullie input en kritische blikken op de inhoud en vormgeving van ons onderzoek, het meewerken aan artikelen, maar zeker ook voor de gezellige lunches na de denkdagen. Ik ben nooit met tegenzin naar België afgereisd, al heb ik misschien wel zo af en toe gevloekt als de NMBS weer eens vertraging had ;). Liesbeth en Eva Dierckx: dank voor jullie betrokkenheid en dat jullie regelmatig aansloten bij de onderzoeksgroepen. Sarah, officieel ben je niet meer werkzaam voor D-SCOPE, maar jij bent wel degene geweest die ons wegwijs heeft gemaakt in de wereld van het onderzoek. Ik hoop dat je tevreden bent met hoe e.e.a. viteindelijk is vormgegeven én hoe wij ons als onderzoekers ontwikkeld hebben. An-Sofie en Sylvia: jullie hebben ons de laatste periode begeleid en ondersteund. Dank voor jullie enthousiasme en hoe jullie alles in goede banen hebben geleid. Ik heb er alle vertrouwen in dat het slotevent een succes wordt! Onderzoekers: het was fijn om het vele werk te kunnen verdelen, te kunnen sparren over het onderzoek en te bespreken waar we tegenaan liepen tijdens het schrijven van artikelen en het veldwerk. Hopelijk houden we ook na afloop van het project contact. Ik ben benieuwd waar we allemaal terecht gaan komen!

Tenslotte dank aan de vele maatschappelijke partners. Zonder jullie was ons project nooit zo'n succes geworden, of eigenlijk überhaupt niet mogelijk geweest. Zonder de andere partners tekort te doen, gaat mijn dank in het bijzonder vit naar Elly, Petra, Veronique en Wendy van de dienst ouderenzorg van het OCMW Tienen. Bedankt voor jullie inzet en dat ik altijd welkom was op jullie kantoor tussen de interviews door. Het was fijn om mijn ervaringen te kunnen delen, maar ook om het soms juist even heel 
ergens anders over te hebben. Petra, we hadden ons geen betere dispatcher kunnen wensen. Jij stond altijd voor ons klaar, maar nog belangrijker, voor de respondenten. Dank voor je betrokkenheid en interesse en succes met je nieuwe project!

Ook wil ik enkele coauteurs, buiten de D-SCOPE collegae, bedanken voor hun bijdrage aan verschillende hoofdstukken in dit proefschrift.

Prof. dr. Stuck, dear Andreas, your comments and input significantly improved the quality and clarity of our systematic review. Thank you for the great collaboration, as well as for your contribution to our symposium in San Francisco.

Linda Op het Veld, dank dat we gebruik mochten maken van jouw dataset waar zoveel werk in is gestoken en je hulp bij het artikel. Het was fijn dat er ook ruimte was om het over andere zaken, zoals nieuwbouwwoningen, te hebben. Ook bedankt voor alle keren dat ik met je mee mocht rijden van en naar Heerlen. Ik heb er alle vertrouwen in dat jij een mooi proefschrift gaat afleveren. Succes met de laatste loodjes!

Ruth, jij hebt in je studietijd meegeholpen met het analyseren van de kwalitatieve interviews en bent inmiddels een collega geworden. Het is mooi om te zien met hoeveel enthousiasme je vertelt over jouw project en dat jij je plek helemaal gevonden hebt.

De collega's van de afdeling HSR, met natuurlijk allereerst mijn kamergenoten Cindy en Linda. Helaas zijn we vaker zonder dan met elkaar op kantoor aanwezig, hetgeen ook wel aangeeft hoe uitdagend jullie projecten zijn. Maar: als we dan samen aanwezig zijn, is er gelukkig ruimte om van alles te bespreken - zowel werkgerelateerd als over dingen die daarbuiten spelen. Ik ben blij dat we nog even kamergenootjes blijven. Hopelijk blijven we ook daarna nog regelmatig samen lunchen - hetgeen op een gegeven moment in het midden van het land zal zijn! Cindy, hopelijk kunnen we snel weer naar Roda JC - PSV, al ben je natuurlijk ook altijd welkom tegen jong PSV ;). Het is bewonderingswaardig hoe je alles combineert en de moed erin houdt, ook op momenten dat bijvoorbeeld de inclusie weer eens tegen zit. Heel veel succes met de afronding van je project, ik heb er alle vertrouwen in dat het goed komt! Maar eerst nog 'even' verhuizen en genieten van jullie tweede kindje dat op komst is! Ook bij jou heb ik er alle vertrouwen in dat je een mooi proefschrift gaat afleveren, Linda. Daarnaast wens ik je alle geluk toe met je kersverse man. Het is altijd leuk om jullie mooie reisverhalen te horen. Ik kom graag op puppybezoek als het zover is!

Ook dank aan de overbuurvrouwen voor de afleiding tijdens en soms ook na het werk. Ingrid, gelukkig kan je er 6 december bij zijn en kunnen we dan proosten op jouw verjaardag! Ik hoop dat je een hele mooie tijd hebt in Canada en ben benieuwd naar je verhalen als je terug bent. 
Tot slot dank aan alle andere collegae - voor de leuke spelletjesavonden, dagjes uit en lunchwandelingen, maar ook voor de feedback tijdens de refereerbijeenkomsten. Dit heeft zeker bijgedragen aan de kwaliteit van de artikelen in dit proefschrift.

Ook mijn oud collega's van de vakgroep Neuropsychologie (Universiteit Maastricht) en Envida wil ik even noemen. Bij jullie heb ik mijn basis mogen leggen als onderzoeker en psycholoog. Daarnaast dank aan mijn (deels) nieuwe collega's van Envida voor het warme welkom (terug). Ik kijk uit naar onze samenwerking!

Lieve vriendinnen, dank voor jullie interesse en de afleiding buiten het werk - hetgeen veelal gepaard gaat met lekker eten, mooie wandelingen, leuke (bord)spellen en zo af en toe een sportieve activiteit. Ann(i)e, dank dat jij me als paranimf bijstaat, zoals je al zo vaak en zolang doet! Ik bewonder hoe je alles combineert, en vooral ruimte maakt om je dromen na te jagen. Ik weet nog dat ik je vaak voor gek verklaarde als jij je hardloopschoenen meenam op vakantie, maar inmiddels weet ook ik hoe fijn het is om hardlopend een nieuwe omgeving te verkennen. Het is leuk dat we dit zo af en toe ook samen kunnen doen.

Mijn (schoon)familie: bedankt voor de interesse in mijn onderzoek, maar zeker ook voor de afleiding daar buiten. Het is altijd fijn als we samen zijn!

Lieve omi, dank voor het delen van je verhalen en je interesse in mijn onderzoek. Jij vond herkenning in wat de respondenten vertelden; en andersom zorgden jouw verhalen ervoor dat ik me beter in hen kon inleven. Het is altijd fijn om samen op pad te gaan. Ook al is het niet gemakkelijk zo zonder opa, ik ben blij om te zien dat je kunt genieten van leuke uitstapjes en de vakanties met mama. Ik hoop dan ook dat je nog lang bij ons bent in goede gezondheid - ik kan je nog niet missen.

Lieve papa en mama. Zonder jullie was ik nooit op dit punt aanbeland. Bedankt voor een zorgeloze jeugd en alle mogelijkheden die jullie geboden hebben. Hoe ouder ik zelf word, hoe meer ik waardeer wat jullie allemaal doen en gedaan hebben. Maar: boven alles bedankt dat jullie nu al ruim 40 jaar samen zijn en het zo leuk hebben met elkaar. Mama, dank je voor al je lekkere baksels, de vitjes naar het theater of leuke steden en dat we nog altijd trouw tweewekelijks bij 't Sjunste óp de welt te vinden zijn. Papa, dankjewel dat ik altijd even kan bellen voor een goed advies en dat je met me mee bent gegaan naar San Francisco. Het was heel bijzonder om met z'n tweetjes op reis te gaan, en dat ook nog ter nagedachtenis aan oma. Ik denk er nog regelmatig met veel plezier aan terug. Zelfs de ochtenden waren best gezellig, ondanks dat we dan beide niet in ons beste humeur zijn $(:)$. 
Jan, mijn grote broer. Ik ben heel blij dat ook jij mij de hele dag bij zal staan als paranimf. De afgelopen jaren zijn we de dag regelmatig samen begonnen hardlopend en soms zelfs zwemmend - hetgeen altijd een goede start was. Toen ik samen ging wonen met Peter hebben we nog even tegenover elkaar gewoond, maar binnenkort gaan jij en Angelique waarschijnlijk naar het noorden verhuizen. Dit zou voor ons jammer zijn, maar ik gun jullie natuurlijk alle geluk. Hopelijk houden we de vitjes en etentjes samen er wel in!

Tot slot de allerleukste en -liefste: Peter. Ook al heb je het idee dat je niet zoveel hebt bijgedragen... dat is natuurlijk wel zo. Achter iedere sterke vrouw staat een sterke man (of is het nu toch andersom...? ()). Dankjewel dat je me liet doorwerken als ik iets écht af moest maken, maar me ook vaak genoeg achter mijn laptop vandaan trok. Bijna 9 jaar geleden stapte je op me af bij Hoen - en sindsdien hebben we een hoop moois meegemaakt en ons leven samen verder opgebouwd. Ik had nooit durven dromen dat we nu samen in ons huis met onze lieve Shabby zouden wonen. De wandelingen en vakanties met z'n drieën waren een goede manier om mijn hoofd leeg te maken en weer met volle moed verder te schrijven aan het proefschrift. Ik kijk uit naar alles wat nog komen gaat samen. Ik hou van jou! 


\section{ABOUT THE AUTHOR}

Anne van der Vorst was born on August 2, 1991 in Brunssum (Limburg, the Netherlands). She attended secondary school (atheneum) in Hoensbroek. After obtaining her bachelor's degree in Health Sciences (2011, Maastricht University), she completed a master's in Forensics, Criminology and Law (2012, Maastricht University). During this master's program, she conducted an internship at the Community Health Services (Geleen). Subsequently, she completed a master's in Mental Health Sciences (2014, Maastricht University). During this program, she first conducted a clinical internship at psychogeriatric and somatic nursing home wards, as well as a geriatric rehabilitation ward (Envida, Maastricht), where she acquired her psychodiagnostics registration (BAPD). Thereafter, she conducted a combined research and clinical internship at Maastricht University (department of Psychiatry and Neuropsychology) and the memory clinic of the Maastricht University Medical Centre+. She also worked as a care assistant at a somatic nursing home ward (Envida, Maastricht).

From 2014 on, she worked as a psychologist at Envida, as well as a research assistant at Maastricht University (department of Psychiatry and Neuropsychology), where she was involved in research on a potential new medicine for people with dementia of the Alzheimer type. In March 2015 she started her PhD trajectory at Maastricht University (department of Health Services Research) and the Vrije Universiteit Brussel (department of Educational Sciences). Her doctorate was part of the D-SCOPE project, which aimed to enable community-dwelling (frail) older people to age in place with a good quality of life. Currently, Anne works as a postdoctoral researcher at Maastricht University (department of Health Services Research), and as a psychologist at Envida. 
$-214-$ 


\section{PUBLICATIONS AND CONFERENCE CONTRIBUTIONS}

\section{PUBLICATIONS}

\section{International journals}

Lambotte, D., De Donder, L., De Roeck, E.E., Hoeyberghs, L.J., van der Vorst, A., Duppen, D., Van der Elst, M., Fret, B., Dury, S., Smetcoren, A.S., Kardol, M.J.M., Engelborghs, S., De Deyn, P.P., De Witte, N., Schols, J.M.G.A., Kempen, G.I.J.M., Zijlstra, G.A.R., De Lepeleire, J., Schoenmakers, B., Verté, D., Dierckx, E. Randomized controlled trial to evaluate a prevention program for frail community-dwelling older adults: A D-SCOPE protocol. BMC Geriatrics. DOI: 10. 186/s12877-018-0875-3.

van der Vorst, A. Op het Veld, L.P.M., De Witte, N., Schols, J.M.G.A., Kempen, G.I.J.M., Zijlstra, G.A.R. (2018). The impact of multidimensional frailty on dependency in activities of daily living and the moderating effects of protective factors. Archives of Gerontology and Geriatrics, 78: 255-26o. DOI: 10.1016/j.archger.2018.06.017.

van der Vorst, A., Zijlstra, G.A.R., De Witte, N., De Lepeleire, J., Kempen, G.I.J.M., Schols, J.M.G.A., D-SCOPE Consortium. (2018). Can proxy assessments serve as a first screener for identifying people at risk for multidimensional frailty? European Geriatric Medicine, 9(4): 501-507. DOI: 0.1007/541999-018-0067-x.

Dury, S., Dierckx, E., van der Vorst, A., Van der Elst, M., Fret, B., Duppen, D., Hoeyberghs, L., De Roeck, E.E., Lambotte, D., Smetcoren, A.S., Schols J.M.G.A., Kempen, G.I.J.M., Zijlstra, G.A.R., De Lepeleire, J., Schoenmakers. B., Verté, D., De Witte, N., Kardol, T., De Deyn, P.P., Engelborghs, S., \& De Donder, L. (2018). Detecting frail, older people and identifying their strengths: results of a mixed-methods study. BMC Public Health, DOI: 10.1186/s12889-018-5088-3.

van der Vorst, A., Zijlstra, G.A.R., De Witte, N., Vogel, R.G.M., Schols, J.M.G.A., Kempen, G.I.J.M., D-SCOPE Consortium. (2017). Explaining Discrepancies in SelfReported Quality of Life in Frail Older People. BMC Geriatrics, DOI: 10.1186/s12877017-0641-y. 
van der Vorst, A., Zijlstra, G.A.R., De Witte, N., Duppen, D., Stuck, A.E., Kempen, G.I.J.M., Schols, J.M.G.A., D-SCOPE consortium (2016). Limitations in activities of daily living in community-dwelling people aged 75 and over: a systematic literature review of risk and protective factors. PLOS ONE, 11(10): e0165127.

Dury, S., De Roeck, E.E., Duppen, D., Fret, B., Hoeyberghs, L., Lambotte, D., Van der Elst, M., van der Vorst, A., Schols J.M.G.A., Kempen, G.I.J.M., Zijlstra, G.A.R., De Lepeleire, J., Schoenmakers. B., Kardol, T., De Witte, N., Verté, D., De Donder, L., De Deyn, P.P., Engelborghs, S., Smetcoren, A.S., \& Dierckx, E. (2017). Identifying frailty risk profiles of home-dwelling older people: focus on sociodemographic and socioeconomic characteristics. Aging \& Mental Health, 21(10), 1031-1039.

\section{Submitted}

De Roeck, E., van der Vorst, A., Engelborghs, S., Zijlstra, G.A.R., \& Dierckx, E. Cognitive frailty in older people with and without cognitive impairment: prevalence and associations with various frailty domains.

\section{National journals}

Smetcoren, A.S., Dury S., De Donder, L., Dierckx, E., De Witte, N., Engelborghs, S., De Deyn, P.P., van der Vorst, A., Van der Elst, M., Lambotte, D., Hoeyberghs, L., Fret, B., Duppen, D., De Roeck, E., Kardol, M., Schoenmakers, B., De Lepeleire, J., Zijlstra, G. A. R., Kempen, G. I. J. M., Schols, J.M.G.A., Verté, D. (2017). Detectie en preventie van kwetsbaarheid: Op zoek naar risicoprofielen voor fysieke, psychische, sociale en omgevingskwetsbaarheid. Tijdschrift voor Gerontologie en Geriatrie, 49(1): 1-11. DOI: 10.1007/s12439-017-0241-5

van der Vorst, A., Zijlstra, G.A.R., De Witte, N., Vogel, R.G.M., Schols, J.M.G.A., Kempen, G.I.J.M., D-SCOPE Consortium. Het verklaren van verschillen in ervaren kwaliteit van leven van kwetsbare ouderen: een 'mixed-method' onderzoek. Tijdschrift voor Gerontologie en Geriatrie. 49(5): 174-186. DOI: 10.1007/s12439-018-0261-9.

\section{CONFERENCE CONTRIBUTIONS}

van der Vorst, A., Op het Veld, L.P.M., De Witte, N., Schols, J.M.G.A., Kempen, G.I.J.M., Zijlstra, G.A.R. Can protective factors moderate the impact of multidimensional frailty on ADL dependency? Second International Scientific Kock Symposium, 19-21 September 2018, Trelleborg, Sweden (poster presentation). 
Van Der Elst, M.C.J., Op het Veld, L.P.M., van der Vorst A., Schols, J.M.G.A., Kempen, G.I.J.M., De Witte, N., Schoenmakers, B., De Lepeleire, J., D-SCOPE Consortium. The validation of the Comprehensive Frailty Assessment Instrument against the (modified) Fried criteria. 17th European Doctoral Conference in Nursing Science, 22-23 June 2018, Maastricht, the Netherlands (abstract). Published in Verpleegkunde, 2018; 33(3): 34.

van der Vorst, A., Op het Veld, L.P.M., De Witte, N., Schols, J.M.G.A., Kempen, G.I.J.M., Zijlstra, G.A.R. Can the relationship between multidimensional frailty and ADL disability be moderated? 24th Nordic Congress of Gerontology, 2-4 May 2018, Oslo, Norway (poster presentation).

van der Vorst, A., De Roeck, E.E., Engelborghs, S, Zijlstra, G.A.R., Dierckx, E., DSCOPE Consortium. What is the prevalence of cognitive frailty, and what is its association with other frailty domains? 24th Nordic Congress of Gerontology, 2-4 May 2018, Oslo, Norway (oral presentation).

van der Vorst, A., Zijlstra, G.A.R., De Witte, N., Kempen, G.I.J.M., Schols, J.M.G.A., DSCOPE consortium. Het meten van multidimensionale kwetsbaarheid: zelfrapportage versus proxy beoordelingen door de huisarts en mantelzorger. $14^{\mathrm{e}}$ Nationaal Gerontologiecongres, 3 November 2017, Ede, the Netherlands (oral presentation). Published in Tijdschrift voor Gerontologie en Geriatrie, 2017; 48(5) (suppl.1): 236.

van der Vorst, A., Zijlstra, G.A.R., De Witte, N., Schols, J.M.G.A., Kempen, G.I.J.M., DSCOPE Consortium. Welke sterktes hebben kwetsbare ouderen met een hoge kwaliteit van leven, vergeleken met kwetsbare ouderen met een lage kwaliteit van leven? $14^{\mathrm{e}}$ Nationaal Gerontologiecongres, 3 November 2017, Ede, the Netherlands (oral presentation). Published in Tijdschrift voor Gerontologie en Geriatrie, 2017; 48(5) (suppl.1): 227.

van der Vorst, A., Zijlstra, G.A.R., De Witte, N., Schols, J.M.G.A., Kempen, G.I.J.M., DSCOPE Consortium. Developing an instrument to measure frailty balance in community-dwelling older people. 21st IAGG World Congress of Gerontology and Geriatrics, 23-27 July 2017, San Francisco, California, USA (oral presentation). Published in Innovation in Aging, 2017; 1(suppl.1): 1006.

van der Vorst, A., Zijlstra, G.A.R., De Witte, N., Kempen, G.I.J.M, Schols, J.M.G.A., DSCOPE Consortium. Balancing factors in community-dwelling people aged 60 years and over. 21st IAGG World Congress of Gerontology and Geriatrics, 23-27 July 2017, San Francisco, California, USA (oral presentation). Published in Innovation in Aging, 2017; 1(suppl.1): 1262. 
De Roeck, E.E., van der Vorst, A., Engelborghs, S., Dierckx, E., D-SCOPE Consortium. Cognitive frailty and its relation with physical, psychological, social and environmental frailty. 21st IAGG World Congress of Gerontology and Geriatrics, 23-27 July 2017, San Francisco, California, USA (abstract). Published in Innovation in Aging, 2017; 1(suppl.1): 1261.

van der Vorst, A., Schols, J.M.G.A., Gobbens, R.J.J. Improving care for frail older people: the importance of multiple domains and perspectives. 5 th European Nursing Congress, 4-7 October 2016, Rotterdam, the Netherlands (symposium abstract). Published in Journal of Advanced Nursing, 2016; 72(suppl.1): 12.

van der Vorst, A., Zijlstra, G.A.R., De Witte, N., Schols, J.M.G.A., Kempen, G.I.J.M. Frailty in community-dwelling older people: a comparison between self-report and proxy assessments. 5th European Nursing Congress, 4-7 October 2016, Rotterdam, the Netherlands (oral presentation). Published in Journal of Advanced Nursing, 2016; 72(suppl. 1): 12-13.

van der Vorst, A., Zijlstra, G.A.R., De Witte, N., Kempen, G.I.J.M., Schols, J.M.G.A, DSCOPE consortium. Risk and protective factors for activities of daily living in community-dwelling (oldest) old: a systematic literature review. British Society of Gerontology 45th Annual Conference, 6-8 July 2016. Stirling, Scotland (oral presentation).

van der Vorst, A., Zijlstra, G.A.R., De Witte, N., Schols, J.M.G.A., Kempen, G.I.J.M. Development of a measurement instrument for the detection of frailty balance in old age. Annual CAPHRI research day, 24 November 2016. Valkenburg, the Netherlands (poster presentation).

van der Vorst, A., Zijlstra, G.A.R., De Witte, N., Duppen, D., Stuck, A.E., Kempen, G.I.J.M., Schols, J.M.G.A. Activities of daily living in community-dwelling older people: initial findings of a systematic review of predictive factors. 37th Wintermeeting Belgian Society for Gerontology and Geriatrics. 26 February 2016. Oostende, Belgium (poster presentation).

van der Vorst, A., Zijlstra, G.A.R., De Witte, N., Schols, J.M.G.A., Kempen, G.I.J.M. Development of a measurement instrument for the detection of frailty balance in old age. MICRA PhD student conference. 14 May 2015. Manchester, United Kingdom (poster presentation). 
$-220-$ 


\section{D-SCOPE}

D-SCOPE (Detection, Support and Care for Older people: Prevention and Empowerment) is een internationaal onderzoeksproject, gefinancierd door het Instituut voor Wetenschap en Technologie [IWT-140027 Strategisch BasisOnderzoek (SBO)] (2015-2018). Het D-SCOPE-consortium is multidisciplinair samengesteld en bestaat uit onderzoekers van vijf universiteiten/hogescholen: Universiteit Maastricht, Universiteit Antwerpen, Hogeschool Gent, Katholieke Universiteit Leuven en Vrije Universiteit Brussel. Als onderzoeksfocus staat de gerichte detectie van kwetsbare ouderen in hun lokale omgeving centraal. Het project draagt bij aan het ontwikkelen van een nieuwe methodiek voor de preventie van kwetsbaarheid van ouderen, zodat zij zo lang mogelijk kwaliteitsvol thuis kunnen blijven wonen. Het D-SCOPE project vertrekt vanuit een multidimensionaal perspectief op kwetsbaarheid (fysieke, cognitieve, psychische, sociale en omgevingskwetsbaarheid) en legt de focus op positieve uitkomstmaten zoals zelfregie, levenstevredenheid en zingeving. Om dit te bereiken werd het D-SCOPE onderzoek opgedeeld in drie fasen. In de eerste fase werden risicoprofielen bepaald op basis van de data van de ouderenbehoefteonderzoeken. In de tweede fase is door middel van individuele interviews bij 121 kwetsbare ouderen nagegaan wat balancerende factoren en scharniermomenten zijn. De derde en laatste fase betrof een gerandomiseerd onderzoek met zowel een experimentele als controlegroep (RCT) in drie testgemeenten (Gent, Knokke-Heist en Tienen) bij 869 ouderen. Hierbij is de D-SCOPE methodiek rond vroegtijdige detectie van kwetsbare ouderen uitgetest aan de hand van de eerder gedefinieerde risicoprofielen van kwetsbaarheid. Ook wordt getracht sterktes die kwetsbare ouderen hebben verder in kaart te brengen.
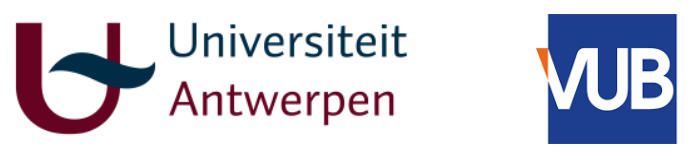

\section{HoGent}

Maastricht University

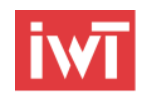

agentschap voor Innovatie 
D-SCOPE (Detection, Support and Care for Older people: Prevention and Empowerment) is an international research project, financed by the Flemish government agency for Innovation by Science and Technology [IWT-140027 Strategisch BasisOnderzoek (SBO)] (2015-2018). The D-SCOPE consortium is a multidisciplinary group composed of researchers from five universities/colleges: Maastricht University, University of Antwerp, University College Ghent, KU Leuven and Vrije Universiteit Brussel. The focus of D-SCOPE is targeted detection of frail older adults in their local environment. The project contributes to the development of new methodologies for the prevention of frailty in older adults, so they can age in their own homes in good quality of life. The D-SCOPE project starts from a multidimensional perspective on frailty, including physical, cognitive, psychological, social and environmental frailty, and focuses on positive outcomes like mastery, life satisfaction and meaning in life. In order to achieve this, the D-SCOPE project was divided in three research phases. In the first phase, risk profiles were determined through data from the Belgian Ageing Studies. In the second phase, balancing factors and life events were explored by means of 121 individual interviews with frail older people. The third and last phase consisted of a randomised study with both an experimental and control group (RCT) in three test municipalities (Ghent, Knokke-Heist and Tienen) among 869 older adults. The D-SCOPE methodology for early detection of frail older adults is hereby tested by previously defined risk profiles for frailty. In addition, strengths frail older people have are explored.

\section{$\checkmark \begin{aligned} & \text { Universiteit } \\ & \text { Antwerpen }\end{aligned}$}

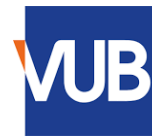

\section{HoGent}

Maastricht University

\section{ivi}

agentschap voor Innovatie

door Wetenschap en Technologie 